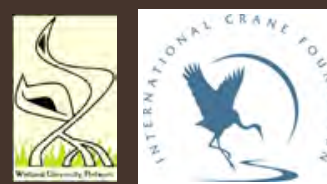

\title{
Persistent Organic Pollutants in Wetlands of the Mekong Basin
}

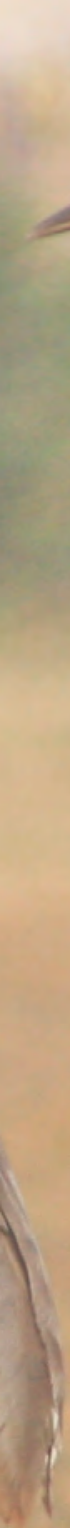

Scientific Investigations Report 2013-5196

U.S. Department of the Interior

U.S. Geological Survey 

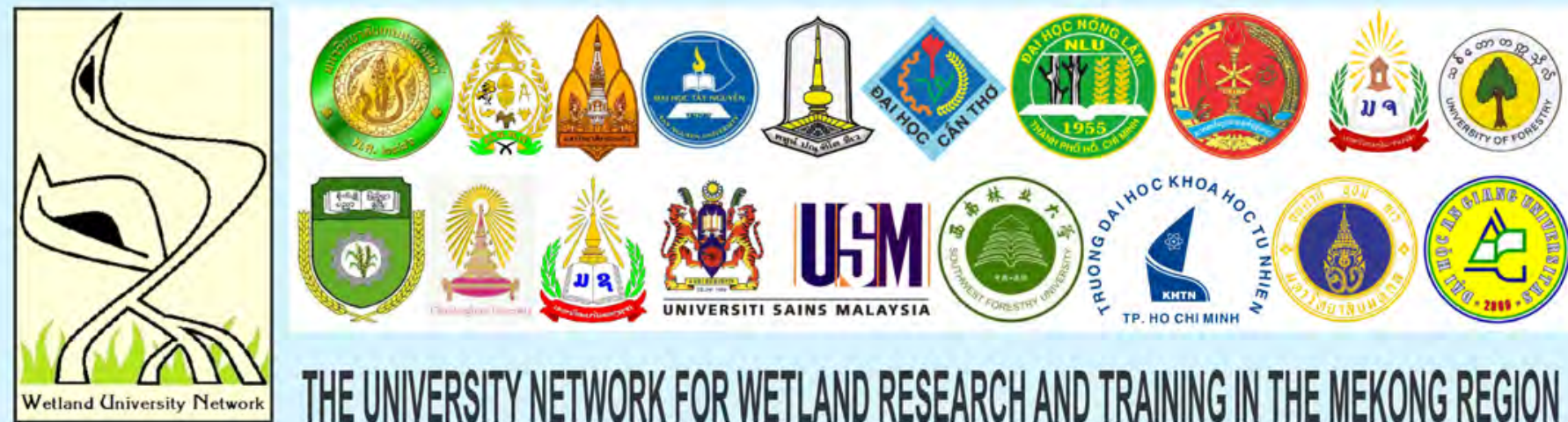

THE UNEERSTTYNETWORKFORWELLADDRESEARCHAD TRANNG WTHE WEKONGREGON

COVER: Adult (red head) and juvenile (brown head) Eastern Sarus Cranes (Grus antigone sharpii) at Tram Chim National Park in proximity to people. Persistant organic pollutants that could pose a risk to both people and cranes were found at Tram Chim. Photograph by Nguyen Van Hung (former University Network for Wetland Research and Training in the Mekong Region student). 


\section{Persistent Organic Pollutants in Wetlands of the Mekong Basin}

By Tran Triet, Jeb Anthony Barzen, Sansanee Choowaew, Jon Michael Engels, Duong Van Ni, Nguyen Anh Mai, Khamla Inkhavilay, Kim Soben, Rath Sethik, Bhuvadol Gomotean, Le Xuan Thuyen, Aung Kyi, Nguyen Huy Du, Richard Nordheim, Ho Si Tung Lam, Dorn M. Moore, and Scott Wilson

Prepared in cooperation with the University Network for Wetland Research and Training in the Mekong Region and the International Crane Foundation

Scientific Investigations Report 2013-5196 


\title{
U.S. Department of the Interior SALLY JEWELL, Secretary
}

\section{U.S. Geological Survey \\ Suzette M. Kimball, Acting Director}

\author{
U.S. Geological Survey, Reston, Virginia: 2014
}

For more information on the USGS — the Federal source for science about the Earth, its natural and living resources, natural hazards, and the environment, visit http://www.usgs.gov or call 1-888-ASK-USGS.

For an overview of USGS information products, including maps, imagery, and publications, visit http://www.usgs.gov/pubprod

To order this and other USGS information products, visit http://store.usgs.gov

Any use of trade, firm, or product names is for descriptive purposes only and does not imply endorsement by the U.S. Government.

Although this information product, for the most part, is in the public domain, it also may contain copyrighted materials as noted in the text. Permission to reproduce copyrighted items must be secured from the copyright owner.

Suggested citation:

Tran, T., Barzen, J., Choowaew, S., Engels, M., Duong, V.N., Nguyen, A.M., Inkhavilay, K., Kim, S., Rath, S., Gomotean, B., Le, X.T, Aung, K., Nguyen, H.D., Nordheim, R., Lam, H.S.T., Moore, D.M., and Wilson, S., 2014, Persistent organic pollutants in wetlands of the Mekong Basin: U.S. Geological Survey Scientific Investigations Report 2013-5196, 140 p., http://dx.doi.org/10.3133/sir20135196.

ISSN 2328-0328 (online) 


\section{Foreword}

It was once believed that wetlands were of no discernible value and represented an impediment to development. They were drained to make way for farmland and to provide space for development. Today, we have come to appreciate not only the stark beauty of these wild places but also their importance to wildlife, natural ecosystems, agriculture, and human health. Wetlands act as nurseries for fish and birds, repositories of plant diversity, cleansers of groundwater resources, and buffers against floods. In the Mekong Basin, they are the connective tissue that binds the Mekong River to the land, preventing erosion and protecting against drought. The wetlands of the Mekong Basin protect mainland Southeast Asia against the ecological challenges, both natural and manmade, that this vast and globally important region faces.

The people of the Greater Mekong Subregion outnumber the population of the United States and represent one of the fastest growing and dynamic regions in the world today. Despite incredible growth and rapid development, the Mekong River Basin still dominates the lives and livelihoods of many of its residents. Roughly 65 million people depend upon the wild fish caught in the Lower Mekong River Basin to meet their dietary needs. According to most estimates, 60 percent of the protein in the diet of this human population comes from fish although the number is even higher in Cambodia, where fish from the Mekong Basin provide virtually all of the protein in the diet of millions. Of equal importance is rice production in the Mekong Delta, where 55 percent of Vietnam's total rice production and two-thirds of the rice traded in the Association of Southeast Asian Nations region is produced.

It is difficult to protect an ecosystem, however, when little is known about the environmental challenges it faces. Despite a growing body of research and improving local capability, many important aspects of this critical ecosystem are still unknown. Research on the wetlands-their health, sustainability, and requisite protections - contains blind spots that are acknowledged by most researchers and environmental scientists working in the region. Recognizing the value of wetland resources and the potential long-term danger posed by persistent organic pollutants, the Department of State worked with the International Crane Foundation to administer and coordinate a Mekong River Basin land-based project to study persistent organic pollutants in the basin's wetlands.

The study yielded several troubling results from an environmental perspective such as indications of the continued use of banned pesticides, including DDT. Original chemicals or metabolites of DDT, endosulfan, hexachlorobenzene, and endrin were most commonly detected by the study. Even though DDT was banned in the 1990s, some use of DDT may still be occurring in the Mekong Basin. The abundance of DDT metabolites (DDE and DDD), found in this study, however, suggests that use of DDT is declining throughout the region.

The overall results of the study regarding POPs were positive and provided a strong baseline for further study and conservation efforts. The results from the study, though not comprehensive, did indicate that the concentration and distribution of endosulfan and its metabolites represent a serious problem requiring further study and management action. Although the total loading of POPs in wetland sediments of the Mekong Basin was generally low, hotspot sites occurred where concentrations exceeded established ecological risk thresholds. 
This project also fostered local technical development as it supported research and analysis by the universities and researchers of the University Network for Wetland Research and Training in the Mekong Region. Not only did this work support greater scientific understanding of the critical challenge posed by POPs contamination, it advanced the development of greater local capability and transboundary cooperation in the field of wetland ecology in the Mekong Basin.

Bryan R. Switzer

Regional Environment, Science, Technology and Health (ESTH) Hub Chief for East and Southeast Asia, U.S. Department of State, U.S. Embassy to Thailand

February 11, 2013 


\section{Preface}

The University Network for Wetland Research and Training in the Mekong Region (University Network) is responsible for the research provided in this report. Since its inception in 2002, researchers within the University Network have conducted 10 wetland training courses with a total of 224 students from 18 member universities and 5 research institutions. Students from all six of the countries within the Mekong Basin, as well as from Japan, Malaysia, New Zealand, and the United States, have participated in these courses. From this foundation of training, three previous joint research investigations evolved: a botanical study of the family Zingiberaceae (involving National University of Laos, Royal Botanic Garden-Edinburgh, Royal University of Phnom Penh, Singapore Botanic Garden, and University of Natural Sciences-Ho Chi Minh City); a bamboo study of Cambodia, Lao People's Democratic Republic, and Vietnam (involving National University of Laos, Royal University of Phnom Penh, University of Natural Sciences-Ho Chi Minh City, and Museum of Natural History-Paris); and Asialink's project on urban wetland ecosystem management (involving University of Natural Sciences-Ho Chi Minh City, Mahidol University, University of Salzburg, and University of Helsinki). This current (2013) research on persistent organic pollutants (POP) in the wetlands of the Mekong Basin is the fourth and most extensive of these collaborations to date.

Wetlands are complicated ecosystems because they include attributes of both terrestrial and aquatic systems. In areas like the Mekong Region, people have historically depended upon wetlands for resources to consume and for transportation. Through a shared dependency on wetlands, and through the shared study of wetlands, both students and instructors of the University Network have learned a basic truth—people of different backgrounds are more similar than not because they share the same resources. This publication exemplifies the benefits of collaboration among the diverse nations of the Mekong Region. The research and the human institutions that are built upon this dual foundation-science and cross-cultural collaboration-are then employed to solve problems in the local environment.

As important, without the physical network of universities located throughout the Mekong Basin, it would not have been possible to acquire a snapshot of POPs over a basin as large or as complex as the Mekong. University collaborations can become a powerful tool in the advancement of science in any region. In the Mekong Basin specifically, the importance of effective collaboration is paramount given myriad development plans that are being advanced; proposed dams, barrages, irrigation systems, large-scale aquaculture, extensive plantations and the like all require people to evaluate tradeoffs and interactions between projects if these development efforts are to be sustainable. The Mekong Basin is protected by perhaps one of the strongest international legal agreements for rivers anywhere. The "Mekong Agreement" compels the four countries of the Lower Mekong Basin-Vietnam, Lao PDR, Thailand, and Cambodia - to collaborate not only to develop the Mekong Basin for the benefit of its inhabitants but also to accomplish this goal on a sustainable basis. An efficient and effective network of universities can serve as a foundation for implementing any international legal agreement such as the one serving the Mekong Basin.

Wetlands of the Mekong Basin represent the geographic and regulatory complexity and diversity of wetlands worldwide as Mekong waters course from the river's glacial source in the Tibetan Plateau approximately 4,350 kilometers to the river mouth in the Mekong Delta. The creation 
and evolution of a network of scientists to fully represent and explore that complexity was deemed necessary, and the University Network has thus exemplified what can be accomplished through extensive collaboration. In no other study and in no other region has such an extensive survey of pollutants been collected within such a short time period.

We hope that the spirit, nature, and products of the University Network will not only continue to advance our knowledge of wetlands in the Mekong Basin but will also provide a collaborative model that other scientists can incorporate to a useful effect beyond what we have imagined thus far.

Jeb Barzen

November 2, 2012 


\section{Acknowledgments}

This project was funded by the International Crane Foundation, to which grants were allocated by the U.S. Department of State, the U.S. Geological Survey (USGS), and the John D. and Catherine T. MacArthur Foundation. In-kind support was provided by Can Tho University, Flatrock Geographics, International Crane Foundation, Mahidol University, Mahasarakham University, National University of Laos, Royal University of Agriculture, Royal University of Phnom Penh, University Network for Wetland Research and Training in the Mekong Region, University of Science-Vietnam National University-Ho Chi Minh City, University of Wisconsin-Madison, and Yezin Agriculture University. The support of these organizations has been instrumental in allowing us to accomplish our goals for studying wetlands in Southeast Asia.

The study represents an international collaboration involving many organizations across Southeast Asia and the United States. From the Mekong River Basin, eight universities participated in the study: Royal University of Phnom Penh and Royal University of Agriculture (Cambodia), the National University of Laos (Lao People's Democratic Republic [PDR]), Yezin Agricultural University (Myanmar), Mahidol University and Mahasarakham University (Thailand), and University of Science-Vietnam National University-Ho Chi Minh City and Can Tho University (Vietnam). These universities are members of the University Network for Wetland Research and Training in the Mekong Region. In the United States, the International Crane Foundation, the USGS National Wetlands Research Center, the USGS Louisiana Water Science Center, and the University of Wisconsin-Madison were participating research institutions.

Field data collection teams were staffed by many dedicated people, including Duong Van $\mathrm{Ni}$ (team leader), Le Dang Khoa, Le Thi Phuong Mai, Nguyen Thi Thoai Nghi, Phung Thi Hang, and Tran Sy Nam from Can Tho University; Nattapon Anooaun, Uthane Chanlabutara, Bhuvadol Gomontean (team leader), Usa Klinhom, Thawatchai Lelahnoi, Wannachai Wannasing, and Komkrit Wongpakhum from Mahasarakham University; Ratchanon Chaba, Sansanee Choowaew (team leader), Farida Duriyapong, Nawasapol Hachit, Tasanee Krutpichai, Gatthalee Kurukul, Kanchana Nakhapakorn, Chitsanuphong Pratum, and Panya Suwannaphan from Mahidol University; Khamfa Chanhthavongsa, Khamla Inkhavilay (team leader), Sengphet Thanusone, and Khamsen Phonesavanh from National University of Laos; Chey Dyna, Heng Chamroeun, Kim Soben (team leader), Ly Kalyan, and Pak Sngoun Pisey from the Royal University of Agriculture; Min Malay, Rath Sethik (team leader), Sak Seap, Som Piseth, and To Chan from Royal University of Phnom Penh; Le Xuan Thuyen (team leader), Nguyen Hoai Bao, Nguyen Viet Quoc, and Nguyen Thai Chung from the University of Science-Vietnam National University-Ho Chi Minh City; and Myint Thaung (former rector), Aung Kyi (team leader), Wonna Aung, and Moe Hnin Phyu from Yezin Agriculture University.

Laboratory analysis was completed by the Central Laboratory for Analysis and Chemistry Department at the University of Science, Vietnam National University-Ho Chi Minh City. Hoang Hanh Uyen, Huynh Thi Thuy Linh, Nguyen Anh Mai (team leader), Nguyen Huy Du, Nguyen Khac Manh, Nguyen Thanh Nho, Nguyen Thi Xuan Mai, Pham Thi Huong, Tran Thi Thanh Thuy, Trieu Quoc An, and Truong Lam Son Hai worked diligently to complete chemical analysis for the large number of samples collected in this project. We also appreciate Dr. Tran Linh Thuoc (rector, University of Science, Vietnam National University-Ho Chi Minh City) for his leadership and support for various project activities carried out at the university and in Vietnam. Likewise, 
Dr. Lammai Phiphakhavong, vice president of National University of Laos, helped guide the extensive project in Lao PDR and received excellent assistance from the faculty of the science and environment departments at National University of Laos.

To implement an interdisciplinary project that encompassed most of the Mekong River Basin, various team members received invaluable training or training support from Charlie Demas (USGS-retired), staff at Rockefeller Refuge (Louisiana, United States), Cindy Thatcher (USGS), Tram Chim National Park (Dong Thap, Vietnam), USGS National Wetlands Research Center, USGS Louisiana Water Science Center, and Scott Wilson (USGS). We thank USGS National Water Quality Laboratory in Denver, Colorado, for analyzing the cross-referenced sediment samples.

Database development was provided by the International Crane Foundation and Paul Wickman (Flatrock Geographics), and the database has been key to maintaining the diverse and extensive dataset reported here. Dorn Moore, Nguyen Thi Thoai Nghi, and Cindy Thatcher provided mapping and geographic information system assistance.

Howell (Hal) Howard, Bryan (Rick) Switzer, Jacoby Carter, Charlie Demas, Leav Phalen, Kate Spear, and Le Bach Mai provided endless coordinating and support services as the team collaborated over the course of this project. The USGS, Pak Pisey, Min Malay, Cindy Thatcher, and Scott Wilson facilitated the implementation of this ambitious project. Charlie Demas and Cindy Thatcher provided insightful and extensive reviews that greatly improved this manuscript. We also thank Jim Harris, Julie Langenberg, Greg Smith, and Kate Spear for comments that guided this manuscript to completion. Nelson Beyer and Dennis Demcheck provided formal reviews of this work and their insight greatly improved this publication. 


\section{Contents}

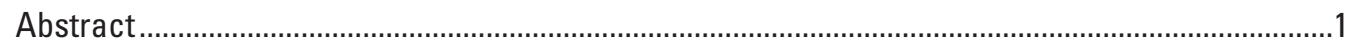

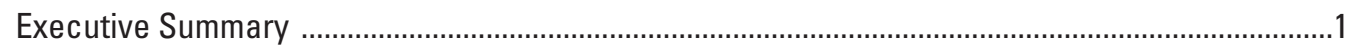

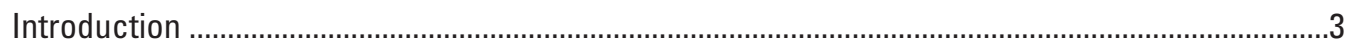

Persistent Organic Pollutants and Their Impacts on Human Health and the Environment .....4

Wetlands of the Mekong Basin and the Main Purpose of this Study .......................................4

The Use and Control of Some Organochlorine Pesticides and Polychlorinated Biphenyls in Countries of the Mekong Basin .....................................................................5

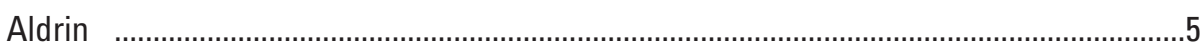

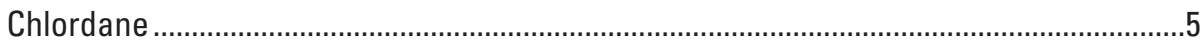

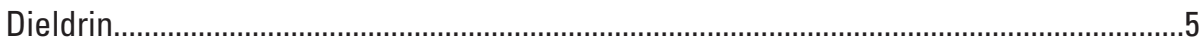

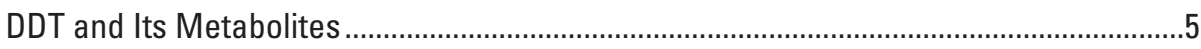

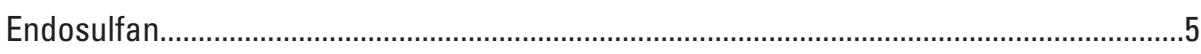

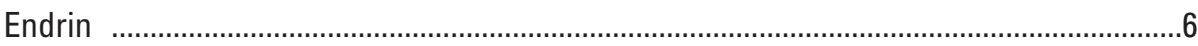

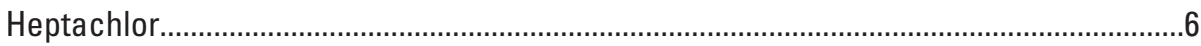

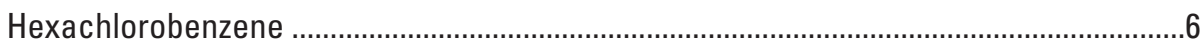

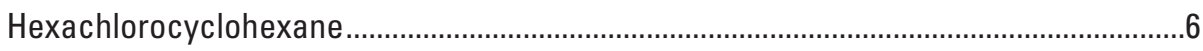

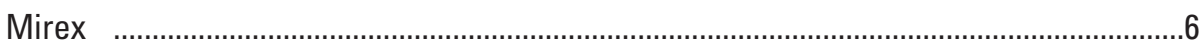

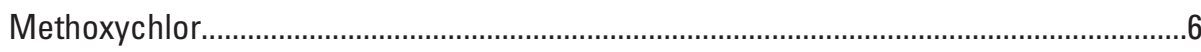

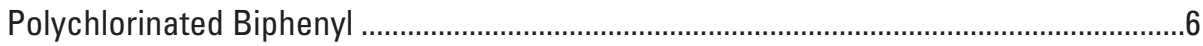

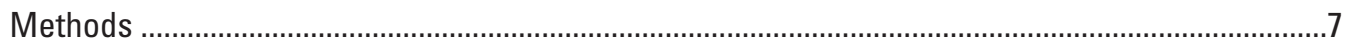

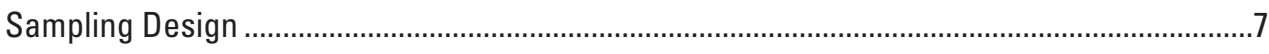

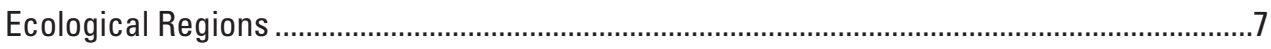

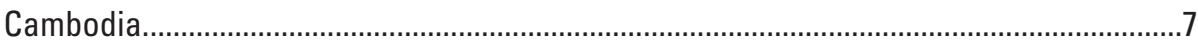

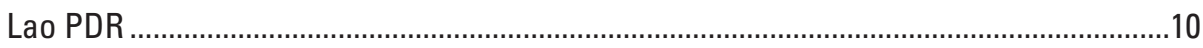

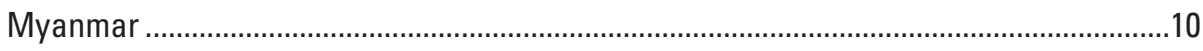

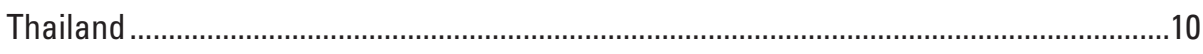

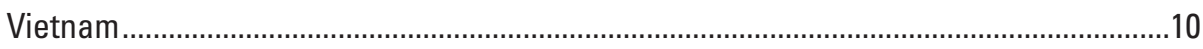

Land Use History and River Connectivity...........................................................................11

Within a Wetland, Choosing the Sample Location .....................................................................11

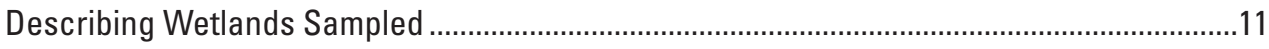

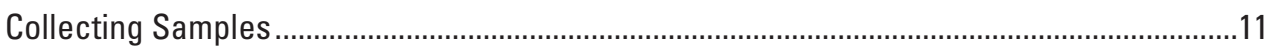

Persistent Organic Pollutant Samples ............................................................................11

Descriptive Soil Samples.......................................................................................................12

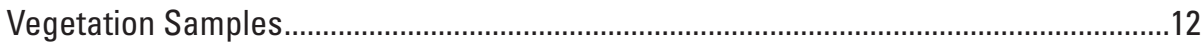

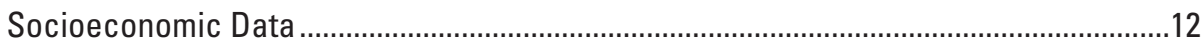

Laboratory Analysis .............................................................................................................. 13

Chemicals and Instruments ................................................................................................ 13

Analytical Procedure for Organochlorine Pesticides.......................................................13

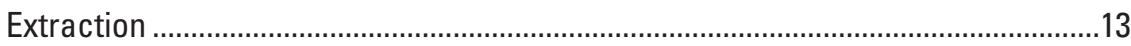

Sample Cleanup ..................................................................................................... 14

Gas Chromatographic Analysis ................................................................................. 16

Analytical Procedure for Polychlorinated Biphenyls ....................................................16

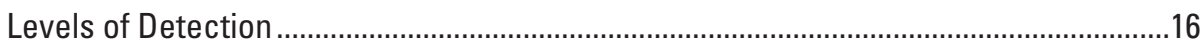

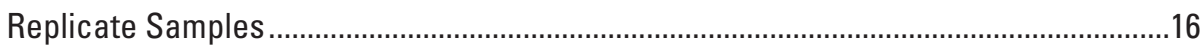


Comparison of Two Different Laboratories with Samples from Tram Chim National Park …………………………....................................16

Database Development and Mapping .................................................................................17

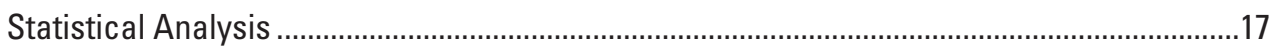

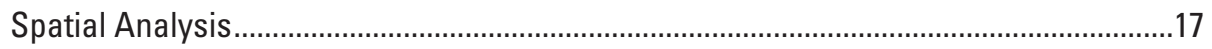

Comparing Persistent Organic Pollutant Values to Wetland Characteristics .................17

Results

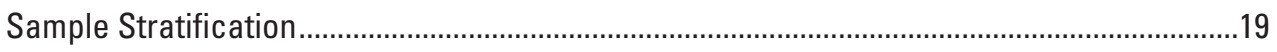

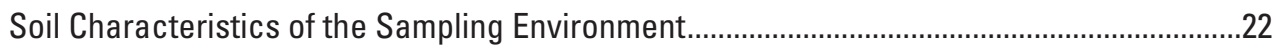

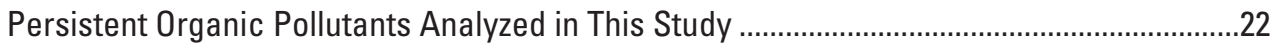

Laboratory Quality Assurance and Control ................................................................24

Results of Organochlorine Pesticide Analysis................................................................24

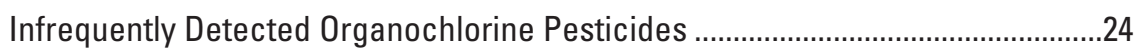

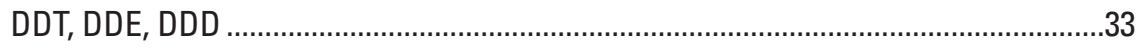

Endosulfan, Endrin, and Hexachlorobenzene …………..........................................3

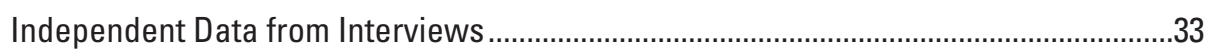

Results of Polychlorinated Biphenyl Analyses .............................................................40

Organochlorine Pesticide Concentration in Relation to Wetland Environment........................40

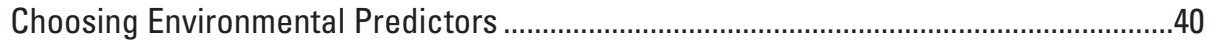

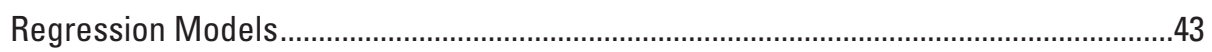

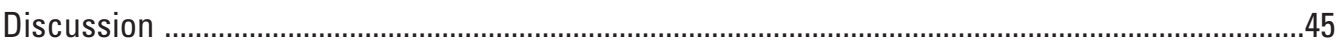

Pattern and Magnitude of Persistent Organic Pollutant Contamination

in Wetlands of the Mekong Basin ...........................................................................4

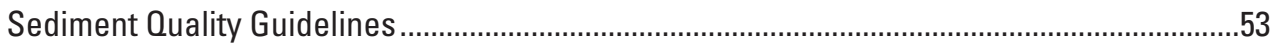

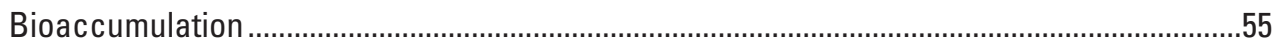

Individual Persistent Organic Pollutant Results …….......................................................5

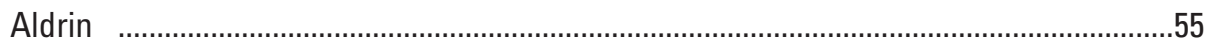

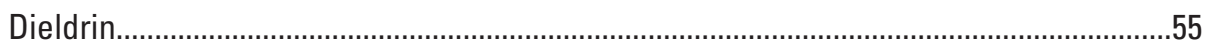

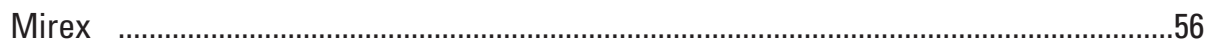

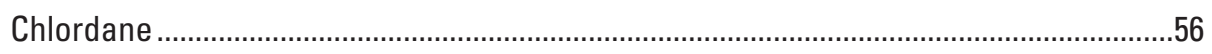

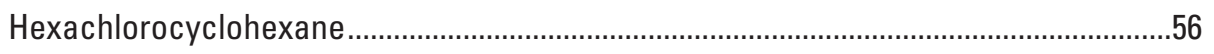

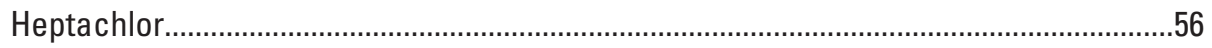

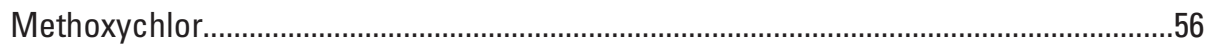

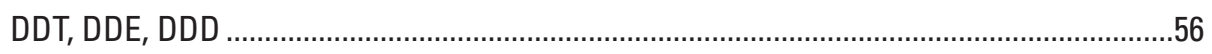

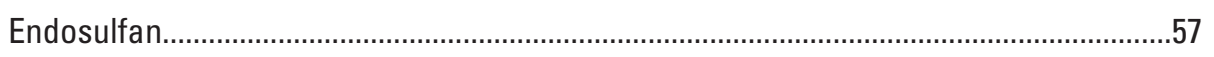

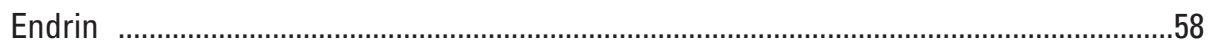

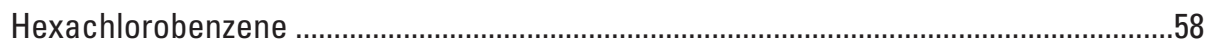

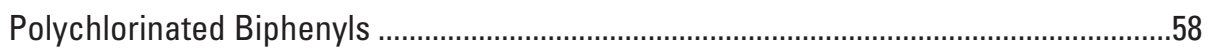

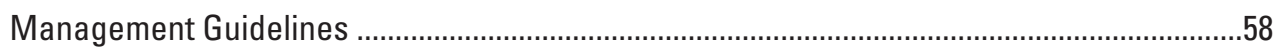

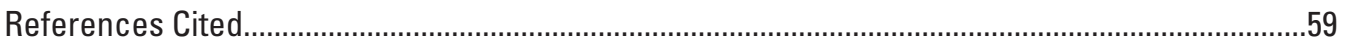

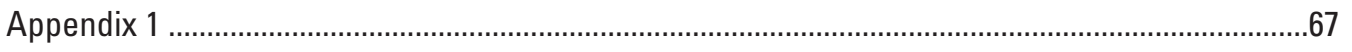

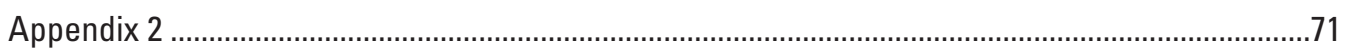

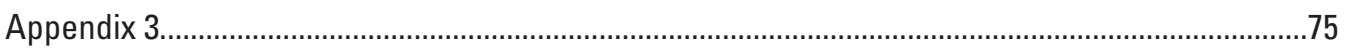

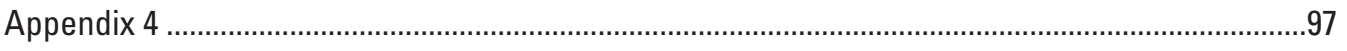

Appendix 5

Appendix 6 109

Appendix 7 135 


\section{Figures}

1. Map showing regional points of interest in the Mekong Basin........................................8

2. Map showing ecological regions within which sediment samples were obtained across the Lower Mekong River Basin during 2011 .................................

3. Chromatographs of spiked samples with different reagents for sulfur removal .............15

4. Graph showing soil colors from 435 of 462 soil samples where soil color was noted

5. Map showing geographic distribution of 531 samples collected from the Lower Mekong River Basin in 2011.

6. Graph showing detection frequency of organochlorine pesticide residues for 21 substances analysed in this study

7. Map showing distribution and concentrations of cis- and trans-chlordane found in 531 sediment samples collected from the Lower Mekong River Basin during 2011

8. Map showing distribution and concentrations of dieldrin found in 531 sediment samples collected from the Lower Mekong River Basin during 2011

9. Map showing distribution and concentrations of DDT, DDE , and DDD found in 531 sediment samples collected from the Lower Mekong River Basin during 2011

10. Graph showing ratio of (DDE + DDD)/ total DDTs found in 531 samples

collected from the Lower Mekong River Basin during 2011.

11. Map showing distribution of DDT, DDD, and DDE concentrations expressed as the ratio found in 531 samples collected from the Lower Mekong River Basin during 2011

12. Map showing distribution and concentrations of endosulfan sulfate, alpha-endosulfan, and beta-endosulfan found in 531 sediment samples collected from the Lower Mekong River Basin during 2011.

13. Map showing distribution and concentrations of endrin and endrin aldehyde found in 531 sediment samples collected from the Lower Mekong River Basin during 2011

14. Map showing distribution and concentrations of hexachlorobenzene found in 531 sediment samples collected from the Lower Mekong River Basin during 2011

15. Frequency of all organochlorines in relation to land use of areas surrounding sampled wetlands.

16. Map showing distribution and concentrations of $P C B_{28}$ found in 61 sediment samples collected from the Lower Mekong River Basin during 2011

\section{Tables}

1. Recoveries and reproducibility of the selected organochlorines by using hexane acetone and diethyl ether acetone as extracting solvents

2. Categorical and numerical environmental predictor variables used in logistic regression analyses

3. Samples collected from different ecological regions nested within each geographical region

4. Samples collected in different wetland systems and subsystems .20 
5. Ecological attributes for sampling point locations within wetlands or for the entire wetland sampled

6. Long-term soil moisture content for the top layer of soil in relation to color and the codes used for analysis.

7. Persistent organic pollutants analyzed in this study. .23

8. Persistent organic pollutants banned worldwide by the Stockholm Convention............23

9. Results of replicate samples as analyzed by Central Laboratory for Analysis and Chemistry Department at the University of Science, Vietnam National University-Ho Chi Minh City and U.S. Geological Survey National Water Quality Laboratory

10. Replicate samples sent to the Central Laboratory for Analysis and Chemistry Department at the University of Science, Vietnam National University-Ho Chi Minh City throughout the laboratory analysis phase that were marked as regular samples but taken from the replicate sample from Hoa An Field Station.

11. Summary of organochlorine pesticide concentration in 531 samples collected from the Lower Mekong Basin during 2011

12. Sites with the highest total organochlorine pesticide loading among 531 samples collected from the Mekong Basin in 2011

13. Median, mean, and standard deviation of total DDTs found in 531 sediment samples collected from the Lower Mekong River Basin in 2011

14. Concentrations of polychlorinated biphenyl compounds in 61 samples collected from the Lower Mekong River Basin during 2011

15. Logistic regression results for presence of organochlorines in seven $\mathrm{OC}$ groups or metabolites found frequently enough in samples to examine statistically, as well as a measure with all OCs combined

16. Organochlorine pesticides and polychlorinated biphenyls detected in sediments from South, East, and Southeast Asian countries.

17. The Canadian Council of Ministers of the Environment's sediment quality guideline for the protection of aquatic life and the U.S. Environmental Protection Agency's Mid-Atlantic sediment screening benchmarks. 


\section{Conversion Factors}

SI to Inch/Pound

\begin{tabular}{|c|c|c|}
\hline Multiply & By & To obtain \\
\hline \multicolumn{3}{|c|}{ Length } \\
\hline centimeter $(\mathrm{cm})$ & 0.3937 & inch (in.) \\
\hline millimeter $(\mathrm{mm})$ & 0.03937 & inch (in.) \\
\hline meter $(\mathrm{m})$ & 3.281 & foot $(\mathrm{ft})$ \\
\hline kilometer $(\mathrm{km})$ & 0.6214 & mile (mi) \\
\hline kilometer $(\mathrm{km})$ & 0.5400 & mile, nautical (nmi) \\
\hline meter $(\mathrm{m})$ & 1.094 & yard (yd) \\
\hline \multicolumn{3}{|c|}{ Area } \\
\hline square meter $\left(\mathrm{m}^{2}\right)$ & 0.0002471 & acre \\
\hline hectare (ha) & 2.471 & acre \\
\hline square meter $\left(\mathrm{m}^{2}\right)$ & 10.76 & square foot $\left(\mathrm{ft}^{2}\right)$ \\
\hline hectare (ha) & 0.003861 & square mile $\left(\mathrm{mi}^{2}\right)$ \\
\hline \multicolumn{3}{|c|}{ Volume } \\
\hline liter (L) & 33.82 & ounce, fluid (fl. oz) \\
\hline liter (L) & 2.113 & pint (pt) \\
\hline liter (L) & 1.057 & quart (qt) \\
\hline liter (L) & 0.2642 & gallon (gal) \\
\hline liter $(\mathrm{L})$ & 61.02 & cubic inch $\left(\right.$ in $\left.^{3}\right)$ \\
\hline milliliter (mL) & 0.03382 & ounce, fluid (fl. oz) \\
\hline microliter $(\mu \mathrm{L})$ & $3.3814 \mathrm{e}-5$ & ounce, fluid (fl. oz.) \\
\hline \multicolumn{3}{|c|}{ Mass } \\
\hline $\operatorname{gram}(\mathrm{g})$ & 0.03527 & ounce, avoirdupois (oz) \\
\hline nanogram (ng) & $3.5274 \mathrm{e}-11$ & ounce, avoirdupois (oz) \\
\hline
\end{tabular}

Temperature in degrees Fahrenheit $\left({ }^{\circ} \mathrm{F}\right)$ may be converted to degrees Celsius $\left({ }^{\circ} \mathrm{C}\right)$ as follows:

${ }^{\circ} \mathrm{C}=\left({ }^{\circ} \mathrm{F}-32\right) / 1.8$

Concentrations of chemical constituents in water are given either in milligrams per liter (mg/L) or micrograms per liter $(\mu \mathrm{g} / \mathrm{L})$.

Frequencies are given in hertz $(\mathrm{Hz})$, equivalent to cycles per second.

Horizontal coordinate information is referenced to the World Geodetic System 1984 (WGS 84). 



\title{
Persistent Organic Pollutants in Wetlands of the Mekong Basin
}

\author{
By T. Tran, ${ }^{1,4}$ J. Barzen, ${ }^{1}$ S. Choowaew, ${ }^{2}$ M. Engels, ${ }^{1}$ N.V. Duong, ${ }^{3}$ M.A. Nguyen, ${ }^{4}$ K. Inkhavilay, ${ }^{5}$ S. Kim, ${ }^{6}$ S. Rath, \\ B. Gomotean, ${ }^{8}$ T.X. Le,${ }^{4}$ K. Aung, ${ }^{9}$ D.H. Nguyen, ${ }^{4}$ R. Nordheim,${ }^{10}$ L.S.T. Ho, ${ }^{10}$ D.M. Moore, ${ }^{1}$ and S. Wilson ${ }^{11}$
}

\section{Abstract}

In this study, the presence and concentration of persistent organic pollutants (POP) were assessed in surface sediments collected from a wide variety of wetlands located throughout the Mekong Basin in Myanmar, Lao People's Democratic Republic (PDR), Thailand, Cambodia, and Vietnam. Of the 39 POPs tested in 531 sediment samples, dichlorodiphenyltrichloroethane (DDT) and its metabolites, endosulfan, hexachlorobenzene (HCB), and endrin were most commonly detected. Even though DDT was banned in the 1990s, some use of DDT may still be occurring in the Mekong Basin. The amount of metabolites for DDT - dichlorodiphenyldichloroethylene (DDE) and dichlorodiphenyldichloroethane (DDD) - found, however, suggests that use of DDT is on the decline throughout the region. HCB and endrin were found distributed broadly throughout the Mekong Basin but not in high amounts. The concentration and distribution of endosulfan and its metabolites represent a serious problem requiring further study and management action. While the total loading of POPs in wetland sediments of the Mekong Basin was generally low, hotspot sites occurred where concentrations exceeded established ecological risk thresholds. For example, wetlands of the open, dry dipterocarp forest of northern Cambodia and Vietnam, as well as wetlands in the Mekong Delta of Vietnam, contained high concentrations of some POPs. High concentrations of POPs were detected in some wetlands important for biodiversity conservation. Hotspots identified in wetlands

\footnotetext{
${ }^{1}$ International Crane Foundation, Baraboo, Wisconsin, USA

${ }^{2}$ Mahidol University, Salaya, Nakhonpathom, Thailand

${ }^{3}$ Can Tho University, Can Tho, Vietnam

${ }^{4}$ University of Science, Ho Chi Minh City, Vietnam

${ }^{5}$ National University of Laos, Vientiane, Lao PDR

${ }^{6}$ Royal Agriculture University, Phnom Penh, Cambodia

${ }^{7}$ Royal University of Phnom Penh, Phnom Penh, Cambodia

${ }^{8}$ Mahasarakham University, Mahasarakham, Thailand

${ }^{9}$ Yezin Agriculture University, Nay Pi Taw, Myanmar

${ }^{10}$ University of Wisconsin, Madison, Wisconsin, USA

${ }^{11}$ U.S. Geological Survey, Lafayette, Louisiana, USA
}

such as the Tonle Sap not only had concentrations of DDT and DDE that exceeded Canadian and U.S. benchmarks, but fauna sampled in the area also showed high degrees of bioaccumulation of the same substances. Further and more extensive attention to monitoring POP presence in water birds, fish, and other aquatic organisms is warranted because of the bioaccumulation of these chemicals at higher levels in the food chain. This study represents a collaboration of eight universities from five countries in the Mekong Region (Myanmar, Lao PDR, Thailand, Cambodia and Vietnam) and four universities and research institutions from the United States. Funding for the study came from the Lower Mekong Initiative, U.S. Department of State.

\section{Executive Summary}

Persistent organic pollutants (POP) are chemicals that induce toxic effects in humans and other organisms. In addition to these pollutants' inherent toxicity, POPs prove problematic because of their resistance to degradation and their accumulative quality. Accumulative quality means that, over time, the quantity of POPs, such as organochlorine pesticides (OC), within the fatty tissues of an organism (especially species at higher trophic levels) increases. POPs also accumulate in soils and sediments. With the bioaccumulation of OCs in the fatty tissues of fish, amphibians, snakes, and water birds, exposure to OCs represents a significant potential threat to people living in the Mekong Basin because these animals make up an extensive part of many people's diets.

The study area encompassed the entire Lower Mekong Basin in Lao People's Democratic Republic (PDR), Thailand, Cambodia, and Vietnam, as well as the basin area in Myanmar, which is often considered to belong to the Upper Mekong Basin. The presence and concentration of POPs were assessed by analyzing surface sediments collected from a wide variety of wetlands located throughout the Mekong Basin. Most POPs are hydrophobic, which means that these pollutants do not dissolve readily in water. When POPs enter an aquatic environment they often bind to organic matter and accumulate 
in wetland sediments. In addition, wetlands are often located within the lower elevations of a landscape and can act as "sinks," or collection areas, for POPs used in the surrounding areas and are, therefore, the ideal matrix for assessing spatial and accumulated concentrations of POPs.

Wetlands of the Mekong Basin are numerous and varied, ranging from small wetlands of a few hundred square meters that are scattered through extensive open, mixed forest to the major flood plain wetlands of the Mekong Delta that are as large as 1 million hectares. Because the hydrology of wetlands that we studied is dominated by a monsoonal climate distributed across the large Mekong Catchment, the characterization and definition of wetlands in the Mekong Basin are complex. We have a limited understanding of the important ecological role wetlands play in the Mekong Basin, especially in their potential role of linking POPs with fish and people.

The main purpose of this study was to assess the magnitude and distribution of POPs across wetlands of the Mekong Basin. Paddy rice farming is the predominant type of agricultural land use in the region, and the study focus for POPs was on the OC pesticide group because OCs were typically incorporated into agricultural pesticides, with a less intensive survey of polychlorinated biphenyls (PCB) that are more typical of industrial pollutants. An attempt also was made to understand how ecological factors might predict the distribution and frequency of POPs found in wetlands. Specifically, the hypothesis was tested that POPs could be distributed over large distances through the extensive stream networks within the Mekong Basin. Lastly, the potential threat that any detected POPs might pose to people and wildlife was assessed.

The majority of wetlands sampled were from palustrine wetland systems, dominated by emergent aquatic vegetation. For sampling sites located on deep water wetlands, about two-thirds of sediment samples came from the limnetic zone and one-third from the littoral zone. Hydrologically, sampled wetlands were equally dispersed between wetlands that were connected to a river by channel flow and wetlands that were not. Wetland hydrological conditions were also balanced between inundated and flowing. The primary composition found in the top layer of each sediment sample was clay or sand, and these sediments were primarily saturated or inundated all year long. The goal of collecting samples from similar wet environments where POPs might aggregate was met.

Of the 21 OCs surveyed for 531 samples collected from wetlands of the Mekong Basin, only a few OCs occurred in high concentrations. Chlordane, dieldrin, hexachlorocyclohexane, and methoxychlor were detected infrequently and at low concentrations. Aldrin, heptachlor, and mirex were not detected in any samples. Original chemicals or metabolites of dichlorodiphenyltrichloroethane (DDT), endosulfan, hexachlorobenzene (HCB), and endrin were most commonly detected in our study. From the 531 sediment samples, a subset of 61 samples were also tested for 18 PCBs. Only 4 samples contained PCBs, and only one isomer of the 18 tested $\left(\mathrm{PCB}_{28}\right)$ was found.
Even though DDT was banned in the 1990s, some use of DDT may still be occurring in the Mekong Basin. The amount of DDT metabolites (dichlorodiphenyldichloroethylene, DDE and dichlorodiphenyldichloroethane, DDD) detected, compared to DDT in an undegraded form, suggested that the use of DDT is on the decline throughout the region. HCB and endrin were found distributed broadly throughout the Mekong Basin but not in high concentrations. The occurrence and distribution of endosulfan, as well as its metabolites, represent a serious problem requiring further study and management action. Although the total concentration of POPs in wetland sediments of the Mekong Basin was generally low, hotspot sites occurred where concentrations exceeded established ecological risk thresholds. Of special concern were sites with high concentrations of DDT, DDE, beta-endosulfan, and endrin.

Evidence of bioaccumulation for OCs has been found in the Mekong Basin in specific areas. The sampled wetland ecosystems provide extensive breeding and juvenile habitat for migratory fish in the Mekong River system. Hotspots identified in wetlands such as the Tonle Sap not only had concentrations of DDT and DDE that exceeded Canadian and United States benchmarks, but fauna sampled in the area also showed significant bioaccumulation of the same substances. With the bioaccumulation of these chemicals at higher levels in the food chain, further and more extensive monitoring of OC bioaccumulation in the fatty tissues of water birds, fish, and other aquatic organisms is warranted.

High concentrations of POPs were detected in some wetlands important for biodiversity conservation. For example, wetlands of the open dry dipterocarp forest of northern Cambodia and Vietnam, as well as wetlands in the Mekong Delta of Vietnam, contained high concentrations of some OCs. Animals congregate in wetlands for water, food, and shelter, thereby potentially allowing deleterious accumulations of POPs in small areas to have broader effects on wildlife populations.

The distribution of OCs in wetlands of the Mekong Basin varied among the 21 OCs tested. Hotspots for chlordane and its metabolites, for example, occurred in Myanmar's and Vietnam's portions of the Mekong Basin but in few other areas. Some hotspots were identified in wetlands under conservation protection in Thailand, although the presence of few OCs were otherwise detected in that country. Identified hotspots should be examined more closely to better understand the presence of POPs and potentially determine the sources as well as temporal factors for accumulation of pollutants.

Though few wetlands were located near fruit and vegetable plantations, OCs were present in almost three-fourths of the wetlands near these types of agricultural land. Most importantly, regression models suggested that wetlands located near urban (populated) areas had more OCs detected than would have occurred by chance. This scenario was true for DDE; DDD; the combination of DDT, DDE, and DDD; HCB; and the combination of all OCs. The regression-model-based data are important because they suggest that the overriding factor influencing OC distribution is the presence of human activities 
and populations. For example, in regression models where OC distribution was considered in combination with landuse data, most OCs appeared to accumulate in wetlands near agricultural land and near populated areas (such as DDT for mosquito control).

Ecological characteristics were helpful in explaining the distribution of OCs throughout the region. OCs are likely distributed by water, moving from land to wetland or moving short distances in streams, but they do not appear to be transported for extensive distances by streams or larger waterways. Though there was evidence that suggested OCs move through river systems, this movement appeared small in significance compared to correlations between the presence of OCs and the various aspects of human occupancy (land use, distance to population centers, failure of POPs to accumulate in wetlands as sampling moved downstream from the Mekong source, and regional effects).

Future actions may include identifying hotspots, analyzing these sites with available information, and increasing the sampling near these sites to determine the extent of the contaminated area. Further examination is needed regarding how bioaccumulation occurs in the fatty tissues of fish, amphibians, snakes, and water birds in the Mekong Basin (particularly in hotspots) and to what degree fish movement, if they are contaminated with POPs, may increase exposure to humans and wildlife. More detailed analyses of hotspots would be an important early step in better understanding the origination and occurrence of hotspots. Other contaminants, such as heavy metals, should also be examined, as these contaminants could pose additional risks. Lastly, monitoring systems to address future issues, such as detecting new hotspots, should be established in the region. The expertise necessary to implement all phases of this monitoring system now exists within the region.

Assessing sediments for POPs over the entire Mekong Basin requires more resources than exist at any one university, government agency, or nonprofit organization. Our solution was to engage eight member universities of the University Network for Wetland Research and Training in the Mekong Region to conduct surveys throughout the region. Financial support for this effort came from the U.S. Department of State, the U.S. Geological Survey, and the John D. and Catherine T. MacArthur Foundation. In-kind support was provided by Can Tho University, Flatrock Geographics, International Crane Foundation, Mahidol University, Mahasarakham University, National University of Laos, Royal University of Agriculture, Royal University of Phnom Penh, University Network for Wetland Research and Training in the Mekong Region, University of ScienceVietnam National University-Ho Chi Minh City, University of Wisconsin-Madison, and Yezin Agriculture University.

\section{Introduction}

Persistent organic pollutants (POP) are industrially synthesized organic chemicals that (1) persist over long time periods in the environment; (2) accumulate in tissues of living organisms and are often found in higher concentrations at upper levels of food chains; (3) are toxic to wildlife and people; and (4) can be transported over long distances by natural processes that involve soil, water, and wind (Wahlstrom, 2003). POPs may be divided into two broad groups: agricultural pesticides (typically organochlorines $[\mathrm{OC}]$ ) and industrial chemicals; however, a few POPs, such as hexachlorobenzene (HCB), pentachlorobenzene, and mirex, were used as both pesticides and industrial chemicals. Polychlorinated biphenyls (PCB) belong solely to the industrial group of POPs. Some POPs, dioxin and furan for example, are generated unintentionally as byproducts of various industrial processes. Problems associated with POPs are not only found in rural areas, where agricultural applications of OC pesticides are the predominant POP usage, but also found in urban and industrial areas, where POP stockpiles and dump sites, industrial manufacturing processes, solid waste landfills, incineration, and disease vector control programs involve the emission of large quantities of POPs (Harrad, 2010).

Many POPs were originally developed and synthesized for use during the 1930-40s (Jones and de Voogt, 1999) and therefore represent relatively old chemistry. POP applications became widespread in North America, Europe, and other industrialized countries during the 1950s and 1960s. By the early 1970s, however, concerns over environmental persistence and adverse effects on humans and wildlife (Carson, 1962) culminated in restricting or halting POP use and production in Europe and North America (Jones and de Voogt, 1999). Subsequent restrictions and bans became worldwide by the late 1990s and early 2000s. In Southeast Asia, most POPs were banned at this time and dichlorodiphenyltrichloroethane (DDT) use was only allowed on a restricted basis for disease control (United Nations Environment Programme Chemicals Branch, 2002, 2003). Environmental burdens and implications for human health from worldwide use of POPs, however, still remain and need to be assessed as well as mitigated (Schwarzenbach and others, 2006).

OC pesticides such as aldrin, dieldrin, endrin, chlordane, lindane, mirex, heptachlor, toxaphene, and DDT are considered the main constituents of POP contamination in developing countries with economies that depend heavily upon agricultural production (Gevao and others, 2010). Even though the production and use of these pesticides ceased in developed countries during the 1970s, they were still produced and used in some developing countries well into the late 1990s, especially in China, India, and Southeast Asia (Loganathan and Kannan, 1994; Voldner and Li, 1995; United Nations Environment Programme Chemicals Branch, 2002; Wong and others, 2005; Li and others, 2007). 


\section{Persistent Organic Pollutants and Their Impacts on Human Health and the Environment}

POPs can cause adverse health effects in wildlife and humans, including damage to the central and peripheral nervous systems; disruption to the immune, endocrine, and reproductive systems; birth defects; and cancer (International Agency for Research on Cancer, 1974; Safe, 1994). In birds, for example, OCs such as DDT disrupt calcium metabolism and cause egg shells to be weak and prone to breakage (Ratcliffe, 1967; Prest and others, 1970; Blus and others, 1972). For bird species in high places on the food chain that eat fish, such as bald eagles (Haliaeetus leucocephalus), reproduction decreased to the point where many populations were or were nearly extirpated because of exposure to OCs (Hickey and Anderson, 1968). For humans, many POPs (for example, aldrin, dieldrin, chlordane, DDT and it metabolites, heptachlor, $\mathrm{HCB}$, hexachlorocyclohexane $[\mathrm{HCH}]$, and $\mathrm{PCBs})$ are considered probable carcinogens (Agency for Toxic Substances and Diease Registry, 1994, 2000b, 2002a, 2002b, 2002d, 2007; U.S. Environmental Protection Agency, 2002; United Nations Environment Programme Chemicals Branch, 2002).

In light of global concerns over the adverse effects of POPs, the Stockholm Convention on Persistent Organic Pollutants (hereinafter referred to as "the Stockholm Convention") was established in May 2004. The Stockholm Convention is an international treaty dedicated to orchestrating an international effort to minimize and eliminate the production and use of POPs, in order to protect people and the environment. Currently (October 2012), the Stockholm Convention lists 18 POPs under "Annex A" (chemicals to be eliminated) and 2 POPs under "Annex B" (chemicals to be used with restriction) (http://chm.pops.int/Convention/ ConventionText/tabid/2232/Default.aspx).

POPs enter freshwater and marine ecosystems through atmospheric deposition, runoff, point-source releases, and other means. Most POPs are hydrophobic and do not dissolve readily in water. Water solubility of POPs can be expressed by their octanol-water partition coefficients, denoted as $\mathrm{K}_{\mathrm{ow}}$. $\mathrm{K}_{\text {ow }}$ is considered one of the most important physicochemical properties relating to environmental behavior of hydrophobic organic compounds (Pontollilo and Eganhouse, 2001).

Logarithms to base 10 of $\mathrm{K}_{\text {ow }}\left(\log \mathrm{K}_{\text {ow }}\right)$ have values from 1 to 7 , with values closer to 7 representing compounds that are mostly insoluble in water. Except for endosulfan $\left(\log \mathrm{K}_{\mathrm{ow}}=3.55\right)$ and HCHs $\left(\log \mathrm{K}_{\mathrm{ow}}=3.72-4.14\right)$, all other OCs included in this study have $\log \mathrm{K}_{\mathrm{ow}}$ values in the range of 5.08-6.91 (Agency for Toxic Substances and Disease Registry, 1994, 1995, 1996, 2000a, 2000b, 2001, 2002a, 2002b, 2002c, 2002d, 2005, 2007), indicating their insolubility in water. When POPs enter an aquatic environment, they sink and are bound to organic matter in sediments. Wetlands are often located in the lower part of a landscape and can act as "sinks," or collection areas for POPs used in the surrounding areas. Wetland sediments are, therefore, the ideal matrix for assessing spatial and temporal concentrations of POPs (Jones and de Voogt, 1999; Gevao and others, 2010).

\section{Wetlands of the Mekong Basin and the Main Purpose of this Study}

Wetlands of the Mekong Basin are numerous and varied, ranging from small wetlands of a few hundred square meters $\left(\mathrm{m}^{2}\right)$ in size and scattered through extensive open dry forest (Nguyen and others, 2004) to major flood plain wetlands of the Mekong Delta (Tran and others, 2000; Safford and others, 2009) that are as large as 1 million hectares (ha). Because the hydrology of the wetlands in the Mekong Basin is dominated by a monsoonal climate distributed across the large Mekong Catchment, their characterization and definition is complex (Mekong River Commission, 2001a; Finlayson and others, 2002). A large proportion of these wetlands remain poorly defined and understood, even though they may be keystone components of many ecosystems, such as the open dry dipterocarp forest (Barzen, 2004; Tran and Nguyen, 2004). Wetlands play an important ecological role in the Mekong Basin, and the data gathered from these wetlands may significantly aid in the study of POPs in Southeast Asia.

The main purpose of our study was to assess the magnitude and distribution of POPs within the wetlands of the Mekong Basin. Because paddy rice farming is the predominant type of agricultural land use in the region, our examination of POPs focused on the OC pesticide group, a group of pesticides that are commonly used in agriculture. The study area encompassed the entire Lower Mekong Basin in Lao PDR, Thailand, Cambodia, and Vietnam, as well as the basin area in Myanmar, which is often considered to belong to the upper Mekong Basin. Landforms of the study area are highly complex and include the mountainous region of northern Lao PDR, the Khorat Plateau in northeast Thailand, the central highlands of Vietnam, the Mekong Lowland, the Tonle Sap Basin, and the Mekong Delta (Gupta, 2009). Within that vast environment, sampling took place only in wetlands, which are often located at the lowest part of the landscape. Attempts also were made to understand what ecological factors might predict why and where POPs were found in various wetlands, and specifically, to test the hypothesis that POPs could be distributed over large distances through the extensive stream networks within the Mekong Basin. Lastly, an attempt was made to highlight threats that any POP contamination found by this study might pose for humans and wildlife in the Mekong Basin. 


\section{The Use and Control of Some Organochlorine Pesticides and Polychlorinated Biphenyls in Countries of the Mekong Basin}

All the POPs described in the following sections were included in this study, and all are currently banned under the Stockholm Convention. Information regarding governmental regulation of these POPs was based on United Nations Environment Programme Chemicals Branch (2002).

\section{Aldrin}

Aldrin was produced and used widely from 1950 to 1980 , mainly to control soil pests such as termites, corn rootworm, wireworm, rice water weevil, and grasshoppers (Agency for Toxic Substances and Disease Registry, 2002d). Aldrin is moderately persistent with a half-life in soil and water ranging from 20 days to 1.6 years (United Nations Environment Programme Chemicals Branch, 2002). In the environment, aldrin can be quickly lost through volatilization or broken down to dieldrin via biotransformation (Zitko, 2003a). Aldrin was banned in Thailand in 1988 and in Cambodia, Lao PDR, and Vietnam in 1992.

\section{Chlordane}

Chlordane was used primarily as an agricultural insecticide, but it was also used for the control of cockroaches, ants, termites, and other household pests (Agency for Toxic Substances and Disease Registry, 1994). Technical chlordane is a mixture of more than 140 compounds, 60 to 85 percent of which are of the two stereoisomers, cis-chlordane and trans-chlordane (Agency for Toxic Substances and Disease Registry, 1994). The half-life in soil is 4 years (United Nations Environment Programme Chemicals Branch, 2002). In some poorly drained soils, chlordane compounds may persist for more than 20 years (Agency for Toxic Substances and Disease Registry, 1994). Chlordane was banned in Vietnam in 1992 and in Thailand in 2000. It was also banned in Cambodia and Lao PDR, but there is no information on the exact time the ban came into effect for these two countries.

\section{Dieldrin}

Dieldrin is chemically similar to aldrin and was used as an agricultural insecticide as well as for termite control in the wood industry (Agency for Toxic Substances and Disease Registry, 2002d). Dieldrin has a half-life of 3 to 4 years and is more persistent in the environment than aldrin (United Nations Environment Programme Chemicals Branch, 2002). Dieldrin was banned in Thailand in 1998 and in Cambodia, Lao PDR, and Vietnam in 1992.

\section{DDT and Its Metabolites}

DDT was once a widely used insecticide for agricultural and public health purposes. DDT was and is still used to kill insects and to control mosquitoes, which function as vectors for diseases such as malaria, dengue fever, and typhus (Agency for Toxic Substances and Disease Registry, 2002a; United Nations Environment Programme Chemicals Branch, 2002; Zitko, 2003a). Dichlorodiphenyldichloroethylene (DDE) and dichlorodiphenyldichloroethane (DDD) are metabolites created by the breakdown of DDT (Agency for Toxic Substances and Disease Registry, 2002a). DDT and its metabolites can persist for long periods in the environment, with half-lives of up to 30 years (Dimond and Owen, 1996). In tropical regions, however, DDT and its metabolites can degrade faster (Agency for Toxic Substances and Disease Registry, 2002a). DDT has not been legally used in the United States since 1972, except in public health emergencies (Agency for Toxic Substances and Disease Registry, 2002a). It was banned in Thailand in 1983 for agricultural purposes and in 2003 for public health applications (United Nations Environment Programme Chemicals Branch, 2002). DDT was also banned in Lao PDR and Vietnam in 1992, as well as in Cambodia (date not specified). In Vietnam, however, large quantities of DDT were still in use after the chemical was banned (United Nations Environment Programme Chemicals Branch, 2002; Pham and others, 2010).

\section{Endosulfan}

Endosulfan was introduced in 1954 as an insecticide (Agency for Toxic Substances and Disease Registry, 2000a) and was effective on more than 100 different types of agricultural insects (United Nations Environment Programme Chemicals Branch, 2002). Technical endosulfan is composed of two isomers, alpha- and betaendosulfan, whereas endosulfan sulfhate is a reaction product found in technical endosulfan. Endosulfan sulfate is also found in the environment as a product of photolysis and biotransformation of endosulfan (Agency for Toxic Substances and Disease Registry, 2000a). In the environment, endosulfan is not as persistent as other POPs, with half-lives of 35 days and 150 days for alpha and beta isomers, respectively (United Nations Environment Programme Chemicals Branch, 2002). Endosulfan is toxic to birds and aquatic organisms (Agency for Toxic Substances and Disease Registry, 2000a) and was added to the Stockholm Convention's "Annex A" POPs to be eliminated in May 2011. There is currently no information on the regulation of endosulfan in countries of the Mekong Region. 


\section{Endrin}

Endrin is a pesticide that was used to control a wide range of agricultural pests, such as insects, rats, and birds. Endrin is toxic to aquatic organisms (plankton, invertebrates, fish), with a median lethal dose (LD50) often smaller than 1 nanogram per milliliter (ng/mL; United Nations Environment Programme Chemicals Branch, 2002). Endrin is persistent for long periods in the environment with a reported half-life of 12 years or longer (United Nations Environment Programme Chemicals Branch, 2002). In the environment, endrin can be transformed into endrin aldehyde, albeit only a small proportion of endrin is transformed in this manner (Agency for Toxic Substances and Disease Registry, 1996). Endrin was banned in Thailand in 1981 and in Cambodia, Lao PDR, and Vietnam in 1992.

\section{Heptachlor}

Heptachlor was used mainly to control soil insects, but it was also used to kill mosquitoes for malaria control (Agency for Toxic Substances and Disease Registry, 2007). In the environment, heptachlor is broken down to a more stable heptachlor epoxide. The half-life of heptachlor in soil is 0.7 to 2 years (Agency for Toxic Substances and Disease Registry, 2007). Heptachlor was banned in Thailand in 1998 and in Cambodia, Lao PDR, and Vietnam in 1992.

\section{Hexachlorobenzene}

HCB was used as a fungicide in seed treatment (Zitko, 2003b); however, it was mainly used as an industrial chemical in the production of fireworks, ammunition, and synthetic rubber (Zitko, 2003b). Additionally, HCB is a byproduct in the production of other chlorinated compounds. Moreover, it can also be released into the environment by solid waste incineration and metallurgical industries (Agency for Toxic Substances and Disease Registry, 2002b). HCB has an average half-life of 2.7 to 4.7 years in soil (United Nations Environment Programme Chemicals Branch, 2002). It was banned in Thailand in 2001, but there is no information on its regulation in Cambodia, Lao PDR, and Vietnam.

\section{Hexachlorocyclohexane}

Two forms of commercial $\mathrm{HCH}$ exist, technical $\mathrm{HCH}$, which is a mixture of mainly alpha-, beta-, delta-, and gamma$\mathrm{HCH}$, and lindane, which is 95 percent pure gamma-HCH (Agency for Toxic Substances and Disease Registry, 2005). Lindane is considered one of the most widely formerly used pesticides in the world. It was used to control a wide array of agricultural insects, as well as in textile and wood preservatives (Agency for Toxic Substances and Disease
Registry, 2005). HCHs have average half-lives of 2 years in soil (United Nations Environment Programme Chemicals Branch, 2002). Lindane was banned in Thailand in 2002, but there was no information about the regulation of HCHs in Cambodia, Lao PDR, Myanmar, and Vietnam.

\section{Mirex}

Mirex was an insecticide used mostly for the control of ants, but it was also used as an industrial chemical (fire retardant) (Zitko, 2003a). Technical mirex consists of 85 percent mirex and 15 percent chlordecone. Mirex is one of the most persistent pesticides, with a half-life of more than 10 years (Agency for Toxic Substances and Disease Registry, 1995). Mirex was banned in Thailand in 1985. It was also banned in Cambodia, Lao PDR, and Vietnam, but no information on when the ban came into effect in these countries could be found.

\section{Methoxychlor}

Methoxychlor is an insecticide and is used for controlling flies, mosquitoes, cockroaches, and other insects (Agency for Toxic Substances and Disease Registry, 2002c). It is not banned by the Stockholm Convention and is currently being used in many countries, including the United States and is considered an effective replacement for DDT (Agency for Toxic Substances and Disease Registry, 2002c). Even though methoxychlor is less harmful to humans and animals than banned OC pesticides, it is still persistent in the environment and can be bioaccumulated (Agency for Toxic Substances and Disease Registry, 2002c). There is no information on the history of methoxychlor usage and regulation in the Mekong Region.

\section{Polychlorinated Biphenyl}

PCBs are industrial chemicals used mainly as insulating materials during the production of transformers and capacitors but may also be found in hydraulic and heat exchange fluids and in lubricating and cutting oils (Agency for Toxic Substances and Disease Registry, 2000b). There are as many as 209 different PCB congeners, about 130 of which may be found in commercial products (Agency for Toxic Substances and Disease Registry, 2000b). PCBs enter the environment through landfill wastes that have products containing PCBs, leaks or fires involving electrical equipment that contain PCBs, illegal or improper disposal of PCB wastes, and municipal or industrial solid waste burning. Once in the environment, PCBs can persist, with half-lives in soil of 6 years or longer (United Nations Environment Programme Chemicals Branch, 2002). PCBs, especially the lighter congeners, can enter the air by evaporating from water and 
soil and can therefore be transported far from their source. The production of PCBs was banned in the United States in 1997 (Agency for Toxic Substances and Disease Registry, 2000b), but PCBs were not banned in Thailand until 2004. There is no information regarding PCB regulation in Cambodia, Lao PDR, and Vietnam.

\section{Methods}

\section{Sampling Design}

The design of this study was based on collecting 550 sediment samples from wetlands distributed throughout the Mekong Basin; the number of samples collected were to be in proportion to the percentage of land mass of the basin associated with each country. We proposed to collect samples from all six countries of the Mekong Basin but received permission to collect samples from only five countries. Wetland abundance for each country, as compared to proportions of land mass, differs so we weighted our samples by the wetland abundance assigned to each country. Beyond inventories of major wetland ecosystems in the Mekong Basin (S. Choowaew, Mahidol University, written commun., 2003), accurate data of wetland abundance and distribution for Southeast Asia are incomplete, so our estimates of wetland abundance were approximate. A priori, concentration and distribution of POPs within each country were hypothesized to be stratified among ecological regions, land-use history, and degree of connectivity with rivers, but lack of extensive wetland maps limited a more quantitative stratified random sampling.

\section{Ecological Regions}

Wetlands in the Mekong Basin vary tremendously. In monsoonal climates, wetlands can fluctuate on an annual basis as their water budgets are affected by large inflows during the wet season and by restricted inflows during the dry season. Wetlands can, therefore, vary each year from having areas of deep standing water (for example, the Tonle Sap Lake, fig. 1) to having areas that are completely dry. With this hydrological variation, the length of the inundated period or the depth of inundation for each particular wetland basin determines much about what species might occur (Tran, 2001; Barzen, 2004; Nguyen and others, 2004). Even though wetlands might be located in close proximity, wetlands can still substantially differ ecologically. For example, Mekong Delta mangrove ecosystems have varying degrees of salt concentration because of tidal and river influences, but they can occur near freshwater peat mounds that have no tidal or river influence (freshwater peat wetlands at $\mathrm{U}$ Minh $\mathrm{Ha}$ located near the mangroves along the $\mathrm{Ca} \mathrm{Mau}$ Peninsula, fig. 1). Wetlands chosen for study were, therefore, stratified according to ecological region to examine the full range of pollutant occurrence that might be affected by how efficiently different molecules decompose in various wetlands.

\section{Cambodia}

In Cambodia, four ecological regions were used to group wetlands in our study (fig. 2): Upper Mekong Delta (the portion of the Mekong Delta in Cambodia, upstream from Vietnam; region 11), Tonle Sap Basin (region 10), Mekong flood plain (region 9), and scattered wetlands of the open, dry dipterocarp forest (region 8).

Samples were collected within several areas of the Upper Mekong Delta in southeastern Cambodia. The Upper Mekong Delta includes deep water wetlands, called the Bassac Marshes (Hout and others, 2003), where samples were collected between the two branches of the Mekong River (the Bassac and Mekong Channels). Additional wetland areas west of the Bassac Channel of the Mekong River were sampled in a flood plain recessional wetland that occurs near Takeo (Hout and others, 2003). Boeung Prek Lapouv Wildlife Sanctuary is a remnant of the flood plain ecosystem that typifies the region (Tran, 2003). Lastly, east of the Mekong Channel of the Mekong River, wetland samples were collected from the upper portion of the Plain of Reeds (Meynell and others, 2012).

Within the Tonle Sap Basin, sediments in the permanent open water zone were sampled as well as sediments from wetlands in the Tonle Sap flood plain, including wetlands at Ang Trapeang Thmor Wildlife Sanctuary (Hong and Goes, 2001, fig. 1), Boeng Tonle Chmar (northeast side of the lake), and the inundated forest (Goes, 2005) that surrounds the west side of the lake.

Lake basins located in the flood plain of the Mekong River from the junction of the Mekong and Tonle Sap Rivers upstream to the city of Kratie were hypothesized to be distinct enough to warrant focused sampling (University Network for Wetland Research and Training in the Mekong Region, 2010, unpub. data). Called the Mekong floodplain wetlands, these ecosystems include lake basins that receive floodwaters directly from the Mekong River.

Numerous wetlands are located in the open dry dipterocarp forests, away from the Mekong and Tonle Sap River flood plains, and vary from several 100 ha to less than 1 ha (Barzen, 2004). With varying size, hydrology, humanuse history, and vegetation communities, a stratified sample of these scattered wetlands of the open dry dipterocarp forest was obtained in association with two tributaries of the Mekong River (Sesan and Srepok Rivers, fig. 1) and one tributary of the Tonle Sap River (Sen River, fig. 1) in Cambodia. 


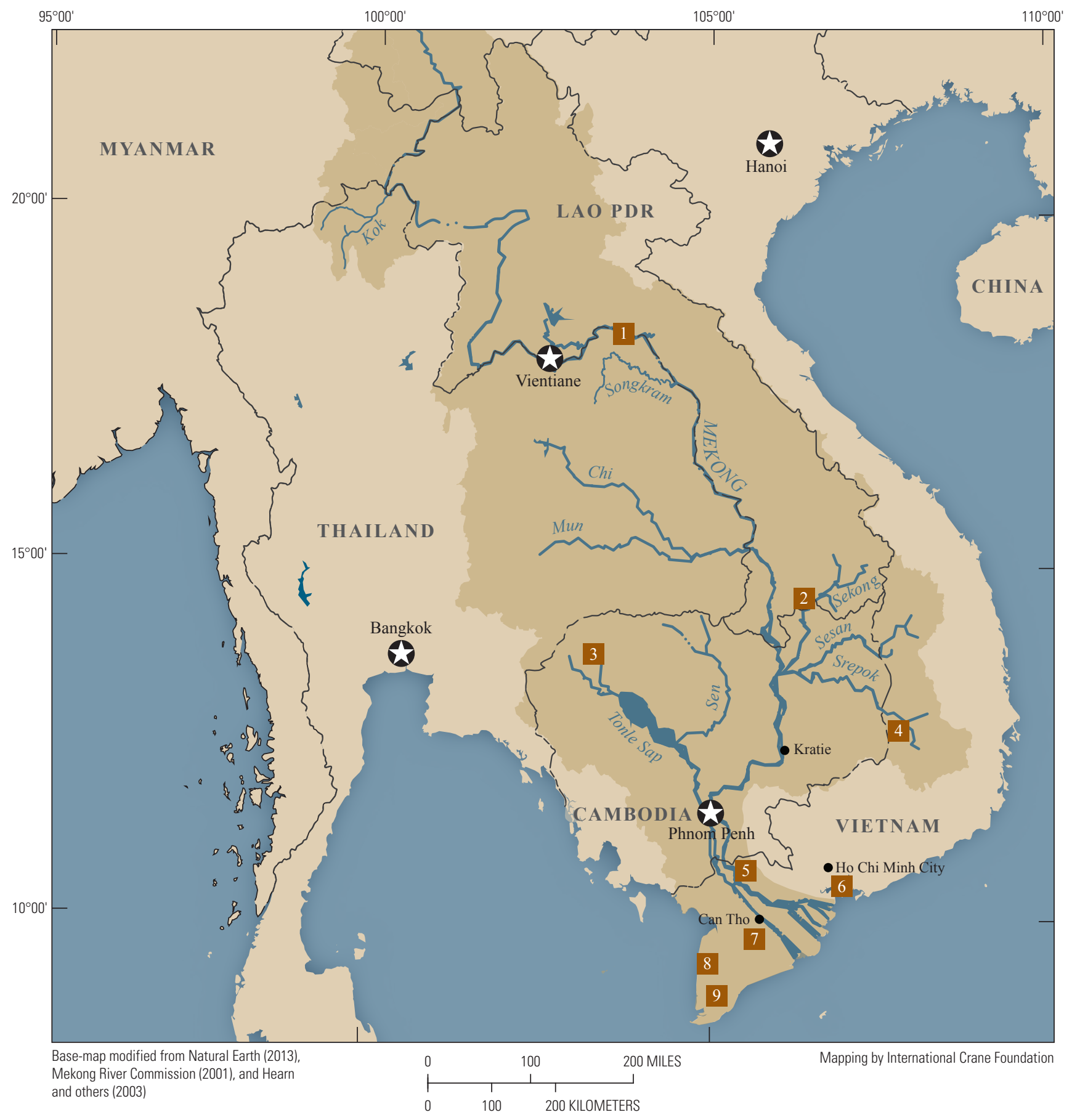

\section{EXPLANATION}

\section{Points of interest in text}

1. Bueng Kan Ramsar Site, Thailand

2. Xepian National Protected Area, Lao PDR

3. Ang Trapeang Thmor Wildlife Sanctuary, Cambodia

4. Yok Don National Park, Vietnam

5. Tram Chim National Park, Vietnam

6. Can Gio National Park, Vietnam

7. Hoa An Field Station, Vietnam

8. U Minh Ha, Vietnam

9. Ca Mau Penisula, Vietnam

Figure 1. Map showing regional points of interest in the Mekong Basin. 


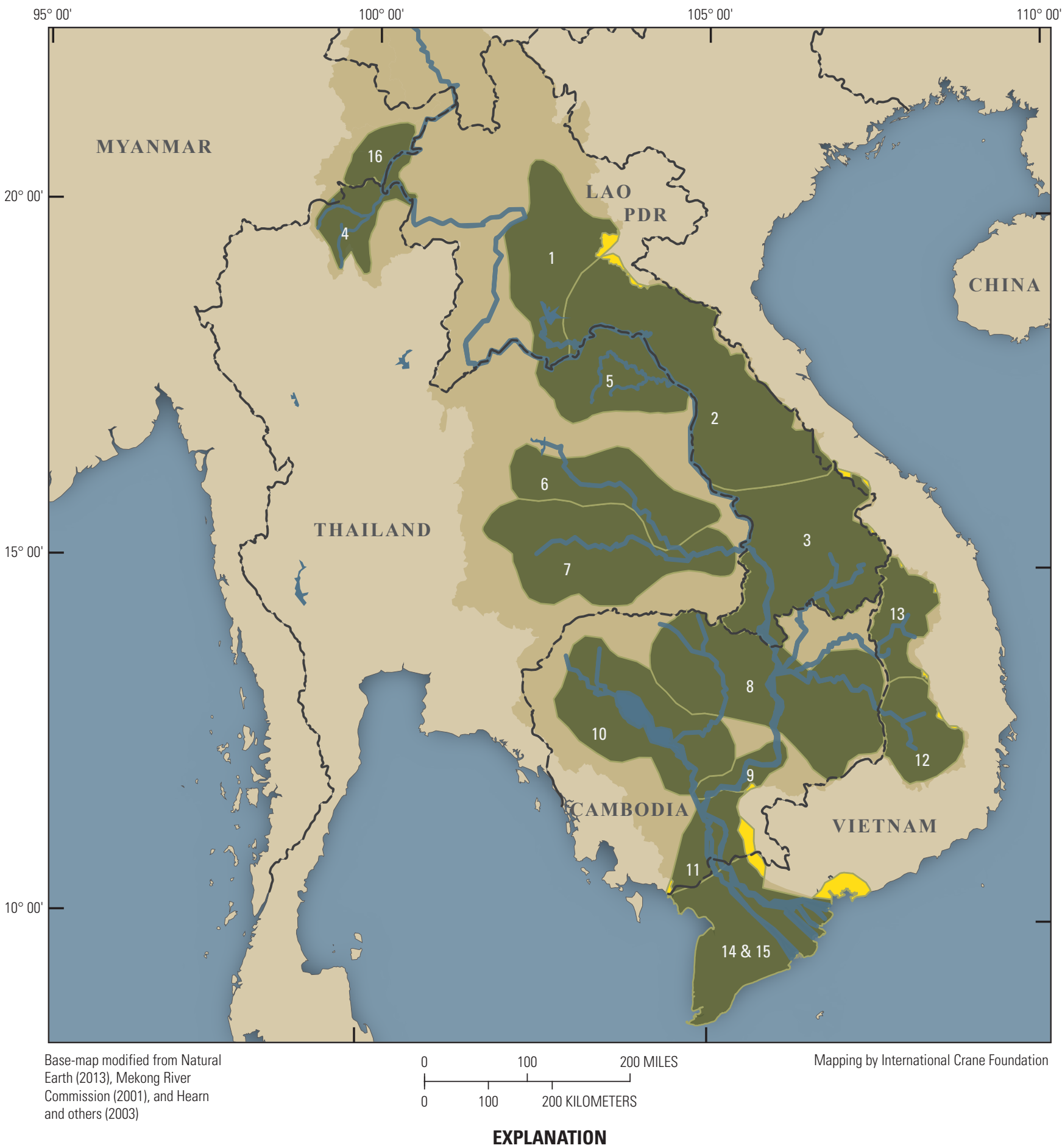

[Ecological regions where sediment samples were obtained]

Ecological regions

1. Northern Lao PDR

2. Central Lao PDR

3. Southern Lao PDR

4. Kok River Basin

5. Songkram River Basin

6. Chi River Basin

7. Mun River Basin

8. Open, dry Dipterocarp forest

9. Mekong Flood Plain

10. Tonle Sap Basin

11. Upper Mekong Delta

12. Srepok River Basin

13. Sesan River Basin

14 \& 15. Coastal//nland Mekong Delta

16. Myanmar Mekong Basin

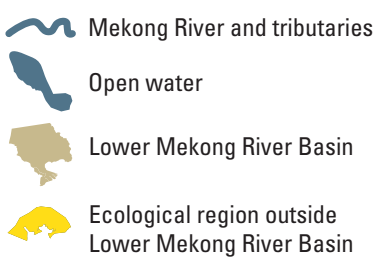

Figure 2. Map showing ecological regions within which sediment samples were obtained across the Lower Mekong River Basin during 2011. A few areas, located outside of the Mekong Basin, were also sampled. 


\section{Lao PDR}

Sampling sites in Lao PDR included wetlands stratified from north to south and approximated the regions defined by the International Union for Conservation of Nature (IUCN) wetland inventory (Claridge, 1996). IUCN's wetland inventory broadly divided the country into three different ecological regions (fig. 2) of northern (region 1), central (region 2), and southern (region 3) Lao PDR. Wetlands sampled in the northern region began in Bokeo Province, which shares borders with Myanmar and Thailand (though no wetlands were sampled in Lao PDR near these two borders), and continued downstream to Luang Prabang and Xiang Khouang Provinces. The northern geographic region overlaps somewhat with what Claridge (1996) defined as "the central region." In this study the central region started in Vientiane Province; included wetlands located in the capital, Vientiane (fig. 1); and extended to Savannakhet Province, which ends upstream from where the Mun River from Thailand joins the Mekong River (fig. 1). Wetlands sampled in the southern ecological region occurred in Champasak and Attapeu Provinces. Isolated wetlands, with less noticeable human impacts, were sampled in National Protected Areas and Provincial Protected Areas such as Xepian National Protected Area (Thewlis and others, 1998; fig. 1) and Dong Khantoung Provincial Protected Area (Duckworth and others, 1999).

\section{Myanmar}

Myanmar contains 2 percent of the Mekong Basin, and the land mass of the Mekong Basin is concentrated just north of the Thai border and just west of Lao PDR (region 16, fig. 2). Sampling sites in Myanmar were all located in the Mekong Basin and found in Tar-chi-laik and Tar-lae Provinces of Shan State. Sampled wetlands included both natural (riverine and associated palustrine) and manmade (mostly rice fields) wetlands. All sampling sites were placed in one ecological zone named "Myanmar Mekong River Basin."

\section{Thailand}

Wetlands sampled in Thailand were concentrated along four tributary river basins of the Mekong River Basin: Kok River Basin in the north (region 4), Songkram River Basin in the northeast (region 5), the Chi River Basin in the central part of the Khorat Plateau (region 6), and the Mun River Basin in the southern portion of the Khorat Plateau (region 7, fig. 2). The Kok River flows into the Mekong River near the border with Myanmar. The Kok River Basin includes wetlands near both the Kok and Ing Rivers. The Songkram River flows into the Mekong River in Nakhon Phanom Province (fig. 1) and region 5 includes numerous wetlands that are hydrologically connected to the Mekong River directly. The Chi River is the largest tributary of the Mun River and contains many wetlands sampled in this study while the Mun River is the largest tributary of the Mekong in Thailand (fig. 1). Wetlands included in the Mun River Basin were found both upstream and downstream from where the Chi River flows into the Mun River (Department of Water Resources, 2009).

\section{Vietnam}

In Vietnam, wetlands were sampled in two major ecological areas: the lower Mekong Delta and the scattered wetlands located in open dry dipterocarp forest in the central highlands (fig. 2). Both ecological regions are adjacent to similar areas in Cambodia. The lower Mekong Delta was further subdivided into inland (region 15) and coastal (region 14) wetlands. Inland wetlands included freshwater sites such as closed basin, flood plain recessional wetlands of the Plain of Reeds. Examples of closed flood plain wetlands in the Plain of Reeds included Tram Chim National Park (fig. 1) and Lang Sen Provincial Reserve (Le, 1993; Beilfuss and Barzen, 1994; Tran, 2005a; Meynell and others, 2012). Open-basin, flood plain recessional wetlands included wetlands such as the Ha Tien Plain (Tran and others, 2000) and Hoa An (Hanhart and $\mathrm{Ni}, 1993$; fig. 1) as well as raised peat swamps (U Minh Ha and U Minh Thuong National Parks; Nguyen, 1990; Safford and others, 1998; Tran, 2005b). Coastal wetlands included mangroves along the Ca Mau Peninsula, as well as estuarine mangroves at the mouth of the Mekong River channels and at Can Gio National Park on the Dong Nai River (Huynh and others, 2003; Tran and Le, 2012; fig. 1). Can Gio estuarine mangroves are not naturally considered part of the Mekong River Basin, but Can Gio can be influenced by canals that link Mekong Delta wetlands, via the Plain of Reeds and the Vam Co River, with wetlands in the Dong Nai River system upstream from Can Gio National Park (Nguyen, 1990).

The central highlands contain lakes, small scattered wetlands, and riverine wetlands that are similar to the ecological region in northern Cambodia described in the preceding "Cambodia" section. Wetlands were sampled in the Srepok (region 12) and Sesan (region 13) River Basins of Vietnam, but the diversity and number of wetlands sampled in the Srepok River were greater because of their more extensive heterogeneity. Wetlands of Yok Don National Park (region 12) tended to vary in size from 0.1 to 1.1 ha (Nguyen and others, 2004; Nguyen, 1996). Outside of Yok Don National Park (fig. 1), larger lakes (with permanent water bodies of 1-500 ha), peat swamps, flood plains, and riverine wetlands were also sampled. Only seven samples were collected along the channel of Sesan River. The flow of the Srepok and the Sesan Rivers, as well as the hydrology of most wetlands connected to these rivers, has been altered by irrigation development and the construction of multiple dams. Rapid forest clearance in the basins may also have induced changes in the hydrology of these wetlands. 


\section{Land Use History and River Connectivity}

Within ecological regions, wetland samples were also stratified by whether or not they were obtained from manmade wetlands, as well as by how inflows to each wetland occurred. Natural wetlands were sampled in equal proportion to manmade wetlands. Reservoirs and rice paddies exemplified manmade wetlands, whereas nonartificial wetlands that were dominated by hydric soils and native hydrophytes were considered natural, even if they were extensively grazed or otherwise used by people. Artificial wetlands were hypothesized to have a greater likelihood of containing POPs than naturally formed wetlands because these wetlands were largely built by people for agricultural purposes.

In addition to how they were formed, wetlands were sampled based on the degree to which they were connected to rivers. If pollutants were moved by river systems, as we hypothesized, then isolated wetlands would have the lowest concentrations of pollutants, followed by wetlands connected to rivers through sheet (nonchannelized surface) flow. Wetlands connected to rivers by channels, therefore, would have an even greater concentration of pollutants than wetlands connected by sheet flow because channel inflows would provide inflows with higher energy and thus more suspended solids, to which pollutants would adhere. A priori, wetlands connected to rivers by both channel and sheet flows would thus have the highest probability of containing pollutants. Subsurface flows (groundwater) were not considered in this analysis.

\section{Within a Wetland, Choosing the Sample Location}

Within each chosen wetland, we selected the lowest elevation from which to sample sediments. Wetlands, because of their low elevation, tend to gather POPs in their sediments (Jones and de Voogt, 1999), so we chose the lowest point of each wetland sampled wherever possible. Most POPs have low water solubility. They can stay in wetland sediment for long periods of time with minimal breakdown and natural decomposition (United Nations Environment Programme Chemicals Branch, 2002); however, some POPs break down relatively quickly under anaerobic conditions, so breakdown is dependent on environmental factors, which need to be considered when interpreting decomposition data for different POPs. Bottom sediments are considered the ultimate sink of POPs in the environment and are often the best matrix for assessing spatial and temporal concentration of hydrophobic organic contaminants (Gevao and others, 2010). Standardizing collection of bottom sediments in the lowest part of each wetland would produce the lowest decomposition rates for POPs if they were present. By collecting samples from the lowest elevation in each wetland, we intended to reduce random variation inherent among different sites within the same wetland so that samples between different wetlands could be compared more effectively. Once chosen, we measured environmental variables at the specific POP sample site as well as more general variables associated more broadly with the wetland itself (such as the presence/absence of invasive species) (see the "Collecting Samples" section).

\section{Describing Wetlands Sampled}

A modified version of the Cowardin wetland classification scheme was followed to classify wetlands at the system, subsystem, and class levels (Cowardin and others, 1979). Specifically, four systems were used: estuarine, lacustrine, palustrine, and riverine. A monsoonal climate has a large influence on the water budgets of wetlands in Southeast Asia, but monsoonal climates are atypical of most regions of North America and therefore not reflected in the Cowardin system. Accordingly, modifications related to vegetation and hydrology were needed to apply the Cowardin wetland classification system to the study area. Terms that describe wetland habitats at "level 4" from the "Asian Wetland Inventory" were used to accomplish this (Finlayson and others, 2002).

\section{Collecting Samples}

\section{Persistent Organic Pollutant Samples}

Samples were collected with stainless steel scoops and placed in stainless steel bowls. A stainless steel petite ponar grab with a 6-inch $\times 6$-inch sampling area and handline operation was used for deep open-water collections in wetlands such as the Tonle Sap Lake. To clean equipment between samples, all equipment was washed with a low phosphate detergent (Liquidnox) and then tap water. The equipment was then rinsed with distilled or deionized water three times, rinsed again with reagent-grade methanol, and air dried in a dust-free environment. Once dried, all sampling equipment was wrapped in aluminum foil, shiny-side out, and sealed in clear plastic bags for transport to the next sample site.

At each site, surface sediments (up to 20 centimeters [cm] deep) were collected at five different locations to form a composite sediment sample. Samples were collected at the center point of the site and 50 meters $(\mathrm{m})$ to the right and left. A fourth sample was collected $50 \mathrm{~m}$ in front of or behind the center point, and the fifth sample was collected $100 \mathrm{~m}$ from the center point in the same direction as the fourth sample. All five samples were mixed in a stainless steel bowl to form the composite sample. The coordinates used to identify the location for the POP sample were recorded at the center point. A photograph was taken of the composite sample, and unusual 
conditions of the composite sample or site were recorded, such as peculiar smells.

Observers worked in pairs; one person was identified as having "clean hands" and another as having "dirty hands." Three pairs of nitrile gloves were worn by both observers. "Clean hands" handled all steps directly related to the sample, whereas "dirty hands" did everything not directly related to the sample. "Clean hands" removed the wrapping from the sampling equipment and the mixing bowl, collected the subsamples with a scoop or a petite ponar grab, placed the subsamples in the bowl, and mixed the subsamples in the bowl. "Dirty hands" opened the outside of the equipment bag, cleared the vegetation from the soil surface prior to sampling, and held the outside of the mixing bowl, while "clean hands" mixed the sample.

After homogenizing the composite sample, "clean hands" cleared the soil sample of any organic material and then filled a fired, amber-baked 500 milliliter $(\mathrm{mL})$ sample bottle with a portion of the sample. "Clean hands" then capped the sample bottle and sealed it with tape to prevent possible opening during shipping, and "dirty hands" labeled the lid of the bottle. Lastly, the sample bottle was placed in Styrofoam to avoid breakage and then placed in a cooler, which was kept in the shade. After sampling, all soil was rinsed from sampling equipment by using water at the sampling location to aid final cleanup in the laboratory. Once back from the field, samples were stored at 4 degrees Celsius $\left({ }^{\circ} \mathrm{C}\right)$.

\section{Descriptive Soil Samples}

Separate soil samples were collected in the dominant vegetation for each wetland site, as close as possible to the lowest substrate elevation of the basin near where each POP sample was taken. By using a soil auger, an undisturbed soil column was collected, $4 \mathrm{~cm}$ in diameter and $100 \mathrm{~cm}$ in length. Soil layers within each column were distinguished by soil depth, color, organic matter content, texture, root density, and biological activity. Soil color was measured with a "Munsell Soil Color Chart" (2009). In some wetlands that contain deep water year-round (Tonle Sap Lake), substrates were too loose to collect a soil profile, so no samples were taken.

To determine the primary soil composition, a simple field technique was used (Bowman and Hutka, 2002). From the top soil layer a sample greater than 2 millimeter $(\mathrm{mm})$ was collected by hand. The sample size was able to fit comfortably in the palm of hand. The soil sample was then moistened with a little water, if it was dry, and kneaded into a bolus. Kneading and addition of water continued until the soil no longer stuck to fingers, and there was no apparent change in plasticity. Then, using a clean, moistened hand, the bolus was placed between thumb and forefinger. Pressure was applied with the thumb as it was slid across the soil (shearing) to extrude a ribbon. A thin, continuous ribbon about $2 \mathrm{~mm}$ thick and 1 $\mathrm{cm}$ wide was the result. The length of the ribbon was then measured to estimate the soil texture. A ribbon length less than $25 \mathrm{~mm}$ was considered sand, one equal to $25-49 \mathrm{~mm}$ was silt, and one greater than $50 \mathrm{~mm}$ was clay.

Similarly, a bolus was created to determine soil moisture at the time of sampling. The same procedures were followed as outlined previously except no water was added; after the bolus was kneaded and formed, it was placed between thumb and forefinger and squeezed. The surfaces of the thumb and forefinger were then observed. If water was visible, the sample was considered "wet." If only a wet water print occurred on the fingers, the sample was considered "moist," and if there was no water print, the sample was "dry" (U.S. Department of Agriculture, 1998).

The color of the top layer of the soil sampled was used to identify the long term (multidecade) soil water content (U.S. Department of Agriculture, 1993). At the red end of the spectrum, the soil was considered "dry and oxidized," whereas at the yellow end of the spectrum, the soil was considered "wet and not exposed to oxygen," creating chemically reduced conditions. Soils that were both yellow and red showed varying degrees of dryness.

\section{Vegetation Samples}

Observers based their estimate of dominant vegetation for the wetland on the vegetation seen immediately around the POP sampling site. Photographs were taken in each cardinal direction to allow verification in the laboratory if questions related to species identification arose. Dominant vegetation was grouped into five vegetation categories (submergent, emergent, shrub, forest, and none) for analysis.

\section{Socioeconomic Data}

Residents that lived near POP sampling locations were interviewed to obtain additional information related to wetland characteristics, wetland resources used by people, surrounding agricultural practices, and uses of agricultural inputs such as pesticides or fertilizers. Occasionally wetlands were isolated and distant from human habitation so it was not possible to find people to interview about the sampled wetland. The information derived from resident interviews provided an independent measure of the relation between human behavior and variables such as long-term wetland soil moisture, hydrological conditions, and biological characteristics that were intended for analysis in relation to POPs. Key methods included (1) field surveys and direct observations on sites; (2) informal interviews with farmers, fishermen, community leaders, and wetland inhabitants; and (3) notes and photographs of human activities within and surrounding wetlands. 
Interview notes included recording information from pesticide labels by photograph or transcribing information listed on bags, bottles and containers (trade names, chemical names, compositions, and use directions) of agricultural inputs observed at sites. A field data collection sheet was developed to organize recorded information and listed guiding questions. Key questions were divided into three major groups, including (1) basic characteristics of the wetland sites such as water sources, maximum water depth, period of water presence, water quality, and trend of change in water permanence among years; (2) types and uses of wetland resources that were important to people such as grazing, fish harvest, collection of vegetation for weaving; and (3) agricultural practices near wetland sites and agricultural inputs, such as pesticides, that were used in the past or were currently being used. In this analysis, several socioeconomic variables were used that had been acquired from interviews: types of pesticides that people were currently using, the number of months the wetland was dry at the deepest point, and land use that occurred in uplands surrounding the wetland sampled.

\section{Laboratory Analysis}

Except where noted, all laboratory analysis was completed at the Central Laboratory for Analysis and Chemistry Department at the University of Science, Vietnam National University-Ho Chi Minh City (VNU). Samples were sent to the laboratory soon after collection, which resulted in groups of 40-60 samples arriving at the laboratory at any one time. All laboratory analysis was completed over 4 months. Each sediment sample was analyzed for $21 \mathrm{OCs}$, and a subset of the sediment samples were analyzed for 18 isomers of PCB.

\section{Chemicals and Instruments}

Sources for substances used in this report include hexane and acetone (HPLC grade), purchased from RCI Labscan Company, Ltd., Thailand; diethyl ether and dichloromethane (for analysis), purchased from Merck and Co.; tetrabutylammonium sulfate and sodium sulfite (for analysis and used to reduce sulfur in the sediments), purchased from Merck and Co.; silica gel (for chromatography), purchased from Scharlau Science Group, Spain; and sodium sulfate, sodium chloride, and ammonium chloride (for analysis), purchased from China. All OC and PCB standards were products of Dr. Ehrenstorfer GmbH (Germany; www. analytical-standards.com). Sodium sulfate and silica gel were baked for 4 hours at 400 and $200{ }^{\circ} \mathrm{C}$, respectively, before use. Extractions of PCBs and OCs were conducted by using the Elmasonic S $180(\mathrm{H})$ ultrasonic unit. An Agilent $6890 \mathrm{~N}$ gas chromatograph (GC), equipped with an electon capture detector (ECD) and a Pegasus III GC equipped with a time-of-flight mass spectrometer (MS), were employed for identification and quantification of all POPs.

\section{Analytical Procedure for Organochlorine Pesticides}

\section{Extraction}

To facilitate analysis and to minimize risk of contamination from extended exposure to the atmosphere, samples were not air-dried. Wet sediments were directly analyzed. The upper water layer above samples collected from the field was discarded by using a Pasteur pipette before the samples were homogenized. The water content in wet sediments ranged from 30 to 70 percent, so the quantified estimate of any concentration level was adjusted for water content and standardized to dried weight. A 2-gram (g) portion (equal to 0.6-1.4-g dried sediments) was removed from the homogenized wet sediments and thoroughly mixed with $10 \mathrm{~g}$ of sodium chloride and $10 \mathrm{~g}$ of ammonium chloride in $100 \mathrm{~mL}$ glass bottles.

Several solvents, either alone or in combination (diethyl ether, dichloromethane, acetone, and hexane), are recommended for Soxhlet extraction of semivolatile and nonvolatile organic compounds from soil and sludge and follow U.S. Environmental Protection Agency (EPA) Method 3540C (Vagi and others, 2007). Though a mixture of acetone and hexane $(50: 50$, volume/volume $[\mathrm{v} / \mathrm{v}])$ is recommended in most publications for OC extraction (including EPA Method $3550 \mathrm{C}$ ), the recoveries and reproducibility of some OCs (endosulfan sulfate; 4,4'-DDT; and methoxychlor) were poor. With more polar solvent mixtures consisting of acetone and diethyl ether, the reproducibility and recoveries of all OCs were equally good in this study (table 1). Diethyl ether and acetone were also chosen as the extracting solvents because of the higher recoveries of 4,4'-DDE; 4,4'-DDD; and 4,4'-DDT, which appeared to occur frequently in sediment samples. Lastly, the more polar solvent mixtures extracted less sulfur from the sample matrices.

The ultrasonic extraction was carried out four times by using solvent mixtures of acetone and diethyl ether with the ratio ranging from $4: 1$ to $1: 1=$ acetone:diethyl ether, $\mathrm{v} / \mathrm{v}$. Ultrasonic extraction was conducted for 30 minutes (min) for each solvent mixture. Temperature of the ultrasonic extraction bath was set at $50{ }^{\circ} \mathrm{C}$ for three extractions and at $60{ }^{\circ} \mathrm{C}$ for the last extraction. Approximately $25 \mathrm{~mL}$ of extracting solvents were used for each extraction step. The glass bottles that contained sediments and extracting solvents were moved around in the ultrasonic extraction bath to minimize the effect of uneven distribution of ultrasonic energy. The extracted samples were then concentrated to about $2 \mathrm{~mL}$ with the aid of a rotary vacuum evaporator and lastly with a gentle air stream. 
Table 1. Recoveries and reproducibility of the selected organochlorines (OC) by using hexane acetone and diethyl ether acetone as extracting solvents.

[HCH, Hexachlorocyclohexane]

\begin{tabular}{lcccc}
\hline \multicolumn{1}{c}{ Organic compound } & \multicolumn{2}{c}{ Hexane : acetone } & \multicolumn{2}{c}{ Diethyl ether : acetone } \\
\hline Alpha-HCH & Recovery (percent) & Residual (percent) & Recovery (percent) & Residual (percent) \\
Beta-HCH & 69.7 & 7.4 & 75.3 & 11.1 \\
Gamma-HCH & 82.1 & 3.6 & 76.7 & 4.1 \\
Delta-HCH & 71.1 & 7.3 & 74.0 & 9.9 \\
Heptachlor & 59.1 & 8.4 & 60.2 & 12.1 \\
Aldrin & 77.4 & 5.6 & 70.9 & 10.1 \\
Heptachlor epoxide & 76.2 & 10.9 & 118.6 & 6.2 \\
Alpha-endosulfan & 67.0 & 4.5 & 65.6 & 10.7 \\
4,4'-DDE & 68.8 & 7.1 & 63.9 & 12.6 \\
Dieldrin & 67.1 & 4.0 & 71.6 & 9.3 \\
Endrin & 64.0 & 4.1 & 62.3 & 11.9 \\
Beta-endosulfan & 86.7 & 4.6 & 69.7 & 4.5 \\
4,4'-DDD & 67.4 & 3.2 & 60.3 & 10.8 \\
Endrin aldehyde & 67.5 & 3.3 & 76.3 & 8.2 \\
Endosulfan sulfate & 72.8 & 5.2 & 68.1 & 9.7 \\
4,4'-DDT & 66.1 & 8.0 & 76.2 & 10.6 \\
Methoxychlor & 59.4 & 26.8 & 83.5 & 13.5 \\
\hline
\end{tabular}

\section{Sample Cleanup}

For silica-gel-column cleanup, $3 \mathrm{~g}$ of the silica gel was allowed to mix thoroughly with $10 \mathrm{~mL}$ of acetone and 100 microliters $(\mu \mathrm{L})$ of water by being shaken for $30 \mathrm{~min}$ in a closed glass tube and was then loaded onto a chromatographic column. The acetone was removed by passing $15 \mathrm{~mL}$ of hexane through the column. Some sodium sulfate was added on the top of the silica gel to trap water from the sample extracts. Thirty $\mathrm{mL}$ of dichloromethane was employed as an eluent. The eluates were concentrated with the aid of a rotary vacuum evaporator, reconstituted in hexane, and divided into two halves. One half was analyzed without sulfur removal for endrin and endrin aldehyde, and the other half was analyzed for the other OCs after undergoing a sulfur treatment before GC-ECD analysis. This process was used because endrin had very high recovery (of up to 150 percent), whereas endrin aldehyde had very low recovery (approximately 30 percent) after sulfur removal with tributylammonium sulfite. Dark yellow extracts, which could have high concentrations of organic contents (humic substances), were subjected to an extra cleaning step by using liquid-liquid extraction with 0.1 molar (M) sodium hydroxide solution before the silica-gelcolumn step.

Three sulfur-removing agents were tested for their efficiency and ease of usage: copper, gold-plated copper, and tetrabutylammonium sulfate/sodium sulfite. Copper could not completely remove sulfur from samples that contained high concentrations of sulfur (a composition typical of most of our samples), especially from Vietnam, Cambodia, and Thailand (fig. $3 A$ ). The gold-plated copper agent efficiently removed sulfur, but $\alpha$-hexachlorobenzene, $\gamma$-hexachlorobenzene, and aldrin had low recoveries that could be because of the decomposition during this step (fig. $3 B$ ). Lastly, tetrabutylammonium sulfate and sodium sulfite were tested according to the EPA Method 3660B. The efficiency of sulfur removal with tetrabutylammonium sulfate and sodium sulfite was the best in comparison to copper and gold-plated copper (fig. $3 C$ ). The recovery of endrin aldehyde was very poor (approximately 40 percent) whereas the recovery of endrin was too high (approximately 150 percent). The reasons for these contrasting results are still unclear but, to solve these problems, endrin and endrin aldehyde were analyzed in extracts before the treatment with tetrabutylammonium sulfate and sodium sulfite.

Preparation of tetrabutylammonium sulfate solution was accomplished by (1) neutralizing tetrabutylammonium hydroxide with 10 percent of sulfuric acid until $\mathrm{pH}$ equaled 7 ; (2) removing organic interferences by extraction with three portions of $20 \mathrm{~mL}$ of hexane; and (3) adding $25 \mathrm{~g}$ of sodium sulfite to the solution. Residual sodium sulfite crystals were discarded to obtain a clear solution. 


\section{$A$}

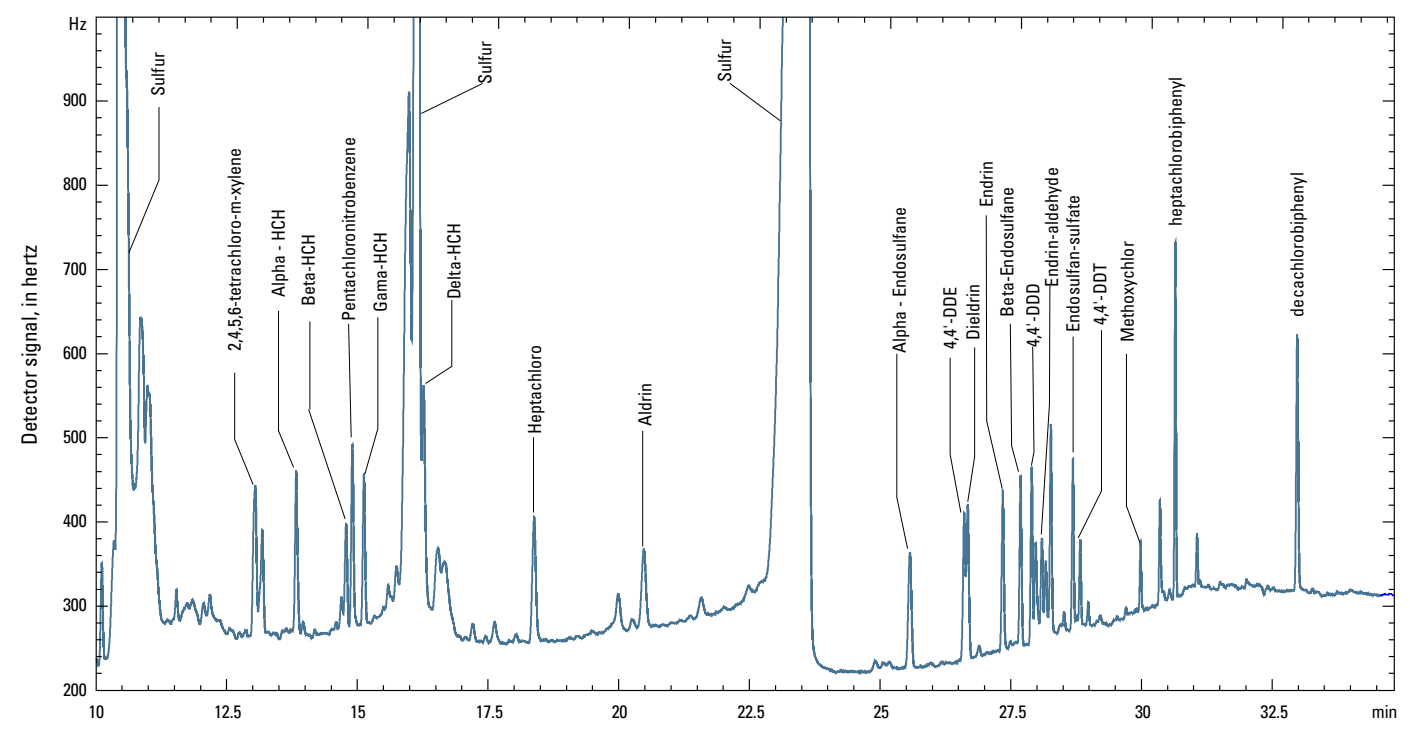

$B$

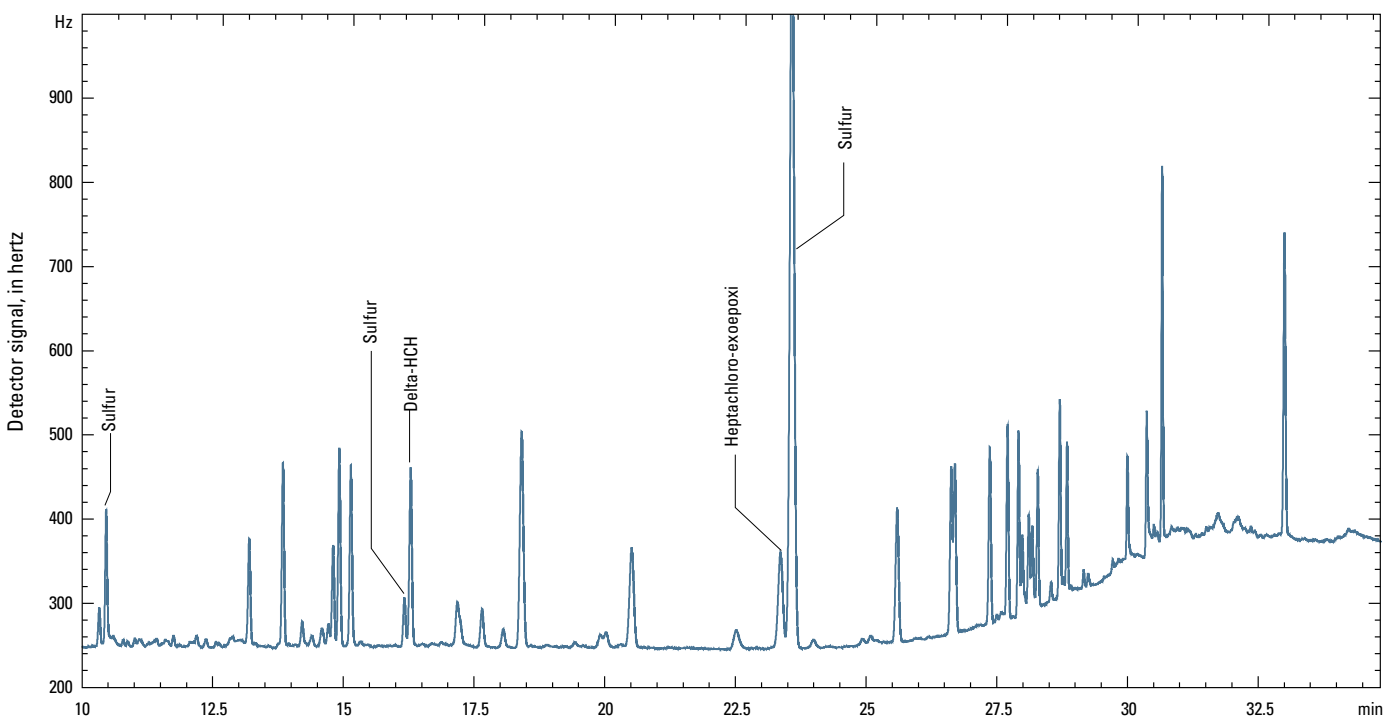

C

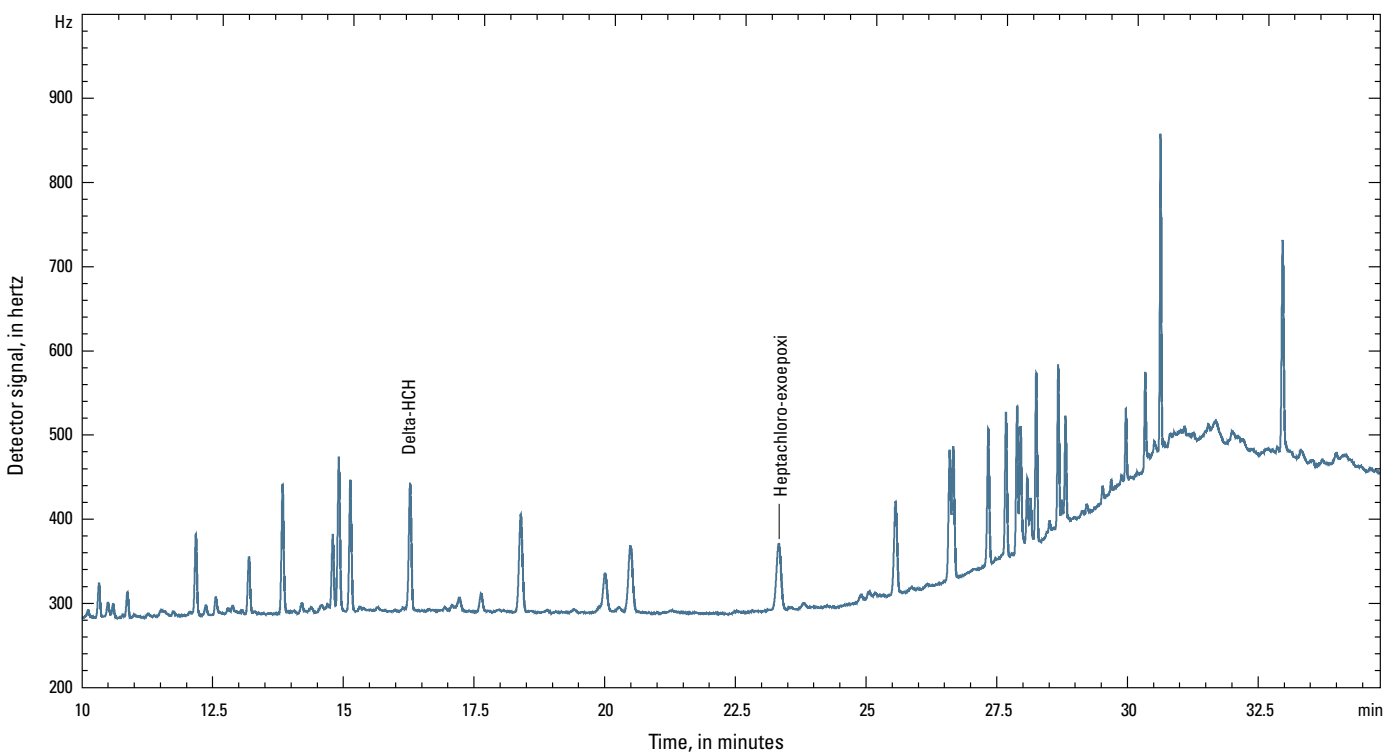

Figure 3. Chromatographs of spiked samples with different reagents for sulfur removal: $A$, copper, $B$, gold-plated copper, and $C$, tetrabutylammonium sulfate and sodium sulfite. 
Sulfur removal was carried out in three steps: (1) combining and shaking $0.5 \mathrm{~mL}$ extracts obtained after treatment with silica gel with $1.5 \mathrm{~mL}$ of hexane, $2 \mathrm{~mL}$ of isopropanol, $1 \mathrm{~mL}$ of $0.1 \mathrm{M}$ tetrabutylammonium sulfate, and $0.1 \mathrm{~g}$ of sodium sulfite for $30 \mathrm{~min}$; (2) removing the reducing agents from the organic layer by liquid-liquid extraction twice with $5 \mathrm{~mL}$ portions of double-distilled water each time. The OC residues in aqueous phase were regained by liquid-liquid extraction twice with $1 \mathrm{~mL}$ hexane portions used for each extraction; and (3) combining all the organic layers from all the extractions, drying the organic solution, and reconstituting in $0.5 \mathrm{~mL}$ of hexane for $\mathrm{GC}$ analysis.

\section{Gas Chromatographic Analysis}

The injector and detector temperatures for GC-ECD were set at 280 and $300{ }^{\circ} \mathrm{C}$, respectively. The split ratio was $1: 10$; nitrogen gas (1 milliliter per minute) was used as carrier gas. The column temperature program was first set at $120^{\circ} \mathrm{C}$ and maintained for 30 seconds. The temperature was then increased to $195^{\circ} \mathrm{C}$ at the rate of 5 degrees Celsius per minute $\left({ }^{\circ} \mathrm{C} / \mathrm{min}\right)$ and maintained for $7 \mathrm{~min}$. The temperature was then increased to $205^{\circ} \mathrm{C}$ at the rate of $5^{\circ} \mathrm{C} / \mathrm{min}$ and finally increased to $300{ }^{\circ} \mathrm{C}$ at the rate of $15^{\circ} \mathrm{C} / \mathrm{min}$. The final temperature was maintained for $4 \mathrm{~min}$. GC analysis of OCs was performed (1) with a standard mixture containing known concentrations of OCs, (2) with three samples, and (3) with a sample spiked with known amounts of OCs. Different temperature programs were used to confirm the existence of the OCs in case of asymmetric peak shape or abnormal range levels.

Several internal standards $(2,4,5$, 6-tetrachloro-mxylene; pentachloronitrobenzene; heptachlorobiphenyl) and a surrogate compound (decachlorobiphenyl) were added to the samples to control recovery. For each batch of 10 samples, 2 spiked samples and 2 duplicate samples were prepared. Recovery of the surrogate had to be higher than 70 percent for the results of the corresponding batch to be calculated; otherwise, all samples of the subpar batch would have to be extracted and analyzed again. The OC control charts showed that the OC results of spiked samples fell within plus or minus two times the standard deviation for the whole period of the analysis (appendix 1).

\section{Analytical Procedure for Polychlorinated Biphenyls}

Samples were analyzed for 18 isomers of PCB: 8, 18, 28, $31,44,52,70,101,151,149,118,153,105,138,180,170$, 194, and 195. Ultrasonic extractions for all 18 PCB isomers were similar to those for OCs except that $10 \mathrm{~g}$ of sodium sulfate was used instead of $10 \mathrm{~g}$ of ammonium chloride, and hexane:acetone $=1: 1(\mathrm{v} / \mathrm{v})$ was used as the only extracting solvent. Organic contents in the extracts were removed by combining and shaking the extracts with $5 \mathrm{~mL}$ of sulfuric acid (1:1) for $15 \mathrm{~min}$. The PCBs remaining in the acidic layer were regained by undergoing two liquid-liquid extractions with approximately $2 \mathrm{~mL}$ of hexane used each time. The cleanup procedure was repeated in the same way with 5 percent potassium permanganate solution. The extracts were then subjected to silica-gel-column cleaning and sulfur removal as in the OC method. Clean extracts were analyzed with GC-ECD, and positive results were confirmed by GC-MS. The internal standard for PCBs was 1, 2, 3, 4, 5-pentachloro6-nitrobenzene. The PCB control charts showed that the results of spiked samples fell within plus or minus two times the standard deviation for the whole period of the analysis (appendix 2).

\section{Levels of Detection}

Levels of detection (LOD) for all OCs studied are listed in the text of appendix 3. LOD for all PCB isomers studied were similarly listed in appendix 4 . These LODs are method detection limits (Analytical Methods Committee, 1987) reflecting the performance characteristics of the whole analytical system employed in the study. OC and PCB results were presented in three groups: the first group contained values with detection above the LOD, the second group included values with detection below the LOD but larger than zero, and the third group included values with no detection and were noted as zero.

\section{Replicate Samples}

Ten blind, replicate sediment samples, one with each batch of field samples, were submitted to the laboratory as controls. Replicate samples were taken from an aggregated sediment sample consisting of 15 samples collected over an 8-ha field at Hoa An Research Station (Hau Giang Province, Vietnam), which is administered by Can Tho University. This location had received no direct pesticide applications for 30 years, so detection of POPs was not expected. The site is a natural freshwater marsh and is dominated by the emergent aquatic plant Eleocharis dulcis. The wetland has flooded annually during the rainy season, so it could possibly be exposed to pollutants transported by floodwater. Replicate samples were only examined for OCs. No replicate samples were examined for PCB analyses.

\section{Comparison of Two Different Laboratories with Samples from Tram Chim National Park}

Prior to the study, we sought to assess variation between laboratories, to ensure consistency of results, and to conduct a preliminary field study at Tram Chim National Park (Vietnam) to train teams on consistent collection of samples. Tram Chim is a natural wetland on the flood plain of the Mekong Delta, seasonally inundated by rain and Mekong River floodwater. When sampled, the wetland was covered by emergent aquatic vegetation, of which the grass Panicum repens was the dominant species. Tram Chim was gazetted in 1984 (Barzen, 
1991), and since then, no agricultural or industrial chemicals have been directly applied to the soil. Tram Chim, however, is surrounded by rice paddy fields, and agricultural chemicals used in the surrounding areas may have been carried into Tram Chim by floodwater (Beilfuss and Barzen, 1994).

The reference sample was prepared from a single composite of sediment collected from six different locations within a 20-m radius, and was then assessed for POP concentrations by using sampling and laboratory procedures described in previous sections by the Central Laboratory for Analysis and Chemistry Department at the University of Science, VNU-Ho Chi Minh City. The same sample was also tested by the U.S. Geological Survey (USGS) National Water Quality Laboratory (NWQL), Denver, Colorado. In the USGS analysis, the samples were analyzed by using two dissimilar columns (RTX-5 and RTX-1701) and ECDs. ECDs are specific for organohalogen compounds such as the pesticides that were analyzed in this study (Noriega and others, 2004).

\section{Database Development and Mapping}

A Web-based database of the wetlands sampled, including POPs, was developed by using open-source software. The database server was developed in PostgreSQL (PostgreSQL, 2012) with PostGIS (PostGIS, 2012) add-on, and the mapping interface was p.mapper (Burger, 2009), which is a MapServer PHP/MapScript framework. Maps throughout this report were created using MAPublisher 9.2 plug-in (Avenza Systems Inc., 2013) for Adobe Illustrator CS6 (Adobe Systems Inc., 2013). ArcGIS software by Esri was used for data analysis. ArcGIS and ArcMap are the intellectual property of Esri and are used herein under license. Quantum GIS (Quantum GIS Development Team, 2012) was used for some database management, data extraction, and basic map production.

All data were collected in latitude and longitude by using decimal degrees and the World Geodetic System 1984 Datum. The Mekong Basin boundary was drawn from the Mekong River Commission's Outer Watershed Boundary of the Mekong Basin (Mekong River Commission, 2001b). Open water (such as the Tonle Sap) and rivers were illustrated using the USGS Global GIS atlas vector base map of the world with a scale of 1:1,000,000 (Hearn and others, 2003). Other map data included country boundaries and populated places (Natural Earth, 2013).

A variety of map sources was used to provide current provincial boundaries for Cambodia, Thailand, and Vietnam. Provincial boundaries for Cambodia were obtained from the Ministry of Land Management and Administration of Cambodia, the Forest Administration of Cambodia, and JICA Cambodia. Shapefiles of provincial boundaries in Vietnam came from http://www.geovn.com/showthread. php $? \mathrm{t}=14 \&$ page $=1$. A new province in Thailand, named Bueng Kan, was distinguished from Nong Khai Province (http:// www.thaigoodview.com/library/pictures/nongkailarge.jpg).
The World Administrative Units dataset (Esri, 2010) was used for the remainder of provincial boundaries used for Thailand.

\section{Statistical Analysis}

\section{Spatial Analysis}

All spatial analysis used ArcGIS ArcInfo 10.0 (Esri, 2010) with data projected in Asia North Equidistant Conic. The units of measurement were meters. Distance to the nearest urban area and distance to stream parameters were calculated by using the NEAR tool (Esri, 2010). This proximity analysis tool determined the straight line distance from each sample point to the nearest populated place and to the nearest branch of the Mekong River. The distance to source was calculated by creating a point shapefile containing the estimated location of the source of the Mekong River in China. The source location was estimated from Microsoft Bing Maps satellite imagery used to digitize the Upper Mekong River. A straight line distance for every sample point to the source of the Mekong River was then calculated using the NEAR tool. These values were then incorporated into a logistic regression model (see the "Comparing POP Values to Wetland Characteristics" section). The hypothesis for using the distance from the source of the Mekong River to explain POP levels detected was if POPs were easily transported over large distances by river systems then the probability of detection for various substances would increase as distance from the source of the Mekong River increased.

\section{Comparing Persistent Organic Pollutant Values to Wetland Characteristics}

The primary statistical tool used for analyzing POP data was logistic regression. The response was presence "1" or absence " 0 " of a given chemical. Logistic regression requires somewhat different techniques than linear regression, but much of the logic for model selection is similar. A value of "1" was used if the chemical was present, even if it was below the LOD, and " 0 " if the chemical was absent. General linear models (GLM) were used in R statistical software for the analysis (R Development Core Team, 2011). Analysis based upon logistic regression attempted to quantitatively describe attributes of POPs in relation to environmental variables that balance type I (incorrect rejection of a true null hypothesis) and type II (the failure to reject a false null hypothesis) errors.

As a priori predictor variables, we used ecological region, river connection, wetland system/subsystem, wetland type, wetland protection status, hydrological regime, wetland vegetation, surface soil texture, distance to the nearest stream, distance to the source of Mekong River, and distance to the nearest urban area (table 2). We examined key interactions among these variables. All predictor variables were categorical, except for the last three. 
Table 2. Categorical and numerical environmental predictor variables used in logistic regression analyses.

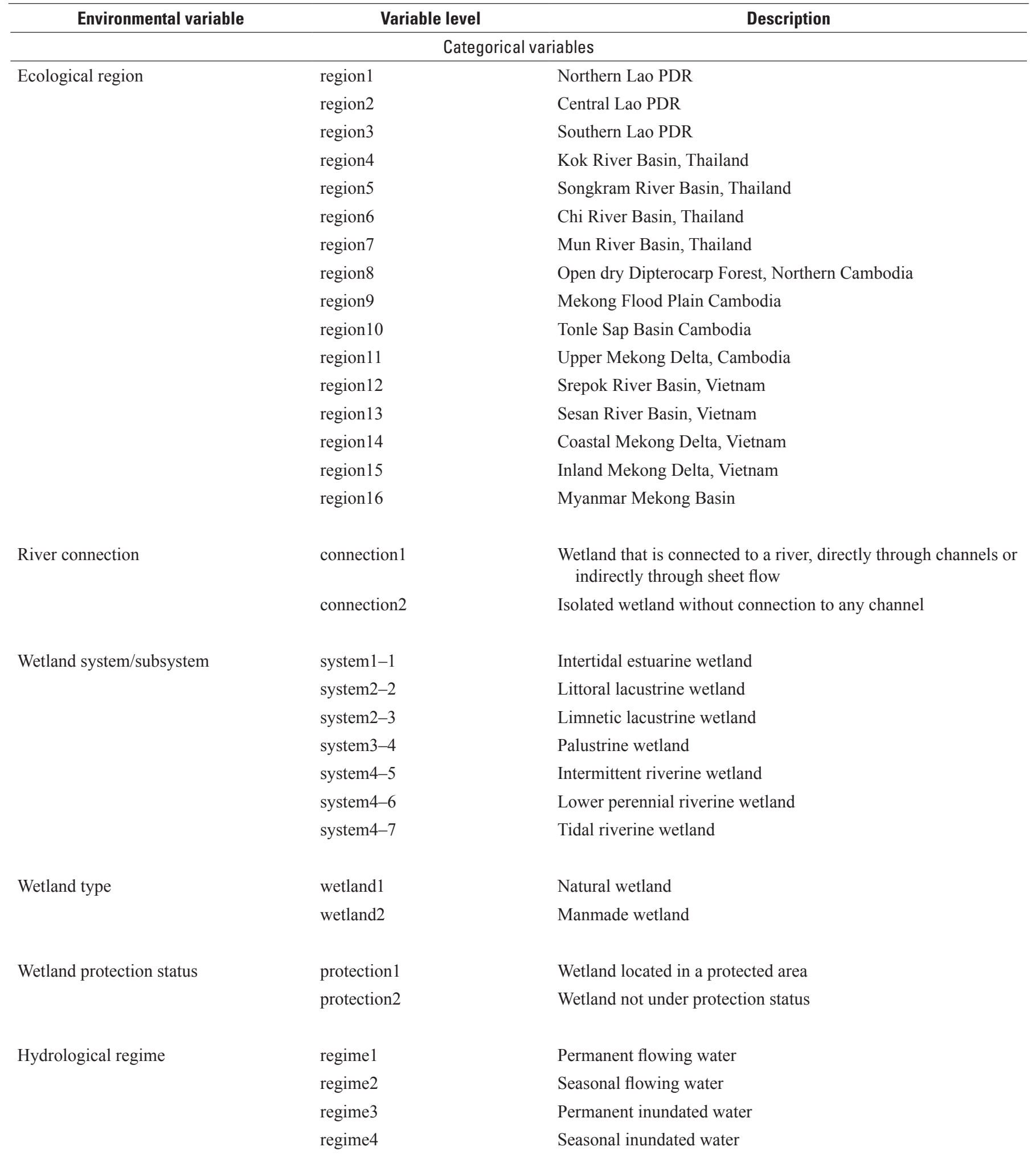


Table 2. Categorical and numerical environmental predictor variables used in logistic regression analyses. - Continued

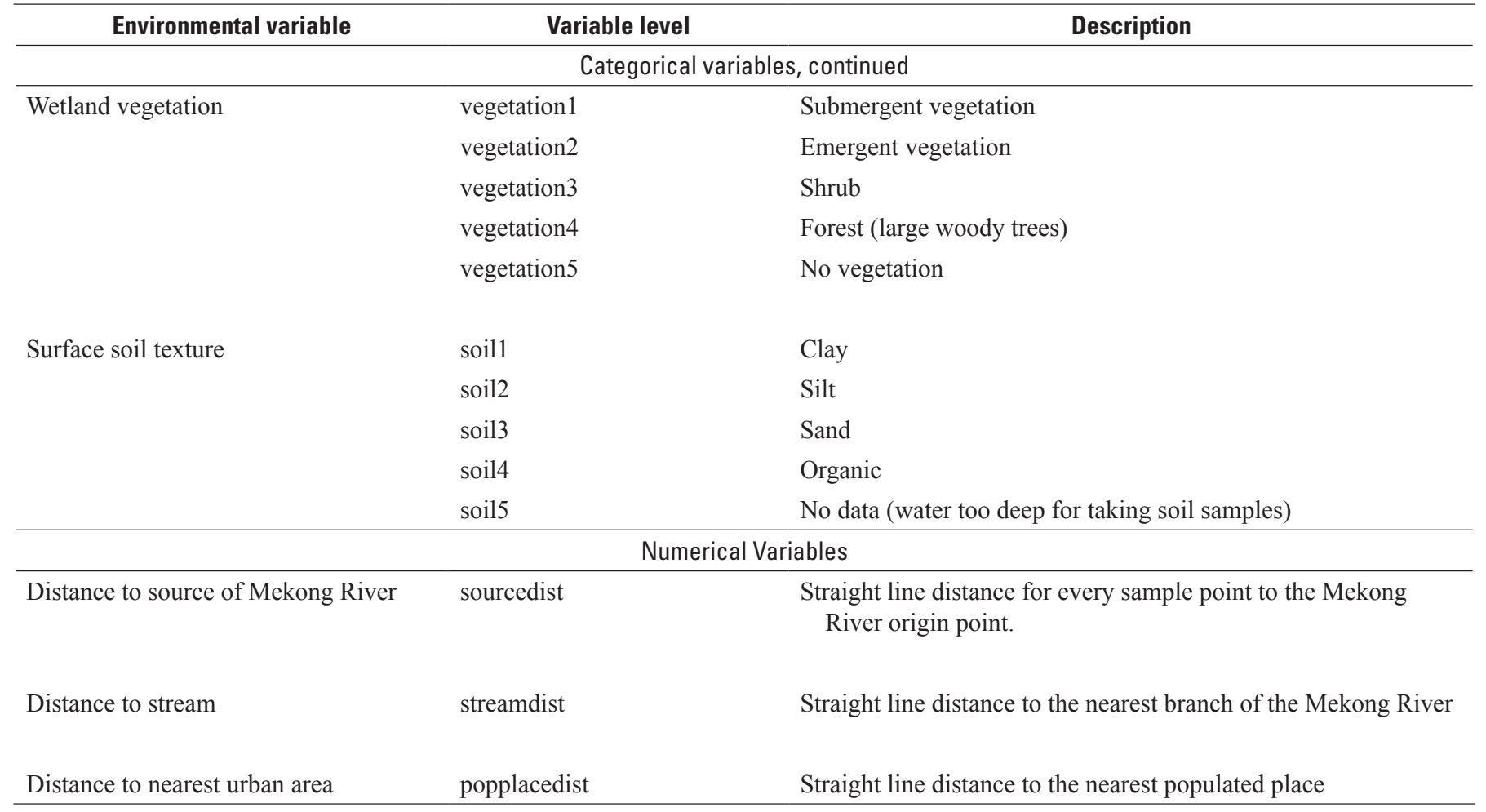

To build a logistic regression model, a backwards elimination procedure was used by employing a criterion that minimized the Akaike Information Criterion (AIC) but maintained the hierarchical principle that no main effect can be eliminated if an interaction term using that effect is still in the model. The AIC is a widely used method for model selection (Akaike, 1974). Specifically, the AIC value was first calculated for the full model and then for all models, removing one term, that did not violate the hierarchical principle. If a smaller model had a lower AIC than the full model and did not violate hierarchy, the smaller model with the lower AIC was selected, given that it had the lowest AIC among all the smaller models calculated, and considered that as a new "full model." Subsequently, the process was repeated to eliminate additional terms until no model with a deleted term had a lower AIC than the "full model." For example, suppose that the elimination of the term "stream distance" results in the lowest AIC. If any interaction term that included "stream distance" was still in the "full model," then "stream distance" (by itself) could not be removed.

To utilize POP data to the greatest extent, a group of related metabolites was combined into a single quantitative variable, which would be affected by the presence or absence of any part. For example, DDT and its two metabolites were combined into one variable, which has a value of " 1 " if there is a nonzero concentration in at least one of the three substances and a value of " 0 " if there is a zero concentration in all of the three substances. The same kind of single quantitative variable was derived for endosulfan (combination of alpha-endosulfan, beta-endosulfan, and endosulfan sulfate) and endrin (combination of endrin and endrin aldehyde).

\section{Results}

\section{Sample Stratification}

A total of 531 sediment samples were collected throughout the Mekong Basin from Myanmar to Vietnam (table 3, appendix 5) for POP analysis. The highest number of samples was collected from Cambodia (37 percent), followed by Lao PDR (23 percent), Vietnam (19 percent), Thailand (15 percent), and Myanmar (6 percent). The largest area of basin landmass among all of the countries that comprise the Mekong Basin is located in Lao PDR (35 percent), followed by Cambodia (18 percent), Thailand (18 percent), Vietnam (11 percent), and Myanmar (2 percent) (Hiro, 2000). There is currently no accurate classification or inventory of wetland systems of each country in the Mekong Basin, so the applied assessment weights based on the total number of wetlands 
Table 3. Samples collected from different ecological regions nested within each geographical region.

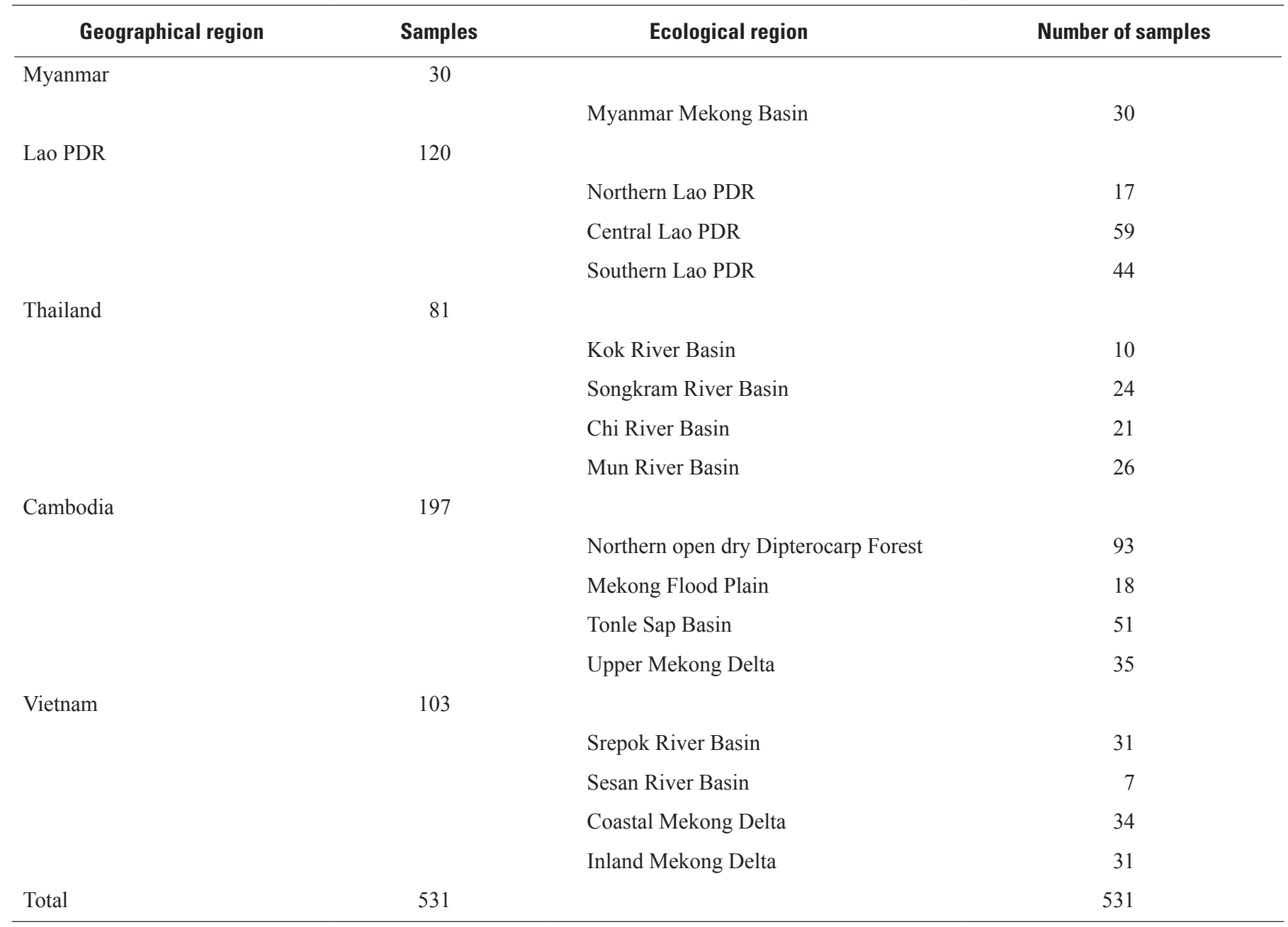

were approximate. Within each country, sampling locations were stratified according to ecological regions located within the Mekong River Basin. These sampling locations attempted to correspond with the distribution of wetlands within those ecological regions (table 3 ).

By following a modified version of the classification system for wetlands and deepwater habitats of the United States (Cowardin and others, 1979), four wetland systems were used in this study - estuarine, lacustrine, palustrine, and riverine (table 4) - from which samples were collected. The majority of sediment samples were collected from palustrine (73 percent) and lacustrine (19 percent) wetlands. Among the lacustrine wetlands, 73 percent of the samples were taken from the limnetic subsystem, meaning that sediments were collected at the deeper, open water part of the lakes, whereas the remainder were taken from littoral subsystems, or along the shoreline of the lakes. All estuarine wetlands that we sampled fell within the intertidal subsystem, meaning that sediment surface is exposed to air during part of the tidal cycle. Riverine wetland samples from this study came from lower perennial
Table 4. Samples collected in different wetland systems and subsystems.

\begin{tabular}{llc}
\hline \multicolumn{1}{c}{ System } & \multicolumn{1}{c}{ Subsystem } & Number of samples \\
\hline Estuarine & & 17 \\
& Intertidal & 27 \\
Lacustrine & & 72 \\
& Littoral & 386 \\
Palustrine & Limnetic & \\
Riverine & & 23 \\
& Lower perennial & 6 \\
Total & Tidal & 531 \\
\hline
\end{tabular}


and tidal subsystems. Tidal riverine subsystems are those sampled in the coastal region of the Mekong Delta in Vietnam, whereas lower perennial subsystems are those sampled along the Mekong River or its tributaries. Cowardin and others (1979) defined no subsystem for palustrine wetlands.

The a priori hypothesis was that ecological attributes of wetlands would help explain the concentration or distribution of organic compounds found in sediment samples. Natural wetland types, for example, might be less polluted than manmade wetland types. Most sediment samples ( 82 percent) were collected from natural wetland types (table 5) rather than manmade wetland types. Further, most samples (72 percent) were collected from wetland types with some level of protection such as national park, wildlife sanctuary, biodiversity conservation area, watershed protection forest, religious sacred site, Wetland of International Importance (Ramsar Convention, 1971), Important Bird Area (Birdlife International, 2004), or fish conservation area (table 5). Manmade wetland types from which samples were collected were mostly reservoirs. The most common types of vegetation encountered at sample sites were emergent (53 percent) and no vegetation ( 23 percent), meaning samples were collected on bare soils or in unvegetated water bodies (table 5).

Submergent (14 percent), shrub (6 percent), and forest cover (4 percent) vegetation types were encountered less frequently.

The connectivity of wetlands to rivers was one of the factors considered when selecting a wetland for sediment sampling. During the wet season, uplands and rivers discharge water into wetlands, so it was proposed that if pollutants were highly mobile, they would accumulate in wetland types receiving more sources of inflow. Wetland types that were not connected to rivers would have fewer pollutants, or lower concentrations of any particular pollutant, than would wetlands that were connected to rivers. Of the sediment samples collected, 49 percent were from isolated wetlands (no connection to any channel), whereas the remaining samples were taken from wetlands that were connected by channel flow (46 percent), sheet flow (1 percent), or both sheet and channel flow (4 percent, table 5). Three flow conditions were used to describe the hydrological regime of sampled wetlands: (1) "flowing"-wetlands that have flowing water; (2) "inundated"-wetlands that have standing water without flow; and (3) "waterlogged"-wetlands that are not inundated but have water in the plant root zones. Within each of these three flow conditions, water could be present all year (permanent) or for part of the year (seasonal). Forty percent of the hydrological regimes sampled here were "flowing," whereas 60 percent were "inundated" (table 5). No samples came from wetlands with "waterlogged" flow conditions. Water permanence, however, was permanent or seasonal, depending upon the flow condition.

In summary, the most typical wetland sampled was a palustrine, natural wetland with some sort of protected status. Samples came predominately from sites dominated by

Table 5. Ecological attributes for sampling point locations within wetlands (soil and vegetation) or for the entire wetland sampled (type, protection status, connection, and flow).

\begin{tabular}{|c|c|c|c|}
\hline Type of wetland & Number of samples & Protection status & Number of samples \\
\hline Natural & 437 & Protection & 382 \\
\hline Manmade & 94 & No-protection & 149 \\
\hline Total & 531 & Total & 531 \\
\hline \multicolumn{2}{|c|}{ Top soil texture } & \multicolumn{2}{|c|}{ Vegetation } \\
\hline Clay & 217 & Submergent & 72 \\
\hline Silt & 59 & Emergent & 283 \\
\hline Sand & 145 & Shrub & 32 \\
\hline Organic & 41 & Forest & 21 \\
\hline No soil sample taken & 69 & No vegetation & 123 \\
\hline Total & 531 & Total & 531 \\
\hline \multicolumn{2}{|c|}{ Connection to river } & \multicolumn{2}{|c|}{ Flow regime } \\
\hline Sheet flow & 6 & Flowing, permanent & 78 \\
\hline Channel flow & 243 & Flowing, seasonal & 136 \\
\hline Both sheet and channel flow & 22 & Inundated, permanent & 279 \\
\hline No connection & 260 & Inundated, seasonal & 38 \\
\hline Total & 531 & Total & 531 \\
\hline
\end{tabular}


emergent vegetation. Hydrologically, sampled wetlands were almost equally dispersed between those wetlands that were connected to a river by channel flow and those wetlands that were isolated; moreover, large numbers of wetland types were represented by flow conditions that were both "inundated" and "flowing." Importantly, samples represented in tables 3-5 were not independently arrayed. For example, a very high fraction of samples collected in a given vegetation zone may be linked to hydrological characteristics such as "inundated" and cannot be considered as truly independent effects on a statistical basis.

\section{Soil Characteristics of the Sampling Environment}

All POP samples were collected from wetland basins during the March-June 2011 sampling period, meaning that samples were collected from the end of the dry season to the beginning of the wet season. Specifically, of the 464 soil profiles taken ( 87 percent of 531 POPs samples taken), 404 samples( 87 percent of 464 soil profiles) were collected where the top soil layer was wet, 56 samples (12 percent) were moist, and 4 samples (1 percent) were dry (appendix 6 ). Because much of the sampling occurred during the early part of the rainy season, the high moisture content of sampled sediments is not surprising.

On average, the top layer of soil was $16.8 \mathrm{~cm}$ deep $(n=464$, range $=1.5-100.0 \mathrm{~cm}$, standard deviation $=15.7)$. Because POP sediment samples were collected from the top $20 \mathrm{~cm}$ of soil, the majority of most POP samples was composed of the top soil horizon. Of the 462 soil texture measures, the primary composition of the top layer of each sample was clay(47 percent) and sand (31 percent). Only 22 percent of the samples had a top layer of soil primarily composed of silt and organic materials (table 5). Samples that were not accompanied with soil cores came from deep water areas where the substrate was too loose to collect and measure or the water was too deep to collect soil cores.

Importantly, these soil and moisture data reflect the soil environment from which the POP samples were taken at the time of sampling but do not reflect the long-term hydrological conditions under which these soils have existed. In monsoonal climates, water permanence varies greatly between wet and dry seasons each year, and the breakdown of POPs that had been deposited in the past would reflect long-term water permanence rather than annual measures of moisture. Interviews of people living near these wetlands (of 459 interviews with data on water permanence) indicated that 92 percent of the wetlands sampled were described as being inundated year round at their deepest point. The deepest point of each wetland is also where POP samples were collected.

Long-term (multiyear) moisture trends were directly measured in the soil by evaluating the color of the top layer of soil and then translating that color into an index of the long-term moisture environment typified by that soil (table 6). Of the POP samples and soil cores collected, most samples came from a moderately wet long-term soil environment (fig. 4). The identification of this environment was corroborated by interviews, which suggested that the 419 wetlands that were sampled never dried out completely, whereas 40 wetlands dried out for at least 1 month each year (range $=1-8$ months dry). Because many of the wetlands where soil cores were not collected were too wet to sample (for example, in the Tonle Sap Lake), this estimate of soil moisture is likely to be slightly biased towards drier soils. The goal of collecting samples from similar environments (wet environments where POPs might aggregate) was met.

\section{Persistent Organic Pollutants Analyzed in This Study}

The 21 OC pesticides analyzed in this study represent all agricultural-based POPs listed under the Stockholm Convention's "Annex A" and "Annex B," except chlordecone and toxaphene (table 7). Conversely, methoxychlor is an OC pesticide that was analyzed in this study but was not listed in the Stockholm Convention's annexes (table 8). Results for all OC samples are listed in appendix 3. In addition to $\mathrm{OC}$ pesticides, a subset of samples were also chosen to be analyzed for PCBs (61 samples or 11.5 percent of all sediment samples collected). The samples analyzed for PCBs (appendix 4) were selected on the basis of their proximity to urban or industrial areas, places where we would expect these substances to be found. There are more than 200 different isomers of PCBs, 18 of which were analyzed in this study (table 7). These isomers are among the PCBs most commonly found in Southeast Asia (Martin and others, 2003).

Table 6. Long-term soil moisture content for the top layer of soil in relation to color and the codes used for analysis.

[R, YR, Y are color codes used in Munsel Soil Color Charts (U.S. Department of Agriculture, 1993)].

\begin{tabular}{lll}
\hline Code & Hue value & $\begin{array}{c}\text { Long-termsoil moisture } \\
\text { content }\end{array}$ \\
\hline 1 & $5 \mathrm{R}$ & Dry \\
2 & $7.5 \mathrm{R}$ & \\
3 & $10 \mathrm{R}$ & \\
4 & $2.5 \mathrm{YR}$ & \\
5 & $5 \mathrm{YR}$ & Wet/dry conditions \\
6 & $7.5 \mathrm{YR}$ & \\
7 & $10 \mathrm{YR}$ & \\
8 & $2.5 \mathrm{Y}$ & \\
9 & $5 \mathrm{Y}$ & Wet \\
\hline
\end{tabular}




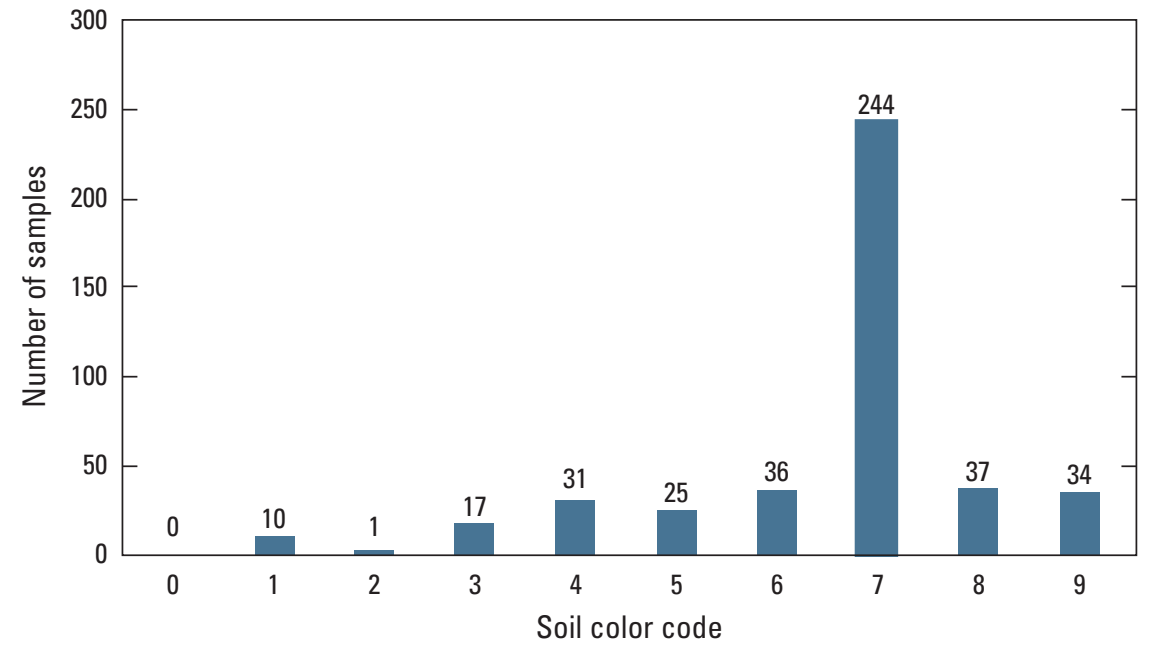

Figure 4. Graph showing soil colors (thus multiyear moisture environment) from 435 of 462 soil samples where soil color was noted.
Table 7. Persistent organic pollutants analyzed in this study.

[HCB, Hexachlorobenzene; HCH, Hexachlorocyclohexane; PCB, Polychlorinated biphenyl]

\begin{tabular}{lc}
\hline \multicolumn{1}{c}{ Organochlorine pesticides } & Polychlorinated biphenyl \\
\hline Aldrin & PCB8 \\
Trans-chlordane & PCB18 \\
Cis-chlordane & PCB28 \\
Dieldrin & PCB31 \\
Endrin & PCB44 \\
Endrin aldehyde & PCB52 \\
Heptachlor & PCB70 \\
Heptachlor epoxide & PCB101 \\
HCB & PCB105 \\
Alpha-HCH & PCB118 \\
Beta-HCH & PCB138 \\
Gamma-HCH (lindane) & PCB149 \\
Delta-HCH & PCB151 \\
Mirex & PCB153 \\
Methoxychlor & PCB170 \\
4,4'-DDT & PCB180 \\
4,4'-DDE & PCB194 \\
4,4'-DDD & PCB195 \\
Alpha-endosulfan & \\
Beta-endosulfan & \\
Endosulfan sulfate & \\
\hline
\end{tabular}

Table 8. Persistent organic pollutants banned worldwide by the Stockholm Convention (as of July 2012).

\begin{tabular}{|c|c|}
\hline POP & Usages \\
\hline \multicolumn{2}{|c|}{ Annex A-Elimination } \\
\hline Aldrin & Insecticide \\
\hline Chlordane & Insecticide \\
\hline Chlordecone & Insecticide \\
\hline Dieldrin & Insecticide \\
\hline Endrin & Insecticide, rodenticide \\
\hline Heptachlor & Insecticide \\
\hline Hexabromobiphenyl & Industrial chemical \\
\hline $\begin{array}{l}\text { Hexabromodiphenyl ether and } \\
\text { Heptabromodiphenyl ether }\end{array}$ & Industrial chemical \\
\hline Hexachlorobenzene & $\begin{array}{l}\text { Pesticide, industrial by- } \\
\text { product chemical }\end{array}$ \\
\hline Alpha-hexachlorocyclohexane & Insecticide \\
\hline Beta-hexachlorocyclohexane & Insecticide \\
\hline Lindane & Insecticide \\
\hline Mirex & $\begin{array}{l}\text { Insecticide, industrial } \\
\text { chemical }\end{array}$ \\
\hline Pentachlorobenzene & $\begin{array}{l}\text { Industrial chemical, } \\
\text { fungicide }\end{array}$ \\
\hline Polychlorinated biphenyls & Industrial chemical \\
\hline Endosulfan and related isomers & Insecticide \\
\hline $\begin{array}{l}\text { Tetrabromodiphenyl ether and- } \\
\text { pentabromodiphenyl ether }\end{array}$ & Industrial chemical \\
\hline Toxaphene & Insecticide \\
\hline \multicolumn{2}{|c|}{ Annex B-restriction } \\
\hline DDT & $\begin{array}{l}\text { Insecticide, mosquito } \\
\text { control }\end{array}$ \\
\hline $\begin{array}{l}\text { Perfluorooctane sulfonic acid } \\
\text { and perfluorooctane sulfonyl } \\
\text { fluoride }\end{array}$ & Industrial chemical \\
\hline
\end{tabular}




\section{Laboratory Quality Assurance and Control}

The reference sample was collected at Tram Chim National Park (Vietnam) in December 2010 and analysed at NWQL and VNU. Results from both laboratories were similar (table 9). Among the 13 POPs that were analyzed by both laboratories, both laboratories returned 10 chemicals with a " 0 " concentration. DDT was detected by both laboratories, with concentrations that suggested DDT was present but at too low a concentration to quantify. Both laboratories detected high concentrations of DDE and DDD in the sample, and the results from NWQL were higher for both DDE and DDD than those from the VNU lab (by 33 percent or less). The detection limits for the POPs analyzed by the two laboratories are comparable with each other (table 9). NWQL was not used for any further analysis of POP samples collected for this study.

In addition to comparing sample results from VNU and NWQL, blind samples also were submitted to VNU to check for consistency. Ten replicate samples, together with other sediment samples, were sent to VNU during the course of analysis. These replicate samples were unknown to the laboratory technicians and were prepared from one soil composite collected at Hoa An Research Station. OC concentrations in the replicate samples were consistent, with few substances detected in any concentration (table 10). When OCs were found, they were always below the LOD.

\section{Results of Organochlorine Pesticide Analysis}

Of the 531 samples collected, 341 samples (64 percent) contained residue from at least one type of OC pesticide (appendix 3). These samples were localized in their distribution throughout the region (fig. 5). Few pollutants were found in samples taken from Thailand, whereas a high percentage of samples taken from Vietnam and Myanmar had at least one type of OC detected. Samples from Lao PDR and Cambodia were more variable in contaminant content.

The most frequently detected pesticide residues (from highest to lowest) were DDE, beta-endosulfan, HCB, endrin, DDT, endosulfan sulfate, DDD, and alpha-endosulfan (fig. 6). Chlordane, dieldrin, $\mathrm{HCH}$, and methoxychlor were detected in less than 5 percent of all samples analyzed. Aldrin, heptachlor, and mirex were not detected in any samples. Total loadings of OC pesticides (sum of all OCs analyzed) ranged from 0.23 to 105.28 nanograms per gram $(\mathrm{ng} / \mathrm{g})$ and had a median value of $2.05 \mathrm{ng} / \mathrm{g}$ (table 11). DDT and its metabolites accounted for more than 79 percent of the total OCs detected. Although OC pesticide residues were distributed widely in wetlands throughout the Mekong Basin, the magnitude of this contamination was low.

Sixteen samples contained OC residues that measured greater than $10 \mathrm{ng} / \mathrm{g}$ (table 12). Among the top 10 sites that had the highest total OC loadings, 6 sites were from Cambodia, 2 from Vietnam, 1 from Lao PDR, and 1 from Thailand (table 12). Four of the 6 top 10 sites in Cambodia were located in Preah Vihear Province, in the open dry dipterocarp forest ecosystem of northern Cambodia. Bueng Kan (Thailand, fig. 1) and the Tram Chim National Park site (Vietnam) are Wetlands of International Importance (Ramsar Convention, 1971). Tram Chim, Bueng Kan, and the four Cambodian sites in Preah Vihear Province are all wetlands that have had little or no pesticide use in the past several decades.

\section{Infrequently Detected Organochlorine Pesticides}

Of the OCs detected in small amounts, chlordane and dieldrin were found most frequently. Chlordane was analyzed for both cis and trans isomers; 14 samples contained residues (13 with cis-chlordane and 1 with trans-chlordane) (fig. 7). The small number of wetland sites for which chlordane residues were detected, the low concentrations (table 11), and the clumped distribution (for example, primarily in the Mekong Delta and in Myanmar) suggested that chlordane is not a widespread contaminant in wetland soils of the Mekong Basin. Chlordane, however, might be an important contaminant in local regions because a few locations were not only clumped in distribution but also had relatively high residue levels (table 11). Like chlordane, dieldrin was detected in a small number of samples ( $n=16)$, but unlike chlordane, only three samples had dieldrin concentrations above the LOD (fig. 8).

Both $\mathrm{HCH}$ and methoxychlor were found infrequently and were at very low concentrations when found. Of the four $\mathrm{HCH}$ metabolites tested (alpha, beta, delta, and gamma), residue was detected in only two samples, both collected in Myanmar, and only one of the samples had concentrations above the LOD (M007, delta-HCH, $1.272 \mathrm{ng} / \mathrm{g}$ ) (appendix $3)$. Other $\mathrm{HCH}$ metabolites were not detected in any samples. Methoxychlor was detected in 11 sediment samples, but all measured residues were below the LOD $(2.0 \mathrm{ng} / \mathrm{g}$; range $=0.22-1.08 \mathrm{ng} / \mathrm{g}$ ). 
Table 9. Results of replicate samples as analyzed by Central Laboratory for Analysis and Chemistry Department at the University of Science, Vietnam National University-Ho Chi Minh City and U.S. Geological Survey National Water Quality Laboratory.

[Unit of persistent organic pollutant (POP) concentration:nanogram per gram dry weight; -, substances not analyzed by designated laboratory; LOD, level of detection; HCB, hexachlorobenzene; HCH, hexachlorocyclohexane; VNU, Vietnam National University Laboratory; USGS, U.S. Geological Survey Laboratory; $<$, less than]

\begin{tabular}{|c|c|c|c|c|}
\hline & LOD VNU & LOD USGS & Results VNU & Results USGS \\
\hline Cis-chlordane & 0.2 & 1.0 & - & 0 \\
\hline Trans-chlordane & 0.4 & 0.5 & - & 0 \\
\hline Trans-nonachlor & - & 1.0 & - & 0 \\
\hline Alpha-endosulfan & 1.0 & 0.5 & 0 & 0 \\
\hline Beta-endosulfan & 1.0 & - & 0 & - \\
\hline Endosulfan sulfate & 1.0 & - & 0 & - \\
\hline Beta-HCH & 1.5 & 0.5 & 0 & 0 \\
\hline Gamma-HCH (Lindane) & 1.0 & 0.5 & 0 & 0 \\
\hline Delta-HCH & 1.0 & - & 0 & - \\
\hline Heptachlor & 1.5 & 1.0 & 0 & 0 \\
\hline Heptachlor epoxide & 1.5 & 1.5 & 0 & 0 \\
\hline $\mathrm{HCB}$ & 1.27 & 3.0 & - & $<3.0$ \\
\hline 4,4'-DDT & 2.0 & 1.0 & $<2.0$ & $<1.0$ \\
\hline Toxaphene & - & 2.0 & - & 0 \\
\hline Aroclor 1016/1242 (PCB mixture) & - & 5.0 & - & 0 \\
\hline Aroclor 1260 (PCB mixture) & - & 5.0 & - & 0 \\
\hline Aroclor 1254 (PCB mixture) & - & 5.0 & - & 0 \\
\hline
\end{tabular}


Table 10. Replicate samples sent to the Central Laboratory for Analysis and Chemistry Department at the University of Science, Vietnam National University-Ho Chi Minh City throughout the laboratory analysis phase that were marked as regular samples but taken from the replicate sample from Hoa An Field Station. These samples were not expected to have any pollutants present.

[Unit of persistent organic pollutant (POP) concentration: nanogram per gram dry weight; CT01 - CT10, code names of ten replicated samples; <, less than; LOD, level of detection]

\begin{tabular}{|c|c|c|c|c|c|c|c|c|c|c|}
\hline & СТ01 & СТ02 & Ст03 & СТ04 & СТ05 & СТ06 & СТ07 & Ст08 & Ст09 & CT10 \\
\hline Dieldrin & 0 & 0 & 0 & 0 & 0 & 0 & 0 & 0 & 0 & 0 \\
\hline $\begin{array}{l}\text { Alpha-endo- } \\
\text { sulfan }\end{array}$ & 0 & 0 & 0 & 0 & 0 & 0 & 0 & 0 & 0 & 0 \\
\hline $\begin{array}{l}\text { Beta-endosul- } \\
\text { fan }\end{array}$ & 0 & $<$ LOD & 0 & 0 & 0 & 0 & $<\mathrm{LOD}$ & 0 & $<\mathrm{LOD}$ & 0 \\
\hline $\begin{array}{l}\text { Endosulfan } \\
\text { sulfate }\end{array}$ & 0 & 0 & 0 & 0 & 0 & 0 & 0 & 0 & 0 & 0 \\
\hline Endrin & 0 & 0 & 0 & 0 & 0 & 0 & 0 & 0 & 0 & 0 \\
\hline $\begin{array}{l}\text { Endrin alde- } \\
\text { hyde }\end{array}$ & 0 & 0 & 0 & 0 & 0 & 0 & 0 & 0 & 0 & 0 \\
\hline Gamma-HCH & 0 & 0 & 0 & 0 & 0 & 0 & 0 & 0 & 0 & 0 \\
\hline Delta-HCH & 0 & 0 & 0 & 0 & 0 & 0 & 0 & 0 & 0 & 0 \\
\hline Heptachlor & 0 & 0 & 0 & 0 & 0 & 0 & 0 & 0 & 0 & 0 \\
\hline $\begin{array}{l}\text { Heptachlor } \\
\text { epoxide }\end{array}$ & 0 & 0 & 0 & 0 & 0 & 0 & 0 & 0 & 0 & 0 \\
\hline 4,4'-DDT & 0 & $<\mathrm{LOD}$ & 0 & 0 & 0 & 0 & $<\mathrm{LOD}$ & 0 & 0 & 0 \\
\hline 4,4'-DDE & 0 & 0 & $<\mathrm{LOD}$ & 0 & $<\mathrm{LOD}$ & 0 & $<\mathrm{LOD}$ & 0 & 0 & 0 \\
\hline 4,4'-DDD & 0 & 0 & 0 & 0 & $<\mathrm{LOD}$ & 0 & 0 & 0 & 0 & 0 \\
\hline
\end{tabular}




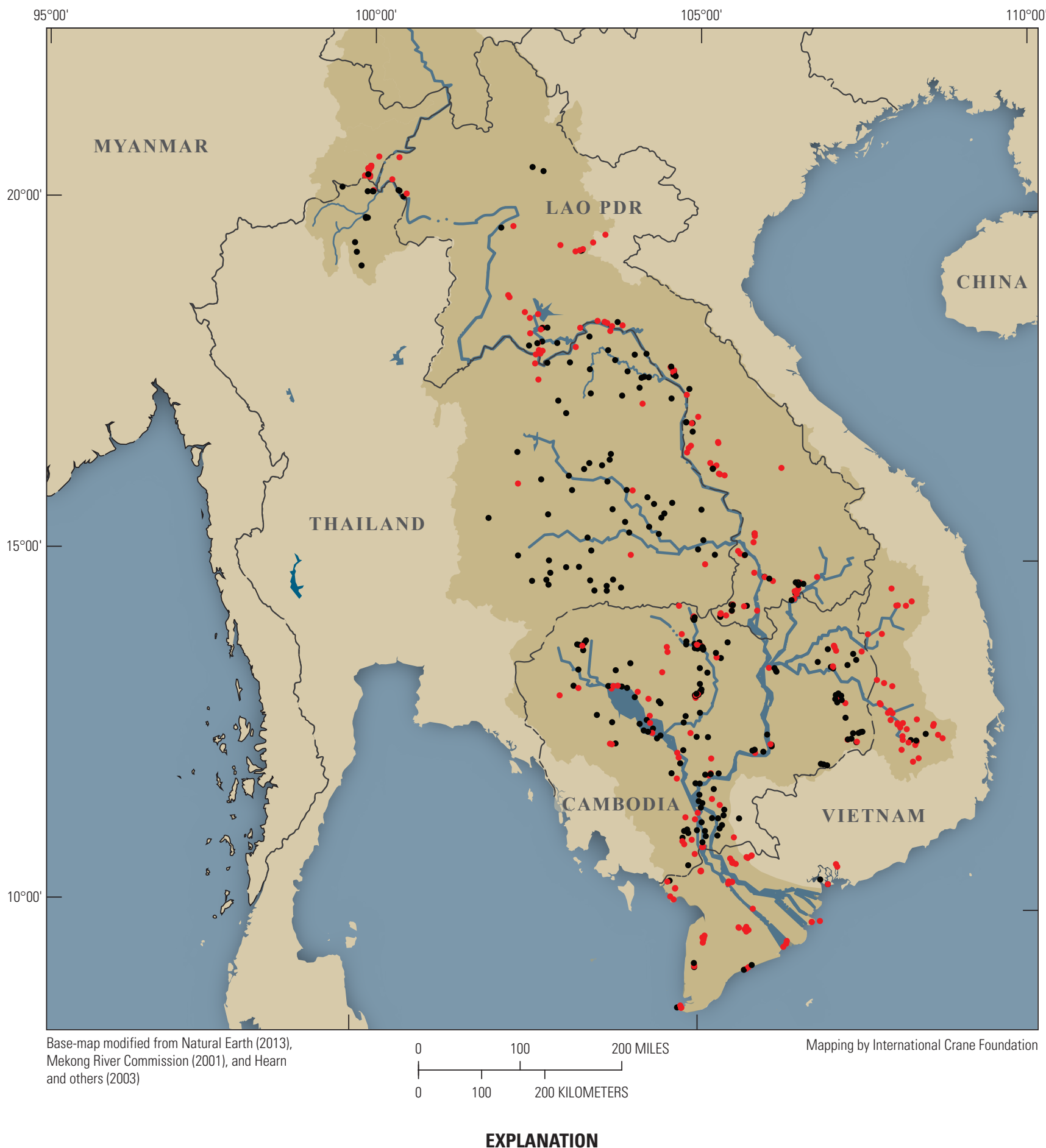

[Organochlorine pesticides (OCs) tested]

- 1 or more OCs detected

- No OCs detected
Mekong River and tributaries

Open water

Lower Mekong River Basin

Figure 5. Map showing geographic distribution of 531 samples collected from the Lower Mekong River Basin in 2011. 


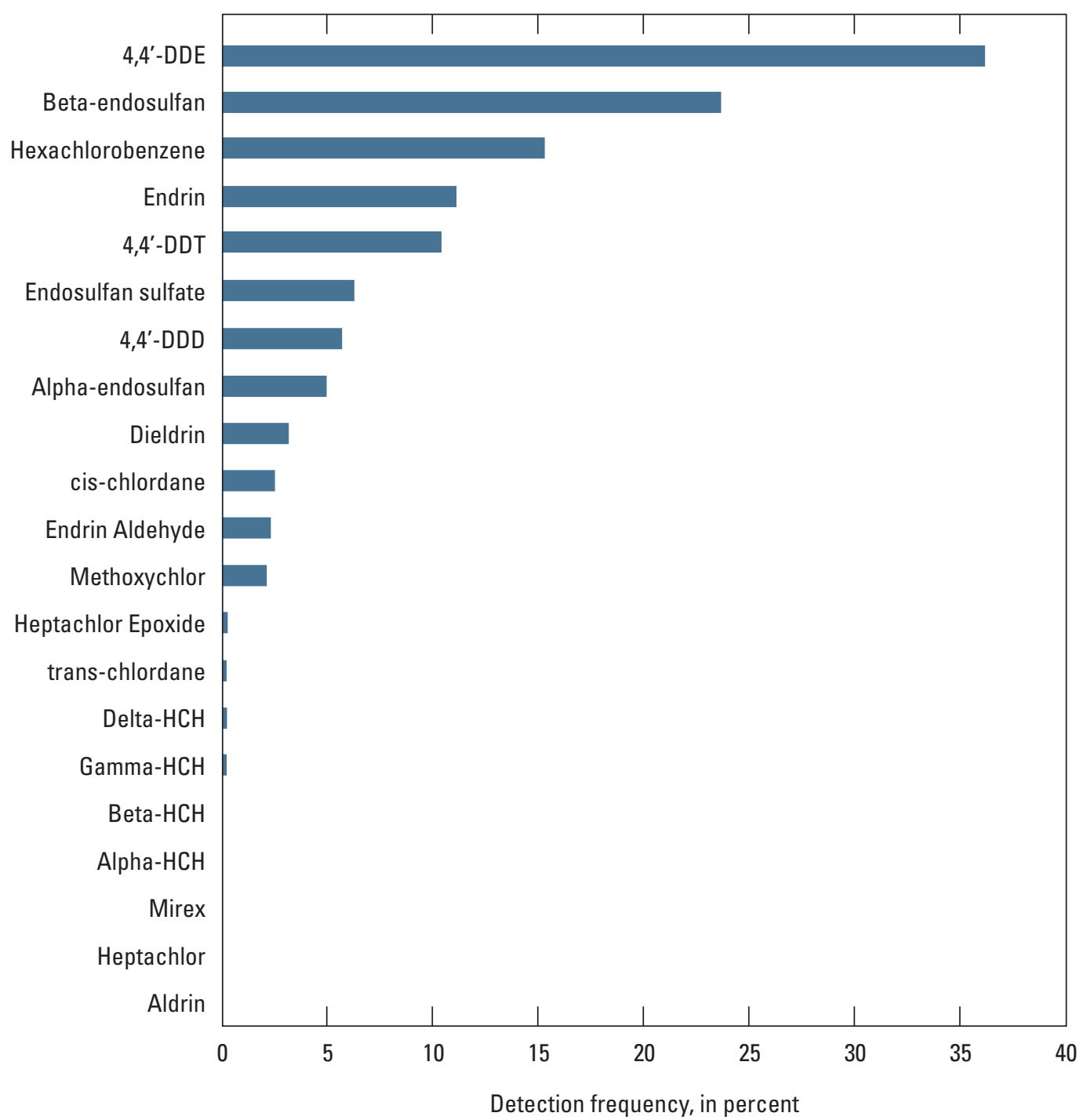

Figure 6. Graph showing detection frequency of organochlorine pesticide residues for 21 substances analysed in this study.

Detection frequency, in percent 
Table 11. Summary of organochlorine pesticide $(\mathrm{OC})$ concentration in 531 samples collected from the Lower Mekong Basin during 2011. All substances were measured in nanograms per gram dry weight.

[LOD, level of detection; $\mathrm{n} 1$, number of samples with positive concentrations of the respective organochlorine pesticide, n2, number of samples with positive concentrations that are smaller than LOD; n3, number of samples with organochlorine pesticide concentrations that are greater than or equal to LOD; ND, not detected; NA, not applicable]

\begin{tabular}{|c|c|c|c|c|c|c|c|c|}
\hline & LOD & n1 & n2 & n3 & $\begin{array}{l}\text { Range of detected } \\
\text { concentrations }\end{array}$ & Median ${ }^{1}$ & Mean' & $\begin{array}{c}\text { Standard } \\
\text { deviation }{ }^{1}\end{array}$ \\
\hline Aldrin & 1.5 & 0 & 0 & 0 & ND & NA & NA & $\mathrm{NA}$ \\
\hline \multicolumn{9}{|l|}{ Chlordane } \\
\hline Trans-chlordane & 0.4 & 1 & 0 & 1 & 0.51 & NA & NA & NA \\
\hline Cis-chlordane & 0.2 & 13 & 2 & 11 & $0.23-3.08$ & 0.56 & 1.01 & 0.96 \\
\hline \multicolumn{9}{|l|}{ DDT, DDE, DDD } \\
\hline 4,4'-DDT & 2 & 55 & 44 & 11 & $2.02-17.11$ & 3.97 & 6.61 & 5.37 \\
\hline 4,4'-DDD & 1 & 30 & 25 & 5 & $1.16-11.53$ & 2.92 & 4.63 & 4.34 \\
\hline 4,4'-DDE & 1 & 192 & 113 & 79 & $1.00-75.66$ & 2.00 & 6.39 & 11.66 \\
\hline Beta-Endosulfan & 1 & 126 & 86 & 40 & $1.04-26.19$ & 1.95 & 4.09 & 5.72 \\
\hline Endosulfan Sulfate & 1 & 33 & 28 & 5 & $1.02-10.47$ & 1.66 & 3.20 & 4.08 \\
\hline Total Endosulfans & NA & 165 & NA & 46 & $1.04-26.19$ & 1.95 & 3.97 & 5.47 \\
\hline \multicolumn{9}{|l|}{ Endrin } \\
\hline Endrin & 1 & 59 & 31 & 28 & $1.02-7.06$ & 1.68 & 2.14 & 1.37 \\
\hline Endrin aldehyde & 1 & 12 & 7 & 5 & $1.27-1.86$ & 1.49 & 1.53 & 0.25 \\
\hline Total Endrins & NA & 68 & NA & 32 & $1.02-7.06$ & 1.61 & 2.06 & 1.30 \\
\hline \multicolumn{9}{|l|}{ Heptachlor } \\
\hline Heptachlor & 1.5 & 0 & 0 & 0 & ND & NA & NA & NA \\
\hline Gamma-HCH & 1.5 & 1 & 1 & 0 & NA & NA & NA & NA \\
\hline Delta-HCH & 1 & 1 & 0 & 1 & 1.27 & NA & NA & NA \\
\hline Total HCHs & NA & 2 & NA & 1 & 1.27 & NA & NA & NA \\
\hline Methoxychlor & 2 & 11 & 11 & 0 & ND & NA & NA & NA \\
\hline Mirex & 0.5 & 0 & 0 & 0 & ND & NA & NA & NA \\
\hline Total OC loading & NA & 341 & NA & 148 & $0.23-105.28$ & 2.05 & 5.94 & 13.12 \\
\hline
\end{tabular}

${ }^{1}$ Medians, means, and standard deviations were calculated using only values of persistent organic pollutant (POP) concentrations greater than LODs.

${ }^{2}$ Where metabolites were summed, values for $\mathrm{n} 2$ were not calculated because more than one metabolite could occur in the same sample. 
Table 12. Sites with the highest total organochlorine pesticide loading (above 10 nanograms per gram) among 531 samples collected from the Mekong Basin in 2011.

[OC, organochlorine pesticide; ng/g, nanogram per gram]

\begin{tabular}{llc}
\hline \multicolumn{1}{c}{ Sample name } & \multicolumn{1}{c}{ Location of sample } & Total OC loading (ng/g) \\
\hline C111 & Preah Vihear Province, Cambodia & 105.28 \\
C183 & Mondolkiri Province, Cambodia & 88.37 \\
T511 & Bueng Kan, northeast Thailand (Ramsar Site) & 50.65 \\
C145 & Ratanakiri Province, Cambodia & 43.78 \\
L010 & Xiang khuang Province, Lao PDR & 43.22 \\
V066 & Srepok River Basin, Daklak Province, Vietnam & 32.58 \\
V003 & Tram Chim National Park, Dong Thap Province, Vietnam (Ramsar Site) & 23.81 \\
C131 & Preah Vihear Province, Cambodia & 21.59 \\
C112 & Preah Vihear Province, Cambodia & 18.43 \\
C117 & Preah Vihear Province, Cambodia & 17.99 \\
C080 & Kampong Thom Province, Cambodia & 17.11 \\
V074 & Dak Lak Province, Vietnam & 16.90 \\
T509 & Nong Khai Province, Thailand & 12.71 \\
V012 & Hau Giang Province, Vietnam & 11.53 \\
V034 & Hon Chong, Kien Giang Province, Vietnam & 10.54 \\
C146 & Ratanakiri Province, Cambodia & 10.49 \\
\hline
\end{tabular}




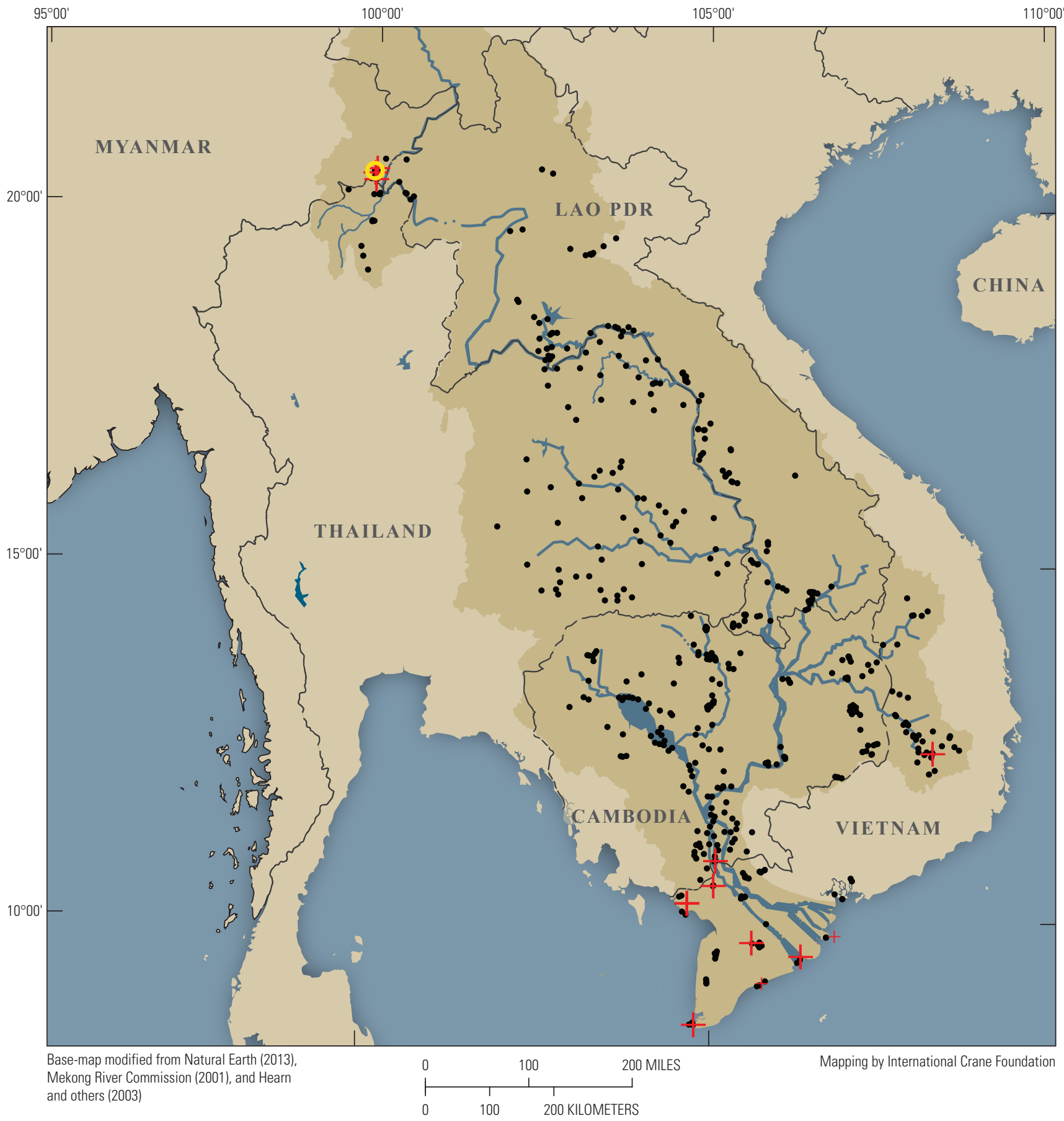

\section{EXPLANATION}

[Amount of Chlordane detected (nanograms/gram of sample)]

Cis-chlordane

$+<$ Level of detection $(0.10-0.19)$

$+0.2-5.0$
Trans-chlordane

$<$ Level of detection (0.10-0.39)

$0.4-5.0$
- No chemical detected

Mekong River and tributaries Open water

Lower Mekong River Basin

Figure 7. Map showing distribution and concentrations of cis- and trans-chlordane found in 531 sediment samples collected from the Lower Mekong River Basin during 2011. 


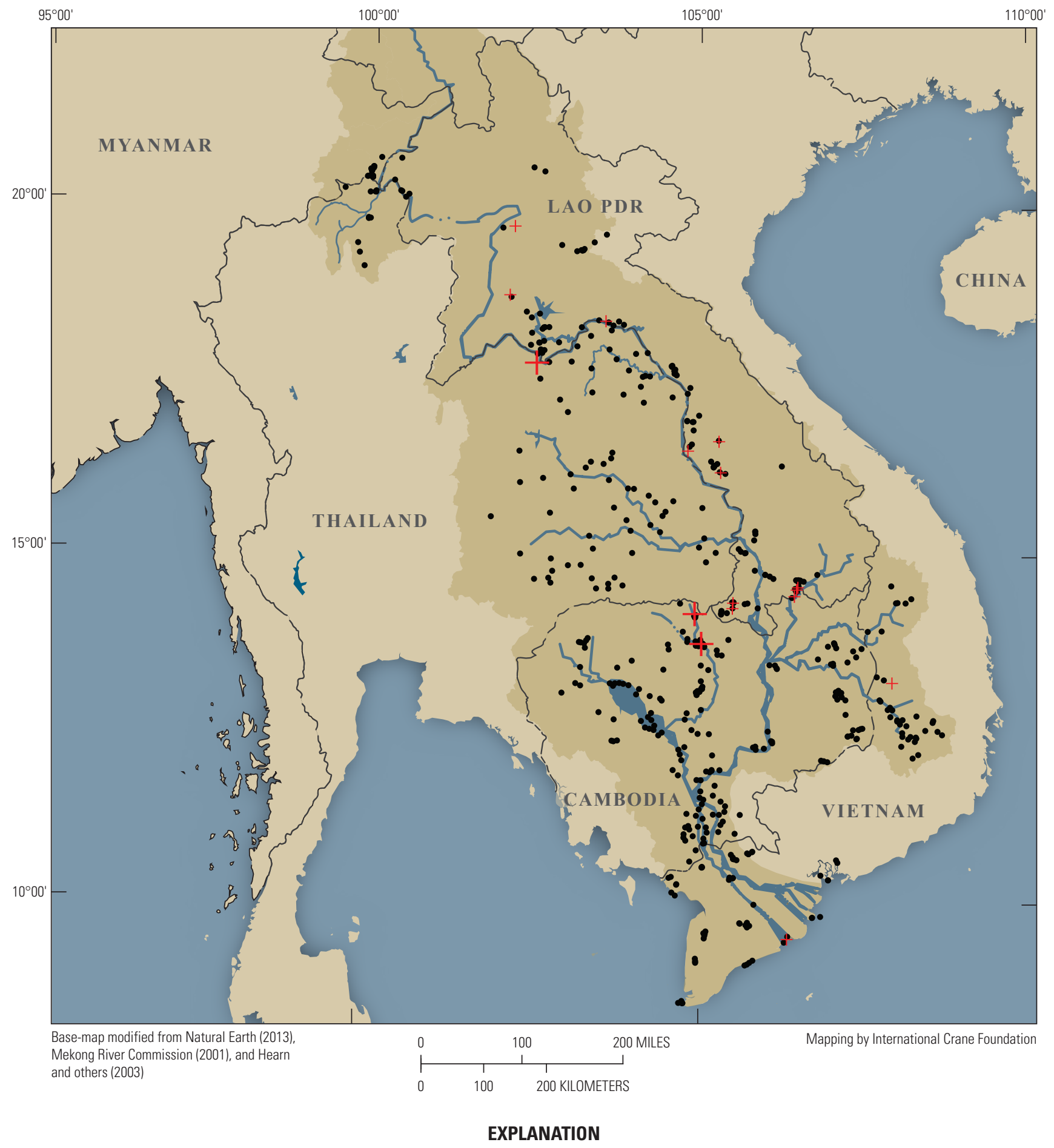

[Amount of Dieldrin detected (nanograms/gram of sample)]

\section{Dieldrin}

$+<$ Level of detection (1.0)

$+1.0-5.0$
- No chemical detected

$\sim$ Mekong River and tributaries

Open water

Lower Mekong River Basin

Figure 8. Map showing distribution and concentrations of dieldrin found in 531 sediment samples collected from the Lower Mekong River Basin during 2011. 


\section{DDT, DDE, DDD}

DDT and its two metabolites, DDE and DDD, were the most frequently detected substances in the Mekong Basin with the presence of at least one of these compounds detected in 236 sediment samples (44 percent of samples). With the exception of Thailand, DDT and its metabolites were also distributed extensively across the Lower Mekong Basin (fig. 9). Individual maximum concentrations of DDT and DDE were the highest among all OC pesticides detected in this study, as were the total maximum concentrations of DDT and its metabolites ( $\Sigma$ DD_s: sum of DDT, DDD, and DDE; table 11). DDE was the most frequently found compound, detected in 192 of 531 samples (36 percent). DDD, conversely, was found in only 30 samples (6 percent). The highest concentrations of DDT were found in Cambodia (C080: Tonle Sap Lake, Kampong Thom Province, 17.11 ng/g; C111: Preah Vihear Province, 15.00 ng/g) and in Lao PDR (L010: Xiengkhoang Province, $11.42 \mathrm{ng} / \mathrm{g}$ ). The highest concentrations of DDE were found in Cambodia (C111: Preah Vihear Province, 75.66 ng/g; C183: Mondolkiri Province, $60.61 \mathrm{ng} / \mathrm{g}$; C145: Ratanakiri Province, $25.90 \mathrm{ng} / \mathrm{g}$ ). The highest concentration of DDD was found in Vietnam, VN102: Hau Giang Province, $11.53 \mathrm{ng} / \mathrm{g}$. Cambodia also had a sample with a high concentration of DDD (C145, Ratanakiri Province, $6.14 \mathrm{ng} / \mathrm{g})$.

Though widespread, the total concentration of DDT and its metabolites varied substantially by country. Myanmar had the lowest average concentration per sample of the five countries surveyed (table 13), whereas Cambodia had the highest average concentration. When means weighted by the frequency of detection were used to compare the level of DDT and its metabolites in each country, samples from Cambodia and Vietnam had higher weighted means than Lao PDR, Myanmar, or Thailand (table 13).

The ratio (DDD+DDE)/(DDD+DDE+DDT) reflects the history of DDT application, where larger values (0.5-1) of the ratio indicated that DDT in the environment had been aged (in other words, degraded), whereas smaller values $(0-0.4)$ indicated more recent use of DDT (Strandberg and others, 1998; Doong and others, 2002a; Pham and others, 2010; Zhang and others, 2011). The majority of ratio values for the samples were between 0.5 and 1 (181 of 236 samples, 77 percent; fig. 10), meaning there had been little recent contamination by DDT. Among 531 samples analyzed, DDT was detected in 55 samples, 24 of which had only DDT and no DDE or DDD, indicating possible recent use of DDT. Lao PDR, the Mekong Delta in Vietnam and Cambodia, as well as the Tonle Sap Basin in Cambodia had sediment concentrations of DDT that suggested recent use, whereas Thailand had no sediment samples that suggested recent use (fig. 11). All other ecological regions contained few sediment samples that indicated recent use of DDT.

\section{Endosulfan, Endrin, and Hexachlorobenzene}

Residues of at least one form of endosulfan were found in 165 sediment samples, 31 percent of all samples collected in the Lower Mekong River Basin (fig. 12). Alpha-endosulfan, beta-endosulfan, and endosulfan sulfate were found in 26, 126, and 33 samples, respectively. The presence of endosulfans tended to be low in Thailand and Myanmar and more frequent in Lao PDR, Cambodia, and Vietnam. The site that had the highest concentration of total endosulfans, however, was in Thailand (T511: Bueng Kan, a Wetland of International Importance, $26.19 \mathrm{ng} / \mathrm{g}$ ) (appendix $3)$. Other sites that had high concentrations of endosulfans (greater than $10 \mathrm{ng} / \mathrm{g}$ ) were in Cambodia (C183: Mondolkiri Province, 23.83 ng/g; C111: Preah Vihear Province, 12.78 ng/g; and C145: Ratanakiri Province, 10.47 ng/g), Lao PDR (L010: Xiengkhoang Province, $14.12 \mathrm{ng} / \mathrm{g}$ ), and Vietnam (V034: 10.54 ng/g) (appendix 3). The site in Vietnam was located in Hon Chong, Kien Giang Province, an important night roost site for the eastern Sarus Cranes (Grus antigone), an endangered species, in the Mekong Delta.

Endrin was detected in 68 samples, 13 percent of the samples analyzed (table 11). High concentrations of endrin were found in the Mekong Delta of both Vietnam and Cambodia, in the Sesan and Srepok River Basins of Vietnam, in wetlands along the main Mekong channel in southern and central Lao PDR, and in the open dry dipterocarp forests along the Sen River in northern Cambodia (fig. 13). Sites that had the highest concentrations of endrin and endrin aldehyde were in Cambodia (C161: Preah Vihear Province, 7.06 ng/g) and Vietnam (V053: Bac Lieu Province, 5.59 ng/g; V075: Daklak Province, 3.79 ng/g; and V094: Kontum Province, $3.14 \mathrm{ng} / \mathrm{g}$ ) (appendix 3).

HCB was detected in 15 percent of the samples taken (81 samples), but only five samples had concentrations higher than the LOD (1.27 ng/g). Even though HCB residues were not found in high concentrations, the fact that HCB was detected in many wetland sites suggests that widespread use of HCB may have occurred in the past in the region (fig. 14). $\mathrm{HCB}$ was more evenly distributed throughout the region than endosulfan or endrin, which were concentrated in a subset of countries or regions.

\section{Independent Data from Interviews}

Interviews of people living near wetlands where POPs were sampled provided an independent assessment of results obtained from analysis of sediment samples. From 101 of the 459 interviews, data were obtained that mentioned pesticides used at the time of the survey or in the last few years, and 76 interviews provided direct information on pesticide use. 


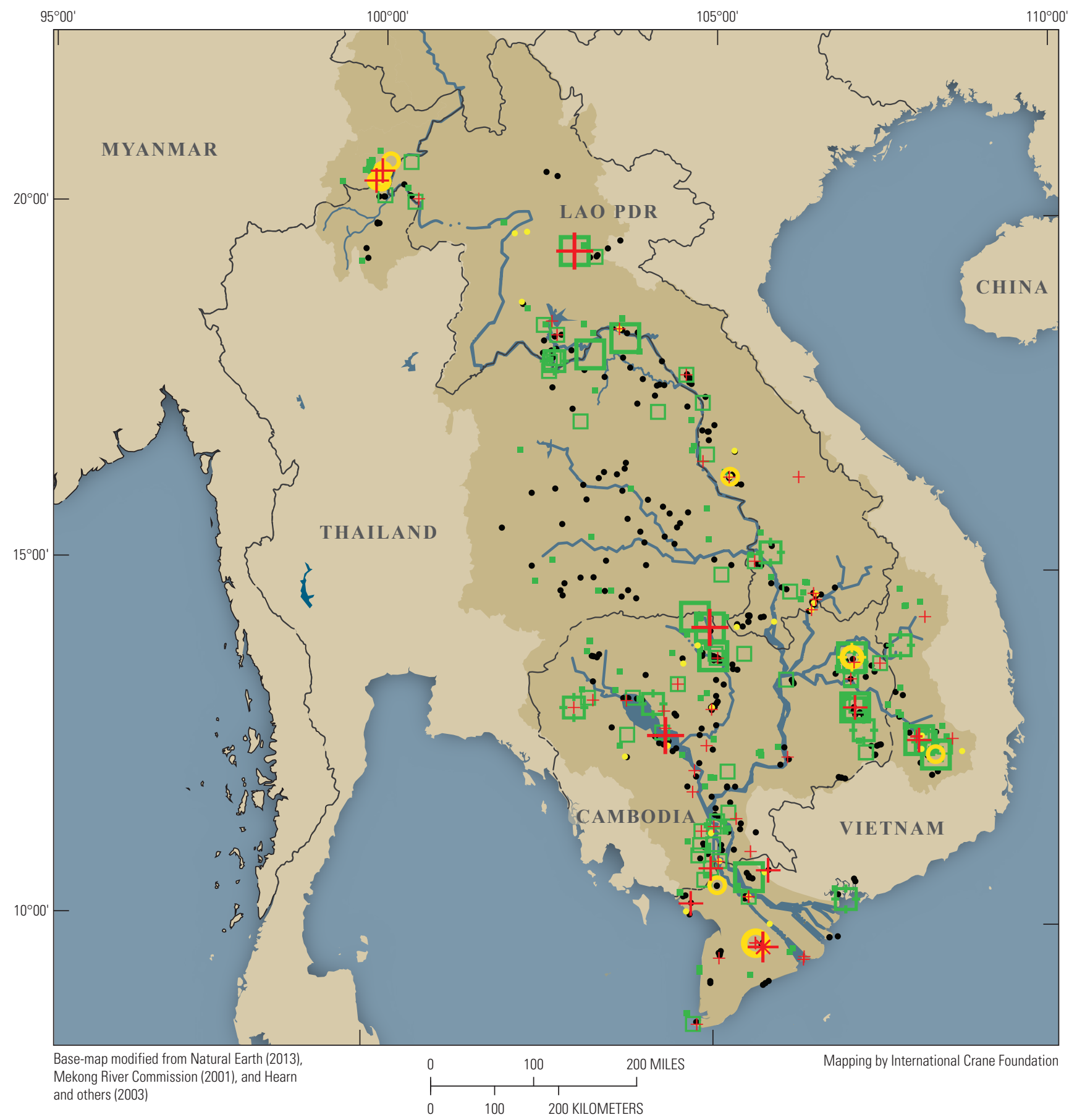

\section{EXPLANATION}

[Amount of DDT and its metabolites detected (nanograms/gram of sample)]

DDT

$+<$ Level of detection (0.10-1.9)

$+2.0-5.0$

* 5.1-10.0

$千>10.0$
DDD

$<$ Level of detection (0.1-0.9)

$1.0-5.0$

$5.1-10.0$

$>10.0$
DDE

- < Level of detection (0.1-0.9)

$\square \quad 1.0-5.0$

t+ 5.1-10.0

$>10.0$
- No chemical detected

Mekong River and tributaries Open water

Lower Mekong River Basin

Figure 9. Map showing distribution and concentrations of DDT, DDE , and DDD found in 531 sediment samples collected from the Lower Mekong River Basin during 2011. 
Table 13. Median, mean, and standard deviation of total DDTs (sum of DDT, DDE, and DDD) found in 531 sediment samples (sorted by country) collected from the Lower Mekong River Basin in 2011.

[Dichlorodiphenyltrichloroethane, DDT; Dichlorodiphenyltrichloroethylene, DDE; Dichlorodiphenyldichloroethane, DDD; Unit of total DDTs, nanograms per gram dry weight; $\mathrm{N}$, number of samples taken in the country; $n$, number of samples that were detected with at least one form of DDT; median, mean, and standard deviation were calculated based on concentrations that are larger than the respective level of detection; weighted means were calculated using the frequency of detection $(\mathrm{n} / \mathrm{N})$ as the weight]

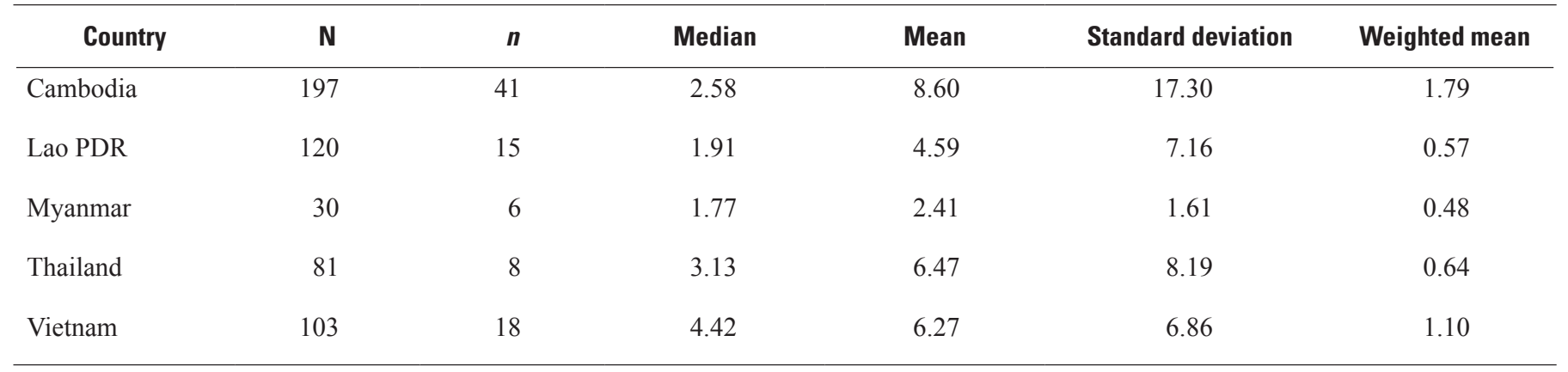

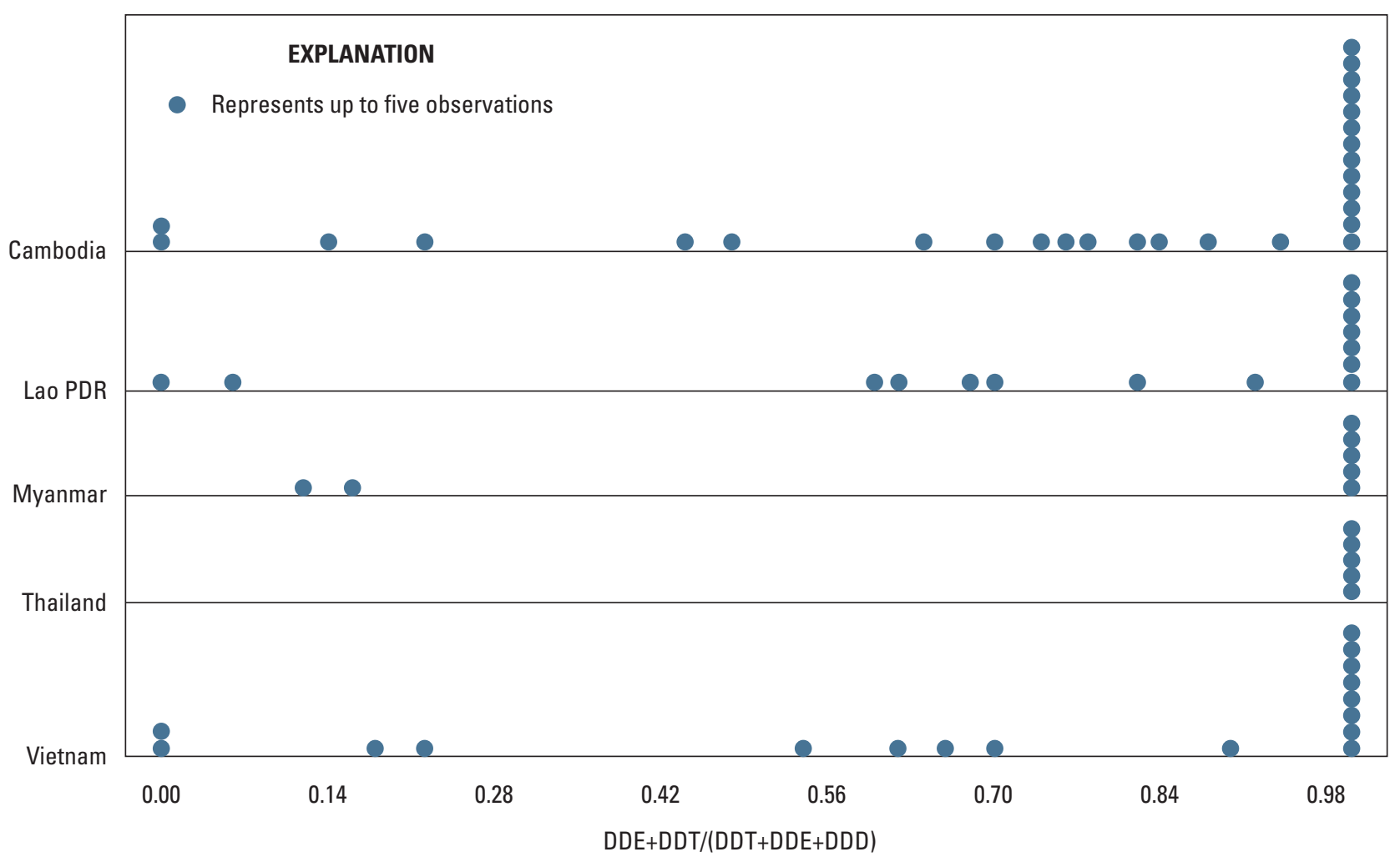

Figure 10. Graph showing ratio of (DDE + DDD)/ total DDTs found in 531 samples collected from the Lower Mekong River Basin during 2011. 


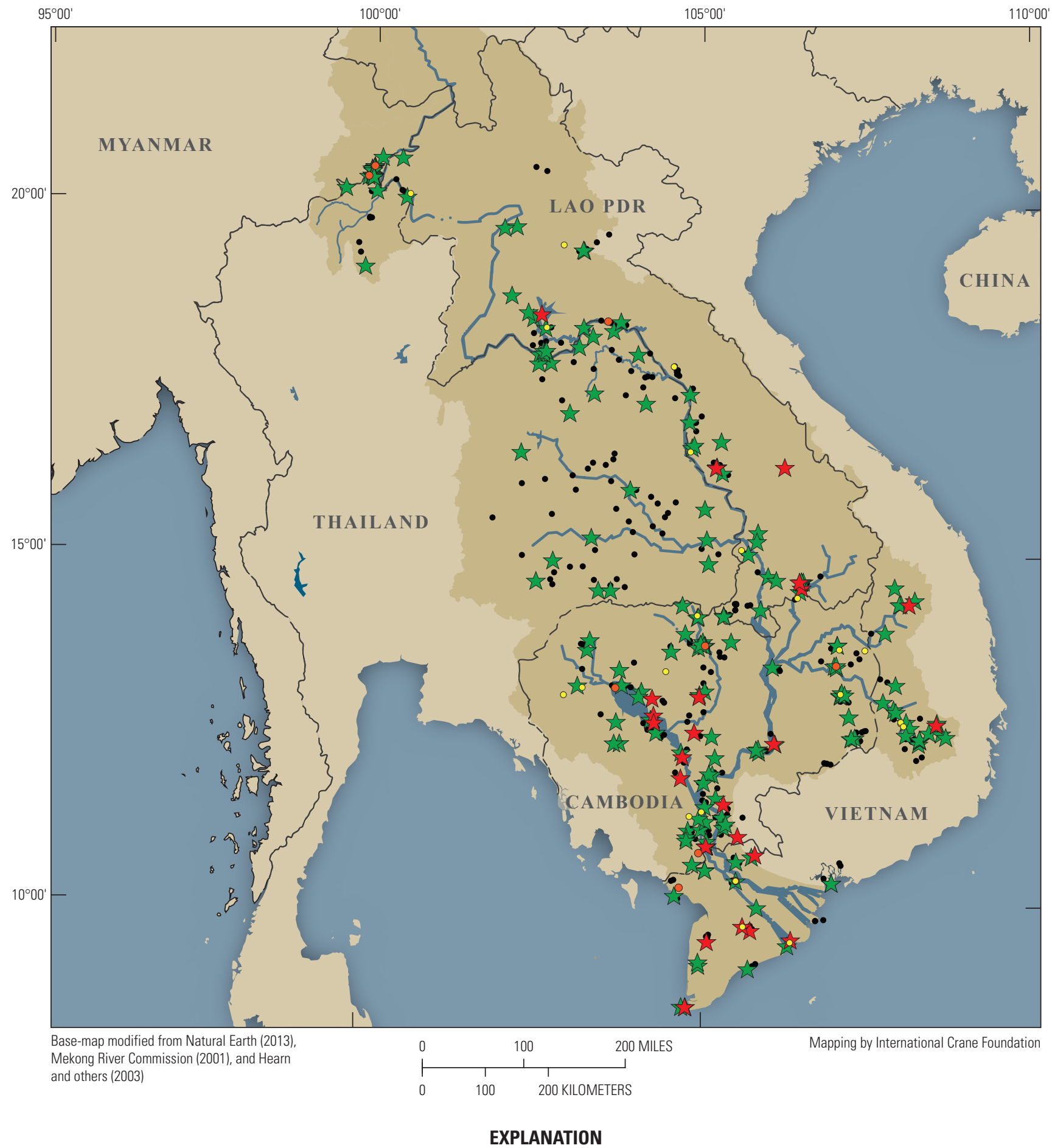

[DDT ratio $(D D D+D D E) /(D D D+D D E+D D T)]$

- No chemical detected

Mekong River and tributaries

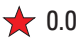

- $0.1-0.4$

○ $0.5-0.9$

ţ 1.0

Figure 11. Map showing distribution of DDT, DDD, and DDE concentrations expressed as the ratio (DDD+DDE)/(DDD+DDE+DDT) found in 531 samples collected from the Lower Mekong River Basin during 2011. 


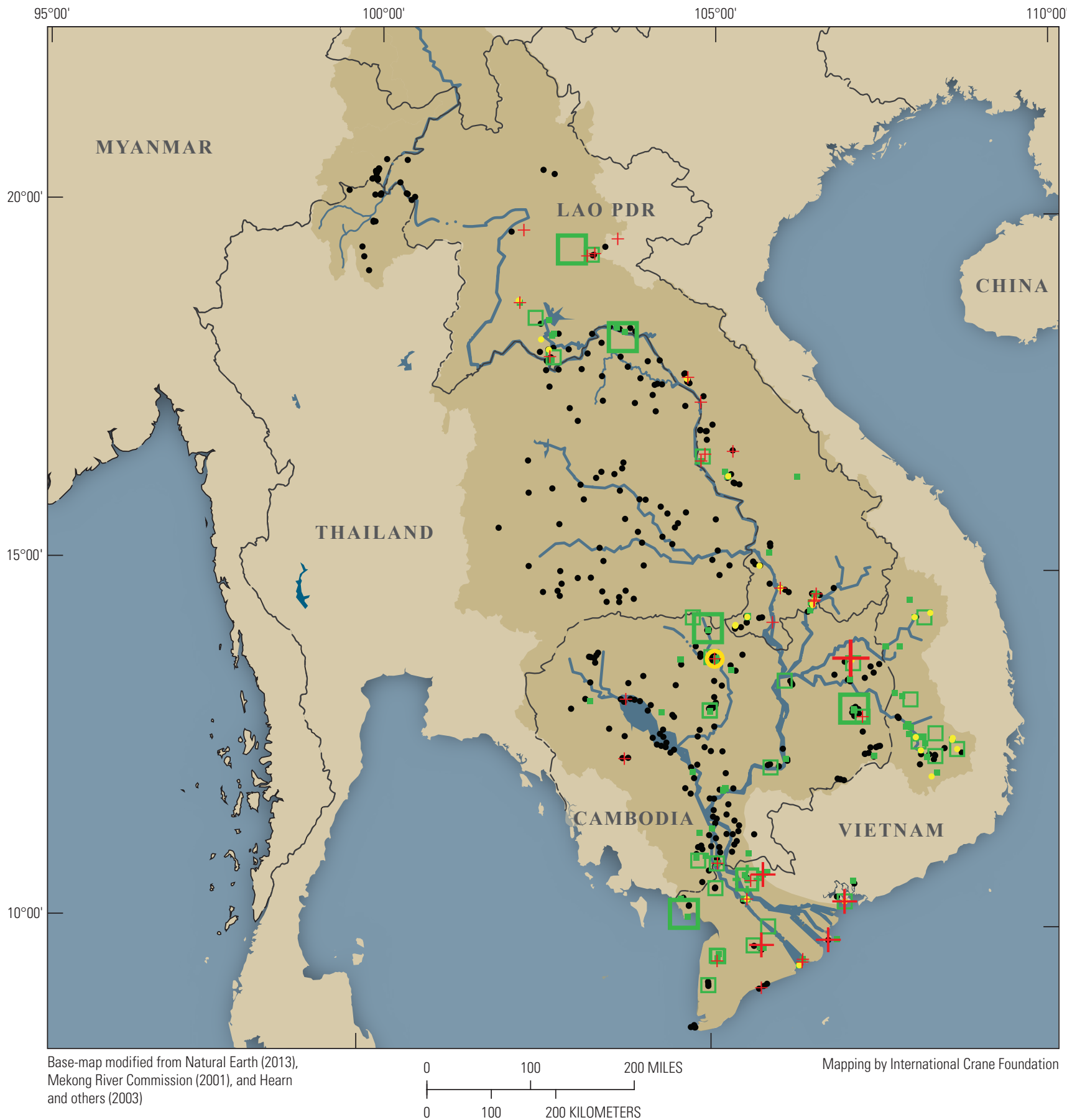

\section{EXPLANATION}

[Amount of endosulfan detected (nanograms/gram of sample)]

\section{Endosulfan sulphate}

$+\quad<$ Level of detection (0.1-0.9)

十 1.0-5.0

米 5.1-10.0

$千>10.0$

\section{Alpha-endosulfan}

c < Level of detection (0.1-0.9)

$1.0-5.0$

\section{Beta-endosulfan}

- < Level of detection (0.1-0.9)

$\square \quad 1.0-5.0$

t. 5.1-10.0

$>10.0$
- No chemical detected

Mekong River and tributaries Open water

Lower Mekong River Basin

Figure 12. Map showing distribution and concentrations of endosulfan sulfate, alpha-endosulfan, and beta-endosulfan found in 531 sediment samples collected from the Lower Mekong River Basin during 2011. 


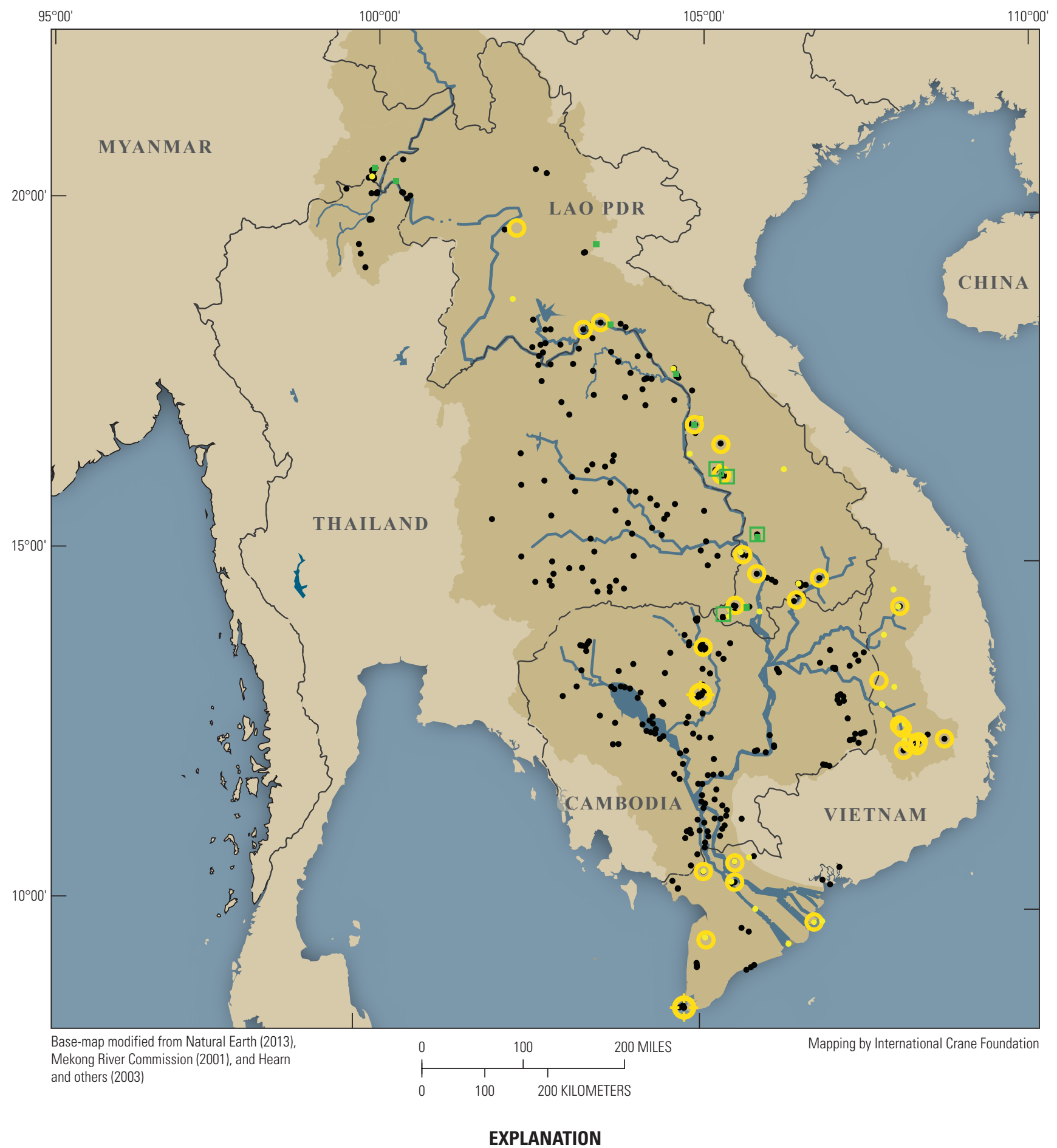

[Amount of endrin and endrin aldehyde detected (nanograms/gram of sample)]

Endrin

$<$ Level of detection $(0.1-0.9)$
$1.0-5.0$
$5.1-10.0$

$<$ Level of detection $(0.1-0.9)$

$5.1-10.0$

\section{Endrin aldehyde}

- < Level of detection (0.1-0.9) $1.0-5.0$

Figure 13. Map showing distribution and concentrations of endrin and endrin aldehyde found in 531 sediment samples collected from the Lower Mekong River Basin during 2011. 


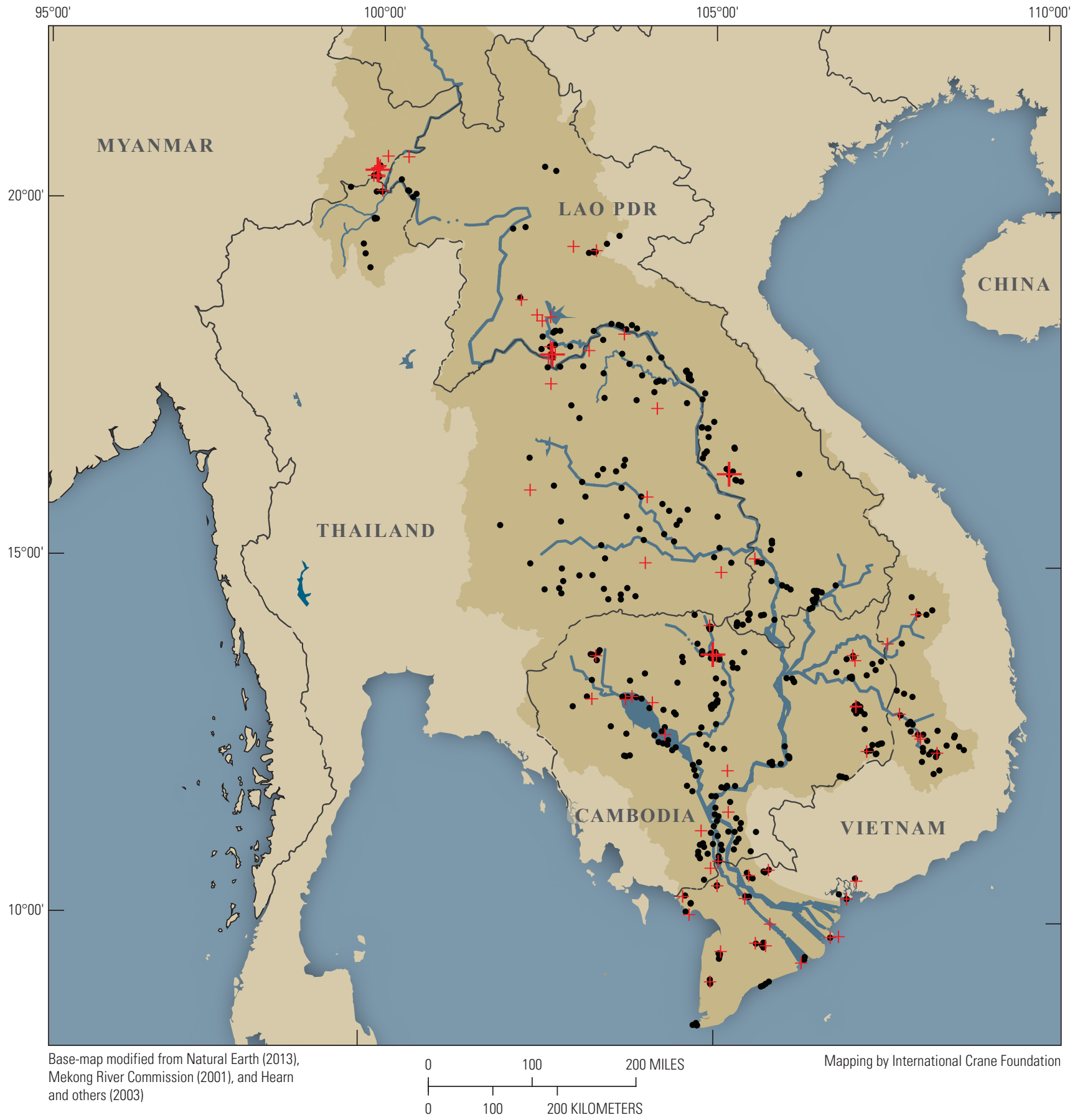

\section{EXPLANATION}

[Amount of hexachlorobenzene detected (nanograms/gram of sample)]

\section{Hexachlorobenzene}

$+<$ Level of detection (0.1-0.9)

$+1.0-5.0$
- No chemical detected

Mekong River and tributaries

Open water

Lower Mekong River Basin

Figure 14. Map showing distribution and concentrations of hexachlorobenzene found in 531 sediment samples collected from the Lower Mekong River Basin during 2011. 
The remaining 25 interviews provided no specific data regarding individual pesticides used. From the 76 interviews, only one interview identified an $\mathrm{OC}$ as being used recently (T105: dicofol), whereas the remaining individual pesticides mentioned in 76 interviews referred to families of pesticides that were not OCs. Of these other families, their proportion of use was 40.8 percent carbamates, 10.5 percent other pesticides (2,4-D acid, metaldehyde, and chlorinated isocyanurate), 7.9 percent glyphosate, 6.6 percent organophosphates, 5.3 percent pyrethroids, 5.3 percent biopesticides, and 22.4 percent unknown pesticides (pesticides that had names but no known active ingredient: andrin, dovil, gold taess, inpitune, iso propylammo, nato, noksin 25 , and til avil).

Also from the 459 interviews, land uses were identified that surround the wetlands we sampled. Pesticide uses from interviews were then compared to the presence of OCs that were found in sediment samples of the same wetlands (fig. 15). Our hypothesis was, if agricultural land uses were causing OCs to accumulate in wetlands, then more OCs would be found in wetlands with agricultural land uses nearby than would be found in wetlands that were distant from agricultural land uses. For all OCs combined, OCs were present in onethird to one-half of the wetlands when rice, eucalyptus, and rubber were the dominant adjoining agricultural land uses (fig. 15A). Though few wetlands were located near fruit and vegetable plantations, OCs were present in almost threefourths of the wetlands near these plantations.

Our study also attempted to group wetlands into three different categories that would be less influenced by agriculture. Once grouped, these wetlands were compared to wetlands that exist near agricultural land uses. First, interviews that identified no agricultural land uses occurring nearby and that mentioned native vegetation growing around the wetlands were reviewed. Wetlands meeting these criteria were called nonagricultural wetlands (fig. 15). Second, among nonagricultural wetlands, wetlands were selected that were more likely to be unaffected by people, namely natural wetlands not connected to the river: palustrine or lacustrine (littoral only) systems that had inundated (seasonal or permanent). These wetlands were called control 1 wetlands. Third, wetlands were examined that matched the control 1 criteria but were found only in protected areas. These wetlands were called control 2 wetlands and were the most remote of the wetlands sampled. Interestingly, more than 50 percent of wetlands in all three groupings still contained OCs (fig. 15A).

Except in the control 2 wetlands category, DDT and its metabolites, DDE and DDD, made up more than half of the OCs present in wetlands near all types of land use (fig. $15 B)$. Endrin generally made up less than half of the OCs present in wetlands near all land uses but was most frequent in sampled wetlands that were near eucalyptus plantations, nonagricultural wetlands, and control 2 wetlands (fig. 15C). HCB was also infrequently found in wetlands (fig. 15D), was nearly absent from the control wetlands and was most frequently found in samples from wetlands located near areas where rice was being grown and near fruit and vegetable plantations. No other OCs were located in the three types of nonagricultural samples.

\section{Results of Polychlorinated Biphenyl Analyses}

Of the 61 samples tested for PCBs (11.5 percent of 531 samples), only 4 ( 2 in Cambodia, 1 in Lao PDR, and 1 in Vietnam) contained any form of PCB (fig. 16), and all four samples contained the same isomer, $\mathrm{PCB}_{28}$ (table 14). Samples for each country were selected on the basis of the proximity of the sample sites to urban or industrial areas. $\mathrm{PCB}_{28}$ was detected near Vientiane (Lao PDR) and near Ho Chi Minh City (Vietnam), two major urban centers. Conversely, $\mathrm{PCB}_{28}$ was also found in two samples from the Tonle Sap Basin (Cambodia), which is distant from any major urban center, and was absent from samples taken near Phnom Penh or other larger cities in Cambodia.

\section{Organochlorine Pesticide Concentration in Relation to Wetland Environment}

Patterns of OC distribution were apparent among different countries within the Mekong Basin and may be best explained by social factors such as the history of pesticide use and the regulations controlling use established within the region. But to what extent might ecological factors, especially those related to wetlands, further explain patterns of OC distribution?

\section{Choosing Environmental Predictors}

Logistic regression was used to examine the relation between OCs and the ecological characteristics of the wetlands where sediment samples were collected. The purpose was to identify wetland variables that associated with the presence of OCs in the Mekong Basin and to test how mobile OCs might be within the basin. The seven OC groups or metabolites included in the analysis were endosulfan (a combination of alpha-endosulfan, beta-endosulfan, and endosulfan sulfate); endrin (a combination of endrin and endrin aldehyde); HCB; DDT; DDE; DDD; and the combination of DDT, DDE, and DDD. All other OCs were excluded from the analysis because of their scarcity in the samples collected. In this analysis, each $\mathrm{OC}$ was present or absent. The concentration of an OC in any one sample was not used. Concentrations that indicated an OC was present, but were below the LOD, were recorded as being present (having a value of one). A response variable also was analyzed named "All OCs." Eight categorical environment predictors were examined as well as three numerical variables, all of which are defined in table 2. Metrics for these categorical and numerical variables are listed in appendix 6 . 
A.

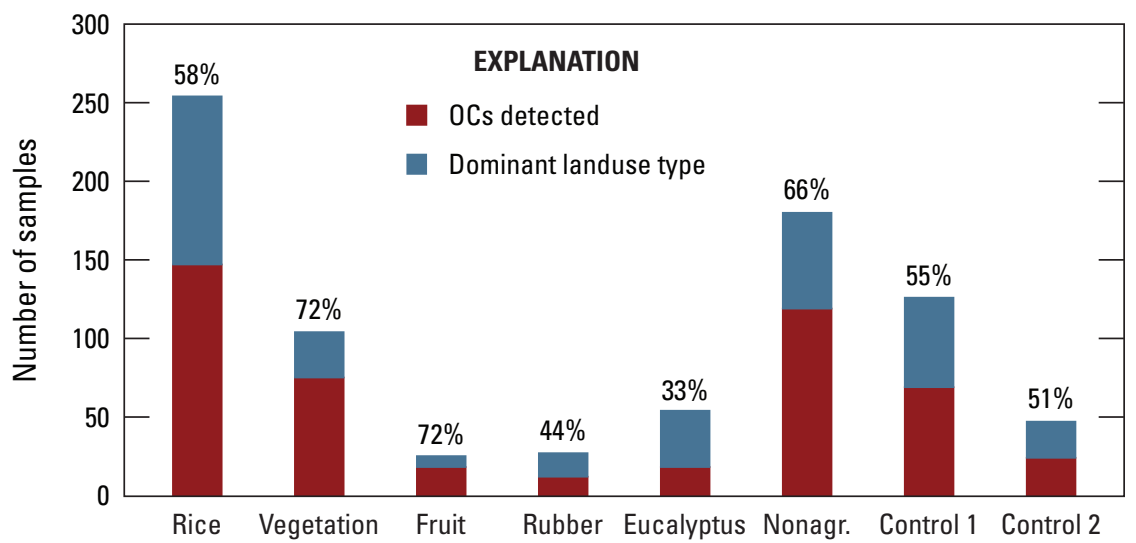

B.

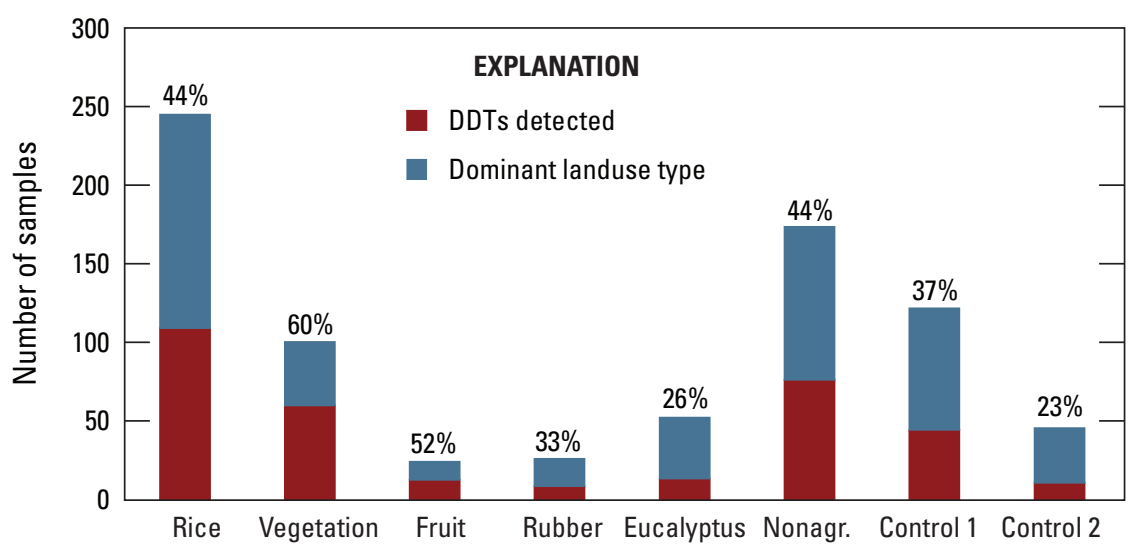

C.

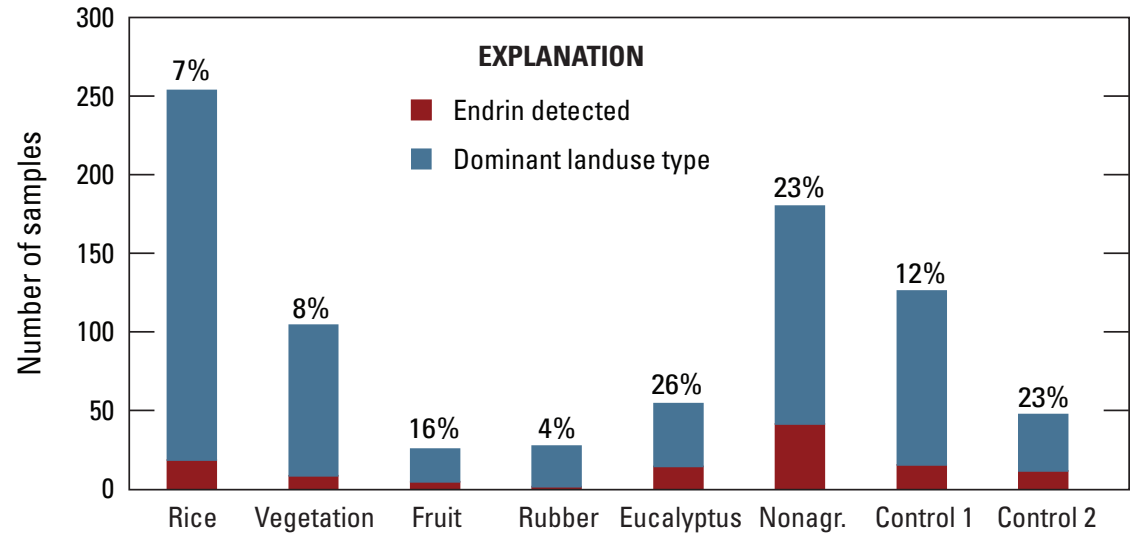

D.

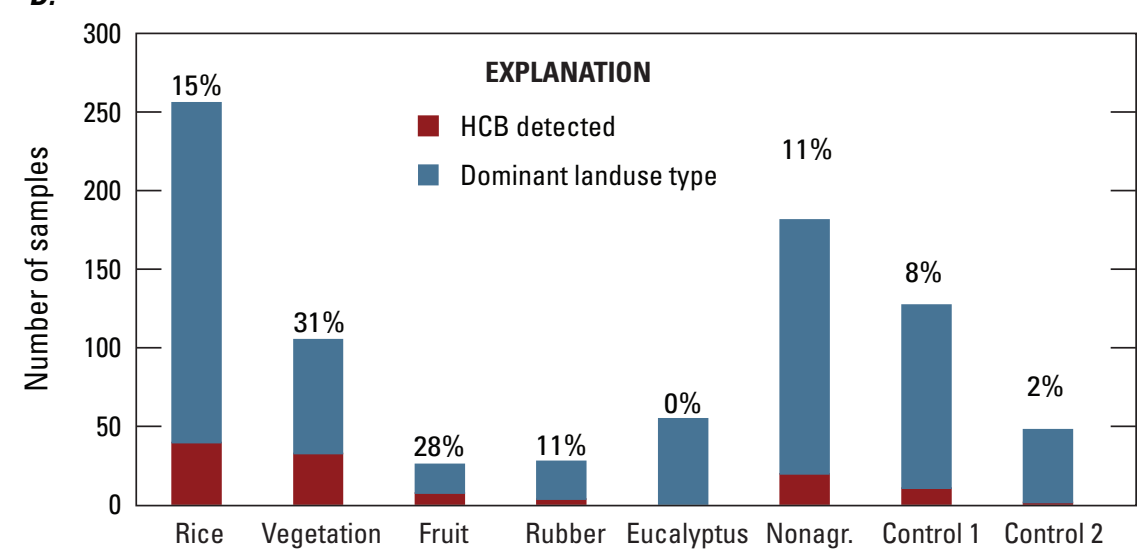

Figure 15. Frequency of all organochlorines $(\mathrm{OC})$ in relation to land use of areas surrounding sampled wetlands. $A, \mathrm{OC}$ detected in wetlands; $B$, a combination of DDT, DDE, and DDD (called DDTs) ; $C$, endrin; $D$, hexachlorobenzene (HCB). 


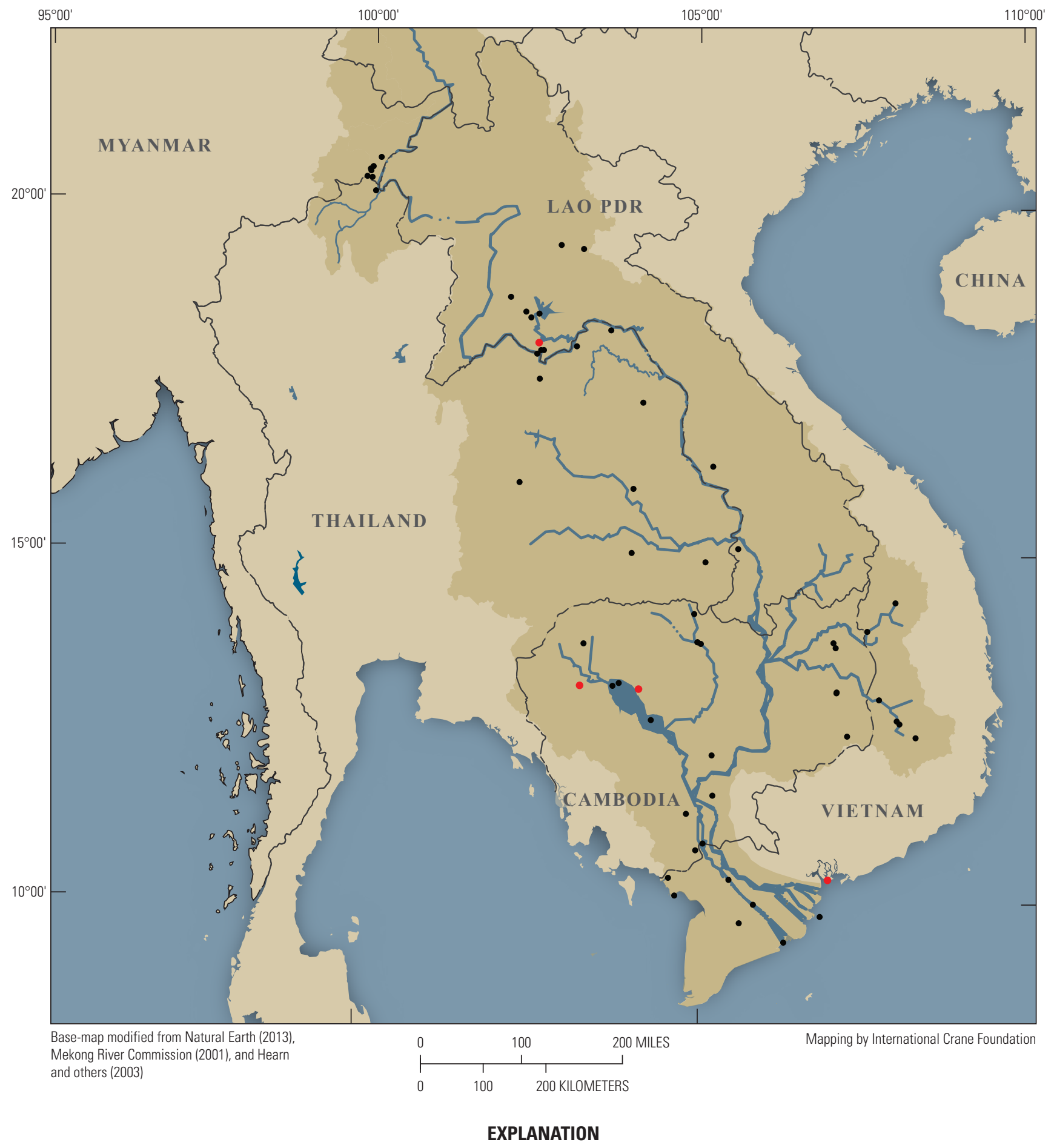

[Amount of PCBs detected (nanograms/gram of sample)]

- No PCBs detected

- $>0.4$ (Level of detection)
- No chemical detected

$\sim$ Mekong River and tributaries Open water

Lower Mekong River Basin

Figure 16. Map showing distribution and concentrations of $\mathrm{PCB}_{28}$ found in 61 sediment samples collected from the Lower Mekong River Basin during 2011. 
Table 14. Concentrations of polychlorinated biphenyl (PCB) compounds in 61 samples collected from the Lower Mekong River Basin during 2011.

[PCB, polychlorinated biphenyl; PCB concentrations are in nanograms per gram dry weight; ND, not detected]

\begin{tabular}{lcccc}
\hline $\begin{array}{c}\text { Country } \\
\text { (fig. 15) }\end{array}$ & $\begin{array}{c}\text { Number of samplesana- } \\
\text { lyzed for PCB }\end{array}$ & $\begin{array}{c}\text { Number of samples with } \\
\text { positive results for PCB }\end{array}$ & Results (PCB28) & Sample name \\
\hline Cambodia & 19 & 2 & 1.92 & 2.37 \\
& 11 & 1 & 2.05 & ND \\
Lao PDR & 6 & 0 & ND \\
Myanmar & 10 & 0 & 1.05 \\
Thailand & 15 & 1 & \\
Vietnam & 61 & 4 & V100 \\
Total & & 0 & \\
\hline
\end{tabular}

\section{Regression Models}

The presence of any of the three forms for endosulfan was best predicted by the variable "region" (table 15). Specifically, Myanmar Mekong Basin, Sesan and Srepok River Basins in Vietnam, all three regions in Lao PDR, and coastal and inland areas of the Mekong Delta in Vietnam were regions with high endosulfan detections (table 15). Detailed regression analysis results are given in appendix 7 .

The variable "region" was also important in the regression model for endrin, as well as wetland system, distance to stream, and distance to the source of the Mekong River (table 15). Wetlands located far from streams had fewer endrin detections than wetlands located close to streams as well (table 15).

The best model to explain where DDE was most frequently detected included ecological region, sediment texture, distance to source of the Mekong River, and distance to urban areas (table 15). Southern Lao PDR, the open dry dipterocarp forests of northern Cambodia, the Sesan and Srepok River Basins of Vietnam, and the Mekong Delta of Cambodia and Vietnam were regions with more DDE detections than found in samples collected from other regions. The farther from urban areas a sample was taken, the less DDE was detected. Distance from the source of the Mekong River also had a significantly negative coefficient suggesting that wetlands of the upper basin had more samples containing DDE than did samples taken from wetlands in the lower basin.

The regression model that best explained where DDD was most frequently detected involved river connection, hydrological regime, distance to streams, and distance to urban areas (table 15). Distance to stream and distance to urban areas predictors were marginally significant with negative coefficients suggesting that wetland sites located far from streams or far from urban areas had fewer DDD detections than expected. The interaction between distance to stream and distance to urban area was also marginally significant meaning that the wetlands located far from streams did not tend to contain DDD, unless they were near urban areas. Wetlands with a "flowing water-seasonal" hydrological regime seemed to have fewer samples that contained DDD than did wetlands dominated by other types of hydrological regime. If "flowing water-seasonal" hydrological regimes were more oxygenated than other hydrological regimes, then breakdown of DDT would be reduced, resulting in fewer metabolites. DDT, however, was not found more abundantly in wetlands with "flowing waterseasonal" hydrological regimes.

The regression model that best explained where DDT was most frequently detected involved river connection, wetland protection, and soil variables (table 15). Wetlands that were connected to streams and wetlands in protected areas tended to have fewer DDT detections. DDT was detected in wetlands with clay and silt surface soil textures more often than in wetlands with other kinds of surface soil textures.

For the combination of DDT, DDE, and DDD, important regression model predictors were ecological region, surface soil texture, and distance to urban areas (table 15). Wetlands with clay and silt surface soil textures tended to have more detections of DDT and its metabolites. All three OCs were less frequently detected in wetlands that were farther away from urban areas. Basins of the Chi, Mun, and Kok Rivers as well as coastal areas of the Mekong Delta stand out as regions with infrequent detections of these combined OCs. As predicted by the regression model, residues of DDE, DDD, and DDT were most frequently detected in all regions of Cambodia, Vietnam (except coastal areas of the Mekong Delta), Lao PDR, and Myanmar. The Songkram River Basin was the only ecological region in Thailand where DDT and its metabolites were found frequently. 
Table 15. Logistic regression results for presence of organochlorines $(\mathrm{OC})$ in seven $\mathrm{OC}$ groups or metabolites found frequently enough in samples to examine statistically, as well as a measure with all OCs combined. Eight categorical and three numerical environmental variables (table 2) were used as predictors.

[The criterion for model selection was minimization of the Akaike Information Criterion. The (partial) p-values for each term are denoted as: ***, $\mathrm{p}<0.001$; **, $\mathrm{p}<0.01 ; *, \mathrm{p}<0.05$; and ${ }^{\circledR}, \mathrm{p}<0.1$. A '+' for predictors indicated a positive coefficient associated with the predictor variable whereas '-' indicated a negative coefficient]

\section{Organochlo- rinepesticides} (OCs)
Model

\section{Significant coefficients}

\begin{tabular}{|c|c|c|}
\hline Endosulfan & Endosulfan response $\sim$ region & $\begin{array}{l}+ \text { Region1 }(*), \text { Region } 2(* *) ;+ \text { Region3 }(*) ; \\
\quad \text { Region8 }\left({ }^{@}\right) ; \text { Region9 }\left({ }^{@}\right) ;+ \text { Region12(***);+Region13(* } \\
\quad * *) ;+ \text { Region14(**);+Region15(***); +Region16(**) }\end{array}$ \\
\hline Endrin & $\begin{array}{l}\text { Endrin response } \sim \text { region }+ \text { system }- \text { streamdist }+ \text { source- } \\
\quad \text { dist }+ \text { streamdist } x \text { sourcedist }\end{array}$ & $\begin{array}{l}+ \text { Region13(@);-streamdist }(* *) ;+ \text { streamdist x source- } \\
\quad \operatorname{dist}(* *)\end{array}$ \\
\hline DDE & DDE response $\sim$ region + soil - sourcedist - popplacedist & 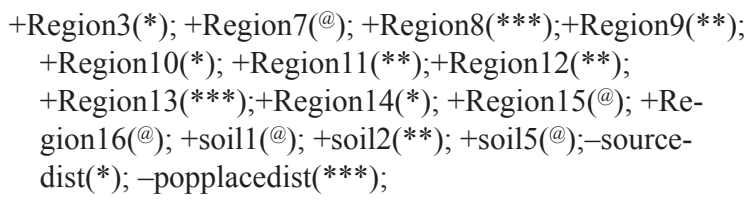 \\
\hline DDD & $\begin{array}{l}\text { DDD response } \sim \text { connection - regime - streamdist - pop- } \\
\text { placedist - streamdist x popplacedist }\end{array}$ & $\begin{array}{l}\text {-regime } 2\left({ }^{@}\right) ; \text {-streamdist }(*) ;- \text { popplacedist }\left({ }^{@}\right) ;- \text { streamdist } \\
\quad \text { x popplacedist }\left({ }^{@}\right)\end{array}$ \\
\hline DDT & DDT response $\sim$ connection - protection + soil & $\begin{array}{l}+ \text { connection } 1\left({ }^{@}\right) ;- \text { protection } 1\left({ }^{@}\right) ;+\operatorname{soil1}(*) ;+\operatorname{soil} 2(* * *) \\
\quad+\operatorname{soil}\left({ }^{@}\right)\end{array}$ \\
\hline $\mathrm{DDT}+\mathrm{DDE}+\mathrm{DDD}$ & $\mathrm{DDT}+\mathrm{DDE}+\mathrm{DDD}$ response $\sim$ region + soil - popplacedist & 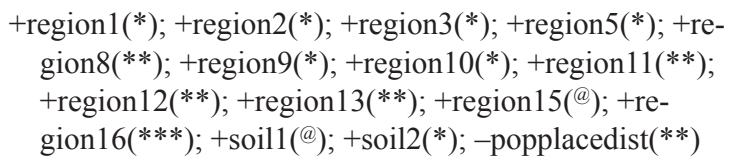 \\
\hline $\mathrm{HCB}$ & $\begin{array}{l}\text { HCB response } \sim \text { region - vegetation }+ \text { soil - sourcedist - } \\
\text { popplacedist }\end{array}$ & $\begin{array}{l}+\operatorname{region} 12(* *) ;+ \text { region } 14(* *) ;+\operatorname{region} 15(*) ;- \text { vegeta- } \\
\quad \operatorname{tion} 3(* *) ;+\operatorname{soil} 5(*) ;-\operatorname{sourcedist}(*) ;-\operatorname{popplacedist}(* *)\end{array}$ \\
\hline All OCs & All OCs response $\sim$ region + popplacedist & $\begin{array}{l}+ \text { region } 1(* * *) ;+ \text { region } 2(* * *) ;+ \text { region } 3(* * *) ; \\
\quad+\text { region } 5(*) ;+ \text { region } 8(* *) ;+ \text { region } 9(*) ;+ \text { re- } \\
\quad \text { gion } 10(*) ;+ \text { region } 11(*) ;+ \text { region } 12(* * *) ; \\
\quad+\text { region } 14(* * *) ;+ \text { region } 16(* * *) ;-\operatorname{popplacedist~}\left({ }^{(}\right)\end{array}$ \\
\hline
\end{tabular}


Variables that best predicted the presence of HCB included ecological region, wetland vegetation, surface soil texture, distance to source of the Mekong River, and distance to urban areas (table 15). The sites with HCB present contrasted with those with other OCs present. HCB was more likely to be found in sandy soils and wetlands with shrubby vegetation, whereas other OCs tended to be found in clay soils and wetlands located farther downstream and away from urban areas. Vegetation characteristics were not important with other OCs. More detections of HCB tended to be found in the Srepok River Basin, as well as both coastal and inland areas of Vietnam's Mekong Delta, than in other regions of the Mekong Basin that were sampled.

Given the variety of models used to explain the patterns of distribution for each of the major groups of OCs, few variables were able to explain the distribution patterns for all OCs combined (table 15). The logistic regression model for all OCs included only two important predictors: ecological region and distance to urban areas. All regions in Cambodia, Myanmar, and Lao PDR tended to have higher concentrations of at least one type of OC. Heavy concentrations of OCs were also seen in Vietnam (except for coastal parts of the Mekong Delta and the Sesan River Basin). Except for the Songkram River Basin (region 5, table 2), ecological regions in Thailand were relatively free of most OC contamination. Even though only marginally significant, wetlands located farther from urban areas were less likely to have detectable levels of OC residues than wetlands located closer to urban areas.

\section{Discussion}

Laboratory quality assurance and control verified the comparability of results between laboratories (NWQL and VNU), as well as the consistency of OC concentrations in the blind, replicate samples submitted to the VNU laboratory. Comparisons with other studies should, therefore, be direct and not require modification based on differences among laboratories. Even though samples were collected from a broad range of wetlands located throughout Mekong River Basin, the sampling protocol attempted to minimize variation within wetlands so that variation among wetlands in Mekong River Basin could be more clearly assessed. For example, wetland soil samples were collected from the deepest part of wetland basins and from top soil layers, thereby providing consistent soil environments typical of water-saturated, wetland soils. The focus of the comparisons, therefore, were the differences among samples taken from a wide variety of wetlands typical of the Mekong Basin. The chance of finding and measuring POPs consistently was maximized by sampling under environmental conditions in which substance breakdown was minimized and by sampling from an ecosystem with the tendency of gathering waters (and thus pesticides) from the surrounding landscapes.

\section{Pattern and Magnitude of Persistent Organic Pollutant Contamination in Wetlands of the Mekong Basin}

This study is the first attempt ever to assess the pattern and magnitude of POP contamination in the Mekong Basin. With 531 sediment samples collected from more than 450 different wetlands located over an area of approximately 463,000 square kilometers, this study is among the largest POP assessment projects worldwide. As such, results from this project are directly comparable to any regional survey of POPs. The main subject for POP assessment in this study is wetland ecosystems, predominantly inland freshwater wetlands. The study, therefore, complements many previous POP studies in South, East, and Southeast Asia regions, which focused mostly on other environments such as marine, coastal, agricultural, industrial, or urban environments. Lastly, the Stockholm Convention lists most of the POPs focused upon by this study (table 8).

Even though residues of $\mathrm{OC}$ pesticides were found in wetlands located throughout the Mekong Basin, the total loadings of OCs were relatively low compared to those found in other Asian countries' environments. Higher levels of OCs and PCBs have been found in agricultural soils, urban areas, and coastal marine ecosystems (Ramesh and others, 1991; Iwata and others, 1994; Phuong and others, 1998; Malik and others, 2009; Pham and others, 2010; Lv and others, 2010; Kumarasamy and others, 2012) (table 16). It is not known, however, if higher levels of POPs would have occurred in freshwater wetlands located in the same areas of these other studies.

In the Mekong Basin, some sites with the highest total loading of OCs were located in areas of conservation importance. For example, the open dry dipterocarp forests in northern Cambodia (Preah Vihear, Mondolkiri, and Ratanakiri Provinces), Bueng Kan Wetland of International Importance in Thailand, and Tram Chim National Park (also a Wetland of International Importance) in Vietnam had high concentrations of DDT and its metabolites, as well as endosulfans and endrins. OCs are known to have adverse effects on wildlife, especially water birds and fish, as well as people (Carson, 1962; U.S. Environmental Protection Agency, 2002; United National Environment Programme Chemicals Branch, 2003). The presence of high OC concentrations in these protected wetlands calls for further studies on the impacts of POP residues on wildlife in the region (see "Bioaccumulation" section).

All of the OCs found in this study have been banned in Southeast Asia since the 1990s (United National Environment Programme Chemicals Branch, 2002) and their lack of recent use, indicated by people interviewed, suggests that those bans have been effective. For example, in the interviews, only one OC was reported as still being used, but these compounds have long half-lives and persist in the environment for decades. 
Table 16. Organochlorine pesticides (OCs) and polychlorinated biphenyls (PCBs) detected in sediments from South, East, and Southeast Asian countries.

[Unit of persistent organic pollutants (POPs), nanograms per gram dry weight; ND, not detected; <, less than; Max., maximum]

\begin{tabular}{|c|c|c|c|c|c|c|c|c|}
\hline $\begin{array}{l}\text { Sampling } \\
\text { locations }\end{array}$ & Year $^{1}$ & $\mathbf{N}^{2}$ & Type & Aldrin & $\mathrm{CHL}^{3}$ & Endo $^{4}$ & Endr $r^{5}$ & Dieldrin \\
\hline Mekong Basin & 2011 & 531 & Wetland sediments & ND & $0.233-3.08$ & $1.04-26.19$ & $1.02-7.06$ & $1.37-1.84$ \\
\hline \multicolumn{9}{|c|}{ River sediments } \\
\hline $\begin{array}{c}\text { Lao PDR and } \\
\text { Thailand }\end{array}$ & 2005 & 18 & $\begin{array}{l}\text { River sediments and } \\
\text { urban canal }\end{array}$ & & $0.03-4.9$ & & & \\
\hline $\begin{array}{l}\text { Vietnam, Mekong } \\
\text { River Delta }\end{array}$ & $2003-4$ & 24 & River sediments & & $<0.004-1.9$ & & & \\
\hline $\begin{array}{l}\text { Vietnam, Mekong } \\
\text { River Delta }\end{array}$ & 1998 & 16 & $\begin{array}{l}\text { Canal, river and } \\
\text { coastal mudflat }\end{array}$ & ND-0.01 & ND-0.06 & ND-0.49 & ND-0.12 & ND-0.013 \\
\hline Taiwan & 1997-98 & 40 & River sediments & ND-0.15 & & ND-3.78 & ND-0.64 & ND-5.8 \\
\hline India, Vellar River & $1987-89$ & $?$ & River sediments & & & & & \\
\hline \multicolumn{9}{|c|}{ Coastal sediments } \\
\hline $\begin{array}{l}\text { Vietnam, Red } \\
\text { River Delta }\end{array}$ & 1995-96 & 12 & $\begin{array}{l}\text { Delta and coastal } \\
\text { sediments }\end{array}$ & & & & & \\
\hline $\begin{array}{l}\text { Coastal North } \\
\text { Vietnam }\end{array}$ & 1997 & 5 & Coastal sediments & & & & & \\
\hline \multicolumn{9}{|l|}{ Vietnam, } \\
\hline Hue & 2002 & 13 & Coastal lagoons & & & & & \\
\hline \multicolumn{9}{|l|}{ Vietnam } \\
\hline Ho Chi Minh City & 2004 & 7 & Estuarine sediments & & $0.01-0.06$ & & & \\
\hline $\begin{array}{l}\text { Vietnam, Ha Long } \\
\text { Bay, Hai Phong } \\
\text { Bay }\end{array}$ & $2003-4$ & 41 & Harbor, estuary & ND-0.03 & ND-0.75 & & ND-0.01 & ND-1.05 \\
\hline Singapore & 2003 & 13 & $\begin{array}{l}\text { Coastal marine sedi- } \\
\text { ments }\end{array}$ & $<0.3-1.4$ & $1.4-18.7^{11}$ & $<0.7-4.7$ & $<1.3-8.2$ & $<1.2-4.4$ \\
\hline Korea, Masan Bay & 1997 & 20 & $\begin{array}{l}\text { Coastal marine sedi- } \\
\text { ments }\end{array}$ & ND & ND-2.50 & ND-5.04 & ND & ND \\
\hline $\begin{array}{l}\text { China, Min Jiang } \\
\text { River }\end{array}$ & 1999 & 9 & Estuary sediments & $0.47-2.33$ & & & & \\
\hline $\begin{array}{l}\text { China, Yangtze } \\
\text { estuary }\end{array}$ & 2001 & 14 & Estuary sediments & $0.1-2.48$ & & & ND-1.23 & ND-0.22 \\
\hline \multicolumn{9}{|l|}{ China, } \\
\hline Daya Bay & 2003 & 14 & $\begin{array}{l}\text { Marine and estuary } \\
\text { sediments }\end{array}$ & $0.16-0.42$ & $\begin{array}{l}0.40- \\
1.88^{11}\end{array}$ & $0.38-1.99$ & $0.64-3.45$ & $0.03-0.19$ \\
\hline India, Pichavaram & 1987-89 & $?$ & Mangrove sediments & & & & & \\
\hline India, Hugli River & 1998-2000 & 30 & Estuary mangroves & & & & & \\
\hline $\begin{array}{l}\text { India, Bay of } \\
\text { Bengal }\end{array}$ & 1998 & 20 & Marine sediments & & & & & \\
\hline Taiwan & 1997-98 & 20 & Estuary sediments & ND-25.5 & & ND-10.16 & ND-1.25 & ND-5.37 \\
\hline
\end{tabular}




\begin{tabular}{|c|c|c|c|c|c|c|c|c|c|}
\hline DDE & DDD & DDT & $\sum$ DDTs & НСВ & $\sum \mathrm{HCH}^{6}$ & Hept $^{7}$ & Mirex & $\sum$ PCBs & Reference \\
\hline $1.0-75.66$ & $1.16-11.53$ & $2.02-17.11$ & $1.0-90.67$ & $1.27-3.76$ & 1.27 & 3.03 & ND & $1.05-2.37$ & This study \\
\hline \multicolumn{10}{|c|}{ River sediments } \\
\hline & & & $0.02-52$ & $0.001-0.63$ & $0.005-9.9$ & & & $0.18-300$ & $\begin{array}{c}\text { Sudaryanto and } \\
\text { others } 2011\end{array}$ \\
\hline$<0.01-15$ & $<0.01-46$ & $<0.01-44$ & $<0.01-110$ & $\begin{array}{c}<0.006- \\
0.08\end{array}$ & $<0.02-1.3$ & & & $0.039-9.2$ & $\begin{array}{l}\text { Nguyen and oth- } \\
\text { ers, } 2007 \mathrm{~b}\end{array}$ \\
\hline $0.11-18$ & $0.01-41$ & $\mathrm{ND}-3.5$ & $\begin{array}{l}0.32- \\
67.49^{9}\end{array}$ & & ND-0.89 & ND & & $0.10-2.01$ & $\begin{array}{l}\text { Carvalho and } \\
\text { others, } 2008\end{array}$ \\
\hline \multirow[t]{2}{*}{ ND-3.89 } & ND-3.90 & ND-2.64 & & & $0.12-4.94$ & & & & $\begin{array}{l}\text { Doong and oth- } \\
\text { ers, 2002a }\end{array}$ \\
\hline & & & $0.78-8.60$ & & $1.9-27$ & & & & $\begin{array}{l}\text { Ramesh and oth- } \\
\text { ers, } 1991\end{array}$ \\
\hline \multicolumn{10}{|c|}{ Coastal sediments } \\
\hline \multirow{4}{*}{$1.52-10.17$} & & & $6.2-10.4$ & $0.1-6.5$ & $1.2-33.7$ & & & $0.47-28.1^{8}$ & $\begin{array}{l}\text { Dang and others, } \\
1999\end{array}$ \\
\hline & & & & & & & & $\begin{array}{l}2.03- \\
24.70\end{array}$ & $\begin{array}{l}\text { Frignani and oth- } \\
\quad \text { ers, } 2007\end{array}$ \\
\hline & & & $0.15-5.40$ & $\begin{array}{c}<0.001- \\
0.10\end{array}$ & $<0.001-0.02$ & & & $0.49-2.40$ & $\begin{array}{l}\text { Nguyen and oth- } \\
\text { ers, 2007a }\end{array}$ \\
\hline & & & ND-274 & & ND-1.0 & & ND-0.66 & ND-18.71 & $\begin{array}{l}\text { Hong and others, } \\
2008\end{array}$ \\
\hline $0.92-7.56$ & $0.09-2.43$ & $0.56-4.55$ & $1.57-13.06$ & & $2.99-16.21$ & $0.88-2.77$ & & $\begin{array}{c}15.14 \\
57.93\end{array}$ & $\begin{array}{l}\text { Zhang and oth- } \\
\quad \text { ers, } 2003\end{array}$ \\
\hline ND-0.35 & ND-0.34 & ND- -0.21 & ND-0.57 & & & ND-0.93 & & & $\begin{array}{l}\text { Liu and others, } \\
2003\end{array}$ \\
\hline \multirow[t]{3}{*}{$1.02-6.08$} & $0.79-6.56$ & $4.57-20.77$ & $8.6-30.88$ & & $1.75-4.64$ & $0.11-0.43$ & & & $\begin{array}{l}\text { Wang and others, } \\
2008\end{array}$ \\
\hline & & & $0.25-2.00$ & & $0.90-17.00$ & & & & $\begin{array}{l}\text { Ramesh and oth- } \\
\text { ers, } 1991\end{array}$ \\
\hline & & & $3-119$ & & $3-330$ & & & & $\begin{array}{c}\text { Bhattacharya and } \\
\text { others, } 2003\end{array}$ \\
\hline $0.03-4.42$ & $0.01-2.78$ & $0.01-0.22$ & $0.04-4.79$ & & & & & $0.02-6.57$ & $\begin{array}{r}\text { Rajendran and } \\
\text { others, } 2005\end{array}$ \\
\hline ND-1.84 & ND-6.04 & ND-4.35 & & & & & & & $\begin{array}{l}\text { Doong and oth- } \\
\text { ers, } 2002 b\end{array}$ \\
\hline
\end{tabular}


Table 16. Organochlorine pesticides (OCs) and polychlorinated biphenyls (PCBs) detected in sediments from South, East,and Southeast Asian countries.-Continued

[Unit of persistent organic pollutants (POPs), nanograms per gram dry weight; ND, not detected; <, less than; Max., maximum]

\begin{tabular}{|c|c|c|c|c|c|c|c|c|}
\hline $\begin{array}{l}\text { Sampling } \\
\text { locations }\end{array}$ & Year $^{1}$ & $\mathbf{N}^{2}$ & Type & Aldrin & $\mathrm{CHL}^{3}$ & Endo $^{4}$ & Endr ${ }^{5}$ & Dieldrin \\
\hline \multicolumn{9}{|c|}{ Agricultural sediments } \\
\hline Vietnam & 1990 & 25 & Paddy fields & & & & & \\
\hline Vietnam & 1990 & 18 & $\begin{array}{l}\text { Canals, rivers, } \\
\text { estuaries, paddy } \\
\text { fields }\end{array}$ & & $0.07-20$ & & & \\
\hline Thailand & 1988-90 & 20 & Paddy fields & & & & & \\
\hline India, Vellar River & 1987-89 & $?$ & Paddy fields & & & & & \\
\hline $\begin{array}{l}\text { India, Tamirapa- } \\
\text { rani River }\end{array}$ & $2008-9$ & 48 & Agricultural soils & ND-562 & ND-24 & & ND & ND-1,693 \\
\hline $\begin{array}{l}\text { India, Gomti } \\
\text { River }\end{array}$ & $2004-5$ & 24 & Agricultural soils & ND- 10.89 & ND-3.99 & ND-1.0 & ND-11.96 & ND-1.65 \\
\hline \multicolumn{9}{|l|}{ China, } \\
\hline Tianjin & 2008 & 87 & Agricultural soils & ND-5.61 & & & ND & ND 10.38 \\
\hline \multicolumn{9}{|l|}{ China, } \\
\hline Mulan River & 2009 & 17 & Agricultural soils & & $0.33-3.95$ & $0.38-10.67$ & & \\
\hline \multicolumn{9}{|l|}{ China, } \\
\hline Quilu river & 2009 & 8 & Agricultural soils & & $0.0-1.45$ & $0.4-11.56$ & & \\
\hline \multicolumn{9}{|c|}{ Urban, industrial sediments } \\
\hline $\begin{array}{l}\text { Vietnam, Ho Chi } \\
\text { Minh City }\end{array}$ & 1996 & 11 & $\begin{array}{l}\text { Urban, canal sedi- } \\
\text { ments }\end{array}$ & & & & & \\
\hline North Vietnam & $?$ & 34 & $\begin{array}{l}\text { Urban, industrial, } \\
\text { coastal }\end{array}$ & & & & & \\
\hline Vietnam, Hanoi & 1997 & 12 & $\begin{array}{l}\text { Urban, canal sedi- } \\
\text { ments }\end{array}$ & ND-0.01 & $0.25-0.89$ & & ND-0.1 & $\mathrm{ND}-0.15$ \\
\hline Vietnam & 2002 & 11 & Urban and rural & ND-0.09 & ND-24 & & ND- -0.1 & $\mathrm{ND}-6.2$ \\
\hline \multicolumn{9}{|l|}{ Vietnam, } \\
\hline Ho Chi Minh City & 2004 & 6 & $\begin{array}{l}\text { Urban, canal sedi- } \\
\text { ments }\end{array}$ & & $0.58-4.50$ & & & \\
\hline \multicolumn{9}{|l|}{ Vietnam, } \\
\hline Ho Chi Minh City & 2004 & 9 & $\begin{array}{l}\text { Urban, river sedi- } \\
\text { ments }\end{array}$ & & $0.04-1.00$ & & & \\
\hline Vietnam, Hanoi & 2006 & 39 & $\begin{array}{l}\text { Urban: agricultural } \\
\text { soils }\end{array}$ & & & & & \\
\hline Vietnam, Hanoi & 2006 & 21 & $\begin{array}{l}\text { Urban, industrial } \\
\text { soils }\end{array}$ & & & & & \\
\hline Vietnam, Hanoi & 2006 & 22 & Urban, sewer system & & & & & \\
\hline
\end{tabular}




\begin{tabular}{|c|c|c|c|c|c|c|c|c|c|}
\hline DDE & DDD & DDT & $\sum$ DDTs & НСВ & $\sum \mathrm{HCH}^{6}$ & Hept $^{7}$ & Mirex & $\sum$ PCBs & Reference \\
\hline \multicolumn{10}{|c|}{ Agricultural sediments } \\
\hline & & & $\begin{array}{l}0.73- \\
1,300\end{array}$ & & $0.10-55$ & & & $0.61-320$ & $\begin{array}{l}\text { Vu and others, } \\
1993\end{array}$ \\
\hline \multirow[t]{3}{*}{$0.21-540$} & $0.08-210$ & $0.11-63$ & $0.37-790$ & & $0.13-9.3$ & & & $0.18-630$ & $\begin{array}{l}\text { Iwata and others } \\
1994\end{array}$ \\
\hline & & & $0.61-98$ & & $0.07-1.6$ & & & $1.1-6.2$ & $\begin{array}{l}\text { Vu and others, } \\
1993\end{array}$ \\
\hline & & & $0.93-6.00$ & & $3.7-1,100$ & & & & $\begin{array}{l}\text { Ramesh and oth- } \\
\quad \text { ers, } 1991\end{array}$ \\
\hline ND- 82.8 & ND- 30.4 & ND-461 & ND-857 & & ND-472 & $\mathrm{ND}-75.2$ & ND-88.5 & & $\begin{array}{c}\text { Kumarasamy and } \\
\text { others, } 2012\end{array}$ \\
\hline \multirow[t]{2}{*}{ ND-14.03 } & ND-95.73 & $\begin{array}{c}\text { ND- } \\
206.12\end{array}$ & $1.63-368.7$ & ND-0.98 & ND-155.17 & ND-40.44 & & & $\begin{array}{l}\text { Malik and others, } \\
2009\end{array}$ \\
\hline & & & $\begin{array}{l}\text { ND- } \\
616.98\end{array}$ & & ND-92.74 & ND 6.20 & & & $\begin{array}{l}\text { Lv and others, } \\
2010\end{array}$ \\
\hline $0.03-17.05$ & ND-3.40 & $0.22-8.01$ & $0.91-27.89$ & & $1.2-7.47$ & & & & $\begin{array}{l}\text { Zhang and oth- } \\
\text { ers, } 2011\end{array}$ \\
\hline $0.14-5.44$ & $0.01-1.23$ & $0.03-4.26$ & $1.24-10.04$ & & $0.96-4.11$ & & & & $\begin{array}{l}\text { Zhang and oth- } \\
\quad \text { ers, } 2011\end{array}$ \\
\hline \multicolumn{10}{|c|}{ Urban, industrial sediments } \\
\hline \multirow[t]{2}{*}{$0.98-94.06$} & $\begin{array}{c}0.36 \\
-81.44\end{array}$ & $0.42-98.50$ & $\begin{array}{c}1.76- \\
253.62\end{array}$ & & & & & $\begin{array}{c}9.3- \\
590.50^{8}\end{array}$ & $\begin{array}{l}\text { Phuong and oth- } \\
\text { ers, } 1998\end{array}$ \\
\hline & & & Max: 34 & & Max: $9.5^{10}$ & & & $0.64-120$ & $\begin{array}{l}\text { Pham and others, } \\
2000\end{array}$ \\
\hline $6.70-50.00$ & $0.56-27.10$ & $0.05-0.64$ & $7.40-80.55$ & ND-0.13 & $0.07-3.12$ & & & $\begin{array}{l}0.67- \\
39.50^{8}\end{array}$ & $\begin{array}{l}\text { Dang and others, } \\
2001\end{array}$ \\
\hline \multirow[t]{3}{*}{$0.02-79$} & $0.08-34$ & $0.1-14$ & $0.19-140^{9}$ & ND- 16 & $0.009-0.61$ & ND-0.96 & & & $\begin{array}{l}\text { Kishida and oth- } \\
\text { ers, } 2007\end{array}$ \\
\hline & & & $12-72$ & $<0.1-18$ & ND & & & $46-150$ & $\begin{array}{l}\text { Nguyen and oth- } \\
\text { ers, } 2007 \mathrm{~b}\end{array}$ \\
\hline & & & $0.21-33.00$ & $\begin{array}{l}<0.00 \\
-0.61\end{array}$ & $<0.01-0.03$ & & & $0.33-22.00$ & $\begin{array}{l}\text { Nguyen and oth- } \\
\text { ers, } 2007 a\end{array}$ \\
\hline $\begin{array}{l}<0.02- \\
98.65\end{array}$ & $8.12-49.36$ & $\begin{array}{c}<0.02- \\
40.96\end{array}$ & $\begin{array}{l}<0.02- \\
171.83\end{array}$ & & $<0.05-20.87$ & & & & $\begin{array}{l}\text { Vu and others, } \\
2007\end{array}$ \\
\hline \multirow[t]{2}{*}{$\begin{array}{l}<0.02- \\
36.82\end{array}$} & $\begin{array}{c}<0.02- \\
17.88\end{array}$ & $\begin{array}{c}<0.02- \\
15.45\end{array}$ & $\begin{array}{c}<0.02- \\
67.82\end{array}$ & & $<0.05-7.76$ & & & & $\begin{array}{l}\text { Vu and others, } \\
2007\end{array}$ \\
\hline & & & $6.4-1,100^{9}$ & $<0.2-12$ & $<0.2-36$ & & & $1.3-384$ & $\begin{array}{l}\text { Pham and others, } \\
2010\end{array}$ \\
\hline
\end{tabular}


Table 16. Organochlorine pesticides (OCs) and polychlorinated biphenyls (PCBs) detected in sediments from South, East,and Southeast Asian countries.-Continued

[Unit of persistent organic pollutants (POPs), nanograms per gram dry weight; ND, not detected; <, less than; Max., maximum]

\begin{tabular}{|c|c|c|c|c|c|c|c|}
\hline $\begin{array}{l}\text { Sampling } \\
\text { locations }\end{array}$ & Year $^{1}$ & $\mathbf{N}^{2}$ & Aldrin & $\mathrm{CHL}^{3}$ & Endo $^{4}$ & Endr ${ }^{5}$ & Dieldrin \\
\hline \multicolumn{8}{|c|}{ Urban, industrial sediments, Continued } \\
\hline Thailand & 1990 & 4 & Urban, canals, rivers & $1.4-210$ & & & \\
\hline Indonesia & 1991 & 4 & $\begin{array}{l}\text { Urban, residential } \\
\text { areas }\end{array}$ & $0.16-38$ & & & \\
\hline India & 1989 & 6 & $\begin{array}{l}\text { Urban, river sedi- } \\
\text { ments }\end{array}$ & $0.47-130$ & & & \\
\hline Taiwan & 1990 & 3 & Urban soils & $0.14-5.6$ & & & \\
\hline
\end{tabular}

\footnotetext{
'Year sampling took place;

${ }^{2}$ Number of sediment samples analyzed;

${ }^{3}$ Sum of trans, cis-chlordane, trans-, cis-nonachlor, otherwise noted;

${ }^{4}$ Sum of alpha-, beta-endosulfan and endosulfan sulfate;

${ }^{5}$ Sum of endrin and endrin aldehyde;

${ }^{6}$ Sum of alpha, beta, gamma, and delta hexachlorocyclohexane ( $\left.\mathrm{HCH}\right)$, otherwise noted;

${ }^{7}$ sum of heptachlor and heptachlor epoxide;

${ }^{8}$ as Aroclor 1254 equivalent;

${ }^{9}$ Sum of o,p'DDE, p,p'DDE, o,p'DDD, p,p'DDD, o,p'DDT, p,p'DDT;

${ }^{10} \mathrm{Gamma} \mathrm{HCH}$ (Lindane) only;

${ }^{11}$ Sum of trans-chlordane and cis-chlordane only]
} 


\begin{tabular}{|c|c|c|c|c|c|c|c|c|c|}
\hline DDE & DDD & DDT & $\sum$ DDTs & HCB & $\sum \mathrm{HCH}^{6}$ & Hept $^{7}$ & Mirex & $\sum$ PCBs & Reference \\
\hline \multicolumn{10}{|c|}{ Urban, industrial sediments, Continued } \\
\hline $1.8-59$ & $1.7-100$ & $1.2-100$ & $4.8-170$ & & $2.1-59$ & & & $11-520$ & $\begin{array}{l}\text { Iwata and others, } \\
1994\end{array}$ \\
\hline $0.95-21$ & $0.94-15$ & $0.86-4.4$ & $3.4-42$ & & $0.03-0.09$ & & & $5.90-220$ & $\begin{array}{l}\text { Iwata and others, } \\
1994\end{array}$ \\
\hline $1.9-100$ & $3.0-340$ & $2.8-13$ & $8.0-450$ & & $0.58-38$ & & & $4.8-1,000$ & $\begin{array}{l}\text { Iwata and others, } \\
1994\end{array}$ \\
\hline $0.16-5.2$ & $0.07-3.9$ & $0.12-1.2$ & $0.39-11$ & & $0.29-0.79$ & & & $2.3-230$ & $\begin{array}{l}\text { Iwata and others, } \\
1994\end{array}$ \\
\hline
\end{tabular}


With DDT and its metabolites, it was possible to assess historical use of one family of POPs directly. DDT was found in 24 samples. In these samples, DDT was found as a ratio that suggested it was used after it was banned in Myanmar, Lao PDR, Cambodia, and Vietnam (fig. 11). The countries where DDT use occurred after the ban had undergone civil strife or open warfare, with the most recent strife ending in Cambodia in 1998. With the conclusion of civil upheaval, it has likely become much easier to enforce the ban on POPs.

In wetlands of the Mekong Basin, POP contamination came mainly from a few types of OC pesticides, most importantly DDT, endosulfan, and endrin (and their metabolites). Similarly, many studies in other Asian countries also found that DDT and its metabolites are an important source of POP contamination. The main discrepancy between this study and others was the prevalence of $\mathrm{HCHs}$ and PCBs found by previous studies in various sediment environments. These compounds were frequently found in large concentrations in agricultural soils, estuaries, and urban areas in many other Asian countries by previous studies (table 16). In this study, however, $\mathrm{HCH}$ (appendix 3 ) and PCBs (fig. 16) were almost absent from samples collected from Mekong Basin wetlands.

Though the concentration of $\mathrm{OC}$ residues in wetlands of the Mekong Basin was generally less than concentrations found elsewhere in Asia, OC residues were not distributed evenly throughout the basin. Rather they were strongly confined to a few ecological/geographical regions, especially the Mekong Delta, Srepok River Basin, northern Cambodia, and the Mekong Basin in Myanmar. In these hotspots, concentrations of pollutants were comparable to the levels of POPs found in other studies from the region (table 16) but were not as high as concentrations found in extreme examples of hotspots in India (Kumarasamy and others, 2012; Malik and others, 2009) or Vietnam (Hong and others, 2008). High concentrations of OCs in locations that constitute hotspots may be sufficient, however, to cause significant human health concerns (United National Environment Programme Chemicals Branch, 2002) and should warrant further investigation (see section "Sediment Quality Guidelines"). Though wetlands in Thailand contained fewer contaminated samples and lower POP concentrations in collected samples than those in other Southeast Asian countries, a few hotspots were still found and should not be ignored. Generally, sites of high OC concentration were not distributed widely (fig. 5), but areas of more extensive contamination did occur in the Srepok River Basin of Vietnam, in the Mekong Delta in Vietnam, near Vientiane (Lao PDR), and in Myanmar.

Interviews with residents, who lived near sampled wetlands, provided useful information by identifying other pesticides currently in use that may be of human or environmental concern but are not listed in the Stockholm Convention annexes. The extensive use of carbamates, for example, may pose serious human health and environmental risks (U.S. Environmental Protection Agency, 2004; Miura and Takahashi, 1987). The use of organophosphate pesticides in the Mekong Basin countries, even in smaller proportion as identified from interviewed data, could be of concern because some of these compounds have a high toxicity. Some organophosphate pesticides have been restricted or banned in the United States, as well as in many other countries (Agency for Toxic Substances and Disease Control, 2001).

The assessment of environmental conditions in relation to POP concentration proved useful. Geographical region was the most consistent variable for predicting the presence or absence of endosulfan; endrin; DDE; the combination of DDT, DDE, and DDD; HCB; and all OCs combined (table 15). The connectivity of wetlands to rivers was only important in explaining the presence or absence of DDT and DDD (table 15), but there was a negative relation between distance to stream and both endrin and DDD, meaning that these substances were found more often in wetlands located closer to streams. Overall, connectivity was not an important predictor of POP contamination, thereby indicating that POP contamination in wetlands of the Mekong Basin was localized, rather than being widespread as a result of distribution through river channels.

Wetlands often did not receive direct applications of OCs unless they had been farmed in the past. The contamination of wetlands by OCs, therefore, occurred by surface runoff, which carried residues from the surrounding agricultural or urban areas. Data comparing surrounding land use with the frequency of OC detection (fig. 15) support this contention that the type of surrounding land use influenced the probability of OCs being found in the wetlands sampled. Isolated wetlands (control 2 wetlands) had fewer OC detections than wetlands surrounded by agricultural land. Of course, agricultural land uses during the study do not reflect the agricultural activity that had occurred when the OCs were used (perhaps decades ago), but they did appear to serve as an index to that former use.

Of the 21 OCs analyzed, endosulfan and HCHs had low $\log \mathrm{K}_{\text {ow }}$ values (3.55-4.14). Although $\mathrm{HCH}$ was not detected, endosulfan was widely distributed in wetlands of the Mekong Basin. The wide distribution suggested that endosulfan, given its short half-life and higher solubility, is still being used in the region. Of the OCs that had high $\log K_{o w}$ values (DDT and its metabolites, chlordane, aldrin, dieldrin, and HCB), DDT and its metabolites were commonly found, whereas aldrin, dieldrin, and chlordane were seldom found. Data from this study may not be sufficient to explain the connection between water solubility and the mobility of POPs.

Both HCB and DDE were less likely to be detected in the Lower Mekong Basin (farther from the source of the Mekong River), whereas endrin was more likely to be detected in the Lower Mekong Basin. Statistically, the relation between the frequency of detection for endrin and the distance from the source of the Mekong River was modified by the interaction with distance to stream; distance to the source of the Mekong River was only important when distance to stream was also important (table 15). This correspondence in distances to stream and source of the Mekong River was suggested by 
the tendency of endrin samples to be found along the Mekong River in Lao PDR, along the Sesan and Srepok Rivers in Vietnam, along the Sen River (the major river flowing into the Tonle Sap from the north, fig. 13) in Cambodia, and along the Mekong River channels of the Mekong Delta in Vietnam (fig. 13). Overall, these data do not suggest that there is a gradual accumulation of OCs in the Mekong Basin as wetlands get closer to the mouth of the Mekong River, again confirming that OCs are not likely to be transported over large distances by river systems even though OCs may be transported over shorter distances between streams and wetlands. River transportation of POP residues may also be important in other aquatic environments, such as river estuaries. Previous studies in other Asian countries found large quantities of POP residues in estuaries downstream from large intensive agricultural and urban areas, but the geographic scale of this linkage was still relatively small (Phuong and others, 1998; Doong and others, 2002b; Hong and others, 2003; Liu and others, 2003; Rajendran and others, 2005; Nguyen, Tu, Iwata and others, 2007; Hong and others, 2008; Wang and others, 2008; Zhang and others, 2011; Kumarasamy and others, 2012).

Wetlands located near urban (populated) areas tended to have more OCs detected. This was true for DDE, DDD, and the combination of DDT, DDE, and DDD, as well as for all OCs combined and for HCB (table 15). These data are important because they suggest that the overriding factor influencing $\mathrm{OC}$ distribution is human presence. When combined with landuse data, most OCs appeared to accumulate in wetlands near agricultural lands or near populated places (where DDT is used for mosquito control).

Though the movement of POPs in the river systems of the Mekong Basin did not appear extensive, POPs have been known to spread great distances. For example, POPs have been known to move through the air or through bioaccumulation in migratory organisms (Wahlstrom, 2003). The presence of migratory fish in the Mekong Basin (Baran, 2006) suggests that movement of POPs through bioaccumulation is highly possible and should be studied further.

\section{Sediment Quality Guidelines}

Some OCs in wetland sediments of the Mekong Basin were distributed broadly, but these OCs occurred in low concentrations, except for specific infrequently found locations. Yet concentration alone cannot predict the risk that OCs may pose. Measures of toxicity and exposure are also important in determining risk, and standards provide a baseline to which results can be compared in environmental or human contexts. The Canadian Council of Ministers of Environment (CCME, 2003) has proposed the "Canadian Sediment Quality Guideline for the Protection of Aquatic Life," in which two levels of criteria are presented: (1) interim sediment quality guidelines (ISQGs) - concentration above which adverse effects on aquatic biota may occur, and (2) probable effect level (PEL) concentration above which adverse effects are expected to occur frequently. Separate ISQGs and PEL values were used for freshwater, marine, and estuarine sediments. At the time of this study (November 2012), however, concentrations related to some of the POPs analyzed were not available in the CCME guideline.

No general sediment quality guideline applies to the entire United States. Though each State has its own set of environmental standards, the EPA has developed sediment screening benchmarks for use in regional ecological risk assessments. The most complete regional standard is the sediment screening benchmark used in the Mid-Atlantic Risk Assessment Program, which serves five States and the District of Columbia (U.S. Environmental Protection Agency, 2006). Unlike the CCME guideline, the Mid-Atlantic EPA sediment screening benchmark provided only one level of assessment for each pollutant, but it did establish separate benchmarks for freshwater and marine sediment types. Though other smaller differences existed between the CCME and EPA criteria, both benchmarks were generally similar. Even though the POPs analyzed in this study were more thoroughly represented in the EPA sediment screening benchmark, values were used from both guidelines, when relevant, for this study (table 17).

Compared to the CCME guideline for freshwater sediments, all concentrations of chlordane, dieldrin, and gamma-HCH (lindane) found in this study were below their respective ISQGs. These concentrations were also lower than their respective EPA freshwater sediment screening benchmarks. The only sample detected with heptachlor epoxide in this study (V068: $3.03 \mathrm{ng} / \mathrm{g}$, appendix 3) had a concentration higher than the PEL for heptachlor epoxide $(2.74 \mathrm{ng} / \mathrm{g})$ and higher than the EPA sediment screening benchmark $(2.47$ $\mathrm{ng} / \mathrm{g})$. All concentrations of methoxychlor found in this study were lower than the benchmarks set by EPA $(18.70 \mathrm{ng} / \mathrm{g}$ for freshwater sediments and $29.60 \mathrm{ng} / \mathrm{g}$ for marine sediments) (appendix 3).

Six samples from this study contained endrin concentrations that exceeded the CCME ISQGs $(2.67 \mathrm{ng} / \mathrm{g})$ but were lower than the PEL (62.4 ng/g). The EPA benchmark for endrin $(2.22 \mathrm{ng} / \mathrm{g})$ is lower than its CCME ISQGs counterpart, and eight sites from this study had endrin concentrations above the environmental risk threshold. Seventeen wetland sites from this study had beta-endosulfan concentrations higher than the EPA benchmark (2.14 ng/g), whereas only 1 site (C145: 10.47 $\mathrm{ng} / \mathrm{g}$ ) had an endosulfan sulfate concentration that exceeded the benchmark (5.40 ng/g). CCME benchmarks for endosulfans were not listed. All of the alpha-endosulfan concentrations found in this study were below the EPA benchmark for freshwater sediments $(2.14 \mathrm{ng} / \mathrm{g})$.

Among the 55 concentrations of DDT detected, 17 samples had levels that exceeded the CCME ISQGs (1.19 $\mathrm{ng} / \mathrm{g}$ ), and 5 samples exceeded the PEL (4.77 ng/g). For DDE, 63 concentrations were equal or higher than the ISQGs for freshwater sediments $(1.42 \mathrm{ng} / \mathrm{g})$, and 17 samples were higher than the PEL (6.75 ng/g). One sample, C111, had a DDE concentration of $75.66 \mathrm{ng} / \mathrm{g}$, over 10 times the PEL standard (appendix 3). For DDD, two concentrations detected 
Table 17. The Canadian Council of Ministers of the Environment's sediment quality guideline for the protection of aquatic life and the U.S. Environmental Protection Agency's Mid-Atlantic sediment screening benchmarks.

[Unit of POPs: nanogram per gram dry weight (ng/g); ISQG, Interim sediment quality guideline; PEL, Probable effect level; -, no information]

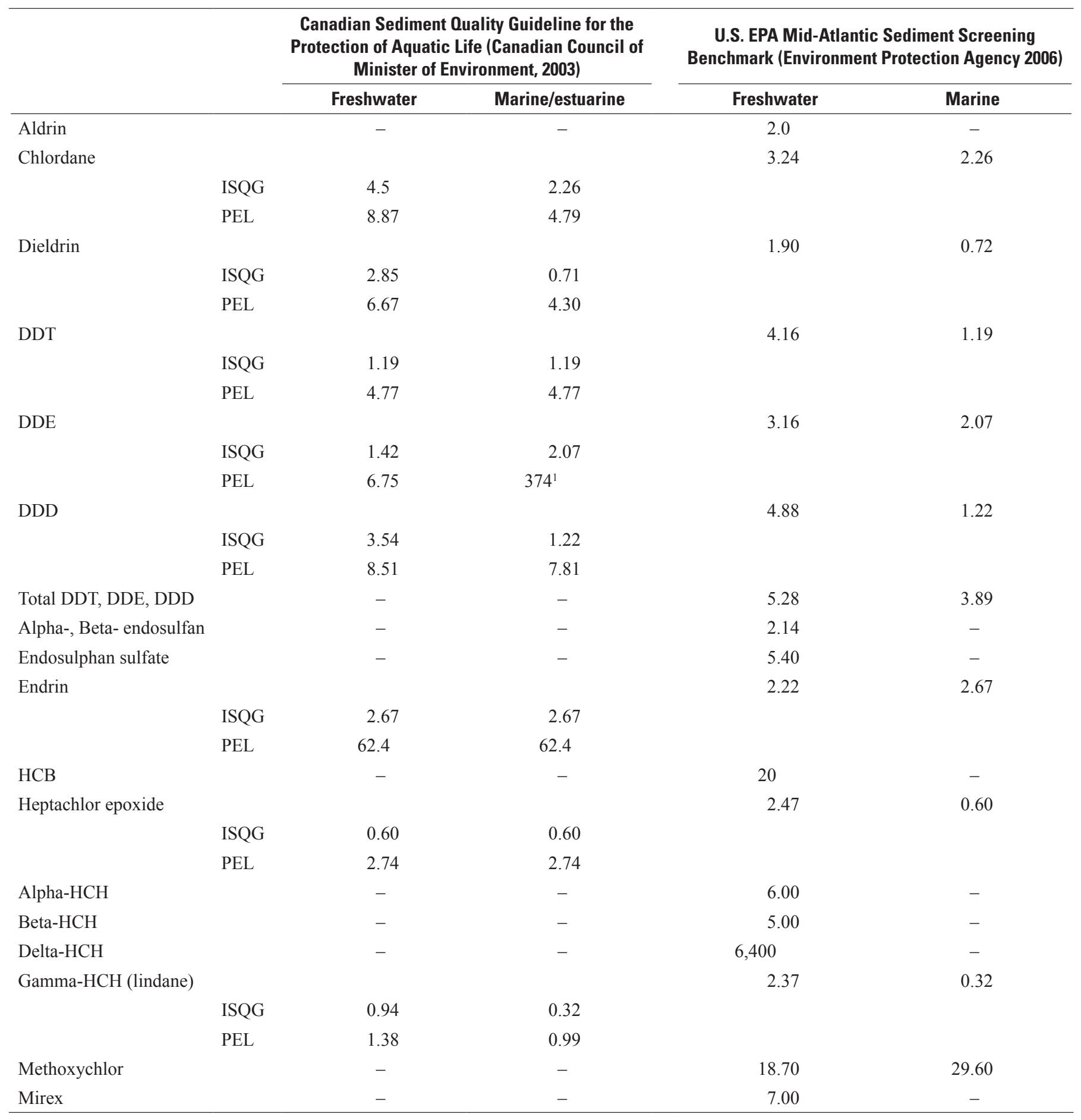

\footnotetext{
${ }^{1}$ This value $(374 \mathrm{ng} / \mathrm{g})$ is suspiciously high, but it is what stated in the original document and in Environment Canada's website, http://ceqg-rcqe.ccme.ca/.
} 
in this study were higher than the ISQGs $(3.54 \mathrm{ng} / \mathrm{g})$, and one (V012: $11.53 \mathrm{ng} / \mathrm{g}$ ) was higher than the PEL (8.51 $\mathrm{ng} / \mathrm{g})$. The EPA freshwater sediment screening benchmark values for DDT, DDE, and DDD were all higher than the corresponding CCME guidelines (table 17). The EPA also provided freshwater as well as marine sediment screening benchmarks for the combination of DDT, DDE, and DDD $(5.28 \mathrm{ng} / \mathrm{g}$ for freshwater sediments and $3.89 \mathrm{ng} / \mathrm{g}$ for marine sediments). Compared to the EPA criteria for the combination of DDT, DDE, and DDD, 25 and 36 sites found in this study exceeded sediment benchmarks for freshwater and marine systems, respectively.

Although the total loading of POPs in wetland sediments of the Mekong Basin were generally low, hotspot sites occurred where concentrations exceeded established ecological risk thresholds. Of special concern were sites with high concentrations of DDT, DDE, beta-endosulfan, and endrin. Hotspot data will be useful in planning followup studies on the effects of POPs on both wildlife and people in the Mekong Basin.

\section{Bioaccumulation}

The major pathway by which POP residues in sediments affect wildlife and people is through bioaccumulation. In a study from the Mekong Delta in Vietnam, Carvalho and others (2008) found strong positive correlations between the concentrations of DDT, endosulfan, and PCBs in sediments and concentrations of the same substances in tissues of mollusks collected from the area. Ikemoto and others (2008) also estimated that bioaccumulation of DDT occurred in the Mekong Delta at an average rate of 3.3 times per trophic level from sediment to phytoplankton, crustacean, and fish.

Monirith and others (1999) found high concentrations of several OCs in marine and freshwater fish collected in Cambodia. Total DDT concentrations of up to 2,000 ng/g were found in the fatty tissues of fish caught from the Tonle Sap Lake. These concentrations are over 20 times higher than the highest, total DDT concentrations found in sediments collected during this study, as well as during other previous studies in the same area (table 16). Monirith and others (2000) also demonstrated that the average concentrations of DDTs, PCBs, chlordane, HCHs, and HCB in fish were several times higher than those in green mussels (Perna viridis) living in the same area but at a lower trophic level in Cambodia and other Southeast Asian countries. Several hotspots with DDT and DDE concentrations that exceeded CCME and EPA benchmarks were identified by this study in the Tonle Sap Lake. Given the evidence of bioaccumulation found in other studies, these hotspots should be investigated further.
A study by Tu and others (2002) on OC residues in resident birds of northern Vietnam showed concentrations of total DDTs up to $13,000 \mathrm{ng} / \mathrm{g}$ lipid weight (range of mean values between 140-6,200 ng/g) and concentrations of PCBs up to $2,400 \mathrm{ng} / \mathrm{g}$ lipid weight (range of mean values between $250-2,400 \mathrm{ng} / \mathrm{g}$ lipid weight). DDT concentrations up to 77,000 $\mathrm{ng} / \mathrm{g}$ lipid weight in resident birds of Vietnam were detected by Kunisue and others (2003), and very high concentrations of DDTs were also found in the fatty tissues of the white-breasted waterhen (Amaurornis phoenicurus), a resident water bird of Cambodia (Monirith, Kunisue, and others, 2003). These studies reveal that further study of bioaccumulation is needed within the Mekong Basin.

\section{Individual Persistent Organic Pollutant Results}

\section{Aldrin}

In this study, aldrin was not detected in any wetland sediment sample. It is possible that, given its short half-life and ability to biotransform, aldrin was present in wetlands of Southeast Asia but was no longer detectable. Carvalho and others (2008) analyzed 16 canal and river sediment samples from the Mekong Delta in Vietnam and only detected a very low concentration $(0.01 \mathrm{ng} / \mathrm{g})$ of aldrin in one sample. In other Asian studies, aldrin was found in small concentrations in urban canal sediments from Vietnam (Dang and others, 2001; Kishida and others, 2007), in river sediments from Taiwan (Doong and others, 2002a), as well as in various estuary and coastal sediments from northern Vietnam (Hong and others, 2008), Singapore (Wurl and Obbard, 2005), and China (Liu and others, 2003; Zhang and others, 2003; Wang and others, 2008). Elevated concentrations of aldrin were found in agricultural soils of India (Malik and others, 2009; Kumarasamy and others, 2012) and China (Lv and others, 2010).

\section{Dieldrin}

Dieldrin was found in only 16 samples (fig. 8) and in only 3 samples with concentrations above LOD, thereby indicating that it was not a major environmental concern in wetlands of the Mekong Basin. Previous studies in other Asian countries also found dieldrin in small concentrations (table 16). Low concentrations of dieldrin were found in sediments from the Mekong Delta, Vietnam (Carvalho and others, 2008). Only the study by Kumarasamy and others (2012) found high concentrations (up to $1,693 \mathrm{ng} / \mathrm{g}$ ) of dieldrin in agricultural soils of the Tamiraparani River Basin, Tamil Nadu Province, India. 


\section{Mirex}

Mirex was not detected in any sediment sample analyzed in this study and was only found in a few previous studies of Asian environs. Small concentrations of mirex were detected in estuary sediments in Ha Long Bay, Vietnam by Hong and others (2008) and in marine sediments collected from Singapore by Wurl and Obbard (2005). Kumarasamy and others (2012) detected high concentrations of mirex (70-88 ng/g) in agricultural soils in the Tamiraparani River, Tamil Nadu Province, India by Kumarasamy and others (2012).

\section{Chlordane}

In this study, chlordane was found in low concentrations from a small number of samples $(n=14)$, thereby suggesting that chlordane was not a major environmental concern in wetlands of the Mekong Basin. Cis-chlordane was the metabolite mostly detected. Other studies also detected chlordane contamination in small amounts in the Mekong Delta of Vietnam (Nguyen, Tu, Kajiwara, and others, 2007; Carvalho and others, 2008); in river sediments from Lao PDR and Thailand (Sudaryanto and others, 2011); in estuary sediments near Ho Chi Minh City (Nguyen, Tu, Iwata, and others, 2007); in Ha Long and Hai Phong Bay, northern Vietnam (Hong and others, 2008); and in coastal marine sediments from China (Liu and others, 2003; Zhang and others, 2003; Wang and others, 2008), India (Malik and others, 2009), and Korea (Hong and others, 2003). Iwata and others (1994), however, found high concentrations (up to $210 \mathrm{ng} / \mathrm{g}$ ) of chlordane in agricultural and urban soils from Vietnam, Thailand, Indonesia, India, and Taiwan (table 16). More recently, chlordane was found in high concentrations in agricultural soils in India (Kumarasamy and others, 2012) and in coastal marine sediments from Singapore (Wurl and Obbard, 2005).

\section{Hexachlorocyclohexane}

Within the wetlands of the Mekong Basin, Myanmar was the only region in this study found to have $\mathrm{HCH}$ contamination. Only two sites (M007: delta-HCH at $1.272 \mathrm{ng} / \mathrm{g}$ and M008: gamma-HCH $0.045 \mathrm{ng} / \mathrm{g}$; appendix 3) had samples where $\mathrm{HCH}$ was detected and these samples had only low concentrations. In contrast, many previous studies of Asia frequently detected $\mathrm{HCH}$ in various concentrations (table 16) and types of sediment. HCHs were found in small concentrations in river sediments of the Mekong Delta in Vietnam (Nguyen, Tu, Kajiwara, and others, 2007), as well as in river sediments in Taiwan (Doong and others, 2002a). For coastal marine sediments, low amounts of HCHs were detected in Red River estuary in Vietnam (Dang and others, 1998), Dong Nai River estuary (near Ho Chi Minh City) in Vietnam (Nguyen, Tu, Iwata, and others, 2007), Ha Long Bay in Vietnam (Hong and others, 2008), Masan Bay in South Korea (Hong and others,
2003), and Daya Bay in China (Wang and others, 2008). Other studies found high concentrations of $\mathrm{HCHs}$ in coastal marine sediments (33-330 ng/g), for example in northern Vietnam (Dang and others, 1999), in Singapore (Wurl and Obbard, 2005), and in Hugli River estuary of India (Bhattacharya and others, 2003). HCHs were often detected in high concentrations in agricultural soils in many Asian countries (table 16). Very high concentrations (up to $1,100 \mathrm{ng} / \mathrm{g}$ ) of $\mathrm{HCHs}$ were found in India in the Vellar River Basin (Ramesh and others, 1991), the Gomti River Basin (Malik and others, 2009), and the Tamiraparani River Basin (Kumarasamy and others, 2012).

\section{Heptachlor}

This study found heptachlor epoxide in only one sample (V068: $3.032 \mathrm{ng} / \mathrm{g}$, appendix 3) and found no samples containing heptachlor. Previous studies (table 16) found small concentrations of heptachlor in coastal marine sediments in Singapore (Wurl and Obbard, 2005), China (Liu and others, 2003; Zhang and others, 2003; Wang and others, 2008), and South Korea (Hong and others, 2003). High concentrations of heptachlor also were detected in agricultural soils in India (Malik and others, 2009; Kumarasamy and others, 2012).

\section{Methoxychlor}

In this study, methoxychlor was detected in very low concentrations in only a few samples, which were well below CCME and EPA benchmarks (table 17). Methoxychlor was not analyzed in previous POP contamination studies in Asian countries.

\section{DDT, DDE, DDD}

Given the persistence and history of use for this compound, it is understandable that DDT, and its metabolites DDE and DDD, were found to be the leading persistent organic pollutant in wetlands of the Mekong Basin. Fortyfour percent of samples collected contained concentrations of DDT, DDE, or DDD. DDT concentrations, specifically, contributed significantly to the total loading of OCs in most samples analyzed. High concentrations of DDT, DDE, and DDD were found in wetlands of conservation importance, which means that measures to mitigate adverse effects to wetland organisms, especially fish and water birds, in the Mekong Region should be adopted and that past actions have long-term consequences. As shown by a CCME review (1999) that studied freshwater wetlands in North America, high concentrations of DDT and its metabolites in wetland sediment correspond to lower species richness of several groups of benthic invertebrates. 
Regression analysis demonstrated that wetlands located close to urban areas were more likely to contain some form of DDT than their remote counterparts. This finding may be related to the use of DDT for mosquito control in highly populated urban areas. Evidence of recent, or even current, use of DDT was found in this study. Since most substances in this family of pollutants came from DDE (a metabolite that occurs after degradation of DDT), however, contaminated areas largely represent past, not recent, use of DDT within the region. A reduction in the application of DDT was also observed in previous studies of Asia (Doong and others, 2002a; Nguyen, Tu, Kajiwara, and others, 2007; Nguyen, $\mathrm{Tu}$, Iwata, and others, 2007; $\mathrm{Vu}$ and others, 2007; Malik and others, 2009; Zhang and others, 2011; Kumarasamy and others, 2012). Still, DDE is known to be toxic to humans and wildlife (Zitko, 2003a) and appears to persist.

Many previous studies (table 16) in Asia also established DDT and its metabolites as the most common POPs found. Concentrations of DDT, DDE, and DDD found in this study were similar to those found in river sediments in the Mekong Delta of Vietnam (Nguyen, Tu, Kajiwara, and others, 2007; Carvalho and others, 2008), in river and canal sediments in Laos and Thailand (Sudaryanto and others, 2011), in coastal sediments in the Masan Bay of Korea (Hong and others, 2003), in mangrove sediments in the Hugli River estuary of India (Bhattacharya and others, 2003), in paddy soils in Thailand and Vietnam (Vu and others, 1993; Iwata and others, 1994), in canal sediments from Ho Chi Minh City of Vietnam (Phuong and others, 1998; Nguyen, Tu, Iwata, and others, 2007), in canal sediments and industrial soils in Hanoi (Dang and others, 2001; Vu and others, 2007), and in urban soils of Indonesia, Thailand, and Taiwan (Iwata and others, 1994).

The concentrations of DDT, DDE, and DDD found in this study, however, are substantially higher than those found in coastal sediments in northern Vietnam (Dang and others, 1998; Dang and others, 1999), in the Dong Nai River estuary of Vietnam (Nguyen, Tu, Iwata, and others, 2007), in Singapore (Wurl and Obbard, 2005), in China (Liu and others, 2003; Zhang and others, 2003; Wang and others, 2008), and in India (Ramesh and others, 1991; Rajendran and others, 2005). DDT concentrations in Mekong Basin wetland sediments were also higher than those detected in agricultural soils in the Vellar River Basin in India (Ramesh and others, 1991), as well as the Mulan and Quilu River Basins in China (Zhang and others, 2011). Even so, some previous studies detected markedly higher concentrations of DDT and its metabolites in agricultural soils as compared to wetland soils studied in this report. For example, Vu and others (1993) and Iwata and others (1994) found concentrations of total DDTs ranging from $790 \mathrm{ng} / \mathrm{g}$ to $1,300 \mathrm{ng} / \mathrm{g}$ in paddy fields of central Vietnam and in municipal sewage systems of Ho Chi Minh City; these values were an order of magnitude larger than the highest concentration of DDTs found in this study (table 11). Kumarasamy and others (2012) also found high concentrations up to $857 \mathrm{ng} / \mathrm{g}$ of DDT, DDD, and DDE in agricultural fields in the Tamiraparani River Basin in India. High concentrations of total DDTs were also found in agricultural soils in China ( $\mathrm{Lv}$ and others, 2010) and in urban areas up to $1,100 \mathrm{ng} / \mathrm{g}$ from areas such as canal sediments in Hanoi (Pham and others, 2010). The measurement of higher concentrations for DDT and its metabolites in paddy fields (cited in this paper), as opposed to the lower concentration of DDTs measured in wetlands (this study), further suggests that DDT and its metabolites are not moving downstream substantially after the initial application.

Many previous studies have also concluded that DDT and its metabolites are the most dominant OC residues found in mussels, fish, and birds in the countries of the Mekong Region (Kannan and others, 1995; Monirith and others, 1999, 2000; Monirith, Kunisue, and others, 2003; Monirith, Ueno, and others, 2003; Nguyen, Tu, Kajiwara, and others, 2007; Kunisue and others, 2003; Carvalho and others, 2008). These species typically use wetlands during some phase of their life cycles. Even if concentrations of DDT and its metabolites are lower in wetlands than in agricultural fields, wildlife species could have greater access to these toxic substances in wetlands.

DDE was the form of DDT found most frequently, and in the highest concentrations, in this study. DDT degrades to DDE under aerobic conditions and to DDD under anaerobic conditions (Agency for Toxic Substances and Disease Registry, 2002a). Sediment samples collected in this study were derived mostly from wetlands in anaerobic conditions (table 6, fig. 4), so the higher concentration of DDE was unexpected. Given that DDE was the predominant residue detected in wetlands of the Mekong Basin, it was probable that DDT had been applied in agricultural or populated areas near wetlands and decomposed before accumulating in wetland sediments. Previous studies also found higher concentrations of DDE, as compared to DDT or DDD, in sediments (Dang and others, 2001; Hong and others, 2003; Nguyen, Tu, Kajiwara, and others, 2007; Carvalho and others, 2008).

\section{Endosulfan}

In this study, at least one form of endosulfan was detected in 165 wetland sediment samples ( 31 percent of all samples analyzed). Given its short half-life and higher water solubility compared to other OCs, frequently detected endosulfan residues in wetlands indicate recent, or even current, broad scale use of endosulfan in the Lower Mekong Basin countries, which is a concern because of the toxicity of this substance. Importantly, endosulfan concentrations in river, coastal, marine, and agricultural sediments were lower than endosulfan concentrations found in wetlands sampled in this study (table 16). Endosulfan is probably one of the most problematic POPs for wetlands of the Mekong Basin because of its widespread use. 


\section{Endrin}

Endrin and endrin aldehyde were found in 68 samples (13 percent of all samples). Endrin concentrations in wetlands of the Mekong Basin were comparable to coastal marine sediments collected in Singapore (Wurl and Obbard, 2005) and to agricultural soils of the Gomti River Basin in India (Malik and others, 2009). Endrin concentrations found in this study, however, were significantly higher than those found in river sediments in the Mekong Delta (Carvalho and others, 2008), in river and coastal sediments in Taiwan (Doong and others, 2002a; 2002b), as well as in coastal sediments of $\mathrm{Ha}$ Long Bay in Vietnam (Hong and others, 2008), in the Yangtze River estuary in China (Liu and others, 2003), and in the Daya Bay in China (Wang and others, 2008). Endrin concentrations found in wetlands of the Mekong Basin were even higher than those found in agricultural soils in the Tamiraparani River in India (Kumarasamy and others, 2012) and the Tianjin Province of China (Lv and others, 2010), as well as in urban canal sediments in Hanoi, Vietnam (Dang and others, 2001; Kishida and others, 2007) (table 16).

\section{Hexachlorobenzene}

Concentrations of HCB were found in 81 samples (15 percent of all samples analyzed). The concentrations detected were higher than those found in river sediments in Lao PDR and Thailand (Sudaryanto and others, 2011), in the Mekong Delta of Vietnam (Nguyen, Tu, Kajiwara, and others, 2007), in coastal sediments of the Dong Nai River estuary in Vietnam (Nguyen, Tu, Iwata, and others, 2007), in marine sediments from Masan Bay in South Korea (Hong and others, 2003), and in agricultural soils from the Gomti River Basin in India (Malik and others, 2009) (table 16). Other studies found higher HCB concentrations in urban canal sediments in Hanoi and Ho Chi Minh City (Kishida and others, 2007; Nguyen, Tu, Iwata, and others, 2007; Pham and others, 2010).

\section{Polychlorinated Biphenyls}

This study showed that PCBs were not important pollutants in wetlands of the Mekong Basin. PCBs, however, were frequently found by previous POP studies in Asia with high concentrations of PCBs found in estuary, coastal marine, and urban, industrial sediments (table 16).

\section{Management Guidelines}

The distribution and concentration of DDT, endosulfan, and endrin in the Mekong Basin were the greatest of the POPs examined in this study. Further, concentrations of endosulfan, endrin, and HCB were higher in wetlands from this study than found in different environments of the same region measured in other studies. Concentrations of other POPs in the Mekong Basin were relatively low. Of the five countries surveyed, Thailand had the lowest frequency of POP occurrence. Contamination by DDT, endosulfan, and endrin will need further investigation to understand possible effects on humans and wildlife. Even though most other POPs were found infrequently or at low concentrations, specific areas still had concentrations of these pollutants that were high enough to warrant attention because they exceeded established benchmarks. These specific areas, or hotspots, may pose a serious threat to people and wildlife. Further study of hotspots would be helpful in mapping troublespots more accurately, and management guidelines could be developed for how human health and environmental risks can be minimized. This is especially important because hotspots occurred in populated places as well as in wetlands of conservation importance. Additionally, the extent to which bioaccumulation may have occurred in each hotspot would be useful to investigate further.

Publication of reports specific to regions in each of the five countries is one important step that could also be completed. These reports would be helpful if they identified new hotspots, illucidated the extent of known hotspots, analyzed POP distributions and listed the concerns that are unique to each country. The use of endosulfans, for example, may be more of a concern in Vietnam than in other countries, so analyses of endosulfans might receive more emphasis in a publication from Vietnam than from the other countries that were surveyed.

The relation between POP concentrations in wetland soils and the accumulation of POPs at higher trophic levels has been determined elsewhere, but little is known about how bioaccumulation occurs in the Mekong Basin. Not only does the climate of the Mekong Basin differ from those of temperate regions where POP research has mostly been done, but the extent of biotic interactions that occur in the Mekong Basin differs from temperate regions as well. In the Mekong Basin, the migratory nature of fish (Warren and others, 1998), the tendency of fish to move to wetlands for egg laying, and the large role of fish in the diet of humans and wildlife suggest that there may be significant risks of exposure, even in areas where POPs are not found in sediments or where POPs are found at low concentrations. From this study, we know that POPs do not move extensively through river systems, but their impact may still be considerable because of bioaccumulation and migration in affected species. This hypothesis would benefit from further study.

POPs are not the only pollutants of concern in the Mekong Basin. Further study of other contaminants would be beneficial as well. Exposure to heavy metals, for example, may also increase health risks for humans (Jarup, 2003; Buschmann and others, 2008) and wildlife (Gachal and others, 2006; Dove, 2009). Little sampling for heavy metals has been completed in the Mekong Basin.

Lastly, the establishment of a long-term monitoring program would be useful to address several questions: (1) how might the level of POPs at current contamination sites change in the future; (2) will new POPs appear on the landscape; and (3) how can all areas of potential POP contamination be sampled? In retrospect, remote wetlands may have been 
undersampled in this study, and China was not sampled at all. Though extensive, this survey of POPs may still have missed other areas of contamination. This POP study was conducted by eight universities within the Mekong Region, and all laboratory analysis was completed within the Mekong Region. Expertise, therefore, exists within the Mekong Region, and monitoring can be continued or expanded in an affordable manner.

\section{References Cited}

Adobe Systems, Inc., 2013, Adobe Illustrator version CS6: San Jose, California, Adobe Systems, Inc.

Akaike, H., 1974, A new look at the statistical model identification: IEEE Transactions on Automatic Control, v. 19 , no. 6, p. 716-723.

Agency for Toxic Substances and Disease Registry, 1994, Toxicological profile for chlordane: Atlanta, Ga., U.S. Department of Health and Human Services, 234 p.

Agency for Toxic Substances and Disease Registry, 1995, Toxicological profile for mirex and chlordecone: Atlanta, Ga., U.S. Department of Health and Human Services, 333 p.

Agency for Toxic Substances and Disease Registry, 1996, Toxicological profile for endrin: Atlanta, Ga., U.S. Department of Health and Human Services, 191 p.

Agency for Toxic Substances and Disease Registry, 2000a, Toxicological profile for endosulfan: Atlanta, Ga., U.S. Department of Health and Human Services, 284 p.

Agency for Toxic Substances and Disease Registry, 2000b, Toxicological profile for polychlorinated biphenyls (PCBs): Atlanta, Ga., U.S. Department of Health and Human Services, $765 \mathrm{p}$.

Agency for Toxic Substances and Diseases Conntrol, 2001, Toxicological profile for methyl parathion: Atlanta, Ga., U.S. Department of Health and Human Services, 226 p.

Agency for Toxic Substances and Disease Registry, 2002a, Toxicological profile for DDT, DDD, DDE: Atlanta, Ga., U.S. Department of Health and Human Services, 403 p.

Agency for Toxic Substances and Disease, 2002b, Toxicological profile for hexachlorobenzene: Atlanta, Ga., U.S. Department of Health and Human Services, 352 p.

Agency for Toxic Substances and Disease Registry, 2002c, Toxicological profile for methoxychlor: Atlanta, Ga., U.S. Department of Health and Human Services, 244 p.

Agency for Toxic Substances and Disease Registry, 2002d, Toxicological profile for aldrin/dieldrin: Atlanta, Ga., U.S. Department of Health and Human Service, 303 p.
Agency for Toxic Substances and Disease Registry, 2005, Toxicological profile for alpha-, beta-, gamma-, and deltahexachlorocyclohexane: Atlanta, Ga., U.S. Department of Health and Human Services, 325 p.

Agency for Toxic Substances and Disease Registry, 2007, Toxicological profile for heptachlor and heptachlor epoxide: Atlanta, Ga., U.S. Department of Health and Human Services, $158 \mathrm{p}$.

Analytical Methods Committee, 1987, Recommendations for the definition, estimation and use of the detection limits: Analyst, v. 112, p. 199-204.

ArcGIS Online, 2013, accessed Janaury 12, 2011, at http:// www.arcgis.com/about/.

Avenza Systems, Inc., 2013, MAPublisher, version 9.2: Toronto, Ontario.

Baran, Eric, 2006, Fish migration triggers in the Lower Mekong Basin and other tropical freshwater systems: Vientiane, Lao People's Democratic Republic, MRC Technical Paper No. 14, Mekong River Commission, 56 p.

Barzen, Jeb, 1991, Restoration mixes science, people and luck in Vietnam: The ICF Bugle, v. 17, no. 2, p. 2-3.

Barzen, Jeb, 2004, An aerial survey of wetlands in northern Cambodia 2001: Phnom Penh, Cambodia, International Crane Foundation, Cambodia Office, 64 p.

Beilfuss, R., and Barzen, Jeb, 1994, Hydrological wetland restoration in the Mekong Delta, Vietnam, in Mitsch, W.J., ed., Global wetlands - Old world and new: Amsterdam, Elsevier Science B.V., p. 453-468.

Bhattacharya, B., Sarkar, S., and Mukherjee, N., 2003, Organochlorine pesticide residues in sediments of a tropical mangrove estuary, India-Implications for monitoring: Environment International, v. 29, p. 587-592.

Birdlife International, 2004, Important bird areas in AsiaKey sites for conservation: Cambridge, United Kingdom, BirdLife International Conservation Series, v. 13, 297 p.

Blus, L.G., Gish, L.D., Belisle, A.A., and Prouty, R.M., 1972, Logarithmic relationship of DDE residues to egg-shell thinning: Nature, v. 235, p. 376-377.

Bowman, G.M., and Hutka, J., 2002, Particle size analysis, in McKenzie, N.J., Cresswell, H.P., and Coughlan, K.J., eds., Soil physical measurement and interpretation for land evaluation: Collingwood, Victoria, Australia, CSIRO Publishing, p. 224-239.

Burger, A., 2009, p.mapper-A mapserver PHP/mapscript framework (version 4.2.0): accessed February 25, 2013, at http://www.pmapper.net/index.shtml. 
Buschmann, J., Berg, M., Stengel, C., Winkel, L., Sampson, M., Trang, P., and Viet, P., 2008, Contamination of drinking water resources in the Mekong Delta floodplainsArsenic and other trace metals pose serious health risks to population: Environment International, v. 34, p. 756-764.

Canadian Council of Ministers of the Environment, 1999, Canadian sediment quality guidelines for the protection of aquatic life-DDT, DDE, and DDD, in Canadian Council of Ministers of the Environment, 1999, Canadian environmental quality guidelines: Winnipeg, Manitoba, $7 \mathrm{p}$.

Canadian Council of Ministers of the Environment, 2003, Canadian environmental quality guidelines-Summary table December 2003: Winnipeg, Manitoba, Canadian Council of Ministers of the Environment, accessed October 17, 2012, at http://www.ccme.ca/publications/ceqg_rcqe. html.

Carson, Rachel, 1962, Silent spring: Boston, Mass., Houghton Mifflin, 368 p.

Carvalho, F., Villeneuve, J., Cattini, C., Tolosa, I., Dao, T., and Dang, N., 2008, Agrochemical and polychlorobyphenyl (PCB) residues in the Mekong River Delta, Vietnam: Marine Pollution Bulletin, v. 56, p. 1476-1485.

Claridge, G., 1996, Inventory of wetlands in Lao PDR: Gland, Switzerland, International Union for Conservation of Nature and United Nations Environment Programme, 287 p.

Cowardin, L.M., Carter, V., Golet, F.C., and LaRoe, E.T., 1979, Classification of wetlands and deepwater habitats of the United States (version 04DEC1998): Washington, D.C., U.S. Department of the Interior, Fish and Wildlife Service, Northern Prairie Wildlife Research Center, 131 p.

Dang Duc Nhan, Cavalho, F.P., Nguyen Manh Am, Nguyen Quoc Tuan, Nguyen Thi Hai Yen, Villeneuve, J.P., and Cattini, C., 2001, Chlorinated pesticides and PCBs in sediments and molluscs from freshwater canals in the Hanoi region: Environmental Pollution, v. 112, p. 311-320.

Dang Duc Nhan, Nguyen Manh Am, Cavalho, F.P., Villeneuve, J.P., and Cattini, C., 1999, Organochlorine pesticides and PCBs along the coast of north Vietnam: The Science of the Total Environment, v. 237/238, p. 363-371.

Dang Duc Nhan, Nguyen Manh Am, Nguyen Chu Hoi, Luu Van Dieu, Cavalho, F.P., Villeneuve, J.P., and Cattini, C., 1998, Organochlorine pesticides and PCBs in the Red River Delta, North Vietnam: Marine Pollution Bulletin, v. 36, p. 742-749.

Department of Water Resources, 2009, Map of major and sub watershed of Thailand (1st ed.): Bangkok, Thailand, Bureau of Research, Development, and Hydrology, Ministry of Natural Resources Environment, Sahamit Printing \& Publishing, 69 p. [in Thai language].
Dimond, J.B., and Owen, R.B., 1996, Long-term residue of DDT compounds in forest soils in Maine: Environmental Pollution, v. 92, p. 227-230.

Doong, R., Peng, C.K.., Sun, Y., and Liao, P., 2002a, Composition and distribution of organochlorine pesticide residues in surface sediments from the Wu-Shi River Estuary, Taiwan: Marine Pollution Bulletin, v. 45, p. 246-253.

Doong, R., Sun, Y., Lioa, P., Peng, C., and Wu, S., 2002b, Distribution and fate of organochlorine pesticide residues in sediments from the selected rivers in Taiwan: Chemosphere, v. 48, p. 237-246.

Dove, V., 2009, Mortality investigation of the Mekong Irrawaddy river dolphin (orcaellabrevirostris) in Cambodia based on necropsy sample analysis: World Wildlife Fund Technical Report, 72 p.

Duckworth, J.W., Salter, R.E., and Khounboline, K., eds., 1999, Wildlife in Lao P.D.R.—1999 status report: Vientiane, Lao People's Democratic Republic, International Union for Conservation of Nature, Wildlife Conservation Society, and Centers for Protected Areas and Watershed Management, $275 \mathrm{p}$.

Esri, 2010, Esri data \& maps 10: An Esri White Paper, accessed September 18, 2013, at

http://downloads.esri.com/support/whitepapers/ao_/Esri_ Data_and_Maps_10.pdf .

Finlayson, C.M., Begg, G.W., Howes, J., Davies, J., Tagi, K., and Lowry, J., 2002, A manual for an inventory of Asian wetlands (version 1.0.): Kuala Lumpur, Malaysia, Wetlands International Global Series 10, 72 p.

Frignani, M., Piazza, R., Belluci, L.G., Cu, N.H., Zangrando, R., Albertazzi, S., Moret, I., Romano, S., and Gambaro, A., 2007, Polychlorinated biphenyls in sediments of the Tam Giang-Cau Hai Lagoon, Central Vietnam: Chemosphere, v. 67, p. $1786-1793$.

Gachal, G.S., Slater, F.M., Zaibu Nisa, Ayaz Hussain Qadri and Zuhra, 2006, Ecological effect to the status of the Indus Dolphin: Pakistan Journal of Biological Science, v. 9, p. 2117-2121.

Gevao, B., Alegria, H., Jaward, F., and Beg, M., 2010, Persistent organic pollutants in developing world, in Harrad, S., ed., 2010, Persistent organic pollutants: Wiley, Blackwell Publishing, p. 137-169.

Goes, F., 2005, Four years of waterbird conservation activities in Prek Toal Core Area, Tonle Sap Biosphere Reserve (2001-2004): Phnom Penh, Cambodia, Wildlife Conservation Society Cambodia Program, 149 p. 
Gupta, A., 2009, Geology and landforms of the Mekong Basin, in Cambell, I.C., ed., The Mekong-Biophysical environment of an international river basin: Academic Press, p. 29-51.

Hanhart, K., and Ni, D.V., 1993, Water management on rice fields at Hoa An, Mekong Delta, Vietnam, in Dent, D.L., and Mensvoort, M.E.F. van, eds., Selected papers of the Ho Chi Minh City symposium on acid sulphate soils: Wageningen, Netherlands, International Institute for Land Reclamation and Improvement, p. 161-165.

Harrad, S., 2010, Beyond the Stockholm Convention-An introduction to current issues and future challenges in POPs research, in Harrad, S., ed., Persistent organic pollutants: Wiley, Blackwell Publishing, p. 1-4.

Hearn, P., Hare, J.T., Schruben, P., Sherrill, D., LaMar, C., Tsushina, P., 2003, Global GIS - Global Coverage DVD, American Geological Institute.

Hickey, J.J., and Anderson, D.W., 1968, Chlorinated hydrocarbons and eggshell changes in raptorial and fisheating birds: Science, v. 162, p. 271-273.

Hiro, H., 2000, Mekong-Environment and development: New York, United Nations University Press, 398 p.

Hong, C., and Goes, F., eds., 2001, Conservation activities at Ang Trapeang Thmor Sarus Crane Conservation Area 1998-2000: Phnom Penh, Cambodia, Wildlife Conservation Society Cambodia Program, 171 p.

Hong, S.H., Yim, U.H., Shim, W.J., Oh, I.R., and Lee, I.S., 2003, Horizontal and vertical distribution of PCBs and chlorinated pesticides in sediments from Masan Bay, Korea: Marine Pollution Bulletin, v. 46, p. 244-253.

Hong, S.H., Yim, U.H., Shim, W.J., Oh, R., Viet, P.H., and Park, P.S., 2008, Persistent organochlorine residues in estuarine and marine sediments from Ha Long Bay, Hai Phong Bay, and Ba Lat Estuary, Vietnam: Chemosphere, v. 72, p. 1193-1202.

Hout, S.K., Bunnat, P., Poole, C.M., Tordoff, A.W., Davidson, P., and Delattre, E., 2003, Directory of important bird areas in Cambodia-Key sites for conservation: Phnom Penh, Cambodia, Birdlife International Indochina Programme, $25 \mathrm{p}$.

Huynh Thi Minh Hang, Hirose, K., Do Van Quy, Tran Triet, Nguyen Hong Anh, Maruyama, Y., and Shiokawa, Y., 2003, Geo-environmental research for Can Gio Mangrove Forest, Vietnam: Asian Journal of Geoinformatics, v. 3, no. 3 , p. 3-11.
Ikemoto, T., Nguyen Phuc Cam Tu, Watanabe, M.X., Okuda, N., Omori, K., Tanabe, S., Bui Cach Tuyen, and Takeuchi, I., 2008, Analysis of biomagnifications of persistent organic pollutants in the aquatic food web of the Mekong Delta, South Vietnam using stable carbon and nitrogen isotopes: Chemosphere, v. 72, p. 104-114.

International Agency for Research on Cancer, 1974, IARC monographs on the evaluation of carcinogenic risks to humans-Volume 5, some organochlorine pesticides, summary of data reported and evaluation: World Health Organization, accessed October 1, 2012, at http:// monographs.iarc.fr/ENG/Monographs/vol5/volume5.pdf [Last updated March 17, 1998].

Iwata, H., Tanabe, S., Sakai, N., Nishimura, A., and Tatsukawa, R., 1994, Geographical distribution of persistent organochlorines in air, water, and sediments from Asia and Oceania, and their implications for global redistribution from lower latitudes: Environmental Pollution, v. 85, p. 15-33.

Jarup, L., 2003, Hazards of heavy metal contamination: British Medical Bulletin, v. 68, no. 1, p. 167-182.

Jones, K.C., and de Voogt, P., 1999, Persistent organic pollutants (POPs) - State of the science: Environmental Pollution, v. 100, p. 209-221.

Kannan, K., Tanabe, S., and Tatsukawa, R., 1995, Geographical distribution and accumulation features of organochlorine residues in fish in tropical Asia and Oceania: Environmental Science and Technology, v. 29, p. 2673-2683.

Kishida, M., Imamura, K., Maeda, Y., Tran Thi Ngoc Lan, Nguyen Thi Phuong Thao, and Pham Hung Viet, 2007, Distribution of persistent organic pollutants and polycyclic aromatic hydrocarbon in sediment samples from Vietnam: Journal of Health Science, v. 53, p. 291-301.

Kumarasamy, P., Govindaraj, S., Vignesh, S., Rajendran, R.B., and James, R.A., 2012, Anthropogenic nexus on organochlorine pesticides pollution-A case study with Tamiraparani River Basin, South India: Environmental Monitoring and Assessment, v. 184, p. 3861-3873.

Kunisue, T., Watanabe, M., Subramanian, A., Sethuraman, A., Titenko, A., Vo, Q., Prudente, M., and Tanabe, S., 2003, Accumulation features of persistent organochlorines in resident and migratory birds from Asia: Environmental Pollution, v. 125, p. 157-172.

Le Cong Kiet, 1993, Dong Thap Muoi-Restoring the mystery forest of the Plain of Reeds: Restoration \& Management Notes, v. 11, no. 2, p. 102-105. 
Li, A., Tanabe, G., Jiang, P., and Lam, K.S., 2007, Persistent organic pollutants in Asia-Sources, distributions, transport and fate: Elsevier Science, 825 p.

Liu, M., Yang, Y., Hou, L., Xu, S., Ou, D., Zhang, B., and Liu, Q., 2003, Chlorinated organic contaminants in surface sediments from the Yangtze estuary and nearby coastal areas, China: Marine Pollution Bulletin, v. 46, p. 672-676.

Loganathan, B.G., and Kannan, K., 1994, Global organochlorine contamination trends-An overview: Ambio, v. 23, p. 187-191.

Lv, J., Shi, R., Cai, Y., Liu, Y., Wang, Z., Fen, J., and Zhao, M., 2010, Assessment of 20 organochlorine pesticides (OCPs) pollution in suburban soil in Tianjin, China: Bulletin of Environmental Contamination and Toxicology, v. 85 , p. $137-141$.

Malik, A., Ojha, P., and Singh, K.P., 2009, Levels and distribution of persistent organochlorine pesticide residues in water and sediments of Gomti River (India) - A tributary of the Ganges River: Environmental Monitoring and Assessment, v. 148, p. 421-435.

Martin, M., Richarson, B., and Lam, P., 2003, Harmonization of polychlorinated biphenyl (PCB) analysis for ecotoxicological interpretation of Southeast Asian environmental media-What is the problem?: Marine Pollution Bulletin, v. 46, p. 159-170.

Mekong River Commission, 2001a, Developing a wetland classification system for the Lower Mekong Basin: Results from a series of regional and national workshops, Inventory and Management of Wetlands in the Lower Mekong Basin Project: Mekong River Commission Inventory of Wetlands in the Lower Mekong Basin (Project Phase 2), 141 p.

Mekong River Commission, 2001b, Outer Watershed Boundary of Lower Mekong Basin, accessed April 1, 2013, at http://portal.mrcmekong.org/master-catalogue/ search?giai=9506000003818_lmbouterE01009qj.

Meynell, P.J., Nguyen Huu Thien, Duong Van Ni, Tran Triet, der Schans, M. van, Shulman, D., Thompson, J., Barzen, J., and Shepherd, G., 2012, An integrated fire and water management strategy using the ecosystem approachTram Chim National Park, Vietnam, in Gunawardena, E.R.N., Gopal, B., and Kotagama, H., eds., Ecosystems and integrated water resources management in South Asia: New Dehli, Routledge, p. 199-228.
Miura, T., and Takahashi, R.M., 1987, Impact of fenoxycarb, a carbamate growth regulator, on some aquatic invertebrates abundant in mosquito breeding habitats: Journal of the American Mosquito Control Association, v. 3, p. 476-480.

Monirith, I., Kunisue, T., Iwata, H., Tanabe, S., and Tana, T.S., 2003, Accumulation of persistent organochlorines in resident white-breasted waterhens (Amaurornis phoenicurus) from Cambodia: Marine Pollution Bulletin, v. 46, p. 1341-1358.

Monirith, I., Nakata, H., Tanabe, S., and Tana, T., 1999, Persistent organochlorine residues in marine and freshwater fish in Cambodia: Marine Pollution Bulletin, v. 38, p. 604-612.

Monirith, I., Nakata, H., Watanabe, M., Takahashi, S., Tanabe, S., and Tana, T., 2000, Organochlorine contamination in fish and mussels from Cambodia and other Asian countries: Water Science and Technology, v. 42, p. 241-252.

Monirith I., Ueno, D., Takahashi, S., Nakata, H., Sudaryanto, A., Subramanian, A., Karauppiah, S., Ismail, A., Muchtar, M., Xheng, J., Richardson, B., Prudente, M., Nguyen Duc Hue, Tana, T., Tkalin, A.V., and Tanabe, S., 2003, Asia-Pacific mussel watch-Monitoring contamination of persistent organochlorine compounds in coastal waters of Asian countries: Marine Pollution Bulletin, v. 46, p. 281-300.

Munsell Soil Color Charts, 2009, Munsell soil color charts: Grand Rapids, Michigan, Munsell Color.

Natural Earth, 2013, 1:10m Cultural Vectors, accessed April 1, 2013, at http://naturalearthdata.com/downloads.

Nguyen Hoai Bao, Tran Triet, and Barzen, J., 2004, Status survey and community awareness raising for conservation of the Sarus Crane (Grus antigone) in Yok Don National Park: Ha Noi, Viet Nam, Government of Viet Nam (FPD), United Nations Office for Project Services, United Nations Development Programme, and Scott Wilson Asia-Pacific Ltd., PARC Project VIE/95/G31, 12 p.

Nguyen Hung Minh, Tu Binh Minh, Iwata, H., Kajiwara, N., Kunisue, T., Takahashi, S., Pham Hung Viet, Bui Cach Tuyen, and Tanabe, S., 2007a, Persistent organic pollutants in sediments from Sai Gon Dong Nai River Basin, Vietnam - Levels and temporal trends: Archives of Environmental Contamination and Toxicology, v. 52, p. 458-465. 
Nguyen Hung Minh, Tu Binh Minh, Kajiwara, N., Kunisue, T., Iwata, H., Pham Hung Viet, Nguyen Phuc Cam Tu, Bui Cach Tuyen, and Tanabe, S., 2007, Pollution sources and occurrences of selected persistent organic pollutants (POPs) in sediments of the Mekong River Delta, south Vietnam: Chemosphere, v. 67, p. 1794-1801.

Nguyen Ngoc Tran, ed., 1990, Technical report of national integrated research program 60B of Mekong Rver Delta: National Committee of Science and Technology, 200 p. [In Vietnamese].

Nguyen, V.C., ed., 1996, National geographic atlas: Vietnam General Department of Land Administration, 163 p.

Noriega, M.C., Wydoski, D.S., and Foreman, W.T., 2004, Methods of analysis by the U.S. Geological Survey National Water Quality Laboratory-Determination of organochlorine pesticides and polychlorinated biphenyls in bottom and suspended sediment by gas chromatography with electron-capture detection, U.S. Geological Survey Water-Resources Investigation Report 03-4293, 46 p.

Pham Manh Hoai, Nguyen Thuy Ngoc, Nguyen Hung Minh, Pham Hung Viet, Berg, M., Alder, A., and Giger, W., 2010, Recent levels of organochlorine pesticides and polychlorinated biphenyls in sediments of the sewer system in Hanoi, Vietnam: Environmental Pollution, v. 158, p. 913-920.

Pham Hung Viet, Pham Manh Hoai, Nguyen Hung Minh, Ngoc, N.T., and Hung, P.T., 2000, Persistent organochlorine pesticides and polychlorinated biphenyls in some agricultural and industrial areas in northern Vietnam: Water Science and Technology, v. 42, p. 223-229.

Phuong, P.K., Son, C.P.N., Sauvain, J.J., and Tarradelas, J., 1998, Contaminations by PCBs, DDTs and heavy metals in sediments of Ho Chi Minh City's canals, Vietnam: Bulletin of Environmental Contamination and Toxicology, v. 60 , p. $347-354$.

Pontollilo, J., and Eganhouse, R., 2001, The search for reliable aqueous solubility (Sw) and octanolwater coefficient $\left(\mathrm{K}_{\mathrm{ow}}\right)$ data for hydrophobic organic compounds - DDT and DDE as a case study: U.S. Geological Survey Water-Resources Investigation Report 01-4201, $51 \mathrm{p}$.

PostGIS (version 2.0.1), 2012, [Software]: accessed May 1, 2013, at http://postgis.refractions.net/.

PostGreSQL (version 1.14.2), 2012, [Software]: accessed May 1, 2013, at www.postgresql.org/.
Prest, I., Jefferies, D.J., and Moore, N.W., 1970, Polychlorinated bipheneyls in wild birds in Britain and their avian toxicity: Environmental Pollution, v. 1, p. 3-26.

Quantum GIS Development Team (version 1.7.4-Wroclaw), 2012, [Software]: accessed May 1, 2013, at http://qgis. osgeo.org.

R Development Core Team, 2011, R-A language and environment for statistical computing, Vienna, Austria, R Foundation for Statistical Computing, 1,706 p.

Rajendran, R.B., Imagawa, T., Tao, H., and Ramesh, R., 2005, Distribution of PCBs, HCHs and DDTs and their ecotoxicological implications in Bay of Bengal, India: Environment International, v. 31, p. 503-512.

Ramesh, A., Tanabe, S., Murase, H., Subramanian, A.N., and Tatsukawa, R., 1991, Distribution and behavior of persistent organochlorine insecticides in paddy soils and sediments in the tropical environment - A case study in South India: Environmental Pollution, v. 74, p. 293-307.

Ramsar Convention, 1971, Convention on wetlands of international importance especially as waterfowl habitat: Ramsar, Iran, UN Treaty Series No. 14583 [As amended by the Paris Protocol, December 3, 1982, and Regina Amendments, May 28, 1987].

Ratcliffe, D.A., 1967, Decrease in eggshell weight in certain birds of prey: Nature, v. 215, p. 208-210.

Safe, S.H., 1994, Polychlorinated bipheneyls (PCBs) environmental impact, biochemical and toxic responses and implications for risk assessment: Critical Reviews in Toxicology, v. 24, p. 87-119.

Safford, R.J., Maltby, E., Ni, D.V., and Branch, N., 2009, Melaleuca wetlands and sustainable development in the Mekong Delta, Vietnam, in Maltby, E., and Barker, T., eds., The wetlands handbook: Oxford, Blackwells Scientific, p. 829-849.

Safford, R.J., Tran, T., Maltby, E., and Duong, N.V., 1998, Status, biodiversity and management of the U Minh Wetlands, Vietnam: Tropical Biodiversity, v. 5, no. 3, p. 217-244.

Schwarzenbach, R., Escher, B.I., Fenner, K., Hofstetter, T.B., Johnson, A., von Gunten, U., and Wehrli, B., 2006, The challenge of micropollutants in aquatic systems: Science, v. 313, p. 1072-1077. 
Strandberg, B., van Bavel, B., Bergvist, P.A., Bronman, D., Ishaq, R., Naf, C., Pettersen, H., and Rappe, C., 1998, Occurrence, sedimentation and spatial variations of organochlorine contaminants in setting particulate matter and sediments in the northern part of the Baltic Sea: Environment and Technology, v. 32, p. 1754-1759.

Sudaryanto, A., Isobe, T., Takahashi, S., and Tanabe, S., 2011, Assessment of persistent organic pollutants in sediments from Lower Mekong River Basin: Chemosphere, v. 82, p. 679-686.

Thewlis, R., Timmins, R., Evans, T., and Duckworth, W., 1998, The conservation status of birds in Laos-A review of key species: Bird Conservation International, v. 8, 159 p.

Tran Triet, 2001, Wetland vegetation of Ang Trapeang Thmor, Banteay Meanchey Province, Cambodia, in Chamnan, H., and Gores, F., eds., Conservation activities at Ang Trapeang Thmor Sarus crane conservation area 1998-2000: Phnom Penh, Cambodia, Wildlife Conservation Society Cambodia Program, p. 147-158.

Tran Triet, 2003, Boeung Prek Lapouv, Takeo Province, Cambodia-A rare wetland of the lower Mekong Basin: ASEAN Biodiversity, v. 3, no. 3-4, p. 27-31.

Tran Triet, 2005a, An introduction to the biophysical environment and management of wetlands of Tram Chim National Park, Dong Thap Province, Vietnam: Ho Chi Minh City, Vietnam National University, Journal of Science and Technology Development, v. 8, no. 6/2005, p. 31-39.

Tran Triet, 2005b, Flora and vegetation of U Minh Thuong National Park, in Sage, N., Kutcher, S., Vinh, N.X., Wilson, P., and Dunlop, J., eds., Biodiversity of U Minh Thuong National Park: Ho Chi Minh City, Agricultural Publishing House, p. 7-19.

Tran Triet and Le Xuan Thuyen, eds., 2012, Dynamic of the mangrove belt of the Saigon-Dongnai estuary and the eastern coast of Mekong Delta: Vietnamese Ministry of Science and Technology, 439 p. [in Vietnamese].

Tran Triet and Nguyen Hoai Bao, 2004, Breeding habitat of the Eastern Sarus crane Grus antigone found in Yok Don National Park, Daklak Province, Vietnam: The Babbler, Birdlife International in Indochina, v. 12, p. 8.

Tran Triet, Safford, R., Tran Duy Phat, Duong Van Ni, and Maltby, E., 2000, Wetland biodiversity overlooked and threatened in the Mekong Delta, Viet Nam - Grassland ecosystems in the Ha Tien Plain: Tropical Biodiversity, v. 7, no. 1, p. 1-24.
Tu Binh Minh, Kunisue, T., Nguyen Thi Hong Yen, Watanabe, M., Tanabe, S., Nguyen Duc Hue, and Vo Quy, 2002, Persistent organochlorine residues and their bioaccumulation profiles in resident and migratory birds from North Vietnam: Environmental Toxicology and Chemistry, v. 21, p. 2108-2118.

United Nations Environment Programme Chemicals Branch, 2002, Regionally based assessment of persistent toxic substances-Southeast Asia and South Pacific report: Geneva, Switzerland, United Nations Environment Program Chemicals Branch, Global Environment Facility, 126 p.

United Nations Environment Programme Chemicals Branch, 2003, Regionally based assessment of persistent organic substances - Global report: Geneva, Switzerland, United Nation Environment Programme Chemicals Branch, Global Environment Facility, 207 p.

United States Department of Agriculture, 1993, Soil survey manual: Washington, D.C., United States Department of Agriculture, Soil Conservation Service, Agriculture Handbook No. 18.

United States Department of Agriculture, 1998, Estimating soil moisture by feel and appearance: Washington, D.C., United States Department of Agriculture, Soil Conservation Service, Program Aid No. 1619, 6 p.

U.S. Environmental Protection Agency, 2002, The foundation for global action on persistent organic pollutants-A United States perspective: Washington, D.C., Office of Research and Development, United States Environment Protection Agency, $167 \mathrm{p}$.

U.S. Environmental Protection Agency, 2004, Interim registration eligibility for carbaryl, list A, case 0080: United States Environmental Protection Agency, 289 p.

U.S. Environmental Protection Agency, 2006, Mid-Atlantic risk assessment-Ecological risk assessment: U.S. Environmental Protection Agency, accessed October 17, 2012, at http://www.epa.gov/reg3hwmd/risk/eco/index.htm.

Vagi, M.C., Petsas, A.S., Kostopouloua, M.N., Karamanolia, M.K., and Lekkas, T.D., 2007, Determination of organochlorine pesticides in marine sediments samples using ultrasonic solvent extraction followed by GC/ECD: Desalination, v. 210, p. 146-156.

Voldner, E.C., and Li, Y.-F., 1995, Global usage of selected persistent organochlorines: Science of the Total Environment, v. 160/161, p. 201-210. 
Vu Duc Thao, Kawano, M., and Tatsukawa, R., 1993, Persistent organochlorines residues in soils from tropical and sub-tropical Asian countries: Environmental Pollution, v. 81, p. 61-71.

Vu Duc Toan, Vu Duc Thao, Walder, J., Schmutz, H., and Cao The Ha, 2007, Contamination by selected organochlorine pesticides (OCPs) in surface soils in Hanoi, Vietnam: Bulletin of Environmental Contamination and Toxicology, v. 78, p. 195-200.

Wahlstrom, B.A., 2003, Criteria for additional POPs, in Fiedler, Heidelore, ed., Persistent organic pollutantsThe handbook of environmental chemistry: Springer, v. 3, p. 31-45.

Wang, Z., Yan, W., Chi, J.S., and Zhang, G., 2008, Spatial and vertical distribution of organochlorine pesticides in sediments from Daya Bay, South China: Marine Pollution Bulletin, v. 56, p. 1578-1585.

Warren, T.J., Chapman, G.C., and Singhanouvong, D., 1998, The upstream dry-season migrations of some important fish species in the Lower Mekong River of Lao PDR: Asian Fisheries Science, v. 11, p. 239-251.

Wong, M.H., Leung, A.O.W., Chan, J.K.Y., and Choi, M.P.K., 2005, A review on the usage of POP pesticides in China, with emphasis on DDT loadings in human milk: Chemosphere, v. 60 , p. $740-752$.

Wurl, O., and Obbard, J.P., 2005, Organochlorine pesticides, polychlorinated biphenyls and polybrominated diphenyl ethers in Singapore's coastal marine sediments: Chemosphere, v. 58, p. $925-933$.

Zhang, J., Qi, S., Xing, X., Tan, L., Gong, X., Zhang, Y., and Zhang, J., 2011, Organochlorine pesticides (OCPs) in soils and sediments, Southeast China-A case study in Xinghua Bay: Marine Pollution Bulletin, v. 62, p. $1270-1275$.

Zhang, Z.L., Hong, H.S., Zhou, J.L., Huang, J., and Yu, G., 2003, Fate and assessment of persistent organic pollutants in water and sediment from Minjiang River estuary, Southeast China: Chemosphere, v. 52, p. 1423-1430.

Zitko, V., 2003a, Chlorinated pesticides-Aldrin, DDT, endrin, dieldrin, mirex, in Fiedler, Heidelore, ed., Persistent organic pollutants-The handbook of environmental chemistry: Springer, v. 3, p. 47-90.

Zitko, V., 2003b, Hexachlorobenzene, in Fiedler, Heidelore, ed., Persistent organic pollutants-The handbook of environmental chemistry: Springer, v. 3, p. 91-122. 



\section{Appendix 1.}

Mean-value-control charts for organochlorines (OCs). The $Y$ axes are the concentrations of OCs determined in samples with spiked levels of 20 parts per billion (ppb). The colored horizons present how the results deviated from the mean value within the warning limits $( \pm 2 \sigma)$ and the control limits $( \pm 3 \sigma)$. Standard deviations are represented by $\sigma$. 

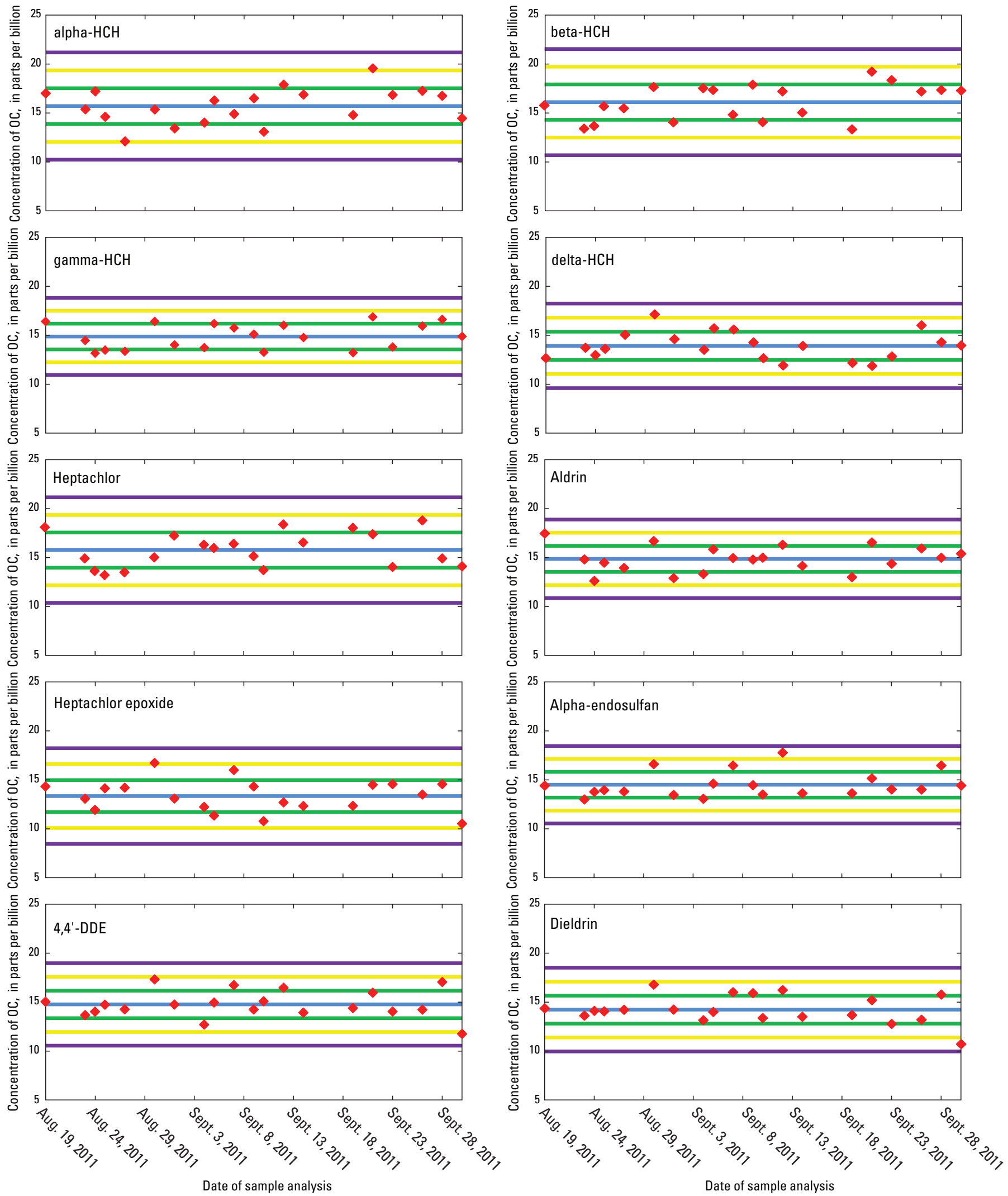

Figure 1.1 Mean-value-control charts for organochlorines (OCs). The $Y$ axes are the concentrations of OCs determined in samples with spiked levels of 20 parts per billion (ppb). The colored horizons present how the results deviated from the mean value within the warning limits $( \pm 2 \sigma)$ and the control limits $( \pm 3 \sigma)$. Standard deviations are represented by $\sigma$. The blue horizon represents the average value. Points falling between blue and green horizons are within one standard deviation from the mean whereas points falling between green and yellow horizons are within two standard deviations of the mean. Points falling between yellow and purple lines fall within three standard deviations from the mean. 

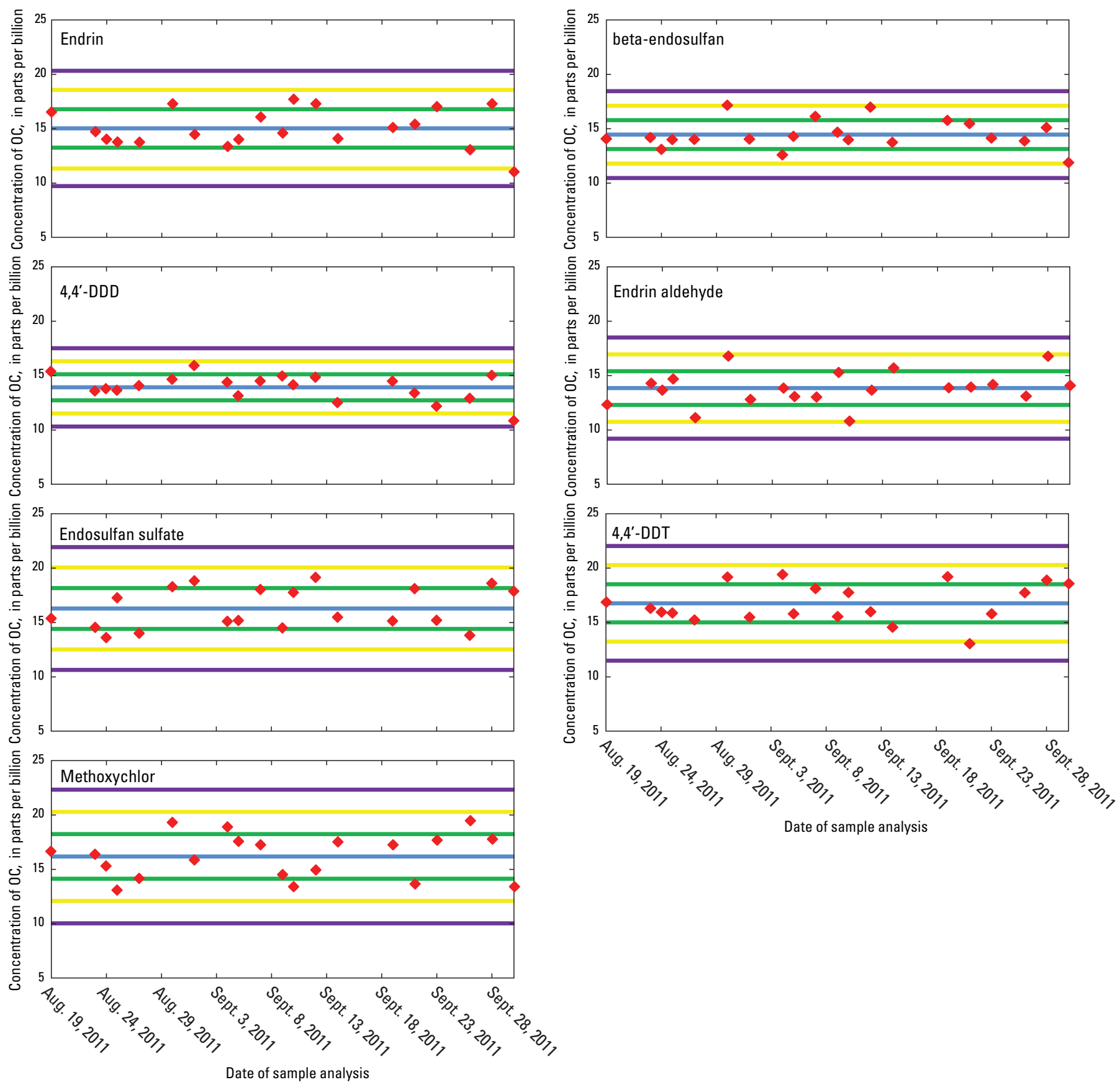

Figure 1.1 Mean-value-control charts for organochlorines (OCs). The $\mathrm{Y}$ axes are the concentrations of OCs determined in samples with spiked levels of 20 parts per billion (ppb). The colored horizons present how the results deviated from the mean value within the warning limits $( \pm 2 \sigma)$ and the control limits $( \pm 3 \sigma)$. Standard deviations are represented by $\sigma$. The blue horizon represents the average value. Points falling between blue and green horizons are within one standard deviation from the mean whereas points falling between green and yellow horizons are within two standard deviations of the mean. Points falling between yellow and purple lines fall within three standard deviations from the mean.-Continued 



\section{Appendix 2.}

Mean-value-control charts for polychlorinated biphenyls (PCBs). The $Y$ axes are the concentrations of PCBs determined in samples with spiked levels of 40 part per billion (ppb). The colored horizons present how the results deviated around the mean value within the warning limits $( \pm 2 \sigma)$ and the control limits $( \pm 3 \sigma)$. Standard deviations are represented by $\sigma$. 

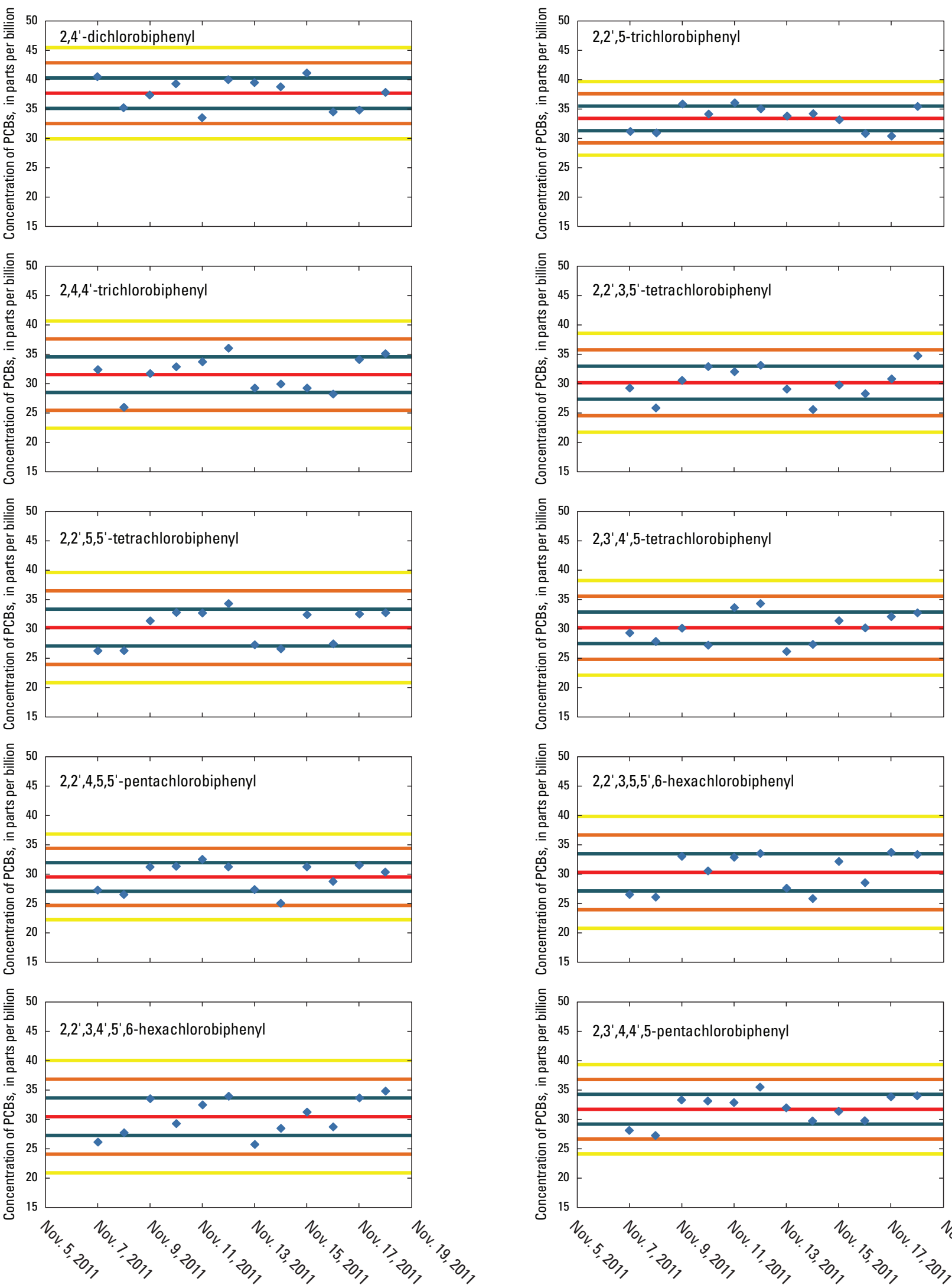

Date of sample analysis

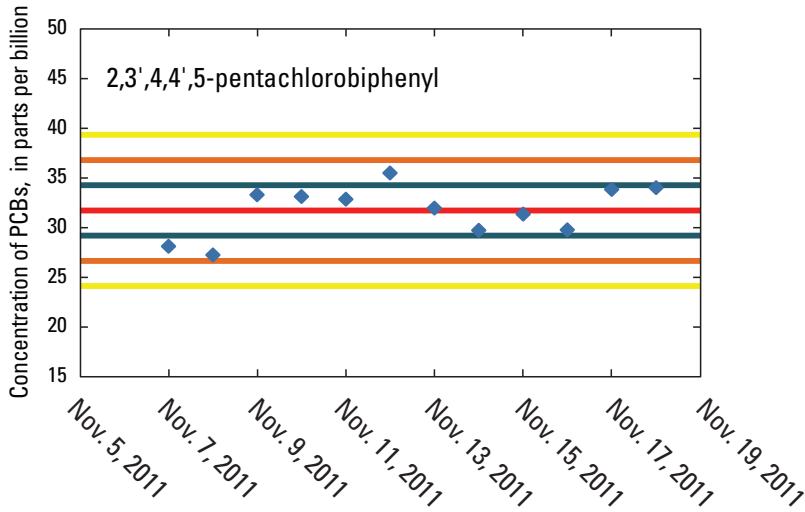

Date of sample analysis

Figure 2.1 Mean-value-control charts for polychlorinated biphenyls (PCBs). The $\mathrm{Y}$ axes are the concentrations of PCBs determined in samples with spiked levels of 40 part per billion ( $\mathrm{ppb}$ ). The colored horizons present how the results deviated around the mean value within the warning limits $( \pm 2 \sigma)$ and the control limits $( \pm 3 \sigma)$. Standard deviations are represented by $\sigma$. The red horizon represents the average value. Points falling between red and blue horizons are within one standard deviation from the mean while points falling between blue and orange horizons fall within 2 standard deviations of the mean. Points falling between orange and yellow lines fall within 3 standard deviations from the mean. 

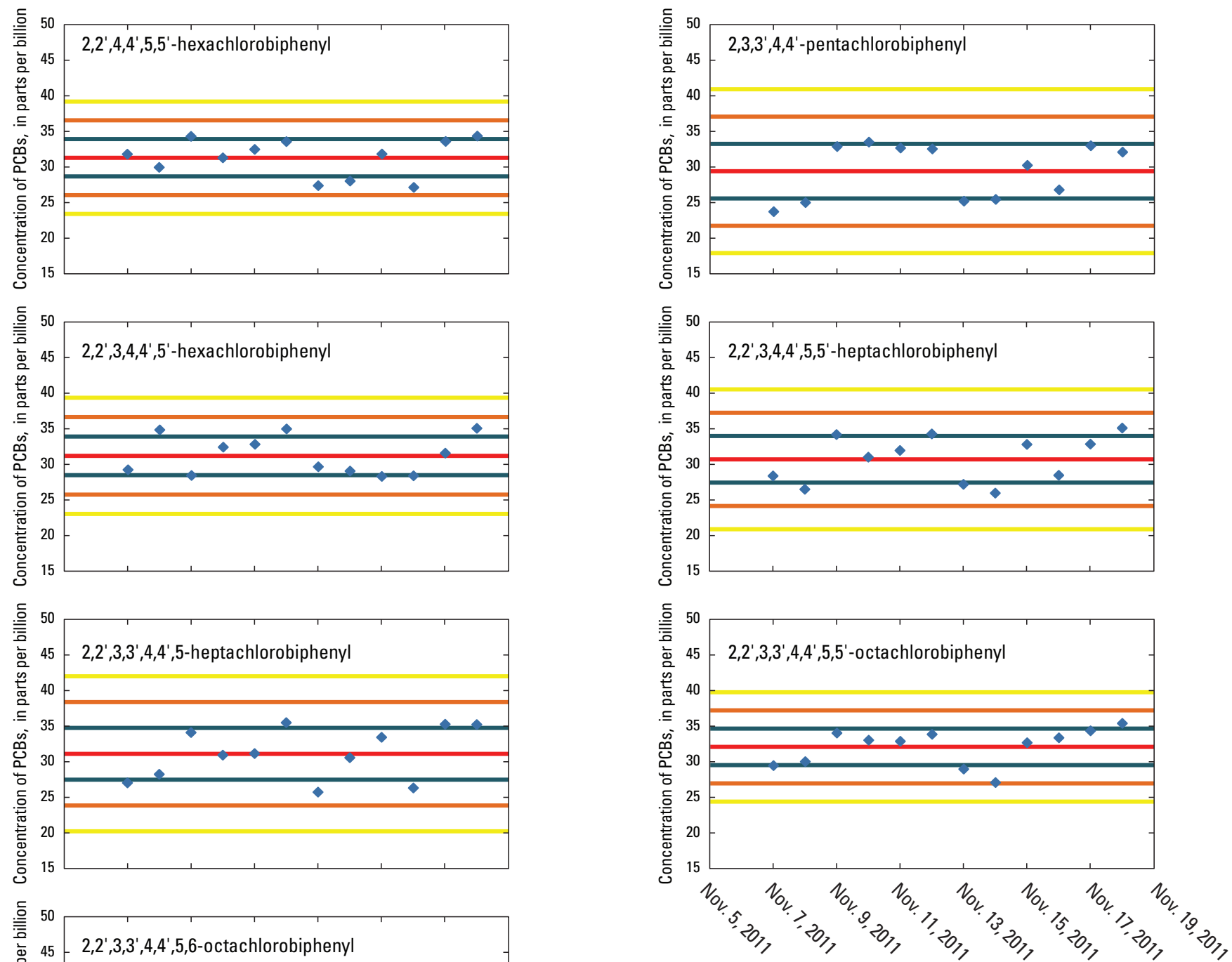

Date of sample analysis

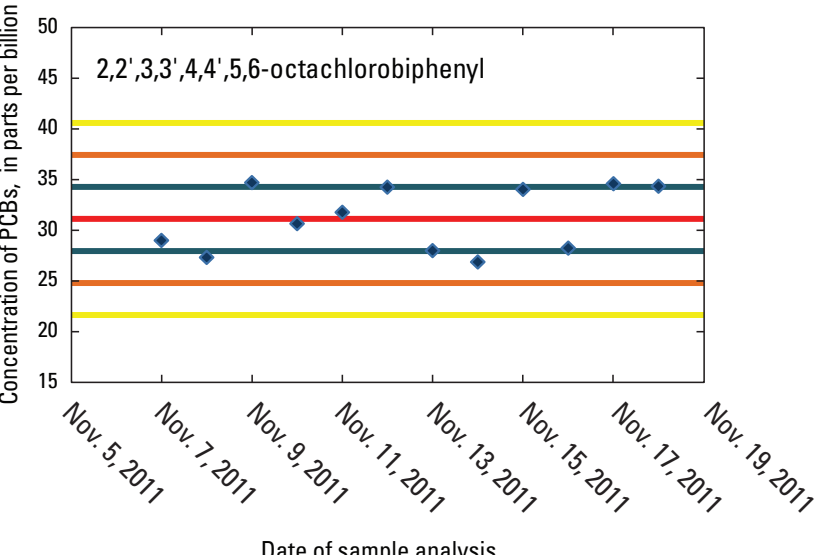

Figure 2.1 Mean-value-control charts for polychlorinated biphenyls (PCBs). The $Y$ axes are the concentrations of PCBs determined in samples with spiked levels of 40 part per billion (ppb). The colored horizons present how the results deviated around the mean value within the warning limits $( \pm 2 \sigma)$ and the control limits $( \pm 3 \sigma)$. Standard deviations are represented by $\sigma$. The red horizon represents the average value. Points falling between red and blue horizons are within one standard deviation from the mean while points falling between blue and orange horizons fall within 2 standard deviations of the mean. Points falling between orange and yellow lines fall within 3 standard deviations from the mean.-Continued 



\section{Appendix 3.}

Concentrations of 21 organochlorine pesticides found in all 531 persistent organic pollutant samples collected in the Lower Mekong River Basin during 2011. Minimum level of detection (LOD) is bolded and provided in the first line. Values measured below LOD are uncertain and should be construed as being present at low concentration but without further quantification. The label C085 was mistakenly used twice, so "A" distinguishes one sample from the other. A " 0 " denotes that, though tested, no OC was detected. All samples were analyzed for all OCs. Concentrations are measured as nanogram per gram dry weight (ng/g). [OC, organochlorine pesticides; LOD, level of detection; POP, persistent organic pollutant] 
Appendix 3. Concentrations of 21 organochlorine pesticides found in all 531 persistent organic pollutant samples collected in the Lower Mekong River Basin during

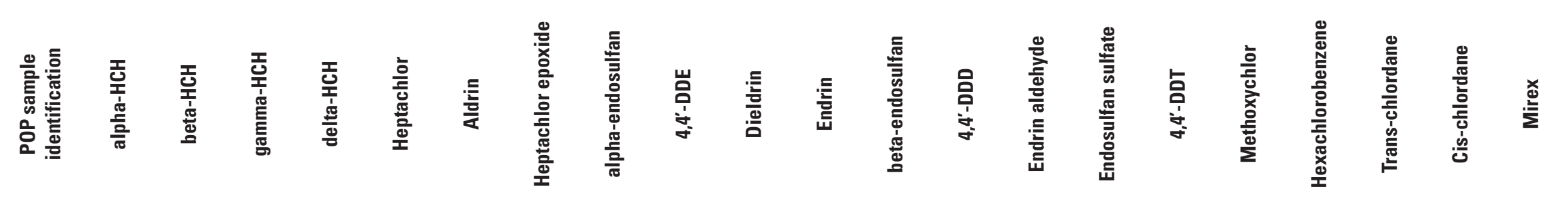

\begin{tabular}{|c|c|c|c|c|c|c|c|c|c|c|c|c|c|c|c|c|c|c|c|c|c|}
\hline LOD & 1 & 1.5 & 1 & 1 & 1.5 & 1.5 & 1.5 & 1 & 1 & 1 & 1 & 1 & 1 & 1 & 1 & 2 & 2 & 1.27 & 0.4 & 0.2 & 0.5 \\
\hline C001 & 0 & 0 & 0 & 0 & 0 & 0 & 0 & 0 & 0 & 0 & 0 & 0 & 0 & 0 & 0 & 0 & 0 & 0 & 0 & 0 & 0 \\
\hline C002 & 0 & 0 & 0 & 0 & 0 & 0 & 0 & 0 & 0 & 0 & 0 & 0 & 0 & 0 & 0 & 0 & 0 & 0.225 & 0 & 0 & 0 \\
\hline $\mathrm{C} 003$ & 0 & 0 & 0 & 0 & 0 & 0 & 0 & 0 & 0.52 & 0 & 0 & 0 & 0 & 0 & 0 & 0 & 0 & 0 & 0 & 0 & 0 \\
\hline C004 & 0 & 0 & 0 & 0 & 0 & 0 & 0 & 0 & 0 & 0 & 0 & 0 & 0 & 0 & 0 & 0 & 0 & 0 & 0 & 0 & 0 \\
\hline C005 & 0 & 0 & 0 & 0 & 0 & 0 & 0 & 0 & 0 & 0 & 0 & 0 & 0 & 0 & 0 & 0 & 0 & 0 & 0 & 0 & 0 \\
\hline C006 & 0 & 0 & 0 & 0 & 0 & 0 & 0 & 0 & 0 & 0 & 0 & 0 & 0 & 0 & 0 & 0 & 0 & 0 & 0 & 0 & 0 \\
\hline $\mathrm{C} 007$ & 0 & 0 & 0 & 0 & 0 & 0 & 0 & 0 & 0.758 & 0 & 0 & 0 & 0 & 0 & 0 & 0 & 0 & 0 & 0 & 0 & 0 \\
\hline C008 & 0 & 0 & 0 & 0 & 0 & 0 & 0 & 0 & 7.115 & 0 & 0 & 0 & 0 & 0 & 0 & 0.974 & 0 & 0 & 0 & 0 & 0 \\
\hline C009 & 0 & 0 & 0 & 0 & 0 & 0 & 0 & 0 & 0.664 & 0 & 0 & 0.956 & 0 & 0 & 0 & 0.185 & 0 & 0.302 & 0 & 0 & 0 \\
\hline C010 & 0 & 0 & 0 & 0 & 0 & 0 & 0 & 0 & 1.19 & 0 & 0 & 0 & 0 & 0 & 0 & 0 & 0 & 0 & 0 & 0 & 0 \\
\hline C011 & 0 & 0 & 0 & 0 & 0 & 0 & 0 & 0 & 0 & 0 & 0 & 0 & 0 & 0 & 0 & 0 & 0 & 0 & 0 & 0 & 0 \\
\hline C012 & 0 & 0 & 0 & 0 & 0 & 0 & 0 & 0 & 0 & 0 & 0 & 0 & 0 & 0 & 0 & 0 & 0 & 0 & 0 & 0 & 0 \\
\hline C013 & 0 & 0 & 0 & 0 & 0 & 0 & 0 & 0 & 0 & 0 & 0 & 0 & 0 & 0 & 0 & 0 & 0 & 0 & 0 & 0 & 0 \\
\hline C014 & 0 & 0 & 0 & 0 & 0 & 0 & 0 & 0 & 1.539 & 0 & 0 & 0 & 0 & 0 & 0 & 0 & 0 & 0 & 0 & 0 & 0 \\
\hline C015 & 0 & 0 & 0 & 0 & 0 & 0 & 0 & 0 & 0 & 0 & 0 & 0 & 0 & 0 & 0 & 0 & 0 & 0 & 0 & 0 & 0 \\
\hline C016 & 0 & 0 & 0 & 0 & 0 & 0 & 0 & 0 & 0.688 & 0 & 0 & 0 & 0 & 0 & 0 & 0 & 0 & 0 & 0 & 0 & 0 \\
\hline C017 & 0 & 0 & 0 & 0 & 0 & 0 & 0 & 0 & 0 & 0 & 0 & 0 & 0 & 0 & 0 & 0 & 0 & 0 & 0 & 0 & 0 \\
\hline C018 & 0 & 0 & 0 & 0 & 0 & 0 & 0 & 0 & 0 & 0 & 0 & 0 & 0 & 0 & 0 & 0 & 0 & 0 & 0 & 0 & 0 \\
\hline C019 & 0 & 0 & 0 & 0 & 0 & 0 & 0 & 0 & 0 & 0 & 0 & 0 & 0 & 0 & 0 & 0 & 0 & 0 & 0 & 0 & 0 \\
\hline $\mathrm{C} 020$ & 0 & 0 & 0 & 0 & 0 & 0 & 0 & 0 & 3.338 & 0 & 0 & 0 & 0 & 0 & 0 & 0 & 0 & 0.282 & 0 & 0 & 0 \\
\hline C021 & 0 & 0 & 0 & 0 & 0 & 0 & 0 & 0 & 0 & 0 & 0 & 0 & 0 & 0 & 0.247 & 0 & 0 & 0 & 0 & 0 & 0 \\
\hline C022 & 0 & 0 & 0 & 0 & 0 & 0 & 0 & 0 & 0 & 0 & 0 & 0 & 0 & 0 & 0 & 0 & 0 & 0 & 0 & 0 & 0 \\
\hline C023 & 0 & 0 & 0 & 0 & 0 & 0 & 0 & 0 & 0.214 & 0 & 0 & 0 & 0 & 0 & 0 & 0.721 & 0 & 0.322 & 0 & 0 & 0 \\
\hline C024 & 0 & 0 & 0 & 0 & 0 & 0 & 0 & 0 & 0 & 0 & 0 & 0 & 0 & 0 & 0 & 0 & 0 & 0 & 0 & 0 & 0 \\
\hline $\mathrm{C} 025$ & 0 & 0 & 0 & 0 & 0 & 0 & 0 & 0 & 0.059 & 0 & 0 & 0 & 0 & 0 & 0 & 0 & 0 & 0 & 0 & 0 & 0 \\
\hline
\end{tabular}


$\| 11111111111111$

\begin{tabular}{|c|c|c|c|c|c|c|c|c|c|c|c|c|c|c|c|c|c|c|c|c|c|}
\hline LOD & 1 & 1.5 & 1 & 1 & 1.5 & 1.5 & 1.5 & 1 & 1 & 1 & 1 & 1 & 1 & 1 & 1 & 2 & 2 & 1.27 & 0.4 & 0.2 & 0.5 \\
\hline $\mathrm{C} 026$ & 0 & 0 & 0 & 0 & 0 & 0 & 0 & 0 & 0 & 0 & 0 & 0 & 0 & 0 & 0 & 0 & 0 & 0 & 0 & 0 & 0 \\
\hline $\mathrm{C} 027$ & 0 & 0 & 0 & 0 & 0 & 0 & 0 & 0 & 0 & 0 & 0 & 0 & 0 & 0 & 0 & 0 & 0 & 0 & 0 & 0 & 0 \\
\hline $\mathrm{C} 028$ & 0 & 0 & 0 & 0 & 0 & 0 & 0 & 0 & 0.855 & 0 & 0 & 0 & 0 & 0 & 0 & 0 & 0 & 0 & 0 & 0 & 0 \\
\hline $\mathrm{C} 029$ & 0 & 0 & 0 & 0 & 0 & 0 & 0 & 0 & 5.788 & 0 & 0 & 0 & 0 & 0 & 0 & 0 & 0 & 0.820 & 0 & 0 & 0 \\
\hline $\mathrm{C} 030$ & 0 & 0 & 0 & 0 & 0 & 0 & 0 & 0 & 4.608 & 0 & 0 & 0 & 0 & 0 & 0 & 1.922 & 0 & 0 & 0 & 0 & 0 \\
\hline $\mathrm{C} 031$ & 0 & 0 & 0 & 0 & 0 & 0 & 0 & 0 & 0 & 0 & 0 & 0.808 & 0 & 0 & 0 & 0.072 & 0 & 0 & 0 & 0 & 0 \\
\hline $\mathrm{C} 032$ & 0 & 0 & 0 & 0 & 0 & 0 & 0 & 0 & 0 & 0 & 0 & 0 & 0 & 0 & 0 & 0 & 0 & 0 & 0 & 0 & 0 \\
\hline $\mathrm{C} 033$ & 0 & 0 & 0 & 0 & 0 & 0 & 0 & 0 & 0 & 0 & 0 & 0 & 0 & 0 & 0 & 0 & 0 & 0 & 0 & 0 & 0 \\
\hline $\mathrm{C} 034$ & 0 & 0 & 0 & 0 & 0 & 0 & 0 & 0 & 0 & 0 & 0 & 0 & 0 & 0 & 0 & 1.96 & 0 & 0 & 0 & 0 & 0 \\
\hline $\mathrm{C} 035$ & 0 & 0 & 0 & 0 & 0 & 0 & 0 & 0 & 0 & 0 & 0 & 0 & 0 & 0 & 0 & 0 & 0 & 0 & 0 & 0 & 0 \\
\hline $\mathrm{C} 036$ & 0 & 0 & 0 & 0 & 0 & 0 & 0 & 0 & 0.347 & 0 & 0 & 0 & 0 & 0 & 0 & 0 & 0 & 0 & 0 & 0 & 0 \\
\hline $\mathrm{C} 037$ & 0 & 0 & 0 & 0 & 0 & 0 & 0 & 0 & 0 & 0 & 0 & 0 & 0 & 0 & 0 & 0 & 0 & 0 & 0 & 0 & 0 \\
\hline $\mathrm{C} 038$ & 0 & 0 & 0 & 0 & 0 & 0 & 0 & 0 & 3.534 & 0 & 0 & 0 & 0 & 0 & 0 & 0 & 0 & 0.264 & 0 & 0 & 0 \\
\hline $\mathrm{C} 039$ & 0 & 0 & 0 & 0 & 0 & 0 & 0 & 0 & 0 & 0 & 0 & 0 & 0 & 0 & 0 & 0 & 0 & 0 & 0 & 0 & 0 \\
\hline $\mathrm{C} 040$ & 0 & 0 & 0 & 0 & 0 & 0 & 0 & 0 & 0 & 0 & 0 & 0 & 0 & 0 & 0 & 0.323 & 0 & 0 & 0 & 0 & 0 \\
\hline $\mathrm{C} 041$ & 0 & 0 & 0 & 0 & 0 & 0 & 0 & 0 & 0 & 0 & 0 & 0 & 0 & 0 & 0 & 0 & 0 & 0 & 0 & 0 & 0 \\
\hline $\mathrm{C} 042$ & 0 & 0 & 0 & 0 & 0 & 0 & 0 & 0 & 0 & 0 & 0 & 0 & 0 & 0 & 0 & 0 & 0 & 0 & 0 & 0 & 0 \\
\hline $\mathrm{C} 043$ & 0 & 0 & 0 & 0 & 0 & 0 & 0 & 0 & 0 & 0 & 0 & 0 & 0 & 0 & 0 & 0 & 0 & 0 & 0 & 0 & 0 \\
\hline $\mathrm{C} 044$ & 0 & 0 & 0 & 0 & 0 & 0 & 0 & 0 & 0 & 0 & 0 & 0.057 & 0 & 0 & 0 & 0.476 & 0 & 0 & 0 & 0 & 0 \\
\hline $\mathrm{C} 045$ & 0 & 0 & 0 & 0 & 0 & 0 & 0 & 0 & 0.884 & 0 & 0 & 0 & 0 & 0 & 0 & 0 & 0 & 0 & 0 & 0 & 0 \\
\hline $\mathrm{C} 046$ & 0 & 0 & 0 & 0 & 0 & 0 & 0 & 0 & 0.183 & 0 & 0 & 0 & 0 & 0 & 0 & 0 & 0 & 0 & 0 & 0 & 0 \\
\hline $\mathrm{C} 047$ & 0 & 0 & 0 & 0 & 0 & 0 & 0 & 0 & 0 & 0 & 0 & 0 & 0 & 0 & 0 & 0 & 0 & 0 & 0 & 0 & 0 \\
\hline $\mathrm{C} 048$ & 0 & 0 & 0 & 0 & 0 & 0 & 0 & 0 & 0.914 & 0 & 0 & 0 & 0 & 0 & 0 & 0 & 0 & 0 & 0 & 0 & 0 \\
\hline C049 & 0 & 0 & 0 & 0 & 0 & 0 & 0 & 0 & 0.842 & 0 & 0 & 0 & 0 & 0 & 0 & 0 & 0 & 0 & 0 & 0 & 0 \\
\hline $\mathrm{C} 050$ & 0 & 0 & 0 & 0 & 0 & 0 & 0 & 0 & 0 & 0 & 0 & 0 & 0 & 0 & 0 & 0 & 0 & 0 & 0 & 0 & 0 \\
\hline $\mathrm{C} 051$ & 0 & 0 & 0 & 0 & 0 & 0 & 0 & 0 & 0 & 0 & 0 & 0 & 0.322 & 0 & 0 & 0 & 0 & 0 & 0 & 0 & 0 \\
\hline $\mathrm{C} 052$ & 0 & 0 & 0 & 0 & 0 & 0 & 0 & 0 & 0.992 & 0 & 0 & 0 & 0 & 0 & 0 & 0 & 0 & 0 & 0 & 0 & 0 \\
\hline $\mathrm{C} 053$ & 0 & 0 & 0 & 0 & 0 & 0 & 0 & 0 & 0 & 0 & 0 & 0 & 0 & 0 & 0 & 0 & 0 & 0 & 0 & 0 & 0 \\
\hline
\end{tabular}


Appendix 3. Concentrations of 21 organochlorine pesticides found in all 531 persistent organic pollutant samples collected in the Lower Mekong River Basin during

\begin{tabular}{|c|c|c|c|c|c|c|c|c|c|c|c|c|c|c|c|c|c|c|c|c|c|}
\hline 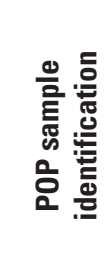 & 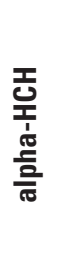 & 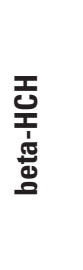 & 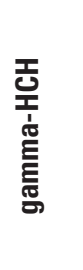 & 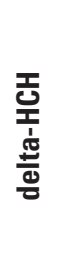 & 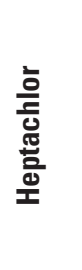 & $\frac{\text { 트늠 }}{\frac{1}{\alpha}}$ & 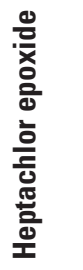 & 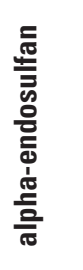 & $\begin{array}{l}\text { 㟔 } \\
\text { 号 } \\
\text { 过 }\end{array}$ & $\frac{\text { 트ㄴㅡㅡㅁ }}{\frac{0}{0}}$ & $\begin{array}{l}\text { 疍 } \\
\text { 至 }\end{array}$ & 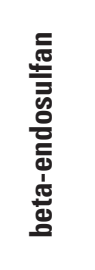 & 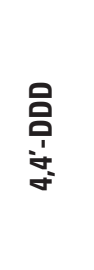 & 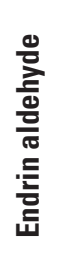 & 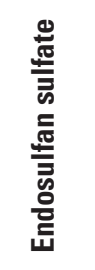 & $\begin{array}{l}\text { 吕 } \\
\text { : } \\
\dot{0} \\
\dot{0}\end{array}$ & 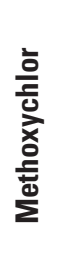 & 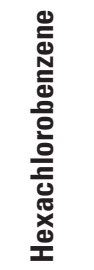 & 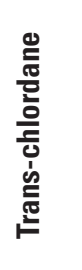 & 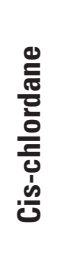 & 를 \\
\hline LOD & 1 & 1.5 & 1 & 1 & 1.5 & 1.5 & 1.5 & 1 & 1 & 1 & 1 & 1 & 1 & 1 & 1 & 2 & 2 & 1.27 & 0.4 & 0.2 & 0.5 \\
\hline $\mathrm{C} 054$ & 0 & 0 & 0 & 0 & 0 & 0 & 0 & 0 & 1.537 & 0 & 0 & 0.685 & 0 & 0 & 0 & 0.885 & 0 & 0 & 0 & 0 & 0 \\
\hline $\mathrm{C} 055$ & 0 & 0 & 0 & 0 & 0 & 0 & 0 & 0 & 1.375 & 0 & 0 & 0 & 0 & 0 & 0 & 0 & 0 & 0 & 0 & 0 & 0 \\
\hline $\mathrm{C} 056$ & 0 & 0 & 0 & 0 & 0 & 0 & 0 & 0 & 2 & 0 & 0 & 0 & 0 & 0 & 0 & 2.224 & 0 & 0.273 & 0 & 0 & 0 \\
\hline $\mathrm{C} 057$ & 0 & 0 & 0 & 0 & 0 & 0 & 0 & 0 & 0 & 0 & 0 & 1.049 & 0 & 0 & 0 & 0 & 0 & 0 & 0 & 0 & 0 \\
\hline $\mathrm{C} 058$ & 0 & 0 & 0 & 0 & 0 & 0 & 0 & 0 & 1.41 & 0 & 0 & 0.541 & 0 & 0 & 0 & 0 & 0 & 0 & 0 & 0 & 0 \\
\hline $\mathrm{C} 059$ & 0 & 0 & 0 & 0 & 0 & 0 & 0 & 0 & 0.411 & 0 & 0 & 0 & 0 & 0 & 0 & 0 & 0 & 0 & 0 & 0 & 0 \\
\hline $\mathrm{C} 060$ & 0 & 0 & 0 & 0 & 0 & 0 & 0 & 0 & 1.289 & 0 & 0 & 0 & 0 & 0 & 0 & 0 & 0 & 0 & 0 & 0 & 0 \\
\hline C061 & 0 & 0 & 0 & 0 & 0 & 0 & 0 & 0 & 0 & 0 & 0 & 0.454 & 0 & 0 & 0 & 0 & 0 & 0 & 0 & 0 & 0 \\
\hline C062 & 0 & 0 & 0 & 0 & 0 & 0 & 0 & 0 & 0 & 0 & 0 & 0 & 0 & 0 & 0 & 0 & 0 & 0 & 0 & 0 & 0 \\
\hline $\mathrm{C} 063$ & 0 & 0 & 0 & 0 & 0 & 0 & 0 & 0 & 0 & 0 & 0 & 0 & 0 & 0 & 0 & 0 & 0 & 0 & 0 & 0 & 0 \\
\hline C064 & 0 & 0 & 0 & 0 & 0 & 0 & 0 & 0 & 4.147 & 0 & 0 & 0 & 0 & 0 & 0 & 0 & 0 & 0 & 0 & 0 & 0 \\
\hline $\mathrm{C} 065$ & 0 & 0 & 0 & 0 & 0 & 0 & 0 & 0 & 1.424 & 0 & 0 & 0.732 & 0 & 0 & 0 & 0.457 & 0 & 0.371 & 0 & 0 & 0 \\
\hline C066 & 0 & 0 & 0 & 0 & 0 & 0 & 0 & 0 & 0 & 0 & 0 & 0 & 0 & 0 & 0 & 0 & 0 & 0 & 0 & 0 & 0 \\
\hline $\mathrm{C} 067$ & 0 & 0 & 0 & 0 & 0 & 0 & 0 & 0 & 0 & 0 & 0 & 0 & 0 & 0 & 0 & 0 & 0 & 0 & 0 & 0 & 0 \\
\hline C068 & 0 & 0 & 0 & 0 & 0 & 0 & 0 & 0 & 0 & 0 & 0 & 0 & 0 & 0 & 0 & 0 & 0 & 0 & 0 & 0 & 0 \\
\hline C069 & 0 & 0 & 0 & 0 & 0 & 0 & 0 & 0 & 2.578 & 0 & 0 & 0 & 0 & 0 & 0 & 0 & 0 & 0 & 0 & 0 & 0 \\
\hline $\mathrm{C} 070$ & 0 & 0 & 0 & 0 & 0 & 0 & 0 & 0 & 0 & 0 & 0 & 0 & 0.637 & 0 & 0 & 0 & 0 & 0 & 0 & 0 & 0 \\
\hline $\mathrm{C} 071$ & 0 & 0 & 0 & 0 & 0 & 0 & 0 & 0 & 0 & 0 & 0 & 0 & 0 & 0 & 0.078 & 0 & 0 & 0 & 0 & 0 & 0 \\
\hline $\mathrm{C} 072$ & 0 & 0 & 0 & 0 & 0 & 0 & 0 & 0 & 0.079 & 0 & 0 & 0 & 0 & 0 & 0 & 0 & 0 & 0 & 0 & 0 & 0 \\
\hline $\mathrm{C} 073$ & 0 & 0 & 0 & 0 & 0 & 0 & 0 & 0 & 0 & 0 & 0 & 0 & 0 & 0 & 0 & 0 & 0 & 0 & 0 & 0 & 0 \\
\hline C074 & 0 & 0 & 0 & 0 & 0 & 0 & 0 & 0 & 0 & 0 & 0 & 0.879 & 0 & 0 & 0 & 0.458 & 0 & 0 & 0 & 0 & 0 \\
\hline $\mathrm{C} 075$ & 0 & 0 & 0 & 0 & 0 & 0 & 0 & 0 & 0 & 0 & 0 & 0 & 0 & 0 & 0 & 0 & 0 & 0 & 0 & 0 & 0 \\
\hline $\mathrm{C} 076$ & 0 & 0 & 0 & 0 & 0 & 0 & 0 & 0 & 0 & 0 & 0 & 0 & 0 & 0 & 0 & 0 & 0 & 0 & 0 & 0 & 0 \\
\hline $\mathrm{C} 077$ & 0 & 0 & 0 & 0 & 0 & 0 & 0 & 0 & 0 & 0 & 0 & 0 & 0 & 0 & 0 & 0 & 0 & 0 & 0 & 0 & 0 \\
\hline
\end{tabular}


\|\|\|\|\|\|\|\|\|\|$\|$

\begin{tabular}{|c|c|c|c|c|c|c|c|c|c|c|c|c|c|c|c|c|c|c|c|c|c|}
\hline LOD & 1 & 1.5 & 1 & 1 & 1.5 & 1.5 & 1.5 & 1 & 1 & 1 & 1 & 1 & 1 & 1 & 1 & 2 & 2 & 1.27 & 0.4 & 0.2 & 0.5 \\
\hline $\mathrm{C} 078$ & 0 & 0 & 0 & 0 & 0 & 0 & 0 & 0 & 0 & 0 & 0 & 0 & 0.311 & 0 & 0 & 0 & 0 & 0 & 0 & 0 & 0 \\
\hline C079 & 0 & 0 & 0 & 0 & 0 & 0 & 0 & 0 & 0 & 0 & 0 & 0 & 0 & 0 & 0 & 0 & 0 & 0 & 0 & 0 & 0 \\
\hline C080 & 0 & 0 & 0 & 0 & 0 & 0 & 0 & 0 & 0 & 0 & 0 & 0 & 0 & 0 & 0 & 17.11 & 0 & 0.411 & 0 & 0 & 0 \\
\hline C081 & 0 & 0 & 0 & 0 & 0 & 0 & 0 & 0 & 3.008 & 0 & 0 & 0 & 0 & 0 & 0 & 0 & 0 & 0 & 0 & 0 & 0 \\
\hline C082 & 0 & 0 & 0 & 0 & 0 & 0 & 0 & 0 & 0 & 0 & 0 & 0 & 0 & 0 & 0 & 0.63 & 0 & 0 & 0 & 0 & 0 \\
\hline $\mathrm{C} 083$ & 0 & 0 & 0 & 0 & 0 & 0 & 0 & 0 & 0 & 0 & 0 & 0 & 0 & 0 & 0 & 0 & 0 & 0 & 0 & 0 & 0 \\
\hline $\mathrm{C} 084$ & 0 & 0 & 0 & 0 & 0 & 0 & 0 & 0 & 0 & 0 & 0 & 0 & 0 & 0 & 0 & 0 & 0 & 0 & 0 & 0 & 0 \\
\hline $\mathrm{C} 085$ & 0 & 0 & 0 & 0 & 0 & 0 & 0 & 0 & 0.033 & 0 & 0 & 0 & 0 & 0 & 0 & 0 & 0.465 & 0 & 0 & 0 & 0 \\
\hline C085A & 0 & 0 & 0 & 0 & 0 & 0 & 0 & 0 & 0 & 0 & 0 & 0 & 0 & 0 & 0 & 0.393 & 0 & 0 & 0 & 0 & 0 \\
\hline C086 & 0 & 0 & 0 & 0 & 0 & 0 & 0 & 0 & 0 & 0 & 0 & 0 & 0 & 0 & 0 & 0 & 0 & 0 & 0 & 0 & 0 \\
\hline C087 & 0 & 0 & 0 & 0 & 0 & 0 & 0 & 0 & 1.831 & 0 & 0 & 1.239 & 0 & 0 & 0 & 0 & 0 & 0 & 0 & 0 & 0 \\
\hline C088 & 0 & 0 & 0 & 0 & 0 & 0 & 0 & 0 & 0 & 0 & 0 & 0 & 0 & 0 & 0 & 0 & 0 & 0 & 0 & 0 & 0 \\
\hline C089 & 0 & 0 & 0 & 0 & 0 & 0 & 0 & 0 & 0 & 0 & 0 & 0.404 & 0 & 0 & 0 & 0.355 & 0.563 & 0 & 0 & 0 & 0 \\
\hline C090 & 0 & 0 & 0 & 0 & 0 & 0 & 0 & 0 & 0.333 & 0 & 0 & 0 & 0 & 0 & 0 & 0 & 0 & 0 & 0 & 0 & 0 \\
\hline C091 & 0 & 0 & 0 & 0 & 0 & 0 & 0 & 0 & 0 & 0 & 0 & 0 & 0 & 0 & 0 & 0 & 0 & 0 & 0 & 0 & 0 \\
\hline C092 & 0 & 0 & 0 & 0 & 0 & 0 & 0 & 0 & 0.064 & 0 & 0 & 0 & 0 & 0 & 0 & 0 & 0 & 0 & 0 & 0 & 0 \\
\hline C093 & 0 & 0 & 0 & 0 & 0 & 0 & 0 & 0 & 0.122 & 0 & 0 & 0 & 0 & 0 & 0 & 0 & 0 & 0 & 0 & 0 & 0 \\
\hline C094 & 0 & 0 & 0 & 0 & 0 & 0 & 0 & 0 & 0.717 & 0 & 0 & 1.087 & 0 & 0 & 0 & 0 & 0 & 0 & 0 & 0 & 0 \\
\hline C095 & 0 & 0 & 0 & 0 & 0 & 0 & 0 & 0 & 0 & 0 & 0 & 0 & 0 & 0 & 0 & 0 & 0 & 0 & 0 & 0 & 0 \\
\hline C096 & 0 & 0 & 0 & 0 & 0 & 0 & 0 & 0 & 0 & 0 & 0 & 0 & 0 & 0 & 0 & 0 & 0 & 0 & 0 & 0 & 0 \\
\hline C097 & 0 & 0 & 0 & 0 & 0 & 0 & 0 & 0 & 2.266 & 0 & 0 & 0 & 0 & 0 & 0 & 0 & 0 & 0.548 & 0 & 0 & 0 \\
\hline C098 & 0 & 0 & 0 & 0 & 0 & 0 & 0 & 0 & 0 & 0 & 0 & 0 & 0 & 0 & 0 & 0 & 0 & 0 & 0 & 0 & 0 \\
\hline C099 & 0 & 0 & 0 & 0 & 0 & 0 & 0 & 0 & 0 & 0 & 0 & 0.435 & 0 & 0 & 0 & 0 & 0 & 0 & 0 & 0 & 0 \\
\hline $\mathrm{C} 100$ & 0 & 0 & 0 & 0 & 0 & 0 & 0 & 0 & 0.048 & 0 & 0 & 0 & 0 & 0 & 0 & 0 & 0 & 0 & 0 & 0 & 0 \\
\hline $\mathrm{C} 101$ & 0 & 0 & 0 & 0 & 0 & 0 & 0 & 0 & 0.623 & 0 & 0 & 0.247 & 0 & 0 & 0 & 0 & 0 & 0 & 0 & 0 & 0 \\
\hline $\mathrm{C} 102$ & 0 & 0 & 0 & 0 & 0 & 0 & 0 & 0 & 0 & 0 & 0 & 0 & 0 & 0 & 0 & 0 & 0 & 0 & 0 & 0 & 0 \\
\hline C103 & 0 & 0 & 0 & 0 & 0 & 0 & 0 & 0 & 0 & 0 & 0 & 0 & 0 & 0 & 0 & 0 & 0 & 0 & 0 & 0 & 0 \\
\hline C104 & 0 & 0 & 0 & 0 & 0 & 0 & 0 & 0 & 0.362 & 0 & 0 & 0 & 0.786 & 0 & 0 & 0 & 0 & 0 & 0 & 0 & 0 \\
\hline C105 & 0 & 0 & 0 & 0 & 0 & 0 & 0 & 0 & 0.966 & 0 & 0 & 0 & 0 & 0 & 0 & 0 & 0 & 0 & 0 & 0 & 0 \\
\hline
\end{tabular}


Appendix 3. Concentrations of 21 organochlorine pesticides found in all 531 persistent organic pollutant samples collected in the Lower Mekong River Basin during

\begin{tabular}{|c|c|c|c|c|c|c|c|c|c|c|c|c|c|c|c|c|c|c|c|c|c|}
\hline 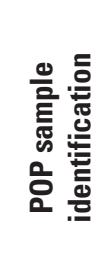 & 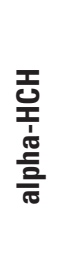 & 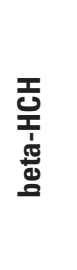 & 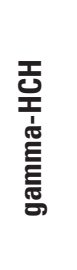 & 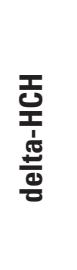 & 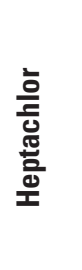 & $\frac{\text { 트는 }}{\frac{1}{\alpha}}$ & 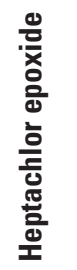 & 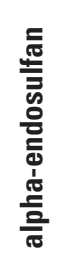 & $\begin{array}{l}\text { 岁 } \\
\text { 号 } \\
\text { 过 }\end{array}$ & $\frac{\text { 튼응 }}{\frac{0}{0}}$ & 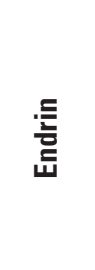 & 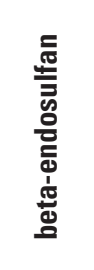 & $\begin{array}{l}\text { 웅 } \\
\text { 号 } \\
\text { 过 }\end{array}$ & 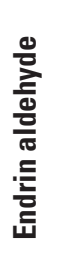 & 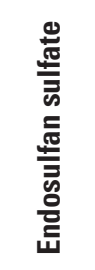 & $\begin{array}{l}\text { 合 } \\
\text { 品 } \\
\text { 过 }\end{array}$ & 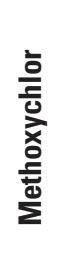 & 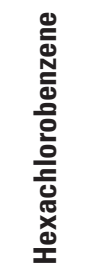 & 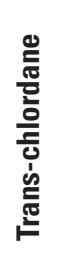 & 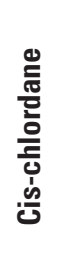 & 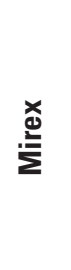 \\
\hline LOD & 1 & 1.5 & 1 & 1 & 1.5 & 1.5 & 1.5 & 1 & 1 & 1 & 1 & 1 & 1 & 1 & 1 & 2 & 2 & 1.27 & 0.4 & 0.2 & 0.5 \\
\hline $\mathrm{C} 106$ & 0 & 0 & 0 & 0 & 0 & 0 & 0 & 0 & 0 & 0 & 0 & 0 & 0 & 0 & 0 & 0 & 0 & 0 & 0 & 0 & 0 \\
\hline $\mathrm{C} 107$ & 0 & 0 & 0 & 0 & 0 & 0 & 0 & 0 & 0 & 0 & 0 & 0 & 0 & 0 & 0 & 0 & 0 & 0 & 0 & 0 & 0 \\
\hline $\mathrm{C} 108$ & 0 & 0 & 0 & 0 & 0 & 0 & 0 & 0 & 0 & 0 & 0 & 0 & 0 & 0 & 0 & 0 & 0 & 0 & 0 & 0 & 0 \\
\hline C109 & 0 & 0 & 0 & 0 & 0 & 0 & 0 & 0 & 0.602 & 0 & 0 & 0.146 & 0 & 0 & 0 & 0 & 0 & 0 & 0 & 0 & 0 \\
\hline C110 & 0 & 0 & 0 & 0 & 0 & 0 & 0 & 0 & 0 & 0 & 0 & 0 & 0 & 0 & 0 & 0 & 0 & 0 & 0 & 0 & 0 \\
\hline C111 & 0 & 0 & 0 & 0 & 0 & 0 & 0 & 0 & 75.66 & 1.835 & 0 & 12.78 & 0 & 0 & 0 & 15 & 0 & 0.304 & 0 & 0 & 0 \\
\hline $\mathrm{C} 112$ & 0 & 0 & 0 & 0 & 0 & 0 & 0 & 0 & 16.37 & 0 & 0 & 2.059 & 0 & 0 & 0 & 0 & 0 & 0 & 0 & 0 & 0 \\
\hline C113 & 0 & 0 & 0 & 0 & 0 & 0 & 0 & 0 & 0 & 0 & 0 & 0 & 0 & 0 & 0 & 0 & 0 & 0 & 0 & 0 & 0 \\
\hline C114 & 0 & 0 & 0 & 0 & 0 & 0 & 0 & 0 & 0.439 & 0 & 0 & 0 & 0.91 & 0 & 0 & 0 & 0 & 0 & 0 & 0 & 0 \\
\hline C115 & 0 & 0 & 0 & 0 & 0 & 0 & 0 & 0 & 0 & 0 & 0 & 0.811 & 0 & 0 & 0 & 0 & 0 & 0 & 0 & 0 & 0 \\
\hline C116 & 0 & 0 & 0 & 0 & 0 & 0 & 0 & 0 & 0 & 0 & 0 & 0 & 0 & 0 & 0 & 0 & 0 & 0 & 0 & 0 & 0 \\
\hline C117 & 0 & 0 & 0 & 0 & 0 & 0 & 0 & 0 & 15.13 & 0 & 0 & 2.866 & 0 & 0 & 0 & 0 & 0 & 0.294 & 0 & 0 & 0 \\
\hline C118 & 0 & 0 & 0 & 0 & 0 & 0 & 0 & 0 & 0.094 & 0 & 0 & 0 & 0 & 0 & 0 & 0 & 0 & 0 & 0 & 0 & 0 \\
\hline C119 & 0 & 0 & 0 & 0 & 0 & 0 & 0 & 0 & 0 & 0 & 0 & 0 & 0 & 0 & 0 & 0 & 0 & 0 & 0 & 0 & 0 \\
\hline $\mathrm{C} 120$ & 0 & 0 & 0 & 0 & 0 & 0 & 0 & 0 & 1.979 & 0 & 0 & 0 & 0 & 0 & 0 & 0 & 0 & 0 & 0 & 0 & 0 \\
\hline $\mathrm{C} 121$ & 0 & 0 & 0 & 0 & 0 & 0 & 0 & 0 & 0 & 0 & 0 & 0 & 0 & 0 & 0 & 0 & 0 & 0 & 0 & 0 & 0 \\
\hline $\mathrm{C} 122$ & 0 & 0 & 0 & 0 & 0 & 0 & 0 & 0 & 0 & 0 & 0 & 0.551 & 0 & 0 & 0 & 0 & 0 & 0 & 0 & 0 & 0 \\
\hline $\mathrm{C} 123$ & 0 & 0 & 0 & 0 & 0 & 0 & 0 & 0 & 0 & 0 & 0 & 0 & 0 & 0 & 0 & 0 & 0 & 0 & 0 & 0 & 0 \\
\hline $\mathrm{C} 124$ & 0 & 0 & 0 & 0 & 0 & 0 & 0 & 0 & 0 & 0 & 0 & 0 & 0 & 0 & 0 & 0 & 0 & 0 & 0 & 0 & 0 \\
\hline $\mathrm{C} 125$ & 0 & 0 & 0 & 0 & 0 & 0 & 0 & 0 & 0 & 0 & 0 & 0 & 0 & 0 & 0 & 0 & 0 & 0 & 0 & 0 & 0 \\
\hline $\mathrm{C} 126$ & 0 & 0 & 0 & 0 & 0 & 0 & 0 & 0 & 0 & 0 & 0 & 0 & 0 & 0 & 0 & 0 & 0 & 0 & 0 & 0 & 0 \\
\hline $\mathrm{C} 127$ & 0 & 0 & 0 & 0 & 0 & 0 & 0 & 2.07 & 3.325 & 1.503 & 2.104 & 0 & 0 & 0 & 0.551 & 0 & 0 & 0.364 & 0 & 0 & 0 \\
\hline $\mathrm{C} 128$ & 0 & 0 & 0 & 0 & 0 & 0 & 0 & 0 & 1.83 & 0 & 0 & 0 & 0 & 0 & 0 & 0 & 0 & 0 & 0 & 0 & 0 \\
\hline C129 & 0 & 0 & 0 & 0 & 0 & 0 & 0 & 0 & 0 & 0 & 0 & 0 & 0 & 0 & 0 & 0 & 0 & 0 & 0 & 0 & 0 \\
\hline $\mathrm{C} 130$ & 0 & 0 & 0 & 0 & 0 & 0 & 0 & 0 & 0 & 0 & 0 & 0 & 0 & 0 & 0 & 0 & 0 & 0 & 0 & 0 & 0 \\
\hline
\end{tabular}


$\|1111\| 111111111$

\begin{tabular}{|c|c|c|c|c|c|c|c|c|c|c|c|c|c|c|c|c|c|c|c|c|c|}
\hline LOD & 1 & 1.5 & 1 & 1 & 1.5 & 1.5 & 1.5 & 1 & 1 & 1 & 1 & 1 & 1 & 1 & 1 & 2 & 2 & 1.27 & 0.4 & 0.2 & 0.5 \\
\hline $\mathrm{C} 131$ & 0 & 0 & 0 & 0 & 0 & 0 & 0 & 0 & 20.18 & 0 & 0 & 0 & 0 & 0 & 0 & 0 & 0 & 1.407 & 0 & 0 & 0 \\
\hline C132 & 0 & 0 & 0 & 0 & 0 & 0 & 0 & 0 & 0 & 0 & 0 & 0 & 0 & 0 & 0 & 0 & 0 & 0 & 0 & 0 & 0 \\
\hline C133 & 0 & 0 & 0 & 0 & 0 & 0 & 0 & 0 & 0 & 0 & 0 & 0 & 0 & 0 & 0 & 0 & 0 & 0 & 0 & 0 & 0 \\
\hline $\mathrm{C} 134$ & 0 & 0 & 0 & 0 & 0 & 0 & 0 & 0 & 0 & 0 & 0 & 0 & 0 & 0 & 0 & 0 & 0 & 0 & 0 & 0 & 0 \\
\hline C135 & 0 & 0 & 0 & 0 & 0 & 0 & 0 & 0 & 0 & 0 & 0 & 0.24 & 0 & 0 & 0 & 0 & 0 & 0 & 0 & 0 & 0 \\
\hline C136 & 0 & 0 & 0 & 0 & 0 & 0 & 0 & 0 & 0 & 0 & 0 & 0 & 0 & 0 & 0 & 0 & 0 & 0 & 0 & 0 & 0 \\
\hline C137 & 0 & 0 & 0 & 0 & 0 & 0 & 0 & 0 & 0.184 & 0 & 0 & 0.633 & 0 & 0 & 0 & 0 & 0 & 0 & 0 & 0 & 0 \\
\hline C138 & 0 & 0 & 0 & 0 & 0 & 0 & 0 & 0 & 0.114 & 0 & 0 & 0 & 0 & 0 & 0 & 0.76 & 0 & 0 & 0 & 0 & 0 \\
\hline C139 & 0 & 0 & 0 & 0 & 0 & 0 & 0 & 0 & 1.981 & 0 & 0 & 0 & 0 & 0 & 0 & 0 & 0 & 0 & 0 & 0 & 0 \\
\hline C140 & 0 & 0 & 0 & 0 & 0 & 0 & 0 & 0 & 0 & 0 & 0 & 0 & 0 & 0 & 0 & 0 & 0 & 0 & 0 & 0 & 0 \\
\hline C141 & 0 & 0 & 0 & 0 & 0 & 0 & 0 & 0 & 0 & 0 & 0 & 0 & 0 & 0 & 0 & 0 & 0 & 0 & 0 & 0 & 0 \\
\hline C142 & 0 & 0 & 0 & 0 & 0 & 0 & 0 & 0 & 0 & 0 & 0 & 0 & 0 & 0 & 0 & 0 & 0 & 0 & 0 & 0 & 0 \\
\hline C143 & 0 & 0 & 0 & 0 & 0 & 0 & 0 & 0 & 2.761 & 0 & 0 & 0.248 & 0 & 0 & 0 & 0 & 0 & 0 & 0 & 0 & 0 \\
\hline C144 & 0 & 0 & 0 & 0 & 0 & 0 & 0 & 0.999 & 0 & 0 & 0 & 0 & 0 & 0 & 0 & 0 & 0 & 0 & 0 & 0 & 0 \\
\hline C145 & 0 & 0 & 0 & 0 & 0 & 0 & 0 & 0 & 25.9 & 0 & 0 & 0 & 6.136 & 0 & 10.47 & 0 & 0 & 1.215 & 0 & 0 & 0 \\
\hline C146 & 0 & 0 & 0 & 0 & 0 & 0 & 0 & 0 & 6.083 & 0 & 0 & 4.403 & 0 & 0 & 0 & 1.333 & 0 & 0.251 & 0 & 0 & 0 \\
\hline C147 & 0 & 0 & 0 & 0 & 0 & 0 & 0 & 0 & 0 & 0 & 0 & 0 & 0 & 0 & 0 & 0 & 0 & 0 & 0 & 0 & 0 \\
\hline C148 & 0 & 0 & 0 & 0 & 0 & 0 & 0 & 0 & 0 & 0 & 0 & 0 & 0 & 0 & 0 & 0 & 0 & 0 & 0 & 0 & 0 \\
\hline C149 & 0 & 0 & 0 & 0 & 0 & 0 & 0 & 0 & 1.471 & 0 & 0 & 0 & 0 & 0 & 0 & 0.498 & 0 & 0 & 0 & 0 & 0 \\
\hline $\mathrm{C} 150$ & 0 & 0 & 0 & 0 & 0 & 0 & 0 & 0 & 0 & 0 & 0 & 0 & 0 & 0 & 0 & 0 & 0 & 0 & 0 & 0 & 0 \\
\hline C151 & 0 & 0 & 0 & 0 & 0 & 0 & 0 & 0 & 0 & 0 & 0 & 0 & 0 & 0 & 0 & 0 & 0 & 0 & 0 & 0 & 0 \\
\hline C152 & 0 & 0 & 0 & 0 & 0 & 0 & 0 & 0 & 1.58 & 0 & 0 & 0.362 & 0 & 0 & 0 & 0 & 0 & 0 & 0 & 0 & 0 \\
\hline C153 & 0 & 0 & 0 & 0 & 0 & 0 & 0 & 0 & 0.363 & 0 & 0 & 0 & 0 & 0 & 0 & 0 & 0 & 0 & 0 & 0 & 0 \\
\hline C154 & 0 & 0 & 0 & 0 & 0 & 0 & 0 & 0 & 1.223 & 0 & 0 & 0 & 0 & 0 & 0 & 1.547 & 0 & 0 & 0 & 0 & 0 \\
\hline $\mathrm{C} 155$ & 0 & 0 & 0 & 0 & 0 & 0 & 0 & 0 & 0 & 0 & 0 & 0 & 0 & 0 & 0 & 0 & 0 & 0 & 0 & 0 & 0 \\
\hline $\mathrm{C} 156$ & 0 & 0 & 0 & 0 & 0 & 0 & 0 & 0 & 1.85 & 0 & 0 & 0 & 0 & 0 & 0 & 0 & 0 & 0 & 0 & 0 & 0 \\
\hline C157 & 0 & 0 & 0 & 0 & 0 & 0 & 0 & 0 & 0 & 0 & 0 & 0 & 0 & 0 & 0 & 0 & 0 & 0 & 0 & 0 & 0 \\
\hline $\mathrm{C} 158$ & 0 & 0 & 0 & 0 & 0 & 0 & 0 & 0 & 0 & 0 & 0 & 0 & 0 & 0 & 0 & 0 & 0 & 0 & 0 & 0 & 0 \\
\hline C159 & 0 & 0 & 0 & 0 & 0 & 0 & 0 & 0 & 0 & 0 & 0 & 0 & 0 & 0 & 0 & 0 & 0 & 0 & 0 & 0 & 0 \\
\hline
\end{tabular}


Appendix 3. Concentrations of 21 organochlorine pesticides found in all 531 persistent organic pollutant samples collected in the Lower Mekong River Basin during

\begin{tabular}{|c|c|c|c|c|c|c|c|c|c|c|c|c|c|c|c|c|c|c|c|c|c|}
\hline 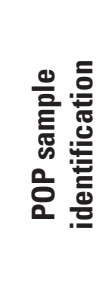 & 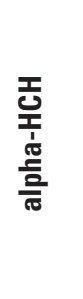 & 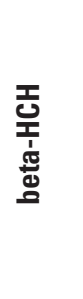 & 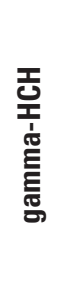 & 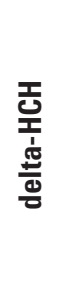 & 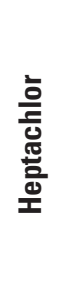 & 竝 & 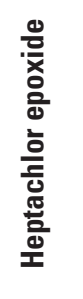 & 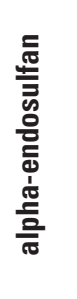 & $\begin{array}{l}\text { 㟔 } \\
\text { 号 } \\
\text { 过 }\end{array}$ & $\frac{\text { 트ㄴㅡㅡㅁ }}{\text { 음 }}$ & 淁 & 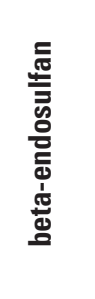 & $\begin{array}{l}\text { 号 } \\
\text { ㅁ } \\
\text { 过 }\end{array}$ & 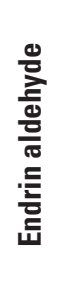 & 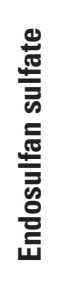 & $\begin{array}{l}\text { 合 } \\
\text { 号 } \\
\text { 过 }\end{array}$ & 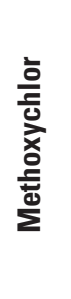 & 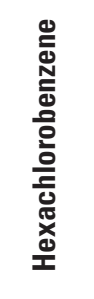 & 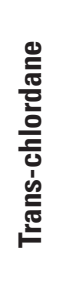 & 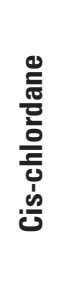 & 亮 \\
\hline LOD & 1 & 1.5 & 1 & 1 & 1.5 & 1.5 & 1.5 & 1 & 1 & 1 & 1 & 1 & 1 & 1 & 1 & 2 & 2 & 1.27 & 0.4 & 0.2 & 0.5 \\
\hline $\mathrm{C} 160$ & 0 & 0 & 0 & 0 & 0 & 0 & 0 & 0 & 0 & 0 & 0 & 0 & 0 & 0 & 0 & 0 & 0 & 0 & 0 & 0 & 0 \\
\hline C161 & 0 & 0 & 0 & 0 & 0 & 0 & 0 & 0 & 0 & 0 & 7.06 & 0 & 0 & 0 & 0 & 0 & 0 & 0 & 0 & 0 & 0 \\
\hline C162 & 0 & 0 & 0 & 0 & 0 & 0 & 0 & 0 & 0 & 0 & 0 & 0 & 0 & 0 & 0 & 0 & 0 & 0 & 0 & 0 & 0 \\
\hline C163 & 0 & 0 & 0 & 0 & 0 & 0 & 0 & 0 & 0 & 0 & 0 & 0 & 0 & 0 & 0 & 0 & 0 & 0 & 0 & 0 & 0 \\
\hline C164 & 0 & 0 & 0 & 0 & 0 & 0 & 0 & 0 & 0.117 & 0 & 0 & 0 & 0 & 0 & 0 & 0 & 0 & 0 & 0 & 0 & 0 \\
\hline C165 & 0 & 0 & 0 & 0 & 0 & 0 & 0 & 0 & 0 & 0 & 0 & 0 & 0.082 & 0 & 0 & 0 & 0 & 0 & 0 & 0 & 0 \\
\hline C166 & 0 & 0 & 0 & 0 & 0 & 0 & 0 & 0 & 0 & 0 & 0 & 0 & 0 & 0 & 0 & 0 & 0 & 0 & 0 & 0 & 0 \\
\hline $\mathrm{C} 167$ & 0 & 0 & 0 & 0 & 0 & 0 & 0 & 0 & 0 & 0 & 0 & 0 & 0 & 0 & 0 & 0 & 0 & 0 & 0 & 0 & 0 \\
\hline $\mathrm{C} 168$ & 0 & 0 & 0 & 0 & 0 & 0 & 0 & 0 & 0 & 0 & 0 & 0 & 0 & 0 & 0 & 0 & 0 & 0 & 0 & 0 & 0 \\
\hline C169 & 0 & 0 & 0 & 0 & 0 & 0 & 0 & 0 & 0 & 0 & 0 & 0 & 0 & 0 & 0 & 0 & 0 & 0 & 0 & 0 & 0 \\
\hline $\mathrm{C} 170$ & 0 & 0 & 0 & 0 & 0 & 0 & 0 & 0 & 0 & 0 & 0 & 0 & 0 & 0 & 0 & 0 & 0 & 0 & 0 & 0 & 0 \\
\hline $\mathrm{C} 171$ & 0 & 0 & 0 & 0 & 0 & 0 & 0 & 0 & 0.286 & 0 & 0 & 1.92 & 0 & 0 & 0 & 0 & 0 & 0 & 0 & 0 & 0 \\
\hline $\mathrm{C} 172$ & 0 & 0 & 0 & 0 & 0 & 0 & 0 & 0 & 0 & 0 & 0 & 1.882 & 0 & 0 & 0 & 0.246 & 0 & 0 & 0 & 0 & 0 \\
\hline $\mathrm{C} 173$ & 0 & 0 & 0 & 0 & 0 & 0 & 0 & 0 & 0 & 0 & 0 & 0.306 & 0 & 0 & 0 & 0 & 0 & 0 & 0 & 0 & 0 \\
\hline C174 & 0 & 0 & 0 & 0 & 0 & 0 & 0 & 0 & 0 & 0 & 0 & 0 & 0 & 0 & 0 & 0 & 0 & 0 & 0 & 0 & 0 \\
\hline C175 & 0 & 0 & 0 & 0 & 0 & 0 & 0 & 0 & 0 & 0 & 0 & 0 & 0 & 0 & 0 & 0 & 0 & 0 & 0 & 0 & 0 \\
\hline C176 & 0 & 0 & 0 & 0 & 0 & 0 & 0 & 0 & 1.424 & 0 & 0 & 0 & 0 & 0 & 0 & 0 & 0 & 0 & 0 & 0 & 0 \\
\hline $\mathrm{C} 177$ & 0 & 0 & 0 & 0 & 0 & 0 & 0 & 0 & 1.822 & 0 & 0 & 0 & 0 & 0 & 0 & 0 & 0 & 0.272 & 0 & 0 & 0 \\
\hline $\mathrm{C} 178$ & 0 & 0 & 0 & 0 & 0 & 0 & 0 & 0 & 0.208 & 0 & 0 & 0 & 0 & 0 & 0 & 0 & 0 & 0 & 0 & 0 & 0 \\
\hline C179 & 0 & 0 & 0 & 0 & 0 & 0 & 0 & 0 & 0.344 & 0 & 0 & 0 & 0 & 0 & 0 & 0 & 0 & 0 & 0 & 0 & 0 \\
\hline $\mathrm{C} 180$ & 0 & 0 & 0 & 0 & 0 & 0 & 0 & 0 & 0 & 0 & 0 & 0 & 0 & 0 & 0 & 0 & 0 & 0 & 0 & 0 & 0 \\
\hline C181 & 0 & 0 & 0 & 0 & 0 & 0 & 0 & 0 & 1.638 & 0 & 0 & 0 & 0 & 0 & 0 & 0 & 0 & 0 & 0 & 0 & 0 \\
\hline C182 & 0 & 0 & 0 & 0 & 0 & 0 & 0 & 0 & 0 & 0 & 0 & 0 & 0 & 0 & 0 & 0 & 0 & 0 & 0 & 0 & 0 \\
\hline C183 & 0 & 0 & 0 & 0 & 0 & 0 & 0 & 0 & 60.61 & 0 & 0 & 23.83 & 0 & 0 & 0 & 3.93 & 0 & 0.251 & 0 & 0 & 0 \\
\hline C184 & 0 & 0 & 0 & 0 & 0 & 0 & 0 & 0 & 7.043 & 0 & 0 & 0.946 & 0 & 0 & 0 & 0 & 0 & 0.415 & 0 & 0 & 0 \\
\hline
\end{tabular}


$\| 11111111111111$

\begin{tabular}{|c|c|c|c|c|c|c|c|c|c|c|c|c|c|c|c|c|c|c|c|c|c|}
\hline LOD & 1 & 1.5 & 1 & 1 & 1.5 & 1.5 & 1.5 & 1 & 1 & 1 & 1 & 1 & 1 & 1 & 1 & 2 & 2 & 1.27 & 0.4 & 0.2 & 0.5 \\
\hline $\mathrm{C} 185$ & 0 & 0 & 0 & 0 & 0 & 0 & 0 & 0 & 0 & 0 & 0 & 0 & 0 & 0 & 0 & 0 & 0 & 0 & 0 & 0 & 0 \\
\hline C186 & 0 & 0 & 0 & 0 & 0 & 0 & 0 & 0 & 0.471 & 0 & 0 & 0.178 & 0 & 0 & 0 & 0 & 0 & 0 & 0 & 0 & 0 \\
\hline C187 & 0 & 0 & 0 & 0 & 0 & 0 & 0 & 0 & 0 & 0 & 0 & 0 & 0 & 0 & 0 & 0 & 0 & 0 & 0 & 0 & 0 \\
\hline C188 & 0 & 0 & 0 & 0 & 0 & 0 & 0 & 0 & 0 & 0 & 0 & 1.819 & 0 & 0 & 0.632 & 0 & 0 & 0 & 0 & 0 & 0 \\
\hline C189 & 0 & 0 & 0 & 0 & 0 & 0 & 0 & 0 & 7.166 & 0 & 0 & 0 & 0 & 0 & 0 & 0 & 0 & 0 & 0 & 0 & 0 \\
\hline C190 & 0 & 0 & 0 & 0 & 0 & 0 & 0 & 0 & 0 & 0 & 0 & 0 & 0 & 0 & 0 & 0 & 0 & 0 & 0 & 0 & 0 \\
\hline C191 & 0 & 0 & 0 & 0 & 0 & 0 & 0 & 0 & 0 & 0 & 0 & 0 & 0 & 0 & 0 & 0 & 0 & 0 & 0 & 0 & 0 \\
\hline C192 & 0 & 0 & 0 & 0 & 0 & 0 & 0 & 0 & 0 & 0 & 0 & 0 & 0 & 0 & 0 & 0 & 0 & 0 & 0 & 0 & 0 \\
\hline C193 & 0 & 0 & 0 & 0 & 0 & 0 & 0 & 0 & 0 & 0 & 0 & 0 & 0 & 0 & 0 & 0 & 0 & 0 & 0 & 0 & 0 \\
\hline C194 & 0 & 0 & 0 & 0 & 0 & 0 & 0 & 0 & 0 & 0 & 0 & 0.579 & 0 & 0 & 0 & 0 & 0 & 0 & 0 & 0 & 0 \\
\hline C195 & 0 & 0 & 0 & 0 & 0 & 0 & 0 & 0 & 0 & 0 & 0 & 0 & 0 & 0 & 0 & 0 & 0 & 0 & 0 & 0 & 0 \\
\hline C196 & 0 & 0 & 0 & 0 & 0 & 0 & 0 & 0 & 0 & 0 & 0 & 0 & 0 & 0 & 0 & 0 & 0 & 0 & 0 & 0 & 0 \\
\hline L001 & 0 & 0 & 0 & 0 & 0 & 0 & 0 & 0 & 0 & 0 & 0.366 & 0 & 0 & 0.558 & 0 & 0 & 0 & 0 & 0 & 0 & 0 \\
\hline L002 & 0 & 0 & 0 & 0 & 0 & 0 & 0 & 0 & 0 & 0 & 0 & 0 & 0 & 0 & 0 & 0 & 0 & 0 & 0 & 0 & 0 \\
\hline L003 & 0 & 0 & 0 & 0 & 0 & 0 & 0 & 0 & 0.317 & 0 & 0 & 0 & 0 & 0 & 0 & 0.131 & 0 & 0 & 0 & 0 & 0 \\
\hline L004 & 0 & 0 & 0 & 0 & 0 & 0 & 0 & 0 & 1.21 & 0 & 0 & 0 & 0 & 0 & 0 & 0 & 0 & 0 & 0 & 0 & 0 \\
\hline L005 & 0 & 0 & 0 & 0 & 0 & 0 & 0 & 0 & 0 & 0 & 0 & 0 & 0 & 0 & 0 & 0 & 0 & 0 & 0 & 0 & 0 \\
\hline L006 & 0 & 0 & 0 & 0 & 0 & 0 & 0 & 0 & 0 & 0 & 0 & 0 & 0 & 0 & 0 & 0 & 0 & 0 & 0 & 0 & 0 \\
\hline L007 & 0 & 0 & 0 & 0 & 0 & 0 & 0 & 0 & 0 & 0 & 0 & 0 & 0 & 0 & 0 & 0 & 0 & 0 & 0 & 0 & 0 \\
\hline L008 & 0 & 0 & 0 & 0 & 0 & 0 & 0 & 0 & 0.152 & 0 & 0 & 0 & 0.12 & 0 & 0 & 0 & 0 & 0 & 0 & 0 & 0 \\
\hline L009 & 0 & 0 & 0 & 0 & 0 & 0 & 0 & 0 & 0 & 0.124 & 1.129 & 0 & 0.042 & 0 & 0.138 & 0 & 0 & 0 & 0 & 0 & 0 \\
\hline L010 & 0 & 0 & 0 & 0 & 0 & 0 & 0 & 0 & 17.67 & 0 & 0 & 14.12 & 0 & 0 & 0 & 11.42 & 0 & 0.607 & 0 & 0 & 0 \\
\hline L011 & 0 & 0 & 0 & 0 & 0 & 0 & 0 & 0 & 0 & 0 & 0 & 0 & 0 & 0 & 0.107 & 0 & 0 & 0 & 0 & 0 & 0 \\
\hline L012 & 0 & 0 & 0 & 0 & 0 & 0 & 0 & 0 & 0 & 0 & 0 & 0 & 0 & 0.65 & 0 & 0 & 0 & 0 & 0 & 0 & 0 \\
\hline L013 & 0 & 0 & 0 & 0 & 0 & 0 & 0 & 0 & 0 & 0 & 0 & 0 & 0 & 0 & 0.047 & 0 & 0 & 0 & 0 & 0 & 0 \\
\hline L014 & 0 & 0 & 0 & 0 & 0 & 0 & 0 & 0 & 0.623 & 0 & 0 & 1.207 & 0 & 0 & 0 & 0 & 0 & 0 & 0 & 0 & 0 \\
\hline L015 & 0 & 0 & 0 & 0 & 0 & 0 & 0 & 0 & 0 & 0 & 0 & 0 & 0 & 0 & 0.084 & 0 & 0 & 0.207 & 0 & 0 & 0 \\
\hline
\end{tabular}


Appendix 3. Concentrations of 21 organochlorine pesticides found in all 531 persistent organic pollutant samples collected in the Lower Mekong River Basin during

\begin{tabular}{|c|c|c|c|c|c|c|c|c|c|c|c|c|c|c|c|c|c|c|c|c|c|}
\hline 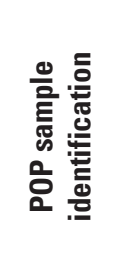 & 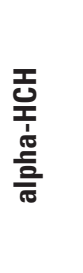 & 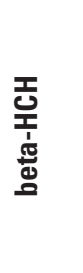 & 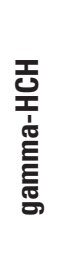 & 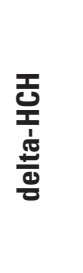 & 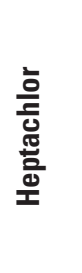 & $\frac{\text { 宣 }}{\frac{1}{\alpha}}$ & 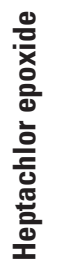 & 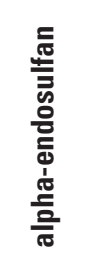 & $\begin{array}{l}\text { 㟔 } \\
\text { 口 } \\
\text { 过 }\end{array}$ & $\frac{\text { 트ㄴㅡㅡㅁ }}{\frac{0}{0}}$ & $\begin{array}{l}\text { 咅 } \\
\text { 至 }\end{array}$ & 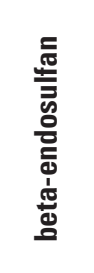 & $\begin{array}{l}\text { 只 } \\
\text { 只 } \\
\text { 号 }\end{array}$ & 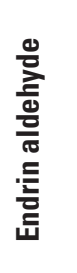 & 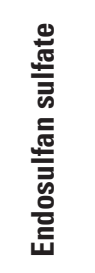 & $\begin{array}{l}\text { 号 } \\
\text { 足 } \\
\text { 过 }\end{array}$ & 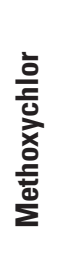 & 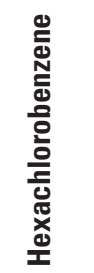 & 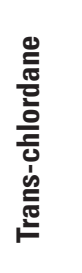 & 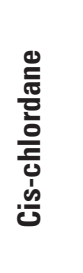 & 嵩 \\
\hline LOD & 1 & 1.5 & 1 & 1 & 1.5 & 1.5 & 1.5 & 1 & 1 & 1 & 1 & 1 & 1 & 1 & 1 & 2 & 2 & 1.27 & 0.4 & 0.2 & 0.5 \\
\hline L016 & 0 & 0 & 0 & 0 & 0 & 0 & 0 & 0 & 0 & 0 & 0 & 0 & 0 & 0 & 0 & 0 & 0 & 0 & 0 & 0 & 0 \\
\hline L017 & 0 & 0 & 0 & 0 & 0 & 0 & 0 & 0 & 2.846 & 0 & 0 & 0 & 0 & 0 & 0 & 0 & 0 & 0 & 0 & 0 & 0 \\
\hline L018 & 0 & 0 & 0 & 0 & 0 & 0 & 0 & 0 & 0 & 0 & 0.935 & 0.241 & 0 & 0 & 0.246 & 0 & 0 & 0.230 & 0 & 0 & 0 \\
\hline L019 & 0 & 0 & 0 & 0 & 0 & 0 & 0 & 0.448 & 0 & 0.16 & 0 & 0 & 0.483 & 0 & 0 & 0 & 0 & 0 & 0 & 0 & 0 \\
\hline L020 & 0 & 0 & 0 & 0 & 0 & 0 & 0 & 0 & 0.679 & 0 & 0 & 2.019 & 0 & 0 & 0 & 0 & 0 & 0.352 & 0 & 0 & 0 \\
\hline L021 & 0 & 0 & 0 & 0 & 0 & 0 & 0 & 0 & 0 & 0 & 0 & 0.001 & 0 & 0 & 0 & 0.035 & 0 & 0.299 & 0 & 0 & 0 \\
\hline L022 & 0 & 0 & 0 & 0 & 0 & 0 & 0 & 0 & 1.045 & 0 & 0 & 0 & 0 & 0 & 0 & 0 & 0 & 0.278 & 0 & 0 & 0 \\
\hline L023 & 0 & 0 & 0 & 0 & 0 & 0 & 0 & 0 & 0 & 0 & 0 & 0 & 0 & 0 & 0 & 0 & 0 & 0 & 0 & 0 & 0 \\
\hline L024 & 0 & 0 & 0 & 0 & 0 & 0 & 0 & 0 & 0 & 0 & 0 & 0.158 & 0 & 0 & 0 & 0 & 0 & 0 & 0 & 0 & 0 \\
\hline L025 & 0 & 0 & 0 & 0 & 0 & 0 & 0 & 0 & 0.39 & 0 & 0 & 0 & 0 & 0 & 0 & 0 & 0 & 0 & 0 & 0 & 0 \\
\hline L026 & 0 & 0 & 0 & 0 & 0 & 0 & 0 & 0 & 2.366 & 0 & 0 & 0.088 & 0 & 0 & 0 & 0.21 & 0 & 0 & 0 & 0 & 0 \\
\hline L027 & 0 & 0 & 0 & 0 & 0 & 0 & 0 & 0.324 & 0 & 0 & 0 & 0 & 0 & 0 & 0 & 0 & 0 & 0 & 0 & 0 & 0 \\
\hline L028 & 0 & 0 & 0 & 0 & 0 & 0 & 0 & 0 & 0 & 0 & 0 & 0 & 0 & 0 & 0 & 0 & 0 & 0 & 0 & 0 & 0 \\
\hline L029 & 0 & 0 & 0 & 0 & 0 & 0 & 0 & 0 & 0 & 0 & 0 & 0 & 0 & 0 & 0 & 0 & 0 & 0 & 0 & 0 & 0 \\
\hline L030 & 0 & 0 & 0 & 0 & 0 & 0 & 0 & 0.277 & 0 & 0 & 0 & 0 & 0 & 0 & 0 & 0 & 0 & 0.240 & 0 & 0 & 0 \\
\hline L031 & 0 & 0 & 0 & 0 & 0 & 0 & 0 & 0 & 0 & 0 & 0 & 0 & 0 & 0 & 0 & 0 & 0 & 0 & 0 & 0 & 0 \\
\hline L032 & 0 & 0 & 0 & 0 & 0 & 0 & 0 & 0 & 0 & 0 & 0 & 0 & 0 & 0 & 0 & 0 & 0 & 0 & 0 & 0 & 0 \\
\hline L033 & 0 & 0 & 0 & 0 & 0 & 0 & 0 & 0 & 4.435 & 0 & 0 & 1.307 & 0 & 0 & 0 & 0 & 0 & 0.249 & 0 & 0 & 0 \\
\hline L034 & 0 & 0 & 0 & 0 & 0 & 0 & 0 & 0 & 9.736 & 0 & 0 & 0.748 & 0 & 0 & 0 & 0 & 0 & 0 & 0 & 0 & 0 \\
\hline L035 & 0 & 0 & 0 & 0 & 0 & 0 & 0 & 0 & 1.544 & 0 & 0 & 0 & 0 & 0 & 0 & 0 & 0 & 1.322 & 0 & 0 & 0 \\
\hline L036 & 0 & 0 & 0 & 0 & 0 & 0 & 0 & 0 & 0 & 0 & 0 & 0 & 0 & 0 & 0.281 & 0 & 0 & 0 & 0 & 0 & 0 \\
\hline L037 & 0 & 0 & 0 & 0 & 0 & 0 & 0 & 0 & 0 & 0 & 1.306 & 0 & 0 & 0 & 0 & 0 & 0 & 0 & 0 & 0 & 0 \\
\hline L038 & 0 & 0 & 0 & 0 & 0 & 0 & 0 & 0 & 0 & 0 & 0 & 0 & 0 & 0 & 0 & 0 & 0 & 0 & 0 & 0 & 0 \\
\hline L039 & 0 & 0 & 0 & 0 & 0 & 0 & 0 & 0 & 0 & 0 & 0 & 0 & 0 & 0 & 0 & 0 & 0 & 0 & 0 & 0 & 0 \\
\hline
\end{tabular}


$\| 11111111111111$

\begin{tabular}{|c|c|c|c|c|c|c|c|c|c|c|c|c|c|c|c|c|c|c|c|c|c|}
\hline LOD & 1 & 1.5 & 1 & 1 & 1.5 & 1.5 & 1.5 & 1 & 1 & 1 & 1 & 1 & 1 & 1 & 1 & 2 & 2 & 1.27 & 0.4 & 0.2 & 0.5 \\
\hline L040 & 0 & 0 & 0 & 0 & 0 & 0 & 0 & 0 & 0 & 0 & 0 & 0 & 0 & 0 & 0 & 0 & 0 & 0 & 0 & 0 & 0 \\
\hline L041 & 0 & 0 & 0 & 0 & 0 & 0 & 0 & 0 & 0 & 0 & 0.126 & 0 & 0 & 0 & 0 & 0.367 & 0.985 & 0 & 0 & 0 & 0 \\
\hline L042 & 0 & 0 & 0 & 0 & 0 & 0 & 0 & 0 & 0.342 & 0 & 0 & 0 & 0 & 0 & 0 & 0 & 0 & 0 & 0 & 0 & 0 \\
\hline L043 & 0 & 0 & 0 & 0 & 0 & 0 & 0 & 0 & 0 & 0 & 0 & 0 & 0.426 & 0 & 0 & 0 & 0 & 0 & 0 & 0 & 0 \\
\hline L044 & 0 & 0 & 0 & 0 & 0 & 0 & 0 & 0 & 0 & 0 & 0 & 0.547 & 0 & 0 & 0 & 0 & 0 & 0 & 0 & 0 & 0 \\
\hline L045 & 0 & 0 & 0 & 0 & 0 & 0 & 0 & 0 & 0.147 & 0 & 0 & 0.093 & 0 & 0 & 0.376 & 0 & 0 & 0 & 0 & 0 & 0 \\
\hline L046 & 0 & 0 & 0 & 0 & 0 & 0 & 0 & 0 & 0 & 0 & 0 & 0 & 0 & 0 & 0 & 0 & 0 & 0 & 0 & 0 & 0 \\
\hline L047 & 0 & 0 & 0 & 0 & 0 & 0 & 0 & 0 & 0.454 & 0.099 & 1.111 & 0.065 & 0.014 & 0 & 0 & 0.042 & 0 & 0 & 0 & 0 & 0 \\
\hline L048 & 0 & 0 & 0 & 0 & 0 & 0 & 0 & 0.29 & 0.187 & 0.559 & 0 & 0 & 0.706 & 0 & 0 & 0 & 0 & 0 & 0 & 0 & 0 \\
\hline L049 & 0 & 0 & 0 & 0 & 0 & 0 & 0 & 0.228 & 0 & 0 & 0 & 0 & 0 & 0 & 0.122 & 0.142 & 0 & 0 & 0 & 0 & 0 \\
\hline L050 & 0 & 0 & 0 & 0 & 0 & 0 & 0 & 0 & 0 & 0.171 & 0 & 0 & 0 & 0 & 0.15 & 0 & 0 & 0 & 0 & 0 & 0 \\
\hline L051 & 0 & 0 & 0 & 0 & 0 & 0 & 0 & 0 & 0 & 0 & 0 & 0.232 & 0 & 0 & 0 & 0 & 0 & 0 & 0 & 0 & 0 \\
\hline L052 & 0 & 0 & 0 & 0 & 0 & 0 & 0 & 0.49 & 0 & 0 & 0 & 0 & 0 & 0 & 0 & 0 & 0 & 0 & 0 & 0 & 0 \\
\hline L053 & 0 & 0 & 0 & 0 & 0 & 0 & 0 & 0 & 0 & 0 & 0 & 0 & 0 & 0 & 0 & 0 & 0 & 0 & 0 & 0 & 0 \\
\hline L054 & 0 & 0 & 0 & 0 & 0 & 0 & 0 & 0.19 & 0 & 0 & 0 & 0 & 0 & 1.855 & 0 & 0 & 0 & 0 & 0 & 0 & 0 \\
\hline L055 & 0 & 0 & 0 & 0 & 0 & 0 & 0 & 0.041 & 0 & 0 & 0 & 0 & 0 & 0 & 0 & 0 & 0 & 0 & 0 & 0 & 0 \\
\hline L056 & 0 & 0 & 0 & 0 & 0 & 0 & 0 & 0 & 0.15 & 0 & 0 & 0 & 0 & 0 & 0 & 0 & 0 & 0 & 0 & 0 & 0 \\
\hline L057 & 0 & 0 & 0 & 0 & 0 & 0 & 0 & 0 & 0 & 0 & 0 & 0 & 0.067 & 0 & 0 & 0 & 0 & 0 & 0 & 0 & 0 \\
\hline L058 & 0 & 0 & 0 & 0 & 0 & 0 & 0 & 0 & 0 & 0 & 0.755 & 0 & 0 & 0 & 0 & 0 & 0 & 0 & 0 & 0 & 0 \\
\hline L059 & 0 & 0 & 0 & 0 & 0 & 0 & 0 & 0 & 0 & 0 & 0 & 0 & 0 & 0 & 0 & 0 & 0 & 0 & 0 & 0 & 0 \\
\hline L060 & 0 & 0 & 0 & 0 & 0 & 0 & 0 & 0 & 0 & 0.755 & 0 & 0 & 0 & 0 & 0 & 0 & 0 & 0 & 0 & 0 & 0 \\
\hline L061 & 0 & 0 & 0 & 0 & 0 & 0 & 0 & 0 & 0 & 0 & 0 & 0 & 0 & 0 & 0 & 0 & 0 & 0 & 0 & 0 & 0 \\
\hline L062 & 0 & 0 & 0 & 0 & 0 & 0 & 0 & 0 & 0 & 0 & 2.287 & 0.066 & 0 & 0 & 0 & 0 & 0 & 0 & 0 & 0 & 0 \\
\hline L063 & 0 & 0 & 0 & 0 & 0 & 0 & 0 & 0 & 0 & 0 & 0 & 0 & 0 & 0 & 0 & 0 & 0 & 0 & 0 & 0 & 0 \\
\hline L064 & 0 & 0 & 0 & 0 & 0 & 0 & 0 & 0.137 & 0 & 0.085 & 0 & 0.164 & 0 & 0 & 0 & 0 & 0 & 0 & 0 & 0 & 0 \\
\hline L065 & 0 & 0 & 0 & 0 & 0 & 0 & 0 & 0 & 0 & 0 & 0 & 0 & 0 & 0.297 & 0 & 0 & 0 & 0 & 0 & 0 & 0 \\
\hline L066 & 0 & 0 & 0 & 0 & 0 & 0 & 0 & 0 & 0 & 0 & 0 & 0 & 0 & 0 & 0 & 0 & 0 & 0 & 0 & 0 & 0 \\
\hline
\end{tabular}


Appendix 3. Concentrations of 21 organochlorine pesticides found in all 531 persistent organic pollutant samples collected in the Lower Mekong River Basin during

\begin{tabular}{|c|c|c|c|c|c|c|c|c|c|c|c|c|c|c|c|c|c|c|c|c|c|}
\hline 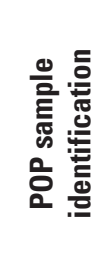 & 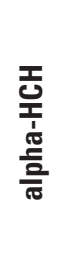 & 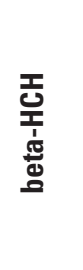 & 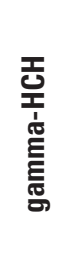 & 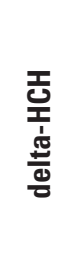 & 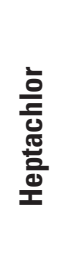 & $\frac{\text { 흔 }}{\frac{1}{\alpha}}$ & 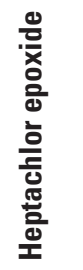 & 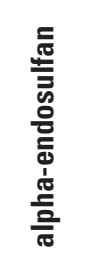 & $\begin{array}{l}\text { 㟔 } \\
\text { 号 } \\
\text { 过 }\end{array}$ & 든 & 站 & 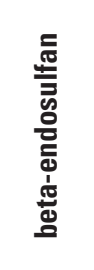 & $\begin{array}{l}\text { 只 } \\
\text { 号 } \\
\text { 过 }\end{array}$ & 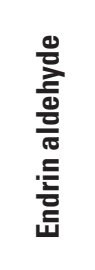 & 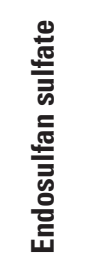 & $\begin{array}{l}\text { 合 } \\
0 \\
\text { 过 }\end{array}$ & 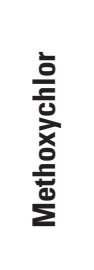 & 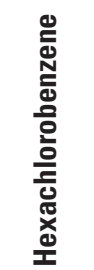 & 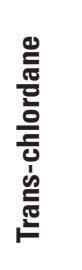 & 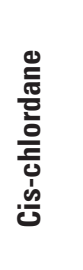 & 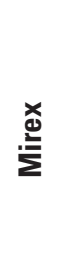 \\
\hline LOD & 1 & 1.5 & 1 & 1 & 1.5 & 1.5 & 1.5 & 1 & 1 & 1 & 1 & 1 & 1 & 1 & 1 & 2 & 2 & 1.27 & 0.4 & 0.2 & 0.5 \\
\hline L067 & 0 & 0 & 0 & 0 & 0 & 0 & 0 & 0 & 0 & 0 & 0.079 & 0 & 0.13 & 0 & 0.036 & 0 & 0 & 0 & 0 & 0 & 0 \\
\hline L068 & 0 & 0 & 0 & 0 & 0 & 0 & 0 & 0 & 0 & 0 & 0 & 0 & 0 & 0 & 0 & 0 & 0 & 0 & 0 & 0 & 0 \\
\hline L069 & 0 & 0 & 0 & 0 & 0 & 0 & 0 & 0 & 2.551 & 0 & 0 & 0 & 0 & 0 & 0 & 0 & 1.079 & 0 & 0 & 0 & 0 \\
\hline L070 & 0 & 0 & 0 & 0 & 0 & 0 & 0 & 0.566 & 0.753 & 0 & 0 & 0 & 0 & 0 & 0.668 & 0 & 0 & 0 & 0 & 0 & 0 \\
\hline L071 & 0 & 0 & 0 & 0 & 0 & 0 & 0 & 0 & 0 & 0 & 0 & 0 & 0 & 0 & 0 & 0 & 0 & 0 & 0 & 0 & 0 \\
\hline L072 & 0 & 0 & 0 & 0 & 0 & 0 & 0 & 0 & 0 & 0 & 2.303 & 0 & 0 & 0 & 0 & 0 & 0 & 0 & 0 & 0 & 0 \\
\hline L073 & 0 & 0 & 0 & 0 & 0 & 0 & 0 & 0 & 1.803 & 0 & 0.26 & 0 & 0 & 0 & 0 & 0.42 & 0 & 0.264 & 0 & 0 & 0 \\
\hline L074 & 0 & 0 & 0 & 0 & 0 & 0 & 0 & 0 & 0.558 & 0 & 0 & 0 & 0 & 0 & 0 & 0 & 0 & 0 & 0 & 0 & 0 \\
\hline L075 & 0 & 0 & 0 & 0 & 0 & 0 & 0 & 0 & 0 & 0 & 1.363 & 0 & 0 & 0 & 0 & 0 & 0 & 0 & 0 & 0 & 0 \\
\hline L076 & 0 & 0 & 0 & 0 & 0 & 0 & 0 & 0.29 & 0 & 0 & 0 & 0 & 0 & 0 & 0 & 0 & 0.555 & 0 & 0 & 0 & 0 \\
\hline L077 & 0 & 0 & 0 & 0 & 0 & 0 & 0 & 0 & 5.928 & 0 & 0 & 0.238 & 0 & 0 & 0 & 0 & 0 & 0 & 0 & 0 & 0 \\
\hline L078 & 0 & 0 & 0 & 0 & 0 & 0 & 0 & 0 & 0 & 0 & 0.824 & 0 & 0 & 0.111 & 0 & 0 & 0 & 0 & 0 & 0 & 0 \\
\hline L079 & 0 & 0 & 0 & 0 & 0 & 0 & 0 & 0 & 0.624 & 0 & 0 & 0 & 0 & 1.569 & 0 & 0 & 0 & 0 & 0 & 0 & 0 \\
\hline L080 & 0 & 0 & 0 & 0 & 0 & 0 & 0 & 0 & 0 & 0 & 0 & 0 & 0 & 0 & 0 & 0 & 0 & 0 & 0 & 0 & 0 \\
\hline L081 & 0 & 0 & 0 & 0 & 0 & 0 & 0 & 0 & 0 & 0 & 0 & 0 & 0 & 1.269 & 0 & 0 & 0 & 0 & 0 & 0 & 0 \\
\hline L082 & 0 & 0 & 0 & 0 & 0 & 0 & 0 & 0 & 0 & 0.226 & 0 & 0 & 0 & 0 & 0 & 0 & 0 & 0 & 0 & 0 & 0 \\
\hline L083 & 0 & 0 & 0 & 0 & 0 & 0 & 0 & 0 & 0.677 & 0 & 1.246 & 0 & 0 & 0 & 0 & 0 & 0 & 0 & 0 & 0 & 0 \\
\hline L084 & 0 & 0 & 0 & 0 & 0 & 0 & 0 & 0 & 0 & 0 & 0 & 0 & 0 & 0 & 0 & 0 & 0 & 0 & 0 & 0 & 0 \\
\hline L085 & 0 & 0 & 0 & 0 & 0 & 0 & 0 & 0 & 0 & 0 & 0 & 0 & 0 & 0 & 0 & 0 & 0 & 0 & 0 & 0 & 0 \\
\hline L086 & 0 & 0 & 0 & 0 & 0 & 0 & 0 & 0 & 0 & 0 & 0.768 & 0.265 & 0 & 0 & 0 & 0.405 & 0 & 0 & 0 & 0 & 0 \\
\hline L087 & 0 & 0 & 0 & 0 & 0 & 0 & 0 & 0 & 0 & 0 & 0 & 0.1 & 1.414 & 1.414 & 0 & 0 & 0 & 0 & 0 & 0 & 0 \\
\hline L088 & 0 & 0 & 0 & 0 & 0 & 0 & 0 & 0.126 & 0 & 0 & 0 & 0 & 0.074 & 0 & 0 & 0 & 0 & 0 & 0 & 0 & 0 \\
\hline L089 & 0 & 0 & 0 & 0 & 0 & 0 & 0 & 0 & 0 & 0 & 0 & 0.215 & 0 & 0 & 0 & 0 & 0 & 0 & 0 & 0 & 0 \\
\hline L090 & 0 & 0 & 0 & 0 & 0 & 0 & 0 & 0 & 0 & 0 & 0 & 0.182 & 0 & 0 & 0 & 0.532 & 0 & 3.764 & 0 & 0 & 0 \\
\hline
\end{tabular}


\|\|\|\|\|\|\|\|\|\|$\|$

\begin{tabular}{|c|c|c|c|c|c|c|c|c|c|c|c|c|c|c|c|c|c|c|c|c|c|}
\hline LOD & 1 & 1.5 & 1 & 1 & 1.5 & 1.5 & 1.5 & 1 & 1 & 1 & 1 & 1 & 1 & 1 & 1 & 2 & 2 & 1.27 & 0.4 & 0.2 & 0.5 \\
\hline L091 & 0 & 0 & 0 & 0 & 0 & 0 & 0 & 0 & 0 & 0 & 0.986 & 0 & 0 & 0 & 0 & 0 & 0 & 0 & 0 & 0 & 0 \\
\hline L092 & 0 & 0 & 0 & 0 & 0 & 0 & 0 & 0 & 0 & 0 & 0 & 0.312 & 0 & 0 & 0 & 0 & 0 & 0 & 0 & 0 & 0 \\
\hline L093 & 0 & 0 & 0 & 0 & 0 & 0 & 0 & 0 & 0 & 0.06 & 1.02 & 0 & 0 & 0 & 0.228 & 0 & 0 & 0 & 0 & 0 & 0 \\
\hline L094 & 0 & 0 & 0 & 0 & 0 & 0 & 0 & 0 & 0 & 0 & 0 & 0 & 0.253 & 0 & 0 & 0 & 0 & 0 & 0 & 0 & 0 \\
\hline L095 & 0 & 0 & 0 & 0 & 0 & 0 & 0 & 0 & 1.91 & 0 & 0 & 0 & 0 & 0 & 0.11 & 0 & 0 & 0 & 0 & 0 & 0 \\
\hline L096 & 0 & 0 & 0 & 0 & 0 & 0 & 0 & 0 & 0.134 & 0 & 0 & 1.139 & 0 & 0 & 0 & 0 & 0 & 0 & 0 & 0 & 0 \\
\hline L097 & 0 & 0 & 0 & 0 & 0 & 0 & 0 & 0 & 0.125 & 0.117 & 0.766 & 0.19 & 0 & 0 & 0.172 & 0.062 & 0 & 0 & 0 & 0 & 0 \\
\hline L098 & 0 & 0 & 0 & 0 & 0 & 0 & 0 & 0 & 0 & 0 & 0 & 0 & 0 & 0 & 0 & 0 & 0 & 0 & 0 & 0 & 0 \\
\hline L099 & 0 & 0 & 0 & 0 & 0 & 0 & 0 & 0 & 0.585 & 0 & 0 & 0 & 0 & 0 & 0 & 0 & 0 & 0 & 0 & 0 & 0 \\
\hline L100 & 0 & 0 & 0 & 0 & 0 & 0 & 0 & 0 & 0 & 0 & 0 & 0 & 0 & 0 & 0 & 0 & 0 & 0 & 0 & 0 & 0 \\
\hline L101 & 0 & 0 & 0 & 0 & 0 & 0 & 0 & 0 & 0 & 0 & 1.449 & 0 & 0 & 0.558 & 0 & 0 & 0 & 0 & 0 & 0 & 0 \\
\hline L102 & 0 & 0 & 0 & 0 & 0 & 0 & 0 & 0 & 0 & 0 & 0 & 0 & 0 & 0 & 0 & 0 & 0 & 0 & 0 & 0 & 0 \\
\hline L103 & 0 & 0 & 0 & 0 & 0 & 0 & 0 & 0 & 0 & 0 & 0.331 & 0 & 0 & 0 & 0 & 0 & 0 & 0 & 0 & 0 & 0 \\
\hline L104 & 0 & 0 & 0 & 0 & 0 & 0 & 0 & 0 & 1.743 & 0 & 0 & 0 & 0 & 0 & 0.012 & 0 & 0 & 0 & 0 & 0 & 0 \\
\hline L105 & 0 & 0 & 0 & 0 & 0 & 0 & 0 & 0 & 0 & 0 & 0 & 0 & 0 & 0 & 0 & 0 & 0 & 0 & 0 & 0 & 0 \\
\hline L106 & 0 & 0 & 0 & 0 & 0 & 0 & 0 & 0 & 0 & 0 & 0 & 0 & 0 & 0 & 0 & 0 & 0 & 0 & 0 & 0 & 0 \\
\hline L107 & 0 & 0 & 0 & 0 & 0 & 0 & 0 & 0.368 & 0 & 0 & 0 & 0 & 0 & 0.972 & 0 & 0 & 0 & 0 & 0 & 0 & 0 \\
\hline L108 & 0 & 0 & 0 & 0 & 0 & 0 & 0 & 0 & 0 & 0 & 0 & 0 & 0 & 0 & 0 & 0 & 0 & 0 & 0 & 0 & 0 \\
\hline L109 & 0 & 0 & 0 & 0 & 0 & 0 & 0 & 0 & 0 & 0 & 0 & 0 & 0 & 0 & 0 & 0 & 0 & 0 & 0 & 0 & 0 \\
\hline L110 & 0 & 0 & 0 & 0 & 0 & 0 & 0 & 0 & 0 & 0 & 0 & 0 & 0 & 0 & 0 & 0 & 0 & 0 & 0 & 0 & 0 \\
\hline L111 & 0 & 0 & 0 & 0 & 0 & 0 & 0 & 0 & 1.222 & 0 & 0.064 & 0 & 0 & 0 & 0 & 0.751 & 0 & 0 & 0 & 0 & 0 \\
\hline L112 & 0 & 0 & 0 & 0 & 0 & 0 & 0 & 0 & 0 & 0 & 0 & 0 & 0 & 0 & 0 & 0 & 0 & 0 & 0 & 0 & 0 \\
\hline L113 & 0 & 0 & 0 & 0 & 0 & 0 & 0 & 0 & 0 & 0 & 0 & 0 & 0 & 0 & 0.08 & 0 & 0 & 0 & 0 & 0 & 0 \\
\hline L114 & 0 & 0 & 0 & 0 & 0 & 0 & 0 & 0 & 0 & 0 & 0 & 0 & 0 & 0 & 0 & 0 & 0.358 & 0 & 0 & 0 & 0 \\
\hline L115 & 0 & 0 & 0 & 0 & 0 & 0 & 0 & 0 & 0.262 & 0 & 0 & 0 & 0 & 0 & 0 & 0 & 0 & 0 & 0 & 0 & 0 \\
\hline L116 & 0 & 0 & 0 & 0 & 0 & 0 & 0 & 0 & 0 & 0 & 0 & 0.038 & 0 & 0 & 0 & 0 & 0 & 0 & 0 & 0 & 0 \\
\hline L117 & 0 & 0 & 0 & 0 & 0 & 0 & 0 & 0 & 0 & 0 & 0 & 0 & 0 & 0.485 & 0 & 0 & 0 & 0 & 0 & 0 & 0 \\
\hline
\end{tabular}


Appendix 3. Concentrations of 21 organochlorine pesticides found in all 531 persistent organic pollutant samples collected in the Lower Mekong River Basin during

\begin{tabular}{|c|c|c|c|c|c|c|c|c|c|c|c|c|c|c|c|c|c|c|c|c|c|}
\hline 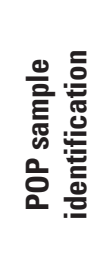 & 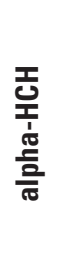 & 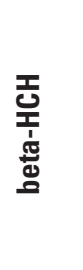 & 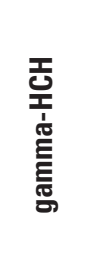 & 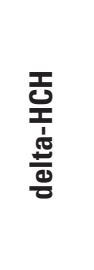 & 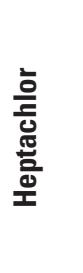 & $\frac{\text { 튼 }}{\frac{0}{\alpha}}$ & 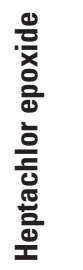 & 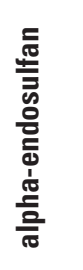 & $\begin{array}{l}\text { 㟔 } \\
0 \\
\dot{0} \\
\dot{0}\end{array}$ & $\frac{\text { 트ㄴㅡㅡㅁ }}{\frac{0}{6}}$ & 砑 & 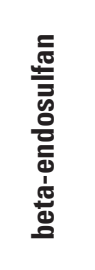 & $\begin{array}{l}\text { 只 } \\
\text { 只 } \\
\text { 莳 }\end{array}$ & 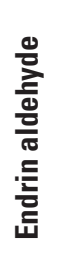 & 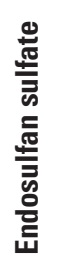 & $\begin{array}{l}\text { 合 } \\
\text { 号 } \\
\text { 过 }\end{array}$ & 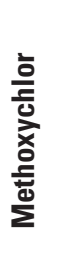 & 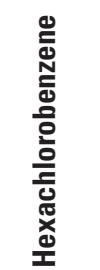 & 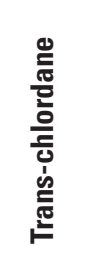 & 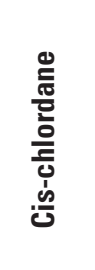 & 亳 \\
\hline LOD & 1 & 1.5 & 1 & 1 & 1.5 & 1.5 & 1.5 & 1 & 1 & 1 & 1 & 1 & 1 & 1 & 1 & 2 & 2 & 1.27 & 0.4 & 0.2 & 0.5 \\
\hline L118 & 0 & 0 & 0 & 0 & 0 & 0 & 0 & 0 & 0 & 0.592 & 0 & 0.927 & 0.143 & 0 & 0 & 1.98 & 0 & 0 & 0 & 0 & 0 \\
\hline L119 & 0 & 0 & 0 & 0 & 0 & 0 & 0 & 0 & 0 & 0 & 1.357 & 0 & 0 & 0 & 0 & 0 & 0 & 0 & 0 & 0 & 0 \\
\hline L120 & 0 & 0 & 0 & 0 & 0 & 0 & 0 & 0 & 0.424 & 0 & 2.78 & 0 & 0 & 0 & 0 & 0 & 0 & 0 & 0 & 0 & 0 \\
\hline M001 & 0 & 0 & 0 & 0 & 0 & 0 & 0 & 0 & 0 & 0 & 0 & 0 & 0 & 0 & 0 & 0 & 0 & 0 & 0 & 0 & 0 \\
\hline M002 & 0 & 0 & 0 & 0 & 0 & 0 & 0 & 0 & 0.207 & 0 & 0 & 0 & 0 & 0 & 0 & 0 & 0 & 0 & 0 & 0 & 0 \\
\hline M003 & 0 & 0 & 0 & 0 & 0 & 0 & 0 & 0 & 0.893 & 0 & 0 & 1.129 & 0 & 0 & 0 & 0 & 0 & 0.425 & 0 & 0 & 0 \\
\hline M004 & 0 & 0 & 0 & 0 & 0 & 0 & 0 & 0 & 0 & 0 & 0 & 1.121 & 0 & 0 & 0 & 0 & 0 & 0 & 0 & 0 & 0 \\
\hline M005 & 0 & 0 & 0 & 0 & 0 & 0 & 0 & 0 & 0 & 0 & 0 & 0 & 0 & 0 & 0 & 0 & 0 & 0 & 0 & 0 & 0 \\
\hline M006 & 0 & 0 & 0 & 0 & 0 & 0 & 0 & 0 & 0.988 & 0 & 0 & 0 & 0 & 0 & 0 & 0 & 0 & 0 & 0 & 0 & 0 \\
\hline M007 & 0 & 0 & 0 & 1.272 & 0 & 0 & 0 & 0 & 0.983 & 0 & 0 & 0.556 & 0 & 0 & 0 & 0 & 0 & 0 & 0 & 0 & 0 \\
\hline M008 & 0 & 0 & 0.045 & 0 & 0 & 0 & 0 & 0 & 0.561 & 0 & 0 & 0 & 0 & 0 & 0 & 0 & 0 & 0.771 & 0 & 0.233 & 0 \\
\hline M009 & 0 & 0 & 0 & 0 & 0 & 0 & 0 & 0 & 0.910 & 0 & 0 & 0.805 & 0 & 0 & 0 & 0 & 0 & 0 & 0 & 0 & 0 \\
\hline M010 & 0 & 0 & 0 & 0 & 0 & 0 & 0 & 0 & 0.918 & 0 & 0 & 1.518 & 0 & 0 & 0 & 0 & 0 & 0.415 & 0 & 0 & 0 \\
\hline M011 & 0 & 0 & 0 & 0 & 0 & 0 & 0 & 0 & 0.261 & 0 & 0 & 0 & 0 & 0 & 0 & 0 & 0 & 0.147 & 0 & 0 & 0 \\
\hline M012 & 0 & 0 & 0 & 0 & 0 & 0 & 0 & 0 & 0.636 & 0 & 0.383 & 0 & 0 & 0 & 0 & 0 & 0 & 0 & 0 & 0 & 0 \\
\hline M013 & 0 & 0 & 0 & 0 & 0 & 0 & 0 & 0 & 0 & 0 & 0 & 1.041 & 0 & 0 & 0 & 0 & 0 & 0.734 & 0 & 0.269 & 0 \\
\hline M014 & 0 & 0 & 0 & 0 & 0 & 0 & 0 & 0 & 0.264 & 0 & 0 & 0 & 0 & 0 & 0 & 0 & 0 & 0.692 & 0 & 0 & 0 \\
\hline M015 & 0 & 0 & 0 & 0 & 0 & 0 & 0 & 0 & 0.248 & 0 & 0 & 0 & 0 & 0 & 0 & 0 & 0 & 0.383 & 0 & 0 & 0 \\
\hline M016 & 0 & 0 & 0 & 0 & 0 & 0 & 0 & 0 & 0.338 & 0 & 0 & 0 & 0 & 0 & 0 & 0 & 0 & 2.191 & 0 & 0 & 0 \\
\hline M017 & 0 & 0 & 0 & 0 & 0 & 0 & 0 & 0 & 0.399 & 0 & 0 & 0 & 0 & 0 & 0 & 0 & 0 & 0.495 & 0 & 0 & 0 \\
\hline M018 & 0 & 0 & 0 & 0 & 0 & 0 & 0 & 0 & 0.306 & 0 & 0 & 0 & 0 & 0 & 0 & 0 & 0 & 0.852 & 0 & 0 & 0 \\
\hline M019 & 0 & 0 & 0 & 0 & 0 & 0 & 0 & 0 & 1.995 & 0 & 0 & 0 & 0 & 0 & 0 & 0 & 0 & 0.813 & 0.513 & 0 & 0 \\
\hline
\end{tabular}




\section{$\|1111\| 111111 \| 11$}

\begin{tabular}{|c|c|c|c|c|c|c|c|c|c|c|c|c|c|c|c|c|c|c|c|c|c|}
\hline LOD & 1 & 1.5 & 1 & 1 & 1.5 & 1.5 & 1.5 & 1 & 1 & 1 & 1 & 1 & 1 & 1 & 1 & 2 & 2 & 1.27 & 0.4 & 0.2 & 0.5 \\
\hline M020 & 0 & 0 & 0 & 0 & 0 & 0 & 0 & 0 & 0 & 0 & 0 & 0.683 & 0 & 0 & 0 & 0 & 0 & 0.274 & 0 & 0 & 0 \\
\hline M021 & 0 & 0 & 0 & 0 & 0 & 0 & 0 & 0 & 0.293 & 0 & 0 & 0.068 & 0 & 0 & 0 & 0 & 0 & 0 & 0 & 0 & 0 \\
\hline M022 & 0 & 0 & 0 & 0 & 0 & 0 & 0 & 0 & 0.843 & 0 & 0 & 0 & 0 & 0 & 0 & 0 & 0 & 0.440 & 0 & 0 & 0 \\
\hline M023 & 0 & 0 & 0 & 0 & 0 & 0 & 0 & 0 & 0 & 0 & 0 & 0 & 0 & 0 & 0 & 0 & 0 & 0.142 & 0 & 0 & 0 \\
\hline M024 & 0 & 0 & 0 & 0 & 0 & 0 & 0 & 0 & 0.170 & 0 & 0 & 0.442 & 0 & 0.889 & 0 & 0 & 0 & 0 & 0 & 0 & 0 \\
\hline M025 & 0 & 0 & 0 & 0 & 0 & 0 & 0 & 0 & 0.939 & 0 & 0 & 2.513 & 0 & 0 & 0 & 4.835 & 0 & 0 & 0 & 0.445 & 0 \\
\hline M026 & 0 & 0 & 0 & 0 & 0 & 0 & 0 & 0 & 0.200 & 0 & 0 & 0 & 0 & 0 & 0 & 0 & 0 & 0.878 & 0 & 0 & 0 \\
\hline M027 & 0 & 0 & 0 & 0 & 0 & 0 & 0 & 0 & 1.000 & 0 & 0 & 1.078 & 0 & 0 & 0 & 0 & 0 & 0.916 & 0 & 0 & 0 \\
\hline M028 & 0 & 0 & 0 & 0 & 0 & 0 & 0 & 0 & 1.122 & 0 & 0 & 0 & 0 & 0 & 0 & 0 & 0 & 0.640 & 0 & 0 & 0 \\
\hline M029 & 0 & 0 & 0 & 0 & 0 & 0 & 0 & 0 & 1.548 & 0 & 0 & 1.184 & 0 & 0 & 0 & 0 & 0 & 0.941 & 0 & 0 & 0 \\
\hline M030 & 0 & 0 & 0 & 0 & 0 & 0 & 0 & 0 & 0.493 & 0 & 0 & 0.629 & 0 & 0 & 0 & 3.974 & 0 & 0 & 0 & 0 & 0 \\
\hline T101 & 0 & 0 & 0 & 0 & 0 & 0 & 0 & 0 & 0 & 0 & 0 & 0 & 0 & 0 & 0 & 0 & 0 & 0 & 0 & 0 & 0 \\
\hline $\mathrm{T} 102$ & 0 & 0 & 0 & 0 & 0 & 0 & 0 & 0 & 0 & 0 & 0 & 0 & 0 & 0 & 0 & 0 & 0 & 0 & 0 & 0 & 0 \\
\hline T103 & 0 & 0 & 0 & 0 & 0 & 0 & 0 & 0 & 0 & 0 & 0 & 0 & 0 & 0 & 0 & 0 & 0 & 0 & 0 & 0 & 0 \\
\hline T104 & 0 & 0 & 0 & 0 & 0 & 0 & 0 & 0 & 0 & 0 & 0 & 0 & 0 & 0 & 0 & 0 & 0 & 0 & 0 & 0 & 0 \\
\hline T105 & 0 & 0 & 0 & 0 & 0 & 0 & 0 & 0 & 0 & 0 & 0 & 0 & 0 & 0 & 0 & 0 & 0 & 0.224 & 0 & 0 & 0 \\
\hline T106 & 0 & 0 & 0 & 0 & 0 & 0 & 0 & 0 & 0 & 0 & 0 & 0 & 0 & 0 & 0 & 0 & 0 & 0 & 0 & 0 & 0 \\
\hline T107 & 0 & 0 & 0 & 0 & 0 & 0 & 0 & 0 & 0.547 & 0 & 0 & 0 & 0 & 0 & 0 & 0 & 0 & 0 & 0 & 0 & 0 \\
\hline T108 & 0 & 0 & 0 & 0 & 0 & 0 & 0 & 0 & 0 & 0 & 0 & 0 & 0 & 0 & 0 & 0 & 0 & 0 & 0 & 0 & 0 \\
\hline T109 & 0 & 0 & 0 & 0 & 0 & 0 & 0 & 0 & 0 & 0 & 0 & 0 & 0 & 0 & 0 & 0 & 0 & 0 & 0 & 0 & 0 \\
\hline $\mathrm{T} 110$ & 0 & 0 & 0 & 0 & 0 & 0 & 0 & 0 & 0.816 & 0 & 0 & 0 & 0 & 0 & 0 & 0 & 0 & 0 & 0 & 0 & 0 \\
\hline $\mathrm{T} 111$ & 0 & 0 & 0 & 0 & 0 & 0 & 0 & 0 & 0 & 0 & 0 & 0 & 0 & 0 & 0 & 0 & 0 & 0 & 0 & 0 & 0 \\
\hline $\mathrm{T} 112$ & 0 & 0 & 0 & 0 & 0 & 0 & 0 & 0 & 0 & 0 & 0 & 0 & 0 & 0 & 0 & 0 & 0 & 0 & 0 & 0 & 0 \\
\hline T113 & 0 & 0 & 0 & 0 & 0 & 0 & 0 & 0 & 0 & 0 & 0 & 0 & 0 & 0 & 0 & 0 & 0 & 0 & 0 & 0 & 0 \\
\hline $\mathrm{T} 114$ & 0 & 0 & 0 & 0 & 0 & 0 & 0 & 0 & 0 & 0 & 0 & 0 & 0 & 0 & 0 & 0 & 0 & 0 & 0 & 0 & 0 \\
\hline T115 & 0 & 0 & 0 & 0 & 0 & 0 & 0 & 0 & 0.208 & 0 & 0 & 0 & 0 & 0 & 0 & 0 & 0 & 0 & 0 & 0 & 0 \\
\hline T116 & 0 & 0 & 0 & 0 & 0 & 0 & 0 & 0 & 0 & 0 & 0 & 0 & 0 & 0 & 0 & 0 & 0 & 0 & 0 & 0 & 0 \\
\hline
\end{tabular}


Appendix 3. Concentrations of 21 organochlorine pesticides found in all 531 persistent organic pollutant samples collected in the Lower Mekong River Basin during

\begin{tabular}{|c|c|c|c|c|c|c|c|c|c|c|c|c|c|c|c|c|c|c|c|c|c|}
\hline 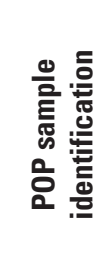 & 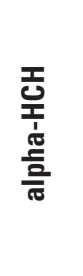 & 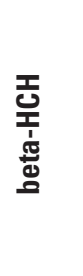 & 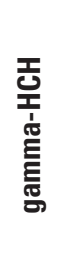 & 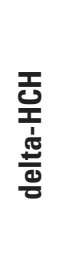 & $\begin{array}{l}\text { 흘 } \\
\text { 를 } \\
\text { ㅎّㅎ } \\
\text { 호 }\end{array}$ & 흔흐 & 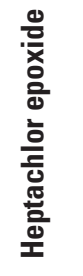 & 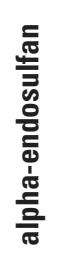 & $\begin{array}{l}\text { 岁 } \\
\text { 口 } \\
\text { 过 }\end{array}$ & $\frac{\text { 튼흥 }}{\frac{0}{0}}$ & 흔 & 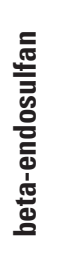 & $\begin{array}{l}\text { 웅 } \\
\text { 只 } \\
\text { 广் }\end{array}$ & 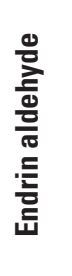 & 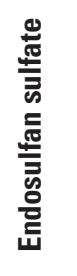 & 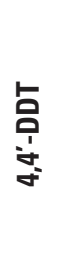 & 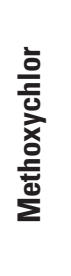 & 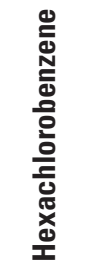 & 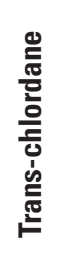 & 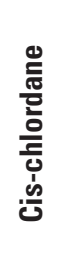 & 离 \\
\hline LOD & 1 & 1.5 & 1 & 1 & 1.5 & 1.5 & 1.5 & 1 & 1 & 1 & 1 & 1 & 1 & 1 & 1 & 2 & 2 & 1.27 & 0.4 & 0.2 & 0.5 \\
\hline T117 & 0 & 0 & 0 & 0 & 0 & 0 & 0 & 0 & 0.415 & 0 & 0 & 0 & 0 & 0 & 0 & 0 & 0 & 0 & 0 & 0 & 0 \\
\hline T118 & 0 & 0 & 0 & 0 & 0 & 0 & 0 & 0 & 0 & 0 & 0 & 0 & 0 & 0 & 0 & 0 & 0 & 0 & 0 & 0 & 0 \\
\hline $\mathrm{T} 119$ & 0 & 0 & 0 & 0 & 0 & 0 & 0 & 0 & 0 & 0 & 0 & 0 & 0 & 0 & 0 & 0 & 0 & 0 & 0 & 0 & 0 \\
\hline $\mathrm{T} 120$ & 0 & 0 & 0 & 0 & 0 & 0 & 0 & 0 & 0 & 0 & 0 & 0 & 0 & 0 & 0 & 0 & 0 & 0 & 0 & 0 & 0 \\
\hline $\mathrm{T} 121$ & 0 & 0 & 0 & 0 & 0 & 0 & 0 & 0 & 0.466 & 0 & 0 & 0 & 0 & 0 & 0 & 0 & 0 & 0 & 0 & 0 & 0 \\
\hline T201 & 0 & 0 & 0 & 0 & 0 & 0 & 0 & 0 & 0 & 0 & 0 & 0 & 0 & 0 & 0 & 0 & 0 & 0 & 0 & 0 & 0 \\
\hline T202 & 0 & 0 & 0 & 0 & 0 & 0 & 0 & 0 & 0 & 0 & 0 & 0 & 0 & 0 & 0 & 0 & 0 & 0 & 0 & 0 & 0 \\
\hline T203 & 0 & 0 & 0 & 0 & 0 & 0 & 0 & 0 & 0 & 0 & 0 & 0 & 0 & 0 & 0 & 0 & 0 & 0 & 0 & 0 & 0 \\
\hline T204 & 0 & 0 & 0 & 0 & 0 & 0 & 0 & 0 & 0 & 0 & 0 & 0 & 0 & 0 & 0 & 0 & 0 & 0.242 & 0 & 0 & 0 \\
\hline T205 & 0 & 0 & 0 & 0 & 0 & 0 & 0 & 0 & 0 & 0 & 0 & 0 & 0 & 0 & 0 & 0 & 0 & 0 & 0 & 0 & 0 \\
\hline T206 & 0 & 0 & 0 & 0 & 0 & 0 & 0 & 0 & 0.034 & 0 & 0 & 0 & 0 & 0 & 0 & 0 & 0 & 0 & 0 & 0 & 0 \\
\hline T207 & 0 & 0 & 0 & 0 & 0 & 0 & 0 & 0 & 0 & 0 & 0 & 0 & 0 & 0 & 0 & 0 & 0 & 0 & 0 & 0 & 0 \\
\hline T208 & 0 & 0 & 0 & 0 & 0 & 0 & 0 & 0 & 0 & 0 & 0 & 0 & 0 & 0 & 0 & 0 & 0 & 0 & 0 & 0 & 0 \\
\hline T209 & 0 & 0 & 0 & 0 & 0 & 0 & 0 & 0 & 0 & 0 & 0 & 0 & 0 & 0 & 0 & 0 & 0 & 0 & 0 & 0 & 0 \\
\hline $\mathrm{T} 210$ & 0 & 0 & 0 & 0 & 0 & 0 & 0 & 0 & 0 & 0 & 0 & 0 & 0 & 0 & 0 & 0 & 0 & 0 & 0 & 0 & 0 \\
\hline $\mathrm{T} 211$ & 0 & 0 & 0 & 0 & 0 & 0 & 0 & 0 & 0 & 0 & 0 & 0 & 0 & 0 & 0 & 0 & 0 & 0 & 0 & 0 & 0 \\
\hline $\mathrm{T} 212$ & 0 & 0 & 0 & 0 & 0 & 0 & 0 & 0 & 0 & 0 & 0 & 0 & 0 & 0 & 0 & 0 & 0 & 0 & 0 & 0 & 0 \\
\hline $\mathrm{T} 213$ & 0 & 0 & 0 & 0 & 0 & 0 & 0 & 0 & 0 & 0 & 0 & 0 & 0 & 0 & 0 & 0 & 0 & 0.343 & 0 & 0 & 0 \\
\hline $\mathrm{T} 214$ & 0 & 0 & 0 & 0 & 0 & 0 & 0 & 0 & 0.33 & 0 & 0 & 0 & 0 & 0 & 0 & 0 & 0 & 0 & 0 & 0 & 0 \\
\hline $\mathrm{T} 215$ & 0 & 0 & 0 & 0 & 0 & 0 & 0 & 0 & 0 & 0 & 0 & 0 & 0 & 0 & 0 & 0 & 0 & 0 & 0 & 0 & 0 \\
\hline T216 & 0 & 0 & 0 & 0 & 0 & 0 & 0 & 0 & 0 & 0 & 0 & 0 & 0 & 0 & 0 & 0 & 0 & 0 & 0 & 0 & 0 \\
\hline $\mathrm{T} 217$ & 0 & 0 & 0 & 0 & 0 & 0 & 0 & 0 & 0 & 0 & 0 & 0 & 0 & 0 & 0 & 0 & 0 & 0 & 0 & 0 & 0 \\
\hline
\end{tabular}


\|\|\|\|\|\|\|\|\|\|$\|$

\begin{tabular}{|c|c|c|c|c|c|c|c|c|c|c|c|c|c|c|c|c|c|c|c|c|c|}
\hline LOD & 1 & 1.5 & 1 & 1 & 1.5 & 1.5 & 1.5 & 1 & 1 & 1 & 1 & 1 & 1 & 1 & 1 & 2 & 2 & 1.27 & 0.4 & 0.2 & 0.5 \\
\hline T218 & 0 & 0 & 0 & 0 & 0 & 0 & 0 & 0 & 0 & 0 & 0 & 0 & 0 & 0 & 0 & 0 & 0 & 0 & 0 & 0 & 0 \\
\hline T219 & 0 & 0 & 0 & 0 & 0 & 0 & 0 & 0 & 0 & 0 & 0 & 0 & 0 & 0 & 0 & 0 & 0 & 0 & 0 & 0 & 0 \\
\hline $\mathrm{T} 220$ & 0 & 0 & 0 & 0 & 0 & 0 & 0 & 0 & 0 & 0 & 0 & 0 & 0 & 0 & 0 & 0 & 0 & 0 & 0 & 0 & 0 \\
\hline $\mathrm{T} 221$ & 0 & 0 & 0 & 0 & 0 & 0 & 0 & 0 & 0 & 0 & 0 & 0 & 0 & 0 & 0 & 0 & 0 & 0 & 0 & 0 & 0 \\
\hline T301 & 0 & 0 & 0 & 0 & 0 & 0 & 0 & 0 & 0.42 & 0 & 0 & 0 & 0 & 0 & 0 & 0 & 0 & 0 & 0 & 0 & 0 \\
\hline T302 & 0 & 0 & 0 & 0 & 0 & 0 & 0 & 0 & 0.762 & 0 & 0 & 0 & 0 & 0 & 0 & 0 & 0 & 0 & 0 & 0 & 0 \\
\hline T303 & 0 & 0 & 0 & 0 & 0 & 0 & 0 & 0 & 0 & 0 & 0 & 0 & 0 & 0 & 0 & 0 & 0 & 0 & 0 & 0 & 0 \\
\hline T304 & 0 & 0 & 0 & 0 & 0 & 0 & 0 & 0 & 1.589 & 0 & 0 & 0 & 0 & 0 & 0 & 0 & 0 & 0.227 & 0 & 0 & 0 \\
\hline T305 & 0 & 0 & 0 & 0 & 0 & 0 & 0 & 0 & 0 & 0 & 0 & 0 & 0 & 0 & 0 & 0 & 0 & 0 & 0 & 0 & 0 \\
\hline T401 & 0 & 0 & 0 & 0 & 0 & 0 & 0 & 0 & 0.745 & 0 & 0 & 0 & 0 & 0 & 0 & 0 & 0 & 0 & 0 & 0 & 0 \\
\hline T402 & 0 & 0 & 0 & 0 & 0 & 0 & 0 & 0 & 0 & 0 & 0 & 0 & 0 & 0 & 0 & 0 & 0 & 0 & 0 & 0 & 0 \\
\hline T403 & 0 & 0 & 0 & 0 & 0 & 0 & 0 & 0 & 0 & 0 & 0 & 0 & 0 & 0 & 0 & 0 & 0 & 0 & 0 & 0 & 0 \\
\hline T404 & 0 & 0 & 0 & 0 & 0 & 0 & 0 & 0 & 0 & 0 & 0 & 0 & 0 & 0 & 0 & 0 & 0 & 0 & 0 & 0 & 0 \\
\hline T405 & 0 & 0 & 0 & 0 & 0 & 0 & 0 & 0 & 0 & 0 & 0 & 0 & 0 & 0 & 0 & 0 & 0 & 0 & 0 & 0 & 0 \\
\hline T406 & 0 & 0 & 0 & 0 & 0 & 0 & 0 & 0 & 0 & 0 & 0 & 0 & 0 & 0 & 0 & 0 & 0 & 0 & 0 & 0 & 0 \\
\hline T407 & 0 & 0 & 0 & 0 & 0 & 0 & 0 & 0 & 0 & 0 & 0 & 0 & 0 & 0 & 0 & 0 & 0 & 0 & 0 & 0 & 0 \\
\hline T408 & 0 & 0 & 0 & 0 & 0 & 0 & 0 & 0 & 0 & 0 & 0 & 0 & 0 & 0 & 0 & 0 & 0 & 0 & 0 & 0 & 0 \\
\hline T409 & 0 & 0 & 0 & 0 & 0 & 0 & 0 & 0 & 0 & 0 & 0 & 0 & 0 & 0 & 0 & 0 & 0 & 0 & 0 & 0 & 0 \\
\hline T410 & 0 & 0 & 0 & 0 & 0 & 0 & 0 & 0 & 4.173 & 0 & 0 & 0 & 0 & 0 & 0 & 0 & 0 & 0.504 & 0 & 0 & 0 \\
\hline T501 & 0 & 0 & 0 & 0 & 0 & 0 & 0 & 0 & 2.087 & 0 & 0 & 0 & 0 & 0 & 0 & 0 & 0 & 0 & 0 & 0 & 0 \\
\hline T502 & 0 & 0 & 0 & 0 & 0 & 0 & 0 & 0 & 0 & 0 & 0 & 0 & 0 & 0 & 0 & 0 & 0 & 0 & 0 & 0 & 0 \\
\hline T503 & 0 & 0 & 0 & 0 & 0 & 0 & 0 & 0 & 0 & 0 & 0 & 0 & 0 & 0 & 0 & 0 & 0 & 0.213 & 0 & 0 & 0 \\
\hline T504 & 0 & 0 & 0 & 0 & 0 & 0 & 0 & 0 & 1.017 & 1.369 & 0 & 0 & 0 & 0 & 0 & 0 & 0 & 0 & 0 & 0 & 0 \\
\hline T505 & 0 & 0 & 0 & 0 & 0 & 0 & 0 & 0 & 4.166 & 0 & 0 & 0 & 0 & 0 & 0 & 0 & 0 & 0.427 & 0 & 0 & 0 \\
\hline T506 & 0 & 0 & 0 & 0 & 0 & 0 & 0 & 0 & 0.1 & 0 & 0 & 0 & 0 & 0 & 0 & 0 & 0 & 0 & 0 & 0 & 0 \\
\hline T507 & 0 & 0 & 0 & 0 & 0 & 0 & 0 & 0 & 0 & 0 & 0 & 0 & 0 & 0 & 0 & 0 & 0 & 0 & 0 & 0 & 0 \\
\hline T508 & 0 & 0 & 0 & 0 & 0 & 0 & 0 & 0 & 0 & 0 & 0 & 0 & 0 & 0 & 0 & 0 & 0 & 0 & 0 & 0 & 0 \\
\hline
\end{tabular}


Appendix 3. Concentrations of 21 organochlorine pesticides found in all 531 persistent organic pollutant samples collected in the Lower Mekong River Basin during

\begin{tabular}{|c|c|c|c|c|c|c|c|c|c|c|c|c|c|c|c|c|c|c|c|c|c|}
\hline 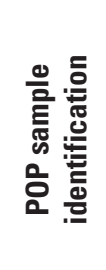 & 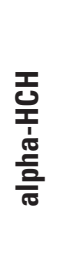 & 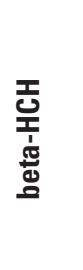 & 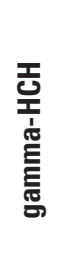 & 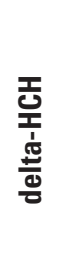 & 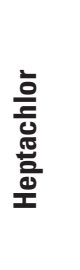 & 裻 & 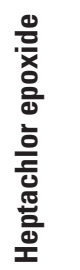 & 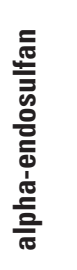 & $\begin{array}{l}\text { 㟔 } \\
0 \\
\dot{1} \\
\dot{0}\end{array}$ & $\frac{\text { 肯 }}{\frac{0}{0}}$ & 疎 & 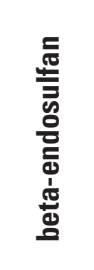 & 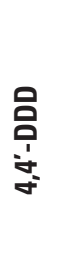 & 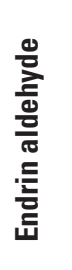 & 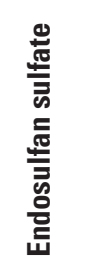 & $\begin{array}{l}\text { 合 } \\
\text { 号 } \\
\dot{8}\end{array}$ & 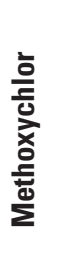 & 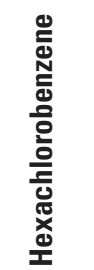 & 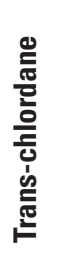 & 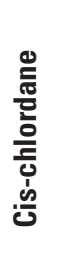 & 峞 \\
\hline LOD & 1 & 1.5 & 1 & 1 & 1.5 & 1.5 & 1.5 & 1 & 1 & 1 & 1 & 1 & 1 & 1 & 1 & 2 & 2 & 1.27 & 0.4 & 0.2 & 0.5 \\
\hline T509 & 0 & 0 & 0 & 0 & 0 & 0 & 0 & 0 & 12.71 & 0 & 0 & 0 & 0 & 0 & 0 & 0 & 0 & 0.343 & 0 & 0 & 0 \\
\hline T510 & 0 & 0 & 0 & 0 & 0 & 0 & 0 & 0 & 0.661 & 0 & 0 & 0 & 0 & 0 & 0 & 0 & 0 & 0 & 0 & 0 & 0 \\
\hline T511 & 0 & 0 & 0 & 0 & 0 & 0 & 0 & 0 & 24.46 & 0 & 0 & 26.19 & 0 & 0 & 0 & 0 & 0 & 0.316 & 0 & 0 & 0 \\
\hline T512 & 0 & 0 & 0 & 0 & 0 & 0 & 0 & 0 & 0 & 0 & 0 & 0 & 0 & 0 & 0 & 0 & 0 & 0 & 0 & 0 & 0 \\
\hline T513 & 0 & 0 & 0 & 0 & 0 & 0 & 0 & 0 & 0 & 0 & 0 & 0 & 0 & 0 & 0 & 0 & 0 & 0 & 0 & 0 & 0 \\
\hline T514 & 0 & 0 & 0 & 0 & 0 & 0 & 0 & 0 & 0.315 & 0 & 0 & 0 & 0 & 0 & 0 & 0 & 0 & 0 & 0 & 0 & 0 \\
\hline T515 & 0 & 0 & 0 & 0 & 0 & 0 & 0 & 0 & 0 & 0 & 0 & 0 & 0 & 0 & 0 & 0 & 0 & 0 & 0 & 0 & 0 \\
\hline T516 & 0 & 0 & 0 & 0 & 0 & 0 & 0 & 0 & 0 & 0 & 0 & 0 & 0 & 0 & 0 & 0 & 0 & 0 & 0 & 0 & 0 \\
\hline T517 & 0 & 0 & 0 & 0 & 0 & 0 & 0 & 0 & 0 & 0 & 0 & 0 & 0 & 0 & 0 & 0 & 0 & 0 & 0 & 0 & 0 \\
\hline T518 & 0 & 0 & 0 & 0 & 0 & 0 & 0 & 0 & 0 & 0 & 0 & 0 & 0 & 0 & 0 & 0 & 0 & 0 & 0 & 0 & 0 \\
\hline T519 & 0 & 0 & 0 & 0 & 0 & 0 & 0 & 0 & 0 & 0 & 0 & 0 & 0 & 0 & 0 & 0 & 0 & 0 & 0 & 0 & 0 \\
\hline T520 & 0 & 0 & 0 & 0 & 0 & 0 & 0 & 0 & 0 & 0 & 0 & 0 & 0 & 0 & 0 & 0 & 0 & 0 & 0 & 0 & 0 \\
\hline T521 & 0 & 0 & 0 & 0 & 0 & 0 & 0 & 0 & 0 & 0 & 0 & 0 & 0 & 0 & 0 & 0 & 0 & 0 & 0 & 0 & 0 \\
\hline T522 & 0 & 0 & 0 & 0 & 0 & 0 & 0 & 0 & 1.546 & 0 & 0 & 0 & 0 & 0 & 0 & 0 & 0 & 0.338 & 0 & 0 & 0 \\
\hline T523 & 0 & 0 & 0 & 0 & 0 & 0 & 0 & 0 & 0 & 0 & 0 & 0 & 0 & 0 & 0 & 0 & 0 & 0 & 0 & 0 & 0 \\
\hline T524 & 0 & 0 & 0 & 0 & 0 & 0 & 0 & 0 & 0.279 & 0 & 0 & 0 & 0 & 0 & 0 & 0 & 0 & 0 & 0 & 0 & 0 \\
\hline V001 & 0 & 0 & 0 & 0 & 0 & 0 & 0 & 0 & 0 & 0 & 0 & 0 & 0 & 0 & 0.103 & 0 & 0 & 0 & 0 & 0 & 0 \\
\hline V002 & 0 & 0 & 0 & 0 & 0 & 0 & 0 & 0 & 0 & 0 & 0 & 0.605 & 0 & 0 & 0 & 0 & 0 & 0 & 0 & 0 & 0 \\
\hline V003 & 0 & 0 & 0 & 0 & 0 & 0 & 0 & 0 & 16.4 & 0 & 2.112 & 5.299 & 0 & 0 & 0 & 0 & 0 & 0 & 0 & 0 & 0 \\
\hline V004 & 0 & 0 & 0 & 0 & 0 & 0 & 0 & 0 & 0 & 0 & 0.04 & 0 & 0 & 0 & 0 & 0 & 0 & 0.337 & 0 & 0 & 0 \\
\hline V005 & 0 & 0 & 0 & 0 & 0 & 0 & 0 & 0 & 0 & 0 & 0 & 0.224 & 0 & 0 & 0 & 0 & 0 & 0 & 0 & 0 & 0 \\
\hline V006 & 0 & 0 & 0 & 0 & 0 & 0 & 0 & 0 & 0 & 0 & 0 & 0.309 & 0 & 0 & 0 & 0 & 0 & 0 & 0 & 0 & 0 \\
\hline
\end{tabular}




\section{\|\|\|\|$\|1\| 1\|\|\|\|$}

\begin{tabular}{|c|c|c|c|c|c|c|c|c|c|c|c|c|c|c|c|c|c|c|c|c|c|}
\hline LOD & 1 & 1.5 & 1 & 1 & 1.5 & 1.5 & 1.5 & 1 & 1 & 1 & 1 & 1 & 1 & 1 & 1 & 2 & 2 & 1.27 & 0.4 & 0.2 & 0.5 \\
\hline V007 & 0 & 0 & 0 & 0 & 0 & 0 & 0 & 0 & 0 & 0 & 0 & 0.362 & 0 & 0 & 0.277 & 0 & 0 & 0 & 0 & 0 & 0 \\
\hline V008 & 0 & 0 & 0 & 0 & 0 & 0 & 0 & 0 & 0 & 0 & 0 & 0.486 & 0.373 & 0 & 1.749 & 0 & 0 & 0 & 0 & 0 & 0 \\
\hline V009 & 0 & 0 & 0 & 0 & 0 & 0 & 0 & 0 & 0 & 0 & 0 & 0.31 & 0 & 0 & 0 & 0 & 0 & 0 & 0 & 0 & 0 \\
\hline V010 & 0 & 0 & 0 & 0 & 0 & 0 & 0 & 0 & 0 & 0 & 0 & 0 & 0 & 0 & 0 & 2.023 & 1.054 & 0.591 & 0 & 0 & 0 \\
\hline V011 & 0 & 0 & 0 & 0 & 0 & 0 & 0 & 0 & 0 & 0 & 0.467 & 0.086 & 0 & 0 & 0 & 0 & 0 & 0 & 0 & 0 & 0 \\
\hline V012 & 0 & 0 & 0 & 0 & 0 & 0 & 0 & 0 & 0 & 0 & 0 & 0 & 11.53 & 0 & 0 & 1.18 & 0 & 0 & 0 & 0 & 0 \\
\hline V013 & 0 & 0 & 0 & 0 & 0 & 0 & 0 & 0 & 0 & 0 & 0 & 4.943 & 0 & 0 & 0 & 1.008 & 0 & 0.291 & 0 & 0.575 & 0 \\
\hline V014 & 0 & 0 & 0 & 0 & 0 & 0 & 0 & 0 & 0 & 0 & 0 & 0.132 & 0 & 0 & 0 & 0 & 0 & 0 & 0 & 0 & 0 \\
\hline V015 & 0 & 0 & 0 & 0 & 0 & 0 & 0 & 0 & 0 & 0 & 0 & 0.151 & 0 & 0 & 0 & 0 & 0 & 0.713 & 0 & 0 & 0 \\
\hline V016 & 0 & 0 & 0 & 0 & 0 & 0 & 0 & 0 & 0 & 0 & 0 & 0 & 0 & 0 & 1.655 & 0 & 0 & 0 & 0 & 0 & 0 \\
\hline V017 & 0 & 0 & 0 & 0 & 0 & 0 & 0 & 0 & 0 & 0 & 0 & 0 & 0 & 0 & 0 & 6.326 & 0 & 0 & 0 & 0 & 0 \\
\hline V018 & 0 & 0 & 0 & 0 & 0 & 0 & 0 & 0 & 0 & 0 & 0.546 & 2.29 & 0.497 & 0 & 0 & 0 & 0 & 0.273 & 0 & 0 & 0 \\
\hline V019 & 0 & 0 & 0 & 0 & 0 & 0 & 0 & 0 & 0 & 0 & 0 & 0 & 0 & 0 & 0 & 0 & 0 & 0.152 & 0 & 0 & 0 \\
\hline V020 & 0 & 0 & 0 & 0 & 0 & 0 & 0 & 0 & 0 & 0 & 0.234 & 0.171 & 0 & 0 & 0 & 0 & 0 & 0 & 0 & 0 & 0 \\
\hline V021 & 0 & 0 & 0 & 0 & 0 & 0 & 0 & 0 & 1.619 & 0 & 2.728 & 0 & 0 & 0 & 0 & 0 & 0 & 0 & 0 & 0 & 0 \\
\hline V022 & 0 & 0 & 0 & 0 & 0 & 0 & 0 & 0 & 0.299 & 0 & 0 & 0.907 & 0 & 0 & 0 & 0.261 & 0 & 0 & 0 & 0 & 0 \\
\hline V023 & 0 & 0 & 0 & 0 & 0 & 0 & 0 & 0.457 & 0 & 0 & 0 & 0 & 0.144 & 0 & 0.732 & 0.665 & 0 & 0 & 0 & 0 & 0 \\
\hline V024 & 0 & 0 & 0 & 0 & 0 & 0 & 0 & 0 & 0 & 0 & 0 & 0 & 0 & 0 & 0 & 0.599 & 0 & 0.488 & 0 & 0 & 0 \\
\hline V025 & 0 & 0 & 0 & 0 & 0 & 0 & 0 & 0 & 0.449 & 0 & 0 & 1.284 & 0 & 0 & 0 & 0 & 0 & 0 & 0 & 0 & 0 \\
\hline V026 & 0 & 0 & 0 & 0 & 0 & 0 & 0 & 0 & 0.992 & 0 & 0 & 0.013 & 0 & 0 & 0 & 0 & 0 & 0 & 0 & 0 & 0 \\
\hline V027 & 0 & 0 & 0 & 0 & 0 & 0 & 0 & 0 & 1.278 & 0 & 0 & 0.109 & 0.051 & 0 & 0.211 & 0 & 0 & 0 & 0 & 0.377 & 0 \\
\hline V028 & 0 & 0 & 0 & 0 & 0 & 0 & 0 & 0 & 0.658 & 0 & 0 & 2.501 & 0 & 0 & 0 & 0 & 0 & 0.398 & 0 & 0.941 & 0 \\
\hline V029 & 0 & 0 & 0 & 0 & 0 & 0 & 0 & 0 & 0.352 & 0 & 0.709 & 0 & 1.158 & 0 & 0 & 0 & 0 & 0 & 0 & 0 & 0 \\
\hline V030 & 0 & 0 & 0 & 0 & 0 & 0 & 0 & 0 & 0 & 0 & 0.393 & 0 & 0 & 0 & 0 & 0 & 0 & 0 & 0 & 0 & 0 \\
\hline V031 & 0 & 0 & 0 & 0 & 0 & 0 & 0 & 0 & 0 & 0 & 1.75 & 0 & 0 & 0 & 0 & 0 & 0 & 0 & 0 & 0 & 0 \\
\hline V032 & 0 & 0 & 0 & 0 & 0 & 0 & 0 & 0 & 0 & 0 & 0 & 0.134 & 0 & 0 & 0 & 0 & 0.22 & 0.379 & 0 & 0 & 0 \\
\hline V033 & 0 & 0 & 0 & 0 & 0 & 0 & 0 & 0 & 0 & 0 & 0 & 0 & 0 & 0 & 0 & 0 & 0 & 0 & 0 & 0 & 0 \\
\hline
\end{tabular}


Appendix 3. Concentrations of 21 organochlorine pesticides found in all 531 persistent organic pollutant samples collected in the Lower Mekong River Basin during

\begin{tabular}{|c|c|c|c|c|c|c|c|c|c|c|c|c|c|c|c|c|c|c|c|c|c|}
\hline 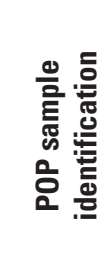 & 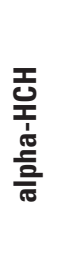 & 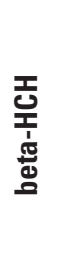 & 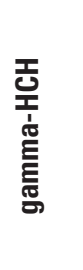 & 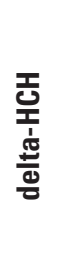 & 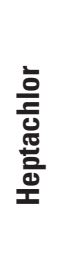 & $\frac{\text { 트늠 }}{\frac{1}{\alpha}}$ & 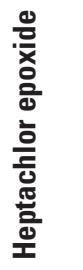 & 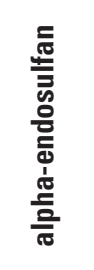 & $\begin{array}{l}\text { 㟔 } \\
\text { 号 } \\
\text { 过 }\end{array}$ & $\frac{\text { 트ㄴㅡㅡㅇ }}{.0}$ & 砑 & 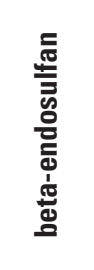 & 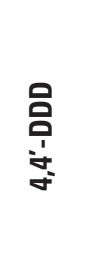 & 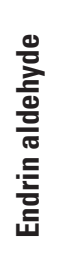 & 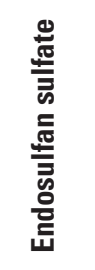 & $\begin{array}{l}\text { 吕 } \\
\text { : } \\
\dot{0} \\
\dot{0}\end{array}$ & 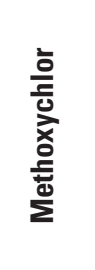 & 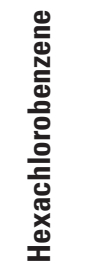 & 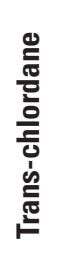 & 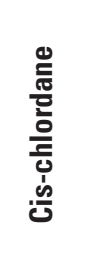 & 를 \\
\hline LOD & 1 & 1.5 & 1 & 1 & 1.5 & 1.5 & 1.5 & 1 & 1 & 1 & 1 & 1 & 1 & 1 & 1 & 2 & 2 & 1.27 & 0.4 & 0.2 & 0.5 \\
\hline V034 & 0 & 0 & 0 & 0 & 0 & 0 & 0 & 0 & 0 & 0 & 0 & 10.54 & 0.893 & 0 & 0 & 0 & 0 & 0 & 0 & 0 & 0 \\
\hline V035 & 0 & 0 & 0 & 0 & 0 & 0 & 0 & 0 & 0 & 0 & 0 & 0.189 & 0 & 0 & 0 & 0 & 0 & 0.548 & 0 & 0 & 0 \\
\hline V036 & 0 & 0 & 0 & 0 & 0 & 0 & 0 & 0 & 0.922 & 0 & 0 & 0 & 0 & 0 & 0 & 3.229 & 0 & 0 & 0 & 2.155 & 0 \\
\hline V037 & 0 & 0 & 0 & 0 & 0 & 0 & 0 & 0 & 0 & 0 & 0 & 0 & 0 & 0 & 0 & 0 & 0 & 0 & 0 & 3.082 & 0 \\
\hline V038 & 0 & 0 & 0 & 0 & 0 & 0 & 0 & 0 & 0 & 0 & 1.209 & 0.846 & 0 & 0 & 0 & 0 & 0 & 0 & 0 & 0 & 0 \\
\hline V039 & 0 & 0 & 0 & 0 & 0 & 0 & 0 & 0 & 0 & 0 & 0 & 0 & 0 & 0 & 0.205 & 0.215 & 0 & 0 & 0 & 0 & 0 \\
\hline V040 & 0 & 0 & 0 & 0 & 0 & 0 & 0 & 0 & 0 & 0 & 0.362 & 1.978 & 0 & 0 & 0 & 0 & 0 & 0 & 0 & 0 & 0 \\
\hline V041 & 0 & 0 & 0 & 0 & 0 & 0 & 0 & 0 & 0 & 0 & 0 & 3.837 & 0 & 0 & 0 & 0 & 0 & 0 & 0 & 0 & 0 \\
\hline V042 & 0 & 0 & 0 & 0 & 0 & 0 & 0 & 0 & 0 & 0 & 0 & 0.791 & 0 & 0 & 0 & 0 & 0 & 0.705 & 0 & 0 & 0 \\
\hline V043 & 0 & 0 & 0 & 0 & 0 & 0 & 0 & 0.194 & 0.095 & 0 & 0 & 0.078 & 0 & 0 & 0 & 0 & 0 & 0.325 & 0 & 0 & 0 \\
\hline V044 & 0 & 0 & 0 & 0 & 0 & 0 & 0 & 0 & 0.457 & 0.566 & 0.367 & 0 & 0 & 0 & 0.227 & 0.237 & 0 & 0 & 0 & 0 & 0 \\
\hline V045 & 0 & 0 & 0 & 0 & 0 & 0 & 0 & 0 & 0 & 0 & 0 & 0.043 & 0 & 0 & 0.117 & 0.223 & 0 & 0 & 0 & 0.477 & 0 \\
\hline V046 & 0 & 0 & 0 & 0 & 0 & 0 & 0 & 0 & 0 & 0 & 0.531 & 0.338 & 0 & 0 & 0 & 0 & 0 & 0.491 & 0 & 0.126 & 0 \\
\hline V047 & 0 & 0 & 0 & 0 & 0 & 0 & 0 & 0 & 0 & 0 & 0.568 & 0 & 0 & 0 & 0 & 0 & 0 & 0 & 0 & 0 & 0 \\
\hline V048 & 0 & 0 & 0 & 0 & 0 & 0 & 0 & 0 & 0 & 0 & 1.473 & 0 & 0 & 0 & 1.111 & 0 & 0 & 0.250 & 0 & 0 & 0 \\
\hline V049 & 0 & 0 & 0 & 0 & 0 & 0 & 0 & 0 & 0 & 0 & 0 & 0 & 0 & 0 & 0 & 0 & 0 & 0 & 0 & 0 & 0 \\
\hline V050 & 0 & 0 & 0 & 0 & 0 & 0 & 0 & 0 & 0 & 0 & 0 & 0 & 0 & 0 & 0 & 0 & 0 & 0 & 0 & 0.102 & 0 \\
\hline V051 & 0 & 0 & 0 & 0 & 0 & 0 & 0 & 0 & 0.526 & 0 & 0 & 0 & 0 & 0 & 0 & 0 & 0 & 0 & 0 & 0 & 0 \\
\hline V052 & 0 & 0 & 0 & 0 & 0 & 0 & 0 & 0 & 0 & 0 & 0 & 0 & 0 & 0 & 0.395 & 0 & 0 & 0 & 0 & 0 & 0 \\
\hline V053 & 0 & 0 & 0 & 0 & 0 & 0 & 0 & 0 & 0.571 & 0 & 5.592 & 0 & 0 & 0 & 0 & 0 & 0 & 0 & 0 & 0.562 & 0 \\
\hline V054 & 0 & 0 & 0 & 0 & 0 & 0 & 0 & 0 & 0 & 0 & 0 & 0 & 0 & 0 & 0 & 1.325 & 0 & 0 & 0 & 0 & 0 \\
\hline V055 & 0 & 0 & 0 & 0 & 0 & 0 & 0 & 0 & 0 & 0 & 0 & 0 & 0 & 0 & 0 & 0 & 0.663 & 0 & 0 & 0 & 0 \\
\hline V056 & 0 & 0 & 0 & 0 & 0 & 0 & 0 & 0 & 1.58 & 0 & 0 & 0 & 0 & 0 & 0 & 0 & 0 & 0 & 0 & 0 & 0 \\
\hline V057 & 0 & 0 & 0 & 0 & 0 & 0 & 0 & 0 & 0.098 & 0 & 0 & 0 & 0 & 0 & 0 & 0 & 0 & 0 & 0 & 0 & 0 \\
\hline
\end{tabular}


$\|1111\| 111111111$

\begin{tabular}{|c|c|c|c|c|c|c|c|c|c|c|c|c|c|c|c|c|c|c|c|c|c|}
\hline LOD & 1 & 1.5 & 1 & 1 & 1.5 & 1.5 & 1.5 & 1 & 1 & 1 & 1 & 1 & 1 & 1 & 1 & 2 & 2 & 1.27 & 0.4 & 0.2 & 0.5 \\
\hline V058 & 0 & 0 & 0 & 0 & 0 & 0 & 0 & 0 & 0 & 0 & 0 & 0 & 0 & 0 & 0 & 0 & 0 & 0.798 & 0 & 0 & 0 \\
\hline V059 & 0 & 0 & 0 & 0 & 0 & 0 & 0 & 0 & 0.355 & 0 & 0 & 2.629 & 0 & 0 & 0 & 0 & 0.372 & 0 & 0 & 0 & 0 \\
\hline V060 & 0 & 0 & 0 & 0 & 0 & 0 & 0 & 0 & 0 & 0 & 0 & 0 & 0 & 0 & 0 & 0 & 0 & 0 & 0 & 0 & 0 \\
\hline V061 & 0 & 0 & 0 & 0 & 0 & 0 & 0 & 0.029 & 0 & 0 & 0 & 0 & 0 & 0 & 0 & 0 & 0 & 0 & 0 & 0 & 0 \\
\hline V062 & 0 & 0 & 0 & 0 & 0 & 0 & 0 & 0 & 0 & 0 & 0 & 0.144 & 0 & 0 & 0 & 0 & 0 & 0 & 0 & 0 & 0 \\
\hline V063 & 0 & 0 & 0 & 0 & 0 & 0 & 0 & 0 & 0 & 0 & 1.717 & 0 & 0 & 0 & 0 & 0 & 0 & 0 & 0 & 0 & 0 \\
\hline V064 & 0 & 0 & 0 & 0 & 0 & 0 & 0 & 0 & 0 & 0 & 0.844 & 0 & 0 & 0 & 0 & 0 & 0 & 0 & 0 & 0 & 0 \\
\hline V065 & 0 & 0 & 0 & 0 & 0 & 0 & 0 & 0 & 0 & 0 & 0 & 0.262 & 0 & 0 & 0 & 0 & 0 & 0 & 0 & 0 & 0 \\
\hline V066 & 0 & 0 & 0 & 0 & 0 & 0 & 0 & 0 & 25.12 & 0 & 1.56 & 3.216 & 0 & 0 & 0 & 2.683 & 0 & 0.290 & 0 & 0 & 0 \\
\hline V067 & 0 & 0 & 0 & 0 & 0 & 0 & 0 & 0.308 & 0.022 & 0 & 0 & 0 & 0 & 0 & 0 & 0 & 0 & 0 & 0 & 0 & 0 \\
\hline V068 & 0 & 0 & 0 & 0 & 0 & 0 & 3.032 & 0.124 & 0 & 0 & 0 & 0.444 & 0 & 0 & 0 & 0.025 & 0 & 0 & 0 & 0 & 0 \\
\hline V069 & 0 & 0 & 0 & 0 & 0 & 0 & 0 & 0 & 0 & 0 & 1.228 & 0 & 0.02 & 0 & 0 & 0 & 0 & 0 & 0 & 0 & 0 \\
\hline V070 & 0 & 0 & 0 & 0 & 0 & 0 & 0 & 0.107 & 0.087 & 0 & 0 & 1.59 & 0 & 0 & 0 & 0 & 0 & 0 & 0 & 0 & 0 \\
\hline V071 & 0 & 0 & 0 & 0 & 0 & 0 & 0 & 0 & 4.645 & 0 & 0 & 0 & 0 & 0 & 0 & 0 & 0 & 0 & 0 & 0 & 0 \\
\hline V072 & 0 & 0 & 0 & 0 & 0 & 0 & 0 & 0 & 0.875 & 0 & 0 & 0 & 0 & 0 & 0 & 0 & 0 & 0 & 0 & 0 & 0 \\
\hline V073 & 0 & 0 & 0 & 0 & 0 & 0 & 0 & 0 & 1.272 & 0 & 2.11 & 0 & 2.922 & 0 & 0 & 0 & 0 & 0.635 & 0 & 0 & 0 \\
\hline V074 & 0 & 0 & 0 & 0 & 0 & 0 & 0 & 0 & 10.2 & 0 & 0 & 4.698 & 0 & 0 & 0 & 0 & 0 & 0 & 0 & 2.010 & 0 \\
\hline V075 & 0 & 0 & 0 & 0 & 0 & 0 & 0 & 0 & 0 & 0 & 3.793 & 0.039 & 0 & 0 & 0 & 0 & 0 & 0 & 0 & 0 & 0 \\
\hline V076 & 0 & 0 & 0 & 0 & 0 & 0 & 0 & 0 & 0.964 & 0 & 1.641 & 0 & 0 & 0 & 0 & 0 & 0 & 0 & 0 & 0 & 0 \\
\hline V077 & 0 & 0 & 0 & 0 & 0 & 0 & 0 & 0 & 0 & 0 & 0 & 0 & 0 & 0 & 0 & 0 & 0 & 0 & 0 & 0 & 0 \\
\hline V078 & 0 & 0 & 0 & 0 & 0 & 0 & 0 & 0.124 & 0 & 0 & 0 & 0.038 & 0.086 & 0 & 0 & 0 & 0 & 0 & 0 & 0 & 0 \\
\hline V079 & 0 & 0 & 0 & 0 & 0 & 0 & 0 & 0 & 5.162 & 0 & 0 & 0.888 & 0 & 0 & 0 & 0 & 0 & 0 & 0 & 0 & 0 \\
\hline V080 & 0 & 0 & 0 & 0 & 0 & 0 & 0 & 0 & 0 & 0 & 0 & 3.831 & 0 & 0 & 0 & 0 & 0 & 0 & 0 & 0 & 0 \\
\hline V081 & 0 & 0 & 0 & 0 & 0 & 0 & 0 & 0.117 & 0.237 & 0 & 0 & 0 & 0 & 0 & 0 & 0.103 & 0 & 0 & 0 & 0 & 0 \\
\hline V082 & 0 & 0 & 0 & 0 & 0 & 0 & 0 & 0 & 0.649 & 0 & 1.443 & 0.514 & 0 & 0 & 0 & 0.409 & 0 & 0.463 & 0 & 0 & 0 \\
\hline V083 & 0 & 0 & 0 & 0 & 0 & 0 & 0 & 0 & 1.105 & 0 & 0.445 & 0.51 & 0.086 & 0 & 0 & 0 & 0 & 0 & 0 & 0 & 0 \\
\hline V084 & 0 & 0 & 0 & 0 & 0 & 0 & 0 & 0 & 0.205 & 0 & 0 & 0.386 & 0 & 0 & 0 & 0 & 0 & 0 & 0 & 0 & 0 \\
\hline V085 & 0 & 0 & 0 & 0 & 0 & 0 & 0 & 0 & 0 & 0 & 0.404 & 0 & 0 & 0 & 0 & 0 & 0 & 0 & 0 & 0 & 0 \\
\hline
\end{tabular}


Appendix 3. Concentrations of 21 organochlorine pesticides found in all 531 persistent organic pollutant samples collected in the Lower Mekong River Basin during

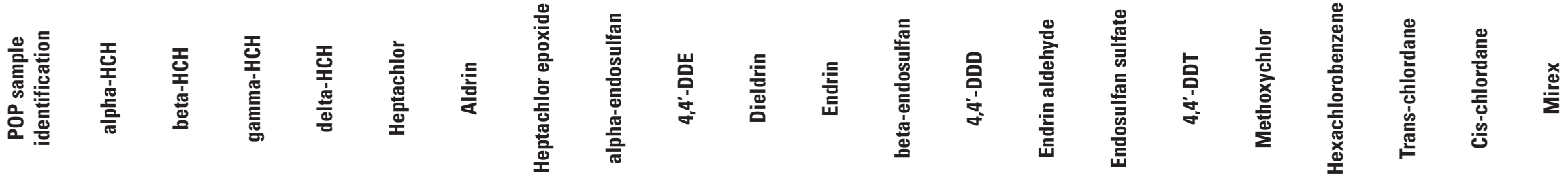

\begin{tabular}{|c|c|c|c|c|c|c|c|c|c|c|c|c|c|c|c|c|c|c|c|c|c|}
\hline LOD & 1 & 1.5 & 1 & 1 & 1.5 & 1.5 & 1.5 & 1 & 1 & 1 & 1 & 1 & 1 & 1 & 1 & 2 & 2 & 1.27 & 0.4 & 0.2 & 0.5 \\
\hline V086 & 0 & 0 & 0 & 0 & 0 & 0 & 0 & 0 & 0.563 & 0 & 0.123 & 0 & 0 & 0 & 0 & 0 & 0 & 0.210 & 0 & 0 & 0 \\
\hline V087 & 0 & 0 & 0 & 0 & 0 & 0 & 0 & 0 & 0 & 0 & 0 & 0.149 & 0 & 0 & 0 & 0 & 0 & 0 & 0 & 0 & 0 \\
\hline V088 & 0 & 0 & 0 & 0 & 0 & 0 & 0 & 0 & 0.225 & 0 & 0 & 0.166 & 0 & 0 & 0 & 0 & 0 & 0 & 0 & 0 & 0 \\
\hline V089 & 0 & 0 & 0 & 0 & 0 & 0 & 0 & 0 & 0 & 0 & 1.869 & 0.252 & 0 & 0 & 0 & 0 & 0 & 0 & 0 & 0 & 0 \\
\hline V090 & 0 & 0 & 0 & 0 & 0 & 0 & 0 & 0 & 0 & 0 & 0 & 0.103 & 0 & 0 & 0 & 0 & 0 & 0 & 0 & 0 & 0 \\
\hline V091 & 0 & 0 & 0 & 0 & 0 & 0 & 0 & 0 & 0.083 & 0.127 & 0.324 & 1.281 & 0 & 0 & 0 & 0 & 0 & 0 & 0 & 0 & 0 \\
\hline V092 & 0 & 0 & 0 & 0 & 0 & 0 & 0 & 0 & 0.449 & 0 & 0.801 & 0.244 & 0 & 0 & 0 & 0 & 0.684 & 0 & 0 & 0 & 0 \\
\hline V093 & 0 & 0 & 0 & 0 & 0 & 0 & 0 & 0.493 & 0.597 & 0 & 0.125 & 0.457 & 0 & 0 & 0 & 0 & 0 & 0.481 & 0 & 0 & 0 \\
\hline V094 & 0 & 0 & 0 & 0 & 0 & 0 & 0 & 0 & 0.982 & 0 & 3.143 & 0 & 0 & 0 & 0 & 0 & 0 & 0 & 0 & 0 & 0 \\
\hline V095 & 0 & 0 & 0 & 0 & 0 & 0 & 0 & 0.142 & 0.03 & 0 & 0 & 0 & 0 & 0 & 0 & 0 & 0 & 0 & 0 & 0 & 0 \\
\hline V096 & 0 & 0 & 0 & 0 & 0 & 0 & 0 & 0 & 0 & 0 & 0 & 1.146 & 0 & 0 & 0 & 0.287 & 0 & 0 & 0 & 0 & 0 \\
\hline V097 & 0 & 0 & 0 & 0 & 0 & 0 & 0 & 0 & 0 & 0 & 0 & 0.036 & 0 & 0 & 0 & 0 & 0 & 0.132 & 0 & 0 & 0 \\
\hline V098 & 0 & 0 & 0 & 0 & 0 & 0 & 0 & 0 & 8.362 & 0 & 0.96 & 0.473 & 0 & 0 & 0 & 0 & 0 & 0 & 0 & 0 & 0 \\
\hline V099 & 0 & 0 & 0 & 0 & 0 & 0 & 0 & 0 & 0 & 0 & 0 & 0 & 0 & 0 & 0 & 0 & 0 & 0 & 0 & 0 & 0 \\
\hline V100 & 0 & 0 & 0 & 0 & 0 & 0 & 0 & 0.62 & 5.259 & 0 & 0 & 1.905 & 0 & 0 & 1.024 & 0 & 0 & 0.475 & 0 & 0 & 0 \\
\hline V101 & 0 & 0 & 0 & 0 & 0 & 0 & 0 & 0 & 0.436 & 0 & 0 & 0 & 0 & 0 & 0 & 0 & 0 & 0 & 0 & 0 & 0 \\
\hline V102 & 0 & 0 & 0 & 0 & 0 & 0 & 0 & 0 & 0 & 0 & 0 & 0 & 0 & 0 & 0 & 0 & 0 & 0.866 & 0 & 0 & 0 \\
\hline V103 & 0 & 0 & 0 & 0 & 0 & 0 & 0 & 0 & 0 & 0 & 0 & 0.119 & 0 & 0 & 0 & 0 & 0 & 0 & 0 & 0 & 0 \\
\hline
\end{tabular}




\section{Appendix 4.}

Concentrations for 18 isomers of polychlorinated biphenyls (PCBs) found in 61 subsamples collected from 531 persistent organic pollutant (POP) samples collected from Southeast Asia in the Lower Mekong River Basin during 2011. Minimum level of detection (LOD) is bolded and provided in the first line. Values measured below LOD are uncertain and should be construed as being present at low concentration but without further quantification. $A$ " 0 " denotes that, though tested, no PCB was detected. Each sample was analyzed for all PCBs. Concentrations are measured as nanogram per gram dry weight $(\mathrm{ng} / \mathrm{g})$. 
Appendix 4. Concentrations for 18 isomers of polychlorinated biphenyls (PCBs) found in 61 subsamples taken from 531 persistent organic pollutant (POP) samples collected from Southeast Asia in the Lower Mekong River Basin during 2011. Minimum level of detection (LOD) is bolded and provided in the first line. Values measured below LOD are uncertain and should be construed as being present at low concentration but without further quantification. A "0" denotes that, though tested, no PCB was detected. Each sample was analyzed for all PCBs. Concentrations are measured as nanogram per gram dry weight $(\mathrm{ng} / \mathrm{g})$.

\begin{tabular}{|c|c|c|c|c|c|c|c|c|c|c|c|c|c|c|c|c|c|c|}
\hline & $\mathrm{PCB}_{8}$ & $\mathrm{PCB}_{18}$ & $\mathrm{PCB}_{28}$ & PCB $_{31}$ & $\mathrm{PCB}_{44}$ & $\mathrm{PCB}_{52}$ & $\mathrm{PCB}_{70}$ & $\mathrm{PCB}_{101}$ & PCB $_{105}$ & $\mathrm{PCB}_{118}$ & $\mathrm{PCB}_{138}$ & $\mathbf{P C B}_{149}$ & PCB $_{151}$ & $\mathbf{P C B}_{153}$ & PCB $_{170}$ & $\mathrm{PCB}_{180}$ & PCB $_{194}$ & PCB $_{195}$ \\
\hline LOD & 1.38 & 0.94 & 0.41 & 0.40 & 0.49 & 0.34 & 0.33 & 0.32 & 0.21 & 0.32 & 0.23 & 0.36 & 0.28 & 0.31 & 0.15 & 0.21 & 0.20 & 0.21 \\
\hline $\mathrm{C} 002$ & 0 & 0 & 0 & 0 & 0 & 0 & 0 & 0 & 0 & 0 & 0 & 0 & 0 & 0 & 0 & 0 & 0 & 0 \\
\hline C009 & 0 & 0 & 1.92 & 0 & 0 & 0 & 0 & 0 & 0 & 0 & 0 & 0 & 0 & 0 & 0 & 0 & 0 & 0 \\
\hline $\mathrm{C} 020$ & 0 & 0 & 0 & 0 & 0 & 0 & 0 & 0 & 0 & 0 & 0 & 0 & 0 & 0 & 0 & 0 & 0 & 0 \\
\hline $\mathrm{C} 023$ & 0 & 0 & 0 & 0 & 0 & 0 & 0 & 0 & 0 & 0 & 0 & 0 & 0 & 0 & 0 & 0 & 0 & 0 \\
\hline C029 & 0 & 0 & 2.37 & 0 & 0 & 0 & 0 & 0 & 0 & 0 & 0 & 0 & 0 & 0 & 0 & 0 & 0 & 0 \\
\hline $\mathrm{C} 038$ & 0 & 0 & 0 & 0 & 0 & 0 & 0 & 0 & 0 & 0 & 0 & 0 & 0 & 0 & 0 & 0 & 0 & 0 \\
\hline C056 & 0 & 0 & 0 & 0 & 0 & 0 & 0 & 0 & 0 & 0 & 0 & 0 & 0 & 0 & 0 & 0 & 0 & 0 \\
\hline $\mathrm{C} 065$ & 0 & 0 & 0 & 0 & 0 & 0 & 0 & 0 & 0 & 0 & 0 & 0 & 0 & 0 & 0 & 0 & 0 & 0 \\
\hline C080 & 0 & 0 & 0 & 0 & 0 & 0 & 0 & 0 & 0 & 0 & 0 & 0 & 0 & 0 & 0 & 0 & 0 & 0 \\
\hline C097 & 0 & 0 & 0 & 0 & 0 & 0 & 0 & 0 & 0 & 0 & 0 & 0 & 0 & 0 & 0 & 0 & 0 & 0 \\
\hline C111 & 0 & 0 & 0 & 0 & 0 & 0 & 0 & 0 & 0 & 0 & 0 & 0 & 0 & 0 & 0 & 0 & 0 & 0 \\
\hline C117 & 0 & 0 & 0 & 0 & 0 & 0 & 0 & 0 & 0 & 0 & 0 & 0 & 0 & 0 & 0 & 0 & 0 & 0 \\
\hline $\mathrm{C} 127$ & 0 & 0 & 0 & 0 & 0 & 0 & 0 & 0 & 0 & 0 & 0 & 0 & 0 & 0 & 0 & 0 & 0 & 0 \\
\hline C131 & 0 & 0 & 0 & 0 & 0 & 0 & 0 & 0 & 0 & 0 & 0 & 0 & 0 & 0 & 0 & 0 & 0 & 0 \\
\hline C145 & 0 & 0 & 0 & 0 & 0 & 0 & 0 & 0 & 0 & 0 & 0 & 0 & 0 & 0 & 0 & 0 & 0 & 0 \\
\hline C146 & 0 & 0 & 0 & 0 & 0 & 0 & 0 & 0 & 0 & 0 & 0 & 0 & 0 & 0 & 0 & 0 & 0 & 0 \\
\hline C177 & 0 & 0 & 0 & 0 & 0 & 0 & 0 & 0 & 0 & 0 & 0 & 0 & 0 & 0 & 0 & 0 & 0 & 0 \\
\hline C183 & 0 & 0 & 0 & 0 & 0 & 0 & 0 & 0 & 0 & 0 & 0 & 0 & 0 & 0 & 0 & 0 & 0 & 0 \\
\hline C184 & 0 & 0 & 0 & 0 & 0 & 0 & 0 & 0 & 0 & 0 & 0 & 0 & 0 & 0 & 0 & 0 & 0 & 0 \\
\hline L010 & 0 & 0 & 0 & 0 & 0 & 0 & 0 & 0 & 0 & 0 & 0 & 0 & 0 & 0 & 0 & 0 & 0 & 0 \\
\hline L015 & 0 & 0 & 0 & 0 & 0 & 0 & 0 & 0 & 0 & 0 & 0 & 0 & 0 & 0 & 0 & 0 & 0 & 0 \\
\hline L018 & 0 & 0 & 0 & 0 & 0 & 0 & 0 & 0 & 0 & 0 & 0 & 0 & 0 & 0 & 0 & 0 & 0 & 0 \\
\hline L020 & 0 & 0 & 0 & 0 & 0 & 0 & 0 & 0 & 0 & 0 & 0 & 0 & 0 & 0 & 0 & 0 & 0 & 0 \\
\hline L021 & 0 & 0 & 0 & 0 & 0 & 0 & 0 & 0 & 0 & 0 & 0 & 0 & 0 & 0 & 0 & 0 & 0 & 0 \\
\hline L022 & 0 & 0 & 0 & 0 & 0 & 0 & 0 & 0 & 0 & 0 & 0 & 0 & 0 & 0 & 0 & 0 & 0 & 0 \\
\hline L030 & 0 & 0 & 2.05 & 0 & 0 & 0 & 0 & 0 & 0 & 0 & 0 & 0 & 0 & 0 & 0 & 0 & 0 & 0 \\
\hline L033 & 0 & 0 & 0 & 0 & 0 & 0 & 0 & 0 & 0 & 0 & 0 & 0 & 0 & 0 & 0 & 0 & 0 & 0 \\
\hline L035 & 0 & 0 & 0 & 0 & 0 & 0 & 0 & 0 & 0 & 0 & 0 & 0 & 0 & 0 & 0 & 0 & 0 & 0 \\
\hline L073 & 0 & 0 & 0 & 0 & 0 & 0 & 0 & 0 & 0 & 0 & 0 & 0 & 0 & 0 & 0 & 0 & 0 & 0 \\
\hline
\end{tabular}




\begin{tabular}{|c|c|c|c|c|c|c|c|c|c|c|c|c|c|c|c|c|c|c|}
\hline & $\mathrm{PCB}_{8}$ & $\mathrm{PCB}_{18}$ & $\mathrm{PCB}_{28}$ & $\mathrm{PCB}_{31}$ & $\mathrm{PCB}_{44}$ & $\mathrm{PCB}_{52}$ & $\mathrm{PCB}_{70}$ & PCB $_{101}$ & PCB $_{105}$ & $\mathrm{PCB}_{118}$ & $\mathrm{PCB}_{138}$ & $\mathrm{PCB}_{149}$ & $\mathrm{PCB}_{151}$ & $\mathrm{PCB}_{153}$ & $\mathrm{PCB}_{170}$ & $\mathrm{PCB}_{180}$ & PCB $_{194}$ & $\mathrm{PCB}_{195}$ \\
\hline L090 & 0 & 0 & 0 & 0 & 0 & 0 & 0 & 0 & 0 & 0 & 0 & 0 & 0 & 0 & 0 & 0 & 0 & 0 \\
\hline M026 & 0 & 0 & 0 & 0 & 0 & 0 & 0 & 0 & 0 & 0 & 0 & 0 & 0 & 0 & 0 & 0 & 0 & 0 \\
\hline M027 & 0 & 0 & 0 & 0 & 0 & 0 & 0 & 0 & 0 & 0 & 0 & 0 & 0 & 0 & 0 & 0 & 0 & 0 \\
\hline M018 & 0 & 0 & 0 & 0 & 0 & 0 & 0 & 0 & 0 & 0 & 0 & 0 & 0 & 0 & 0 & 0 & 0 & 0 \\
\hline M016 & 0 & 0 & 0 & 0 & 0 & 0 & 0 & 0 & 0 & 0 & 0 & 0 & 0 & 0 & 0 & 0 & 0 & 0 \\
\hline M008 & 0 & 0 & 0 & 0 & 0 & 0 & 0 & 0 & 0 & 0 & 0 & 0 & 0 & 0 & 0 & 0 & 0 & 0 \\
\hline M029 & 0 & 0 & 0 & 0 & 0 & 0 & 0 & 0 & 0 & 0 & 0 & 0 & 0 & 0 & 0 & 0 & 0 & 0 \\
\hline T105 & 0 & 0 & 0 & 0 & 0 & 0 & 0 & 0 & 0 & 0 & 0 & 0 & 0 & 0 & 0 & 0 & 0 & 0 \\
\hline T204 & 0 & 0 & 0 & 0 & 0 & 0 & 0 & 0 & 0 & 0 & 0 & 0 & 0 & 0 & 0 & 0 & 0 & 0 \\
\hline $\mathrm{T} 213$ & 0 & 0 & 0 & 0 & 0 & 0 & 0 & 0 & 0 & 0 & 0 & 0 & 0 & 0 & 0 & 0 & 0 & 0 \\
\hline T304 & 0 & 0 & 0 & 0 & 0 & 0 & 0 & 0 & 0 & 0 & 0 & 0 & 0 & 0 & 0 & 0 & 0 & 0 \\
\hline $\mathrm{T} 410$ & 0 & 0 & 0 & 0 & 0 & 0 & 0 & 0 & 0 & 0 & 0 & 0 & 0 & 0 & 0 & 0 & 0 & 0 \\
\hline T503 & 0 & 0 & 0 & 0 & 0 & 0 & 0 & 0 & 0 & 0 & 0 & 0 & 0 & 0 & 0 & 0 & 0 & 0 \\
\hline T505 & 0 & 0 & 0 & 0 & 0 & 0 & 0 & 0 & 0 & 0 & 0 & 0 & 0 & 0 & 0 & 0 & 0 & 0 \\
\hline T509 & 0 & 0 & 0 & 0 & 0 & 0 & 0 & 0 & 0 & 0 & 0 & 0 & 0 & 0 & 0 & 0 & 0 & 0 \\
\hline T511 & 0 & 0 & 0 & 0 & 0 & 0 & 0 & 0 & 0 & 0 & 0 & 0 & 0 & 0 & 0 & 0 & 0 & 0 \\
\hline T522 & 0 & 0 & 0 & 0 & 0 & 0 & 0 & 0 & 0 & 0 & 0 & 0 & 0 & 0 & 0 & 0 & 0 & 0 \\
\hline V013 & 0 & 0 & 0 & 0 & 0 & 0 & 0 & 0 & 0 & 0 & 0 & 0 & 0 & 0 & 0 & 0 & 0 & 0 \\
\hline V018 & 0 & 0 & 0 & 0 & 0 & 0 & 0 & 0 & 0 & 0 & 0 & 0 & 0 & 0 & 0 & 0 & 0 & 0 \\
\hline V019 & 0 & 0 & 0 & 0 & 0 & 0 & 0 & 0 & 0 & 0 & 0 & 0 & 0 & 0 & 0 & 0 & 0 & 0 \\
\hline V024 & 0 & 0 & 0 & 0 & 0 & 0 & 0 & 0 & 0 & 0 & 0 & 0 & 0 & 0 & 0 & 0 & 0 & 0 \\
\hline V032 & 0 & 0 & 0 & 0 & 0 & 0 & 0 & 0 & 0 & 0 & 0 & 0 & 0 & 0 & 0 & 0 & 0 & 0 \\
\hline V035 & 0 & 0 & 0 & 0 & 0 & 0 & 0 & 0 & 0 & 0 & 0 & 0 & 0 & 0 & 0 & 0 & 0 & 0 \\
\hline V043 & 0 & 0 & 0 & 0 & 0 & 0 & 0 & 0 & 0 & 0 & 0 & 0 & 0 & 0 & 0 & 0 & 0 & 0 \\
\hline V046 & 0 & 0 & 0 & 0 & 0 & 0 & 0 & 0 & 0 & 0 & 0 & 0 & 0 & 0 & 0 & 0 & 0 & 0 \\
\hline V066 & 0 & 0 & 0 & 0 & 0 & 0 & 0 & 0 & 0 & 0 & 0 & 0 & 0 & 0 & 0 & 0 & 0 & 0 \\
\hline V073 & 0 & 0 & 0 & 0 & 0 & 0 & 0 & 0 & 0 & 0 & 0 & 0 & 0 & 0 & 0 & 0 & 0 & 0 \\
\hline V082 & 0 & 0 & 0 & 0 & 0 & 0 & 0 & 0 & 0 & 0 & 0 & 0 & 0 & 0 & 0 & 0 & 0 & 0 \\
\hline V086 & 0 & 0 & 0 & 0 & 0 & 0 & 0 & 0 & 0 & 0 & 0 & 0 & 0 & 0 & 0 & 0 & 0 & 0 \\
\hline V093 & 0 & 0 & 0 & 0 & 0 & 0 & 0 & 0 & 0 & 0 & 0 & 0 & 0 & 0 & 0 & 0 & 0 & 0 \\
\hline V097 & 0 & 0 & 0 & 0 & 0 & 0 & 0 & 0 & 0 & 0 & 0 & 0 & 0 & 0 & 0 & 0 & 0 & 0 \\
\hline V100 & 0 & 0 & 1.05 & 0 & 0 & 0 & 0 & 0 & 0 & 0 & 0 & 0 & 0 & 0 & 0 & 0 & 0 & 0 \\
\hline
\end{tabular}





\section{Appendix 5.}

Coordinates of 531 sediment samples collected in the Lower Mekong Basin during 2011. The label C085 was mistakenly used twice, so "A" distinguishes one sample from the other. 
Appendix 5. Coordinates of 531 sediment samples collected in the Lower Mekong Basin during 2011. The label C085 was mistakenly used twice, so "A" distinguishes one sample from the other.

\begin{tabular}{|c|c|c|c|c|c|}
\hline Sample ID & Longitude & Latitude & Sample ID & Longitude & Latitude \\
\hline $\mathrm{C} 001$ & $103^{\circ} 14^{\prime} 59.4^{\prime \prime}$ East & $13^{\circ} 26^{\prime} 46.1$ " North & $\mathrm{C} 042$ & $105^{\circ} 22^{\prime} 40.8^{\prime \prime}$ East & $11^{\circ} 22^{\prime} 25.5^{\prime \prime}$ North \\
\hline $\mathrm{C} 002$ & $103^{\circ} 18^{\prime} 12.9$ ” East & $13^{\circ} 47^{\prime} 13.8^{\prime \prime}$ North & $\mathrm{C} 043$ & $105^{\circ} 36^{\prime} 10.8^{\prime \prime}$ East & $11^{\circ} 19^{\prime} 47.4$ " North \\
\hline $\mathrm{C} 004$ & $103^{\circ} 20^{\prime} 2.55^{\prime \prime}$ East & $13^{\circ} 49^{\prime} 47.7$ " North & $\mathrm{C} 045$ & $105^{\circ} 21^{\prime} 20.5^{\prime \prime}$ East & $11^{\circ} 14^{\prime} 2.25^{\prime \prime}$ North \\
\hline $\mathrm{C} 005$ & $103^{\circ} 13^{\prime} 42.4^{\prime \prime}$ East & $13^{\circ} 48^{\prime} 22.9^{\prime \prime}$ North & $\mathrm{C} 046$ & $105^{\circ} 19^{\prime} 16.9^{\prime \prime}$ East & $11^{\circ} 11^{\prime} 8.15^{\prime \prime}$ North \\
\hline $\mathrm{C} 007$ & $103^{\circ} 19^{\prime} 1.54$ ” East & $13^{\circ} 43^{\prime} 26.6^{\prime \prime}$ North & $\mathrm{C} 048$ & $105^{\circ} 17^{\prime} 55.1$ ” East & $11^{\circ} 19^{\prime} 50.1$ "North \\
\hline $\mathrm{C} 008$ & $102^{\circ} 58^{\prime} 47.8^{\prime \prime}$ East & $13^{\circ} 4^{\prime} 24.7^{\prime \prime}$ North & C049 & $105^{\circ} 4^{\prime} 23.7^{\prime \prime}$ East & $10^{\circ} 59^{\prime} 14.1$ " North \\
\hline $\mathrm{C} 009$ & $103^{\circ} 15^{\prime} 12.0^{\prime \prime}$ East & $13^{\circ} 10^{\prime} 53.5^{\prime \prime}$ North & $\mathrm{C} 050$ & $105^{\circ} 7$ ' 16.5" East & $11^{\circ} 4^{\prime} 29.8^{\prime \prime}$ North \\
\hline $\mathrm{C} 010$ & $103^{\circ} 10^{\prime} 53.8^{\prime \prime}$ East & $13^{\circ} 12^{\prime} 48.1$ " North & $\mathrm{C} 051$ & $104^{\circ} 57^{\prime} 47.8^{\prime \prime}$ East & $11^{\circ} 18^{\prime} 57.6$ " North \\
\hline $\mathrm{C} 014$ & $105^{\circ} 2^{\prime} 54.5^{\prime \prime}$ East & $11^{\circ} 28^{\prime} 59.3$ " North & $\mathrm{C} 055$ & $104^{\circ} 52^{\prime} 6.40^{\prime \prime}$ East & $10^{\circ} 39^{\prime} 22.6^{\prime \prime}$ North \\
\hline $\mathrm{C} 015$ & $105^{\circ} 12^{\prime} 38.8^{\prime \prime}$ East & $11^{\circ} 20^{\prime} 0.03$ ” North & $\mathrm{C} 056$ & $104^{\circ} 57^{\prime} 43.3^{\prime \prime}$ East & $10^{\circ} 49^{\prime} 6.91$ ” North \\
\hline $\mathrm{C} 016$ & $105^{\circ} 8^{\prime}$ '54.3" East & $12^{\circ} 29^{\prime} 35.2^{\prime \prime}$ North & $\mathrm{C} 057$ & $104^{\circ} 48^{\prime} 33.3^{\prime \prime}$ East & $10^{\circ} 57$ ' 26.8 " North \\
\hline $\mathrm{C} 017$ & $104^{\circ} 49^{\prime} 17.0^{\prime \prime}$ East & $12^{\circ} 47^{\prime} 33.3^{\prime \prime}$ North & $\mathrm{C} 058$ & $104^{\circ} 46^{\prime} 56.3^{\prime \prime}$ East & $11^{\circ} 0$ ' $1.51^{\prime \prime}$ North \\
\hline $\mathrm{C} 018$ & $104^{\circ} 25^{\prime} 49.9^{\prime \prime}$ East & $13^{\circ} 0$ ' 1.98 " North & $\mathrm{C} 059$ & $104^{\circ} 47^{\prime} 3.57^{\prime \prime}$ East & $11^{\circ} 2$ ' 59.2” North \\
\hline $\mathrm{C} 019$ & $104^{\circ} 27^{\prime} 13.1^{\prime \prime}$ East & $12^{\circ} 58^{\prime} 24.9$ " North & $\mathrm{C} 060$ & $104^{\circ} 59^{\prime} 34.8^{\prime \prime}$ East & $11^{\circ} 9$ ' 32.5" North \\
\hline $\mathrm{C} 020$ & $103^{\circ} 49^{\prime} 40.7^{\prime \prime}$ East & $13^{\circ} 13^{\prime} 16.3$ " North & $\mathrm{C} 061$ & $104^{\circ} 55^{\prime} 3.95^{\prime \prime}$ East & $11^{\circ} 1$ ' $18.3^{\prime \prime}$ North \\
\hline $\mathrm{C} 021$ & $103^{\circ} 45^{\prime} 47.1^{\prime \prime}$ East & $13^{\circ} 12^{\prime} 58.7$ " North & $\mathrm{C} 062$ & $104^{\circ} 52^{\prime} 1.42^{\prime}$ East & $11^{\circ} 7$ ' 5.08" North \\
\hline $\mathrm{C} 028$ & $104^{\circ} 4^{\prime} 39.4^{\prime \prime}$ East & $13^{\circ} 3$ ' 33.9" North & $\mathrm{C} 069$ & $103^{\circ} 45^{\prime} 1.69^{\prime \prime}$ East & $12^{\circ} 41 ' 51.5 "$ North \\
\hline $\mathrm{C} 029$ & $104^{\circ} 7$ ' 10.6" East & $13^{\circ} 8$ ' 9.73 " North & $\mathrm{C} 070$ & $103^{\circ} 43^{\prime} 18.1$ ” East & $12^{\circ} 23$ ' 22.1" North \\
\hline $\mathrm{C} 030$ & $104^{\circ} 28^{\prime} 31.6^{\prime \prime}$ East & $13^{\circ} 25^{\prime} 7.99$ " North & $\mathrm{C} 071$ & $103^{\circ} 44^{\prime} 57.9^{\prime \prime}$ East & $12^{\circ} 22^{\prime} 54.9$ " North \\
\hline $\mathrm{C} 031$ & $104^{\circ} 16^{\prime} 40.1^{\prime \prime}$ East & $13^{\circ} 2$ ' $12.3^{\prime \prime}$ North & $\mathrm{C} 072$ & $103^{\circ} 48^{\prime} 9.76^{\prime \prime}$ East & $12^{\circ} 23^{\prime} 38.1$ "North \\
\hline $\mathrm{C} 032$ & $105^{\circ} 1$ ' 48.0” East & $12^{\circ} 50^{\prime} 26.6$ " North & $\mathrm{C} 073$ & $104^{\circ} 24^{\prime} 23.6^{\prime \prime}$ East & $12^{\circ} 28$ ' 18.1" North \\
\hline $\mathrm{C} 033$ & $104^{\circ} 47^{\prime} 38.2^{\prime \prime}$ East & $12^{\circ} 42^{\prime} 3.82^{\prime \prime}$ North & $\mathrm{C} 074$ & $104^{\circ} 43^{\prime} 22.4^{\prime \prime}$ East & $12^{\circ} 11 ' 54.8$ " North \\
\hline $\mathrm{C} 034$ & $104^{\circ} 53^{\prime} 35.3^{\prime \prime}$ East & $12^{\circ} 33^{\prime} 2.48^{\prime \prime}$ North & $\mathrm{C} 075$ & $104^{\circ} 44^{\prime} 43.9^{\prime \prime}$ East & $12^{\circ} 6$ ' 57.9" North \\
\hline $\mathrm{C} 035$ & $104^{\circ} 58^{\prime}$ 59.6” East & $12^{\circ} 29^{\prime} 46.8^{\prime \prime}$ North & $\mathrm{C} 076$ & $104^{\circ} 37^{\prime} 13.2^{\prime \prime}$ East & $11^{\circ} 58$ ' 22.9” North \\
\hline $\mathrm{C} 036$ & $105^{\circ} 1 ' 50.4$ ” East & $11^{\circ} 49^{\prime} 40.5$ ” North & $\mathrm{C} 077$ & $104^{\circ} 16^{\prime} 27.1^{\prime \prime}$ East & $12^{\circ} 33^{\prime}$ 55.7" North \\
\hline $\mathrm{C} 037$ & $105^{\circ} 1$ ' $34.8^{\prime \prime}$ East & $11^{\circ} 40^{\prime} 2.83$ " North & $\mathrm{C} 078$ & $104^{\circ} 20^{\prime} 11.2^{\prime \prime}$ East & $12^{\circ} 32^{\prime} 55.8^{\prime \prime}$ North \\
\hline $\mathrm{C} 038$ & $105^{\circ} 12$ ' 34.3” East & $11^{\circ} 36^{\prime} 25.0^{\prime \prime}$ North & $\mathrm{C} 079$ & $104^{\circ} 20^{\prime} 48.3^{\prime \prime}$ East & $12^{\circ} 36$ ' 40.6" North \\
\hline $\mathrm{C} 039$ & $105^{\circ} 14^{\prime} 5.02$ ” East & $11^{\circ} 44^{\prime} 59.4$ ” North & $\mathrm{C} 080$ & $104^{\circ} 18^{\prime} 12.3^{\prime \prime}$ East & $12^{\circ} 41^{\prime} 28.7$ ' North \\
\hline $\mathrm{C} 040$ & $105^{\circ} 19^{\prime} 20.7$ ' East & $11^{\circ} 31^{\prime} 16.7^{\prime \prime}$ North & $\mathrm{C} 081$ & $104^{\circ} 15^{\prime} 16.0^{\prime \prime}$ East & $12^{\circ} 44^{\prime} 2.67$ "North \\
\hline $\mathrm{C} 041$ & $105^{\circ} 23$ ' 16.9” East & $11^{\circ} 27^{\prime} 15.5^{\prime \prime}$ North & $\mathrm{C} 082$ & $104^{\circ} 17^{\prime}$ 53.4” East & $12^{\circ} 47^{\prime} 36.6^{\prime \prime}$ North \\
\hline
\end{tabular}


Appendix 5. Coordinates of 531 sediment samples collected in the Lower Mekong Basin during 2011. The label C085 was mistakenly used twice, so " $A$ " distinguishes one sample from the other.-Continued

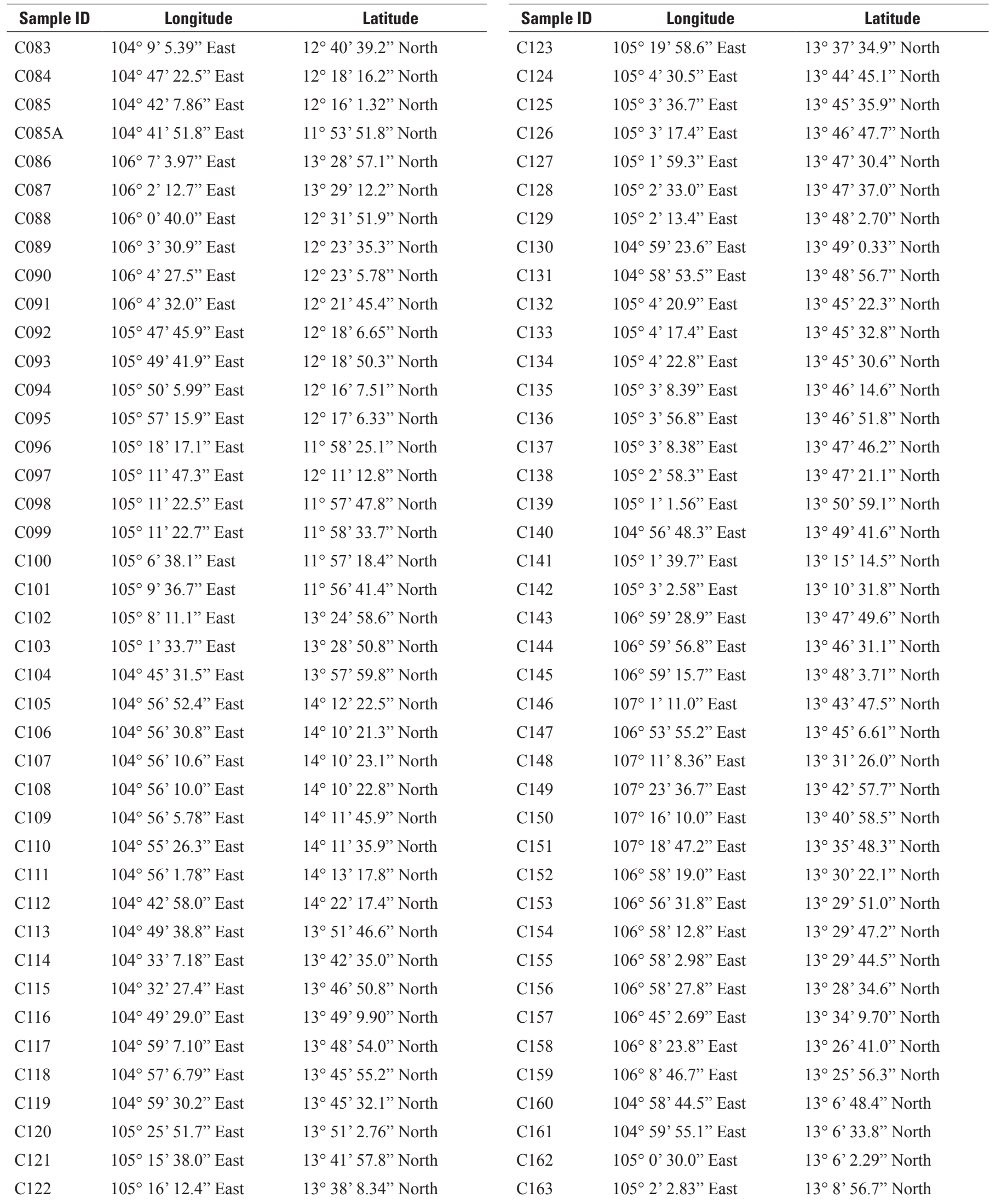


Appendix 5. Coordinates of 531 sediment samples collected in the Lower Mekong Basin during 2011. The label C085 was mistakenly used twice, so " $A$ " distinguishes one sample from the other.-Continued

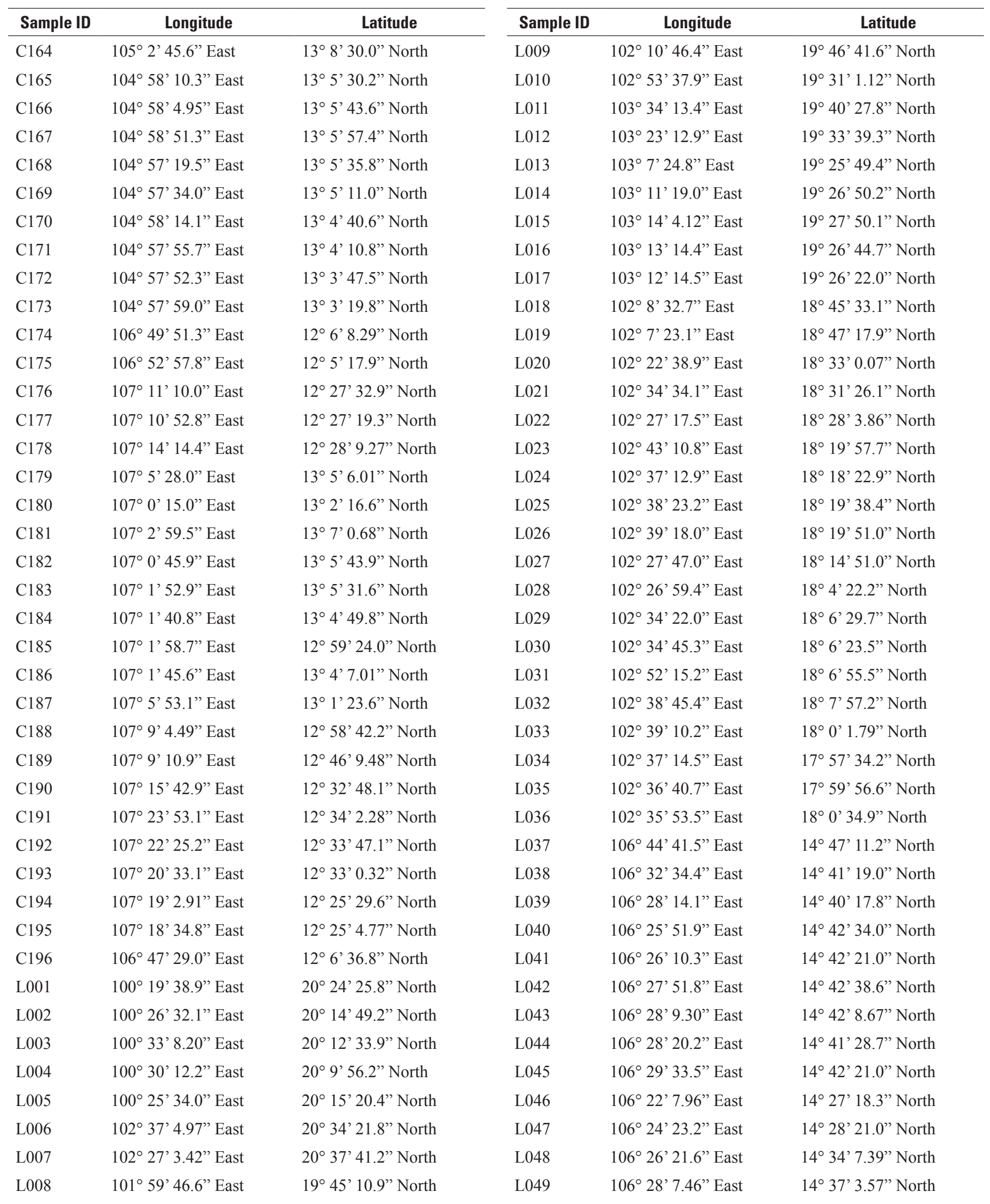


Appendix 5. Coordinates of 531 sediment samples collected in the Lower Mekong Basin during 2011. The label C085 was mistakenly used twice, so " $A$ " distinguishes one sample from the other.-Continued

\begin{tabular}{|c|c|c|c|c|c|}
\hline Sample ID & Longitude & Latitude & Sample ID & Longitude & Latitude \\
\hline L050 & $106^{\circ} 27^{\prime} 30.3^{\prime \prime}$ East & $14^{\circ} 36^{\prime} 4.53^{\prime \prime}$ North & L091 & $105^{\circ} 15^{\prime} 32.7$ " East & $16^{\circ} 22^{\prime} 59.8^{\prime \prime}$ North \\
\hline L051 & $106^{\circ} 24^{\prime} 53.6^{\prime \prime}$ East & $14^{\circ} 35^{\prime} 3.48^{\prime \prime}$ North & L092 & $105^{\circ} 10^{\prime} 2.49$ ” East & $16^{\circ} 25^{\prime} 2.81$ "North \\
\hline L053 & $106^{\circ} 25^{\prime} 32.2^{\prime \prime}$ East & $14^{\circ} 33^{\prime} 18.6^{\prime \prime}$ North & L094 & $105^{\circ} 16^{\prime} 52.8^{\prime \prime}$ East & $16^{\circ} 43^{\prime} 5.05^{\prime \prime}$ North \\
\hline L054 & $105^{\circ} 19^{\prime} 44.1$ " East & $14^{\circ} 16^{\prime} 6.05^{\prime \prime}$ North & L095 & $104^{\circ} 52^{\prime} 45.3^{\prime \prime}$ East & $16^{\circ} 39^{\prime} 48.3^{\prime \prime}$ North \\
\hline L056 & $105^{\circ} 19^{\prime} 22.3$ " East & $14^{\circ} 12^{\prime} 56.8^{\prime \prime}$ North & L097 & $104^{\circ} 49^{\prime} 19.0$ " East & $16^{\circ} 34^{\prime} 2.10^{\prime \prime}$ North \\
\hline L057 & $105^{\circ} 19^{\prime} 18.0$ " East & $14^{\circ} 13^{\prime} 45.3^{\prime \prime}$ North & L098 & $104^{\circ}$ 54' 14.8” East & $16^{\circ} 51$ ' 55.4" North \\
\hline L058 & $105^{\circ} 24^{\prime} 29.7^{\prime \prime}$ East & $14^{\circ} 14^{\prime} 12.0^{\prime \prime}$ North & L099 & $104^{\circ} 48^{\prime} 21.5^{\prime \prime}$ East & $16^{\circ} 59$ ' 48.6" North \\
\hline L059 & $105^{\circ} 29^{\prime} 31.7^{\prime \prime}$ East & $14^{\circ} 18^{\prime} 20.0^{\prime \prime}$ North & L100 & $104^{\circ} 48^{\prime} 27.5^{\prime \prime}$ East & $17^{\circ} 0$ ' 8.89 ” North \\
\hline L063 & $105^{\circ} 29^{\prime} 7.65^{\prime \prime}$ East & $14^{\circ} 23$ ' $30.6^{\prime \prime}$ North & L104 & $104^{\circ} 48^{\prime} 47.2^{\prime \prime}$ East & $17^{\circ} 23$ ' 33.0" North \\
\hline L064 & $105^{\circ} 29^{\prime} 57.8^{\prime \prime}$ East & $14^{\circ} 22$ ' 49.9" North & L105 & $104^{\circ} 51^{\prime} 5.32^{\prime \prime}$ East & $17^{\circ} 28^{\prime} 34.5^{\prime \prime}$ North \\
\hline L065 & $105^{\circ} 40 ’ 16.0$ ” East & $14^{\circ} 22$ ' 1.01 ” North & L106 & $104^{\circ} 38^{\prime} 43.6^{\prime \prime}$ East & $17^{\circ} 39^{\prime} 28.9^{\prime \prime}$ North \\
\hline L066 & $105^{\circ} 42^{\prime} 44.2^{\prime \prime}$ East & $14^{\circ} 22^{\prime} 30.2^{\prime \prime}$ North & L107 & $104^{\circ} 36^{\prime} 32.0^{\prime \prime}$ East & $17^{\circ} 43^{\prime} 3.43^{\prime \prime}$ North \\
\hline L067 & $105^{\circ} 51^{\prime} 47.4$ " East & $14^{\circ} 18^{\prime} 20.8^{\prime \prime}$ North & L108 & $104^{\circ} 37^{\prime} 15.2^{\prime \prime}$ East & $17^{\circ} 42^{\prime} 4.10^{\prime \prime}$ North \\
\hline L068 & $106^{\circ} 2^{\prime} 29.8^{\prime \prime}$ East & $14^{\circ} 45^{\prime} 49.7$ " North & L109 & $104^{\circ} 36^{\prime} 45.3^{\prime \prime}$ East & $17^{\circ} 40^{\prime} 43.2$ "North \\
\hline L069 & $106^{\circ} 5$ ' 42.2" East & $14^{\circ} 43^{\prime} 49.0^{\prime \prime}$ North & L110 & $104^{\circ} 34^{\prime} 42.4^{\prime \prime}$ East & $17^{\circ} 47^{\prime} 40.9$ " North \\
\hline L070 & $105^{\circ} 58^{\prime} 30.3^{\prime \prime}$ East & $14^{\circ} 47^{\prime} 10.5^{\prime \prime}$ North & L111 & $104^{\circ} 34^{\prime} 7.53^{\prime \prime}$ East & $17^{\circ} 47^{\prime} 13.8^{\prime \prime}$ North \\
\hline L077 & $105^{\circ} 48^{\prime} 36.6^{\prime \prime}$ East & $15^{\circ} 17^{\prime} 4.70$ ” North & L118 & $103^{\circ} 34^{\prime} 31.2^{\prime \prime}$ East & $18^{\circ} 25^{\prime} 38.6^{\prime \prime}$ North \\
\hline L078 & $105^{\circ} 49^{\prime} 42.1^{\prime \prime}$ East & $15^{\circ} 22^{\prime} 29.2^{\prime \prime}$ North & L119 & $103^{\circ} 28^{\prime} 11.6^{\prime \prime}$ East & $18^{\circ} 26^{\prime} 22.4^{\prime \prime}$ North \\
\hline L079 & $105^{\circ} 49^{\prime} 36.9^{\prime \prime}$ East & $15^{\circ} 24^{\prime} 47.5^{\prime \prime}$ North & L120 & $103^{\circ} 12 ’ 39.4$ " East & $18^{\circ} 20^{\prime} 14.2$ "North \\
\hline L080 & $105^{\circ} 49^{\prime} 28.2^{\prime \prime}$ East & $15^{\circ} 24^{\prime} 29.1^{\prime \prime}$ North & M001 & $99^{\circ} 57^{\prime} 38.6^{\prime \prime}$ East & $20^{\circ} 28^{\prime} 9.01$ " North \\
\hline L081 & $105^{\circ} 22^{\prime} 49.5^{\prime \prime}$ East & $16^{\circ} 14^{\prime} 29.2^{\prime \prime}$ North & M002 & $99^{\circ} 34^{\prime} 35.7^{\prime \prime}$ East & $20^{\circ} 16^{\prime} 52.4$ " North \\
\hline L082 & $105^{\circ} 18^{\prime} 40.3$ " East & $16^{\circ} 15^{\prime} 23.4$ " North & M003 & $99^{\circ} 59^{\prime} 13.5^{\prime \prime}$ East & $20^{\circ} 26^{\prime} 17.3$ " North \\
\hline L083 & $105^{\circ} 17^{\prime} 46.4^{\prime \prime}$ East & $16^{\circ} 15^{\prime} 54.9$ " North & M004 & $99^{\circ} 59^{\prime} 13.3$ ” East & $20^{\circ} 26^{\prime} 15.6^{\prime \prime}$ North \\
\hline L084 & $105^{\circ} 12^{\prime} 22.7^{\prime \prime}$ East & $16^{\circ} 20^{\prime} 13.4$ " North & M005 & $99^{\circ} 59^{\prime} 11.5^{\prime \prime}$ East & $20^{\circ} 26^{\prime} 19.4$ " North \\
\hline L085 & $105^{\circ} 12$ ' 18.2” East & $16^{\circ} 20^{\prime} 1.21$ ” North & M006 & $99^{\circ}$ 59’ 13.3" East & $20^{\circ} 26^{\prime} 28.0^{\prime \prime}$ North \\
\hline L086 & $106^{\circ} 13^{\prime} 19.8^{\prime \prime}$ East & $16^{\circ} 20^{\prime} 55.5^{\prime \prime}$ North & M007 & $99^{\circ} 59^{\prime} 16.6^{\prime \prime}$ East & $20^{\circ} 26^{\prime} 29.5$ " North \\
\hline L087 & $105^{\circ} 13 ’ 5.66^{\prime \prime}$ East & $16^{\circ} 21^{\prime} 6.55^{\prime \prime}$ North & M008 & $99^{\circ} 59^{\prime} 21.8^{\prime \prime}$ East & $20^{\circ} 26^{\prime} 15.5^{\prime \prime}$ North \\
\hline L088 & $105^{\circ} 13^{\prime} 0.44^{\prime \prime}$ East & $16^{\circ} 21$ ' 16.4 " North & M009 & $99^{\circ} 59^{\prime} 23.3$ " East & $20^{\circ} 26^{\prime} 17.4$ " North \\
\hline L089 & $105^{\circ} 12^{\prime} 46.6^{\prime \prime}$ East & $16^{\circ} 21^{\prime} 26.7$ " North & M010 & $99^{\circ} 58^{\prime}$ 5.77” East & $20^{\circ} 27^{\prime} 27.5$ " North \\
\hline L090 & $105^{\circ} 12^{\prime} 24.0^{\prime \prime}$ East & $16^{\circ} 20^{\prime} 41.4$ " North & M011 & $99^{\circ}$ 59’23.6” East & $20^{\circ} 27^{\prime} 25.0^{\prime \prime}$ North \\
\hline
\end{tabular}


Appendix 5. Coordinates of 531 sediment samples collected in the Lower Mekong Basin during 2011. The label C085 was mistakenly used twice, so " $A$ " distinguishes one sample from the other.-Continued

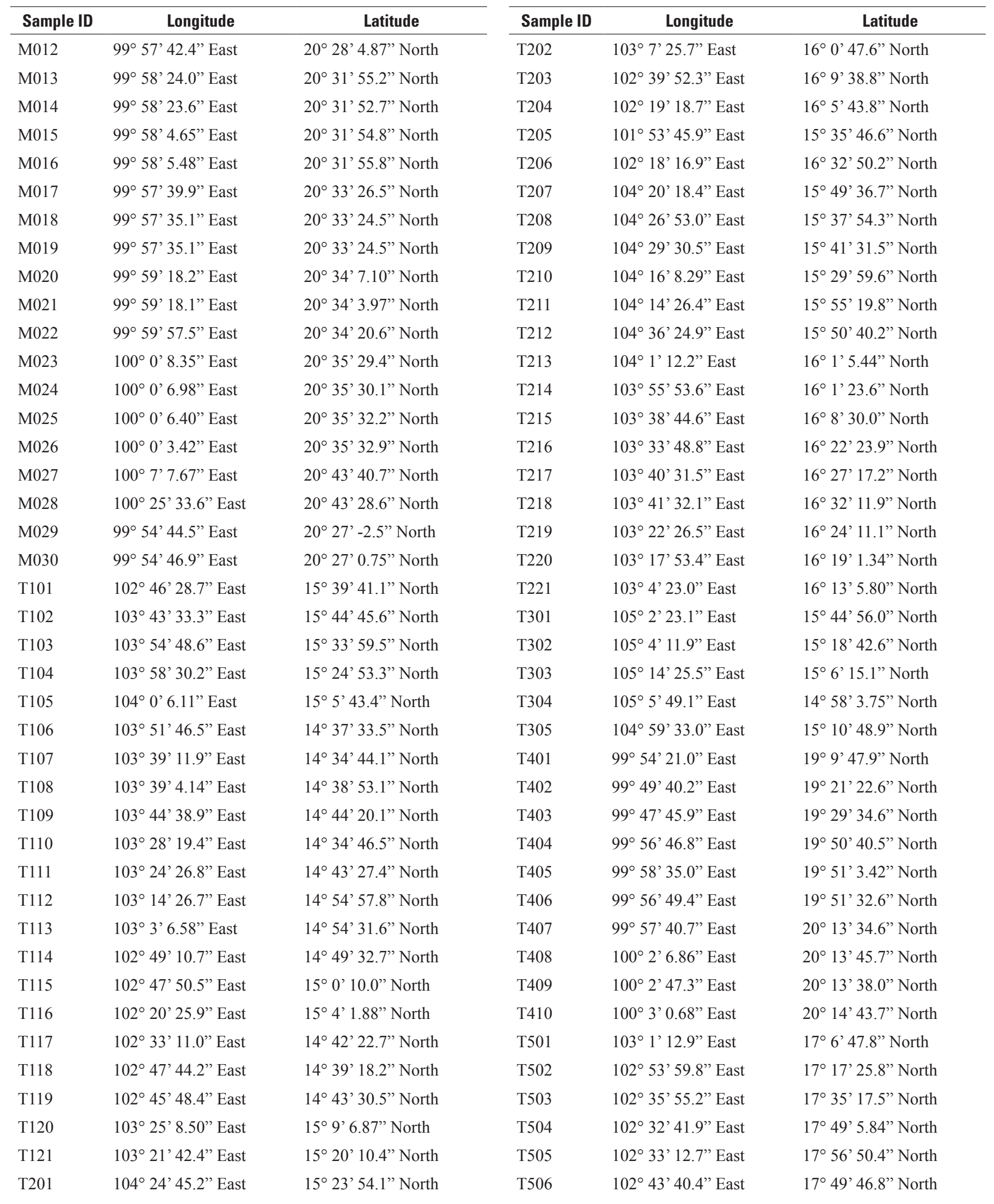


Appendix 5. Coordinates of 531 sediment samples collected in the Lower Mekong Basin during 2011. The label C085 was mistakenly used twice, so " $A$ " distinguishes one sample from the other.-Continued

\begin{tabular}{|c|c|c|c|c|c|}
\hline Sample ID & Longitude & Latitude & Sample ID & Longitude & Latitude \\
\hline T507 & $103^{\circ} 3^{\prime}$ 55.7" East & $17^{\circ} 50^{\prime} 25.6^{\prime \prime}$ North & V024 & $105^{\circ} 4^{\prime} 5.45^{\prime \prime}$ East & $10^{\circ} 55^{\prime} 0.59$ ” North \\
\hline T508 & $103^{\circ} 21 ' 53.5^{\prime \prime}$ East & $17^{\circ} 44^{\prime} 44.5^{\prime \prime}$ North & V025 & $105^{\circ}$ 4’24.7” East & $10^{\circ} 55^{\prime} 9.47$ " North \\
\hline T510 & $103^{\circ} 21^{\prime} 4.39$ ” East & $18^{\circ} 12^{\prime} 48.8^{\prime \prime}$ North & V027 & $105^{\circ} 5^{\prime} 2.03$ " East & $10^{\circ} 55^{\prime} 18.3$ " North \\
\hline T511 & $103^{\circ} 39^{\prime} 43.6^{\prime \prime}$ East & $18^{\circ} 17^{\prime} 48.2^{\prime \prime}$ North & V028 & $105^{\circ} 3$ ' 17.0" East & $10^{\circ} 34^{\prime} 18.7$ " North \\
\hline T513 & $103^{\circ} 44^{\prime} 24.5^{\prime \prime}$ East & $17^{\circ} 52$ ' $52.5^{\prime \prime}$ North & V030 & $105^{\circ} 2^{\prime} 56.8^{\prime \prime}$ East & $10^{\circ} 34^{\prime} 33.5$ " North \\
\hline T514 & $104^{\circ} 1^{\prime} 54.8^{\prime \prime}$ East & $17^{\circ} 57^{\prime} 41.6$ " North & V031 & $105^{\circ} 2^{\prime} 52.9^{\prime \prime}$ East & $10^{\circ} 34^{\prime} 11.5$ " North \\
\hline T515 & $104^{\circ} 12^{\prime} 25.8^{\prime \prime}$ East & $17^{\circ} 58^{\prime} 30.0$ " North & V032 & $104^{\circ} 34^{\prime} 3.17^{\prime \prime}$ East & $10^{\circ} 25^{\prime} 13.3^{\prime \prime}$ North \\
\hline T516 & $104^{\circ} 35^{\prime} 11.4^{\prime \prime}$ East & $17^{\circ} 20^{\prime} 18.4^{\prime \prime}$ North & V033 & $104^{\circ} 36^{\prime} 3.30^{\prime \prime}$ East & $10^{\circ} 26^{\prime} 3.41^{\prime \prime}$ North \\
\hline T520 & $103^{\circ} 55^{\prime} 39.1^{\prime \prime}$ East & $17^{\circ} 43^{\prime} 18.4$ " North & V037 & $104^{\circ} 40^{\prime} 53.6^{\prime \prime}$ East & $10^{\circ} 19^{\prime} 44.2$ "North \\
\hline $\mathrm{T} 521$ & $104^{\circ} 6^{\prime} 32.1^{\prime \prime}$ East & $17^{\circ} 29^{\prime} 21.0^{\prime \prime}$ North & V038 & $105^{\circ} 5^{\prime} 27.7$ " East & $9^{\circ} 35$ ' 17.1" North \\
\hline T522 & $104^{\circ}$ 9’ 20.2” East & $17^{\circ} 15^{\prime} 36.6$ " North & V039 & $105^{\circ}$ 4' 58.6” East & $9^{\circ} 32$ ' 55.5" North \\
\hline T523 & $103^{\circ} 51^{\prime} 1.18^{\prime \prime}$ East & $17^{\circ} 22$ ' 25.4" North & V040 & $105^{\circ} 4^{\prime} 38.3^{\prime \prime}$ East & $9^{\circ} 37^{\prime} 22.5$ " North \\
\hline T524 & $103^{\circ} 22^{\prime} 56.3^{\prime \prime}$ East & $17^{\circ} 24^{\prime} 2.23^{\prime \prime}$ North & V041 & $105^{\circ} 5^{\prime} 49.1$ " East & $9^{\circ} 36^{\prime} 53.7$ " North \\
\hline V001 & $105^{\circ} 33^{\prime} 20.2^{\prime \prime}$ East & $10^{\circ} 40^{\prime} 42.3$ ” North & V042 & $105^{\circ} 6^{\prime} 24.5^{\prime \prime}$ East & $9^{\circ} 38^{\prime} 57.8^{\prime \prime}$ North \\
\hline V002 & $105^{\circ} 31 ' 5.86^{\prime \prime}$ East & $10^{\circ} 41^{\prime} 24.9$ " North & V043 & $106^{\circ} 14^{\prime} 34.2^{\prime \prime}$ East & $9^{\circ} 29^{\prime} 23.1$ " North \\
\hline V003 & $105^{\circ} 30^{\prime} 20.4^{\prime \prime}$ East & $10^{\circ} 41^{\prime} 42.8^{\prime \prime}$ North & V044 & $106^{\circ} 17^{\prime} 2.33^{\prime \prime}$ East & $9^{\circ} 32$ ' 4.37" North \\
\hline V010 & $105^{\circ} 46^{\prime} 52.1^{\prime \prime}$ East & $10^{\circ} 47^{\prime} 35.7$ ' North & V051 & $105^{\circ} 40^{\prime} 30.2^{\prime \prime}$ East & $9^{\circ}$ 9' 37.9" North \\
\hline V011 & $105^{\circ} 42^{\prime} 41.0^{\prime \prime}$ East & $10^{\circ} 46^{\prime} 32.8^{\prime \prime}$ North & V052 & $105^{\circ} 42^{\prime} 28.4^{\prime \prime}$ East & $9^{\circ} 10^{\prime} 24.9$ " North \\
\hline V012 & $105^{\circ} 36^{\prime} 13.4$ " East & $9^{\circ} 45^{\prime} 44.3$ " North & V053 & $104^{\circ} 46^{\prime} 40.9$ " East & $8^{\circ} 36$ ' 53.3” North \\
\hline V013 & $105^{\circ} 35^{\prime} 50.5^{\prime \prime}$ East & $9^{\circ} 46^{\prime} 7.97 ”$ North & V054 & $104^{\circ} 46^{\prime} 15.9^{\prime \prime}$ East & $8^{\circ} 36^{\prime} 45.0 "$ North \\
\hline V014 & $105^{\circ} 41^{\prime} 15.4$ " East & $9^{\circ} 44^{\prime} 27.2$ " North & V055 & $104^{\circ} 45^{\prime} 42.1^{\prime \prime}$ East & $8^{\circ} 38^{\prime} 41.8^{\prime \prime}$ North \\
\hline V015 & $105^{\circ} 44^{\prime} 27.6^{\prime \prime}$ East & $9^{\circ} 43^{\prime} 52.3^{\prime \prime}$ North & V056 & $104^{\circ} 42^{\prime}$ 55.9” East & $8^{\circ} 37$ ' 3.06" North \\
\hline V016 & $105^{\circ} 42^{\prime} 33.7^{\prime \prime}$ East & $9^{\circ} 46^{\prime} 32.1$ " North & V057 & $104^{\circ} 57^{\prime} 18.7^{\prime \prime}$ East & $9^{\circ} 15^{\prime} 20.3$ " North \\
\hline V017 & $105^{\circ} 42^{\prime} 32.4^{\prime \prime}$ East & $9^{\circ} 42 ’ 32.4$ " North & V058 & $104^{\circ} 57^{\prime} 33.4^{\prime \prime}$ East & $9^{\circ} 13$ ' 26.2" North \\
\hline V018 & $105^{\circ} 48^{\prime} 9.53^{\prime \prime}$ East & $10^{\circ} 2$ ' $8.58^{\prime \prime}$ North & V059 & $104^{\circ} 57^{\prime} 33.0^{\prime \prime}$ East & $9^{\circ} 12^{\prime} 29.9$ ” North \\
\hline V019 & $105^{\circ} 26^{\prime} 49.0$ " East & $10^{\circ} 23$ ' 40.4" North & V060 & $104^{\circ} 57^{\prime} 34.1^{\prime \prime}$ East & $9^{\circ} 11$ ' 49.8" North \\
\hline V020 & $105^{\circ} 27^{\prime} 17.3^{\prime \prime}$ East & $10^{\circ} 25^{\prime} 37.0^{\prime \prime}$ North & V061 & $108^{\circ} 7$ '53.6” East & $12^{\circ} 7$ '59.6” North \\
\hline V021 & $105^{\circ} 30^{\prime} 10.7^{\prime \prime}$ East & $10^{\circ} 25$ ' 9.12 " North & V062 & $108^{\circ} 12^{\prime} 49.6^{\prime \prime}$ East & $12^{\circ} 10^{\prime} 56.1$ "North \\
\hline V022 & $105^{\circ} 30^{\prime} 9.29^{\prime \prime}$ East & $10^{\circ} 25^{\prime} 9.83^{\prime \prime}$ North & V063 & $107^{\circ} 58^{\prime} 0.26^{\prime \prime}$ East & $12^{\circ} 18^{\prime} 16.8^{\prime \prime}$ North \\
\hline V023 & $105^{\circ} 30^{\prime} 8.99$ " East & $10^{\circ} 25^{\prime} 10.3$ " North & V064 & $107^{\circ} 59^{\prime} 2.65^{\prime \prime}$ East & $12^{\circ} 26^{\prime} 47.4$ " North \\
\hline
\end{tabular}


Appendix 5. Coordinates of 531 sediment samples collected in the Lower Mekong Basin during 2011. The label C085 was mistakenly used twice, so " $A$ " distinguishes one sample from the other.-Continued

\begin{tabular}{|c|c|c|}
\hline Sample ID & Longitude & Latitude \\
\hline V065 & $107^{\circ} 48^{\prime} 37.2^{\prime \prime}$ East & $12^{\circ} 43^{\prime} 52.6^{\prime \prime}$ North \\
\hline V066 & $107^{\circ} 56^{\prime} 59.4^{\prime \prime}$ East & $12^{\circ} 37^{\prime} 30.4^{\prime \prime}$ North \\
\hline V067 & $108^{\circ} 26^{\prime} 19.5^{\prime \prime}$ East & $12^{\circ} 40^{\prime} 10.7$ " North \\
\hline V068 & $108^{\circ} 25^{\prime} 45.9^{\prime \prime}$ East & $12^{\circ} 38^{\prime} 38.0^{\prime \prime}$ North \\
\hline V069 & $108^{\circ} 33^{\prime}$ 55.5" East & $12^{\circ} 27^{\prime} 51.5^{\prime \prime}$ North \\
\hline V070 & $108^{\circ} 29^{\prime} 59.0^{\prime \prime}$ East & $12^{\circ} 30^{\prime} 49.9$ " North \\
\hline V071 & $108^{\circ} 19^{\prime} 13.2^{\prime \prime}$ East & $12^{\circ} 31^{\prime} 46.1^{\prime \prime}$ North \\
\hline V072 & $108^{\circ} 10^{\prime} 51.6^{\prime \prime}$ East & $12^{\circ} 26^{\prime} 4.45^{\prime \prime}$ North \\
\hline V073 & $108^{\circ} 11^{\prime} 5.13^{\prime \prime}$ East & $12^{\circ} 25^{\prime} 28.4^{\prime \prime}$ North \\
\hline V074 & $108^{\circ} 11^{\prime} 15.8^{\prime \prime}$ East & $12^{\circ} 25^{\prime} 6.29^{\prime \prime}$ North \\
\hline V075 & $108^{\circ} 4$ ' $8.56^{\prime \prime}$ East & $12^{\circ} 24^{\prime} 30.2^{\prime \prime}$ North \\
\hline V076 & $108^{\circ}$ 9' $58.4^{\prime \prime}$ East & $12^{\circ} 22^{\prime} 18.8^{\prime \prime}$ North \\
\hline V077 & $108^{\circ} 6^{\prime} 6.92^{\prime \prime}$ East & $12^{\circ} 26^{\prime} 36.5^{\prime \prime}$ North \\
\hline V078 & $107^{\circ} 58^{\prime}$ 54.6" East & $12^{\circ} 30^{\prime} 0.04^{\prime \prime}$ North \\
\hline V079 & $108^{\circ} 2{ }^{\prime} 39.2^{\prime \prime}$ East & $12^{\circ} 35^{\prime} 58.4^{\prime \prime}$ North \\
\hline V080 & $108^{\circ} 11^{\prime} 34.9^{\prime \prime}$ East & $12^{\circ} 44^{\prime} 18.1^{\prime \prime}$ North \\
\hline V081 & $107^{\circ} 54^{\prime} 38.4^{\prime \prime}$ East & $12^{\circ} 41^{\prime} 8.87^{\prime \prime}$ North \\
\hline V082 & $107^{\circ} 54^{\prime} 35.6^{\prime \prime}$ East & $12^{\circ} 40^{\prime} 5.81^{\prime \prime}$ North \\
\hline V083 & $107^{\circ} 59^{\prime}$ ' 18.6" East & $12^{\circ} 41^{\prime} 13.4$ " North \\
\hline V084 & $107^{\circ} 50^{\prime} 21.8^{\prime \prime}$ East & $12^{\circ} 49^{\prime} 50.2^{\prime \prime}$ North \\
\hline V085 & $107^{\circ} 40^{\prime} 0.37^{\prime \prime}$ East & $12^{\circ} 57^{\prime} 27.7^{\prime \prime}$ North \\
\hline V086 & $107^{\circ} 39^{\prime} 10.7^{\prime \prime}$ East & $12^{\circ} 58^{\prime} 31.1$ " North \\
\hline V087 & $107^{\circ} 46^{\prime} 19.1$ " East & $12^{\circ} 50^{\prime} 8.09^{\prime \prime}$ North \\
\hline V088 & $107^{\circ} 48^{\prime} 23.4^{\prime \prime}$ East & $12^{\circ} 52^{\prime} 4.62^{\prime \prime}$ North \\
\hline V089 & $107^{\circ} 36^{\prime} 51.8^{\prime \prime}$ East & $13^{\circ} 18^{\prime} 25.6^{\prime \prime}$ North \\
\hline V090 & $107^{\circ} 43^{\prime} 7.50^{\prime \prime}$ East & $13^{\circ} 15^{\prime} 43.9^{\prime \prime}$ North \\
\hline V091 & $107^{\circ} 50^{\prime} 18.5^{\prime \prime}$ East & $13^{\circ} 13^{\prime} 0.35^{\prime \prime}$ North \\
\hline V092 & $107^{\circ} 50^{\prime} 17.4^{\prime \prime}$ East & $14^{\circ} 36^{\prime} 53.8^{\prime \prime}$ North \\
\hline V093 & $107^{\circ} 54^{\prime} 23.2^{\prime \prime}$ East & $14^{\circ} 22^{\prime} 12.3^{\prime \prime}$ North \\
\hline V094 & $107^{\circ} 55^{\prime} 44.7^{\prime \prime}$ East & $14^{\circ} 22^{\prime} 27.2^{\prime \prime}$ North \\
\hline V095 & $108^{\circ} 7^{\prime} 58.7$ " East & $14^{\circ} 25^{\prime} 41.3^{\prime \prime}$ North \\
\hline V096 & $108^{\circ} 2^{\prime} 52.4^{\prime \prime}$ East & $14^{\circ} 21^{\prime} 59.3$ " North \\
\hline V097 & $107^{\circ} 29^{\prime} 10.7$ " East & $13^{\circ} 57^{\prime} 44.0^{\prime \prime}$ North \\
\hline V098 & $107^{\circ} 41^{\prime} 29.0^{\prime \prime}$ East & $13^{\circ} 57^{\prime} 58.3^{\prime \prime}$ North \\
\hline V099 & $106^{\circ} 46^{\prime} 38.7^{\prime \prime}$ East & $10^{\circ} 27^{\prime} 12.5^{\prime \prime}$ North \\
\hline V100 & $106^{\circ} 53^{\prime} 13.5^{\prime \prime}$ East & $10^{\circ} 23^{\prime} 9.03^{\prime \prime}$ North \\
\hline V101 & $106^{\circ} 53^{\prime} 13.3^{\prime \prime}$ East & $10^{\circ} 23^{\prime} 11.6^{\prime \prime}$ North \\
\hline V102 & $107^{\circ} 1{ }^{\prime} 25.8^{\prime \prime}$ East & $10^{\circ} 38^{\prime} 11.2^{\prime \prime}$ North \\
\hline V103 & $107^{\circ} 0$ ' 20.4" East & $10^{\circ} 40^{\prime} 23.9$ " North \\
\hline
\end{tabular}




\section{Appendix 6.}

Wetland attribute data for all 531 persistent organic pollutant (POP) samples collected in Southeast Asia during 2011. Codes used for ecological region, river connection, wetland system, wetland subsystem, wetland type, wetland protection status, hydrological regime, wetland vegetation, and surface soil texture are listed in table 2. Country codes are listed as Cambodia (1), Lao PDR (2), Thailand (3), Vietnam (4), and Myanmar (5). Hydrological connection codes describe how rivers were connected to wetlands: surface flow only (1), channel flow (2), both channel and surface flow (3), and no connection to river (4). Measurements for surface soil texture, depth, color, and dampness refer to the top layer of soil only. Soil depth was measured in centimeters (cm). Soil color follows Munsell Color Chart codes (Munsell Soil Color Charts, 2009). Water permanence was measured only as water persisting all year round (permanent) or seasonal. The number of months that the wetland would dry in an average year was estimated. Lastly, human use of lands surrounding each wetland was grouped into the following categories: rice, vegetable (veg), fruit, rubber (rub), eucalyptus (euc), coffee (cof), and none (natural surroundings). For all variables, dashes represent situations where data were absent. Only water permanence, number of months dry, and land use variables were collected through interviews that reflect the wetland in general. All other variables were collected from the POPs sampling point. The label C085 was mistakenly used twice, so " $A$ " distinguishes one sample from the other. 
Appendix 6. Wetland attribute data for all 531 persistent organic pollutant (POP) samples collected in Southeast Asia during 2011. Codes used for ecological region, river connection, wetland system, wetland subsystem, wetland type, wetland protection status, hydrological regime, wetland vegetation, and surface soil texture are listed in table

2. Country codes are listed as Cambodia (1), Lao PDR (2), Thailand (3), Vietnam (4), and Myanmar (5). Hydrological connection codes describe how rivers were connected to wetlands, such as surface flow only (1), channel flow (2), both channel and surface flow (3), and no connection to river (4). Measurements for surface soil texture, depth, color, and dampness refer to the top layer of soil only. Soil depth was measured in centimeters (cm). Soil color follows Munsell Color Chart codes (Munsell Soil Color Charts, 2009). Water permanence was measured only as water persisting all year round (permanent) or seasonal. The number of months that the wetland would dry in an average year was estimated. Finally, human use of lands surrounding each wetland was grouped into the following categories: rice, vegetable (veg), fruit, rubber (rub), eucalyptus (euc), coffee (cof), and none (natural surroundings). For all variables, dashes represent situations where data were absent. Only water permanence, number of months dry, and land use variables were collected through interviews that reflect the wetland in general. All other variables were collected from the P0Ps sampling point. The label C085 was mistakenly used twice, so " $A$ " distinguishes one sample from the other.

\begin{tabular}{|c|c|c|c|c|c|c|c|c|c|c|c|c|c|c|c|c|c|c|}
\hline $\begin{array}{l}\text { 응 } \\
\text { 을 } \\
\text { 鹿 } \\
\text { 옴 }\end{array}$ & 壱 & 흠 & 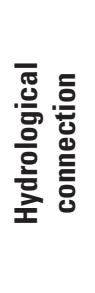 & 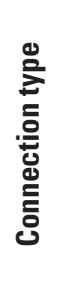 & E⿱ & 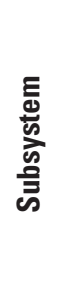 & 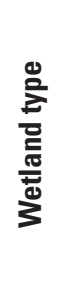 & 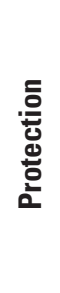 & 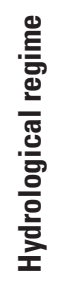 & 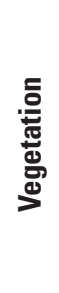 & 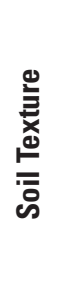 & 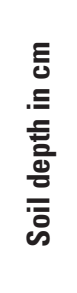 & 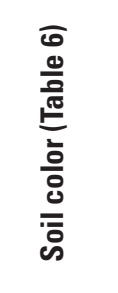 & 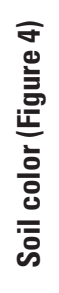 & 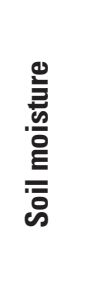 & 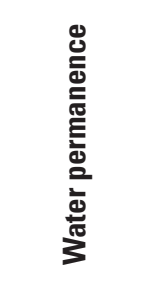 & 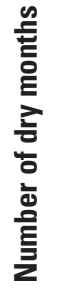 & 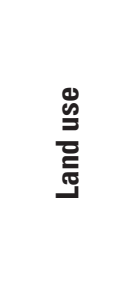 \\
\hline $\mathrm{C} 001$ & 1 & 10 & 4 & 0 & 3 & 4 & 1 & 0 & 4 & 5 & 1 & 5 & $5 \mathrm{Y}$ & 9 & wet & seasonal & 2 & Rice \\
\hline $\mathrm{C} 002$ & 1 & 10 & 4 & 0 & 2 & 2 & 2 & 1 & 3 & 1 & 2 & - & - & - & wet & permanent & 0 & Rice \\
\hline $\mathrm{C} 003$ & 1 & 10 & 4 & 0 & 3 & 4 & 1 & 0 & 4 & 2 & 3 & 12 & $5 \mathrm{Y}$ & 9 & wet & seasonal & 3 & Rice \\
\hline $\mathrm{C} 004$ & 1 & 10 & 4 & 0 & 3 & 4 & 2 & 1 & 3 & 1 & 3 & 8 & $5 \mathrm{R}$ & 1 & wet & permanent & 0 & Rice \\
\hline $\mathrm{C} 005$ & 1 & 10 & 4 & 0 & 3 & 4 & 2 & 1 & 3 & 5 & 3 & 4 & $5 \mathrm{R}$ & 1 & wet & permanent & 0 & Rice \\
\hline $\mathrm{C} 006$ & 1 & 10 & 4 & 0 & 3 & 4 & 2 & 1 & 3 & 2 & 3 & 18.5 & $10 \mathrm{YR}$ & 7 & wet & permanent & 0 & Rice \\
\hline $\mathrm{C} 007$ & 1 & 10 & 4 & 0 & 3 & 4 & 2 & 0 & 3 & 2 & 1 & 10.5 & $10 \mathrm{R}$ & 3 & wet & permanent & 0 & Rice \\
\hline $\mathrm{C} 008$ & 1 & 10 & 4 & 0 & 2 & 3 & 2 & 0 & 3 & 1 & 2 & - & - & - & wet & permanent & 0 & Rice, Veg \\
\hline C009 & 1 & 10 & 2 & 1 & 4 & 6 & 1 & 0 & 1 & 5 & 4 & - & - & - & wet & permanent & 0 & Veg \\
\hline $\mathrm{C} 010$ & 1 & 10 & 2 & 1 & 4 & 6 & 1 & 0 & 1 & 5 & 1 & 4 & $5 \mathrm{YR}$ & 5 & wet & permanent & 0 & Rice \\
\hline $\mathrm{C} 011$ & 1 & 10 & 2 & 1 & 2 & 3 & 1 & 0 & 2 & 5 & 4 & - & - & - & wet & permanent & 0 & Rice \\
\hline $\mathrm{C} 012$ & 1 & 10 & 2 & 1 & 3 & 4 & 1 & 0 & 2 & 5 & 4 & - & - & - & wet & permanent & 0 & Veg \\
\hline $\mathrm{C} 013$ & 1 & 11 & 2 & 1 & 3 & 4 & 1 & 0 & 2 & 2 & 1 & 30 & $5 \mathrm{Y}$ & 9 & moist & permanent & 0 & Rice \\
\hline $\mathrm{C} 014$ & 1 & 11 & 2 & 1 & 3 & 4 & 1 & 0 & 2 & 1 & 1 & 35 & $5 \mathrm{R}$ & 1 & wet & permanent & 0 & Rice, Veg \\
\hline $\mathrm{C} 015$ & 1 & 11 & 4 & 0 & 3 & 4 & 1 & 0 & 3 & 2 & 1 & 3 & $5 \mathrm{YR}$ & 5 & wet & permanent & 0 & Rice \\
\hline $\mathrm{C} 016$ & 1 & 10 & 4 & 0 & 3 & 4 & 2 & 0 & 3 & 2 & 3 & 20 & $5 \mathrm{YR}$ & 5 & wet & permanent & 0 & Rice \\
\hline $\mathrm{C} 017$ & 1 & 10 & 2 & 1 & 2 & 3 & 1 & 0 & 2 & 5 & 3 & 4 & $2.5 \mathrm{YR}$ & 4 & wet & - & - & - \\
\hline $\mathrm{C} 018$ & 1 & 10 & 4 & 0 & 3 & 4 & 1 & 0 & 3 & 1 & 1 & 13 & $5 \mathrm{YR}$ & 5 & wet & permanent & 0 & Rice \\
\hline C019 & 1 & 10 & 4 & 0 & 3 & 4 & 1 & 0 & 3 & 2 & 1 & 5 & $2.5 \mathrm{YR}$ & 4 & wet & permanent & 0 & Rice \\
\hline $\mathrm{C} 020$ & 1 & 10 & 2 & 1 & 2 & 3 & 1 & 0 & 2 & 5 & 3 & 16 & $5 \mathrm{YR}$ & 5 & wet & - & - & - \\
\hline
\end{tabular}




\section{$\|1\| 111\|1\| 1\|\|$}

\begin{tabular}{|c|c|c|c|c|c|c|c|c|c|c|c|c|c|c|c|c|c|c|}
\hline $\mathrm{C} 021$ & 1 & 10 & 2 & 1 & 2 & 3 & 1 & 0 & 2 & 5 & 4 & - & - & - & wet & - & - & - \\
\hline $\mathrm{C} 022$ & 1 & 10 & 2 & 1 & 2 & 3 & 1 & 0 & 2 & 5 & 4 & - & - & - & wet & - & - & - \\
\hline $\mathrm{C} 023$ & 1 & 10 & 2 & 1 & 2 & 3 & 1 & 0 & 2 & 5 & 1 & 8 & $5 \mathrm{Y}$ & 9 & wet & - & - & - \\
\hline $\mathrm{C} 024$ & 1 & 10 & 2 & 1 & 2 & 3 & 1 & 0 & 2 & 5 & 3 & 17 & $5 \mathrm{Y}$ & 9 & wet & - & - & - \\
\hline $\mathrm{C} 025$ & 1 & 10 & 2 & 1 & 2 & 3 & 1 & 1 & 2 & 5 & 1 & 5.5 & $2.5 \mathrm{YR}$ & 4 & wet & permanent & 0 & - \\
\hline $\mathrm{C} 026$ & 1 & 10 & 4 & 0 & 3 & 4 & 1 & 0 & 3 & 2 & 3 & 23 & $5 \mathrm{YR}$ & 5 & wet & permanent & 0 & Rice \\
\hline $\mathrm{C} 027$ & 1 & 10 & 2 & 1 & 2 & 3 & 1 & 0 & 2 & 5 & 3 & 50 & $10 \mathrm{R}$ & 3 & wet & permanent & 0 & Veg \\
\hline $\mathrm{C} 028$ & 1 & 10 & 2 & 1 & 2 & 3 & 1 & 0 & 2 & 5 & 4 & - & - & - & wet & permanent & 0 & Rice, Veg \\
\hline $\mathrm{C} 029$ & 1 & 10 & 2 & 1 & 3 & 4 & 1 & 0 & 2 & 2 & 1 & 11 & $10 \mathrm{R}$ & 3 & wet & permanent & 0 & - \\
\hline $\mathrm{C} 030$ & 1 & 10 & 4 & 0 & 3 & 4 & 1 & 1 & 3 & 2 & 3 & 1.5 & $5 \mathrm{R}$ & 1 & wet & permanent & 0 & Rice \\
\hline $\mathrm{C} 031$ & 1 & 10 & 4 & 0 & 3 & 4 & 1 & 0 & 4 & 2 & 1 & 2 & $5 \mathrm{R}$ & 1 & moist & seasonal & 6 & Rice \\
\hline $\mathrm{C} 032$ & 1 & 10 & 2 & 1 & 3 & 4 & 1 & 0 & 1 & 5 & 1 & 2.5 & $10 \mathrm{R}$ & 3 & wet & permanent & 0 & Rice \\
\hline $\mathrm{C} 033$ & 1 & 10 & 2 & 1 & 4 & 6 & 1 & 0 & 2 & 5 & 3 & 9 & $5 \mathrm{Y}$ & 9 & wet & permanent & 0 & Rice \\
\hline $\mathrm{C} 034$ & 1 & 10 & 2 & 1 & 3 & 4 & 1 & 0 & 2 & 5 & 1 & 9.5 & - & - & moist & permanent & 0 & Rice \\
\hline $\mathrm{C} 035$ & 1 & 10 & 4 & 0 & 3 & 4 & 1 & 0 & 3 & 5 & 3 & 16 & $5 \mathrm{Y}$ & 9 & wet & permanent & 0 & Rice \\
\hline $\mathrm{C} 036$ & 1 & 11 & 4 & 0 & 3 & 4 & 1 & 0 & 3 & 2 & 1 & 13 & $2.5 \mathrm{Y}$ & 8 & wet & permanent & 0 & Rice, Veg \\
\hline $\mathrm{C} 037$ & 1 & 11 & 4 & 0 & 3 & 4 & 1 & 0 & 3 & 2 & 1 & 9 & $2.5 \mathrm{Y}$ & 8 & wet & seasonal & 2 & Rice \\
\hline C038 & 1 & 11 & 2 & 1 & 3 & 4 & 1 & 0 & 2 & 2 & 1 & 14 & $7.5 \mathrm{YR}$ & 6 & wet & seasonal & 3 & Rice, Veg \\
\hline C039 & 1 & 11 & 4 & 0 & 3 & 4 & 1 & 0 & 3 & 2 & 3 & 14 & $10 \mathrm{R}$ & 3 & wet & permanent & 0 & Rice, Veg \\
\hline C040 & 1 & 11 & 2 & 1 & 3 & 4 & 1 & 0 & 2 & 2 & 1 & 32 & $5 \mathrm{Y}$ & 9 & wet & seasonal & 3 & Rice \\
\hline $\mathrm{C} 041$ & 1 & 11 & 3 & 1 & 2 & 2 & 1 & 0 & 2 & 5 & 3 & 9 & $5 \mathrm{Y}$ & 9 & wet & permanent & 0 & Rice \\
\hline $\mathrm{C} 042$ & 1 & 11 & 3 & 1 & 3 & 4 & 1 & 0 & 2 & 2 & 1 & 7 & $2.5 \mathrm{Y}$ & 8 & wet & permanent & 0 & Rice, Veg \\
\hline $\mathrm{C} 043$ & 1 & 11 & 2 & 1 & 2 & 3 & 1 & 0 & 2 & 5 & 1 & 6 & $5 \mathrm{YR}$ & 5 & wet & permanent & 0 & Rice \\
\hline $\mathrm{C} 044$ & 1 & 11 & 4 & 0 & 3 & 4 & 1 & 0 & 4 & 2 & 3 & 7 & $10 \mathrm{R}$ & 3 & wet & seasonal & 1 & Rice \\
\hline C045 & 1 & 11 & 4 & 0 & 3 & 4 & 1 & 0 & 3 & 2 & 3 & 9 & - & - & wet & permanent & 0 & Rice, Veg \\
\hline C046 & 1 & 11 & 2 & 1 & 3 & 4 & 1 & 0 & 2 & 2 & 1 & 7 & $5 \mathrm{R}$ & 1 & wet & permanent & 0 & Rice, Veg \\
\hline C047 & 1 & 11 & 2 & 1 & 3 & 4 & 1 & 0 & 2 & 1 & 1 & 33.5 & $5 \mathrm{YR}$ & 5 & wet & - & - & - \\
\hline $\mathrm{C} 048$ & 1 & 11 & 2 & 1 & 3 & 4 & 1 & 0 & 2 & 2 & 1 & 14 & $5 \mathrm{R}$ & 1 & wet & permanent & 0 & Rice, Veg \\
\hline
\end{tabular}


Appendix 6. Wetland attribute data for all 531 persistent organic pollutant (POP) samples collected in Southeast Asia during 2011. Codes used for ecological region, river connection, wetland system, wetland subsystem, wetland type, wetland protection status, hydrological regime, wetland vegetation, and surface soil texture are listed in table

2. Country codes are listed as Cambodia (1), Lao PDR (2), Thailand (3), Vietnam (4), and Myanmar (5). Hydrological connection codes describe how rivers were connected to wetlands, such as surface flow only (1), channel flow (2), both channel and surface flow (3), and no connection to river (4). Measurements for surface soil texture, depth, color, and dampness refer to the top layer of soil only. Soil depth was measured in centimeters (cm). Soil color follows Munsell Color Chart codes (Munsell Soil Color Charts, 2009). Water permanence was measured only as water persisting all year round (permanent) or seasonal. The number of months that the wetland would dry in an average year was estimated. Finally, human use of lands surrounding each wetland was grouped into the following categories: rice, vegetable (veg), fruit, rubber (rub), eucalyptus (euc), coffee (cof), and none (natural surroundings). For all variables, dashes represent situations where data were absent. Only water permanence, number of months dry, and land use variables were collected through interviews that reflect the wetland in general. All other variables were collected from the P0Ps sampling point. The label C085 was mistakenly used twice, so " $A$ " distinguishes one sample from the other.-Continued

\begin{tabular}{|c|c|c|c|c|c|c|c|c|c|c|c|c|c|c|c|c|c|c|}
\hline $\begin{array}{l}\text { 으 } \\
\text { 을 } \\
\text { 言 } \\
\text { 心 } \\
\text { 음 }\end{array}$ & 壱 & . 흘 & 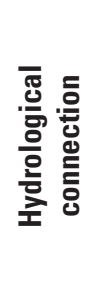 & 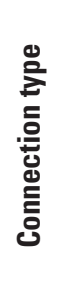 & $\begin{array}{l}E \\
\frac{\bar{J}}{\omega} \\
\vec{\omega}\end{array}$ & 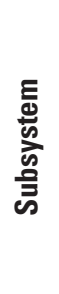 & 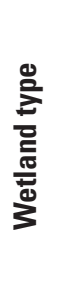 & 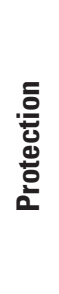 & 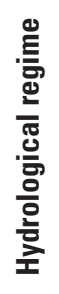 & 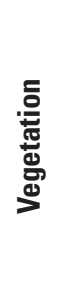 & 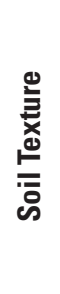 & 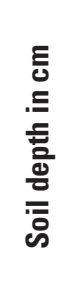 & 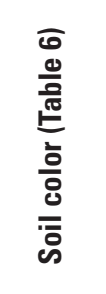 & 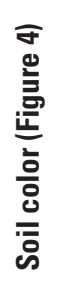 & 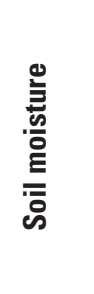 & 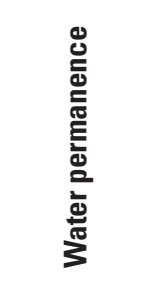 & 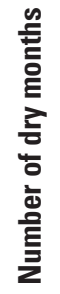 & 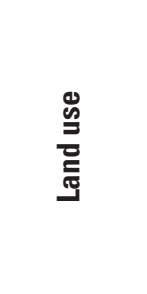 \\
\hline C049 & 1 & 11 & 2 & 1 & 3 & 4 & 1 & 0 & 2 & 2 & 1 & 21 & $2.5 \mathrm{YR}$ & 4 & moist & seasonal & 4 & Rice \\
\hline $\mathrm{C} 050$ & 1 & 11 & 4 & 0 & 3 & 4 & 1 & 0 & 4 & 2 & 1 & 5 & $10 \mathrm{R}$ & 3 & dry & seasonal & 4 & Rice \\
\hline $\mathrm{C} 051$ & 1 & 11 & 4 & 0 & 3 & 4 & 1 & 0 & 3 & 2 & 3 & 2.5 & $10 \mathrm{YR}$ & 7 & wet & permanent & 0 & Rice, Veg \\
\hline $\mathrm{C} 052$ & 1 & 11 & 2 & 1 & 3 & 4 & 1 & 0 & 2 & 2 & 1 & 12 & $7.5 \mathrm{R}$ & 2 & wet & seasonal & 4 & Rice, Veg \\
\hline $\mathrm{C} 053$ & 1 & 11 & 4 & 0 & 3 & 4 & 1 & 0 & 3 & 2 & 1 & 14 & $7.5 \mathrm{YR}$ & 6 & wet & seasonal & 4 & Rice \\
\hline $\mathrm{C} 054$ & 1 & 11 & 4 & 0 & 3 & 4 & 1 & 0 & 3 & 2 & 1 & 17 & $10 \mathrm{R}$ & 3 & wet & permanent & 0 & Rice, Veg \\
\hline $\mathrm{C} 055$ & 1 & 11 & 2 & 1 & 2 & 3 & 1 & 0 & 2 & 5 & 1 & 4 & $10 \mathrm{R}$ & 3 & wet & seasonal & 4 & Rice \\
\hline C056 & 1 & 11 & 2 & 1 & 3 & 4 & 1 & 0 & 2 & 2 & 1 & 13 & $10 \mathrm{YR}$ & 7 & wet & seasonal & 4 & Rice, Veg \\
\hline $\mathrm{C} 057$ & 1 & 11 & 2 & 1 & 2 & 3 & 1 & 0 & 2 & 5 & 3 & 5 & $2.5 \mathrm{Y}$ & 8 & wet & permanent & 0 & Rice \\
\hline $\mathrm{C} 058$ & 1 & 11 & 2 & 1 & 3 & 4 & 1 & 0 & 2 & 2 & 1 & 10.5 & $10 \mathrm{R}$ & 3 & wet & permanent & 0 & Rice, Veg \\
\hline C059 & 1 & 11 & 2 & 1 & 2 & 3 & 1 & 0 & 2 & 5 & 3 & 11 & $10 \mathrm{R}$ & 3 & wet & permanent & 0 & Rice \\
\hline $\mathrm{C} 060$ & 1 & 11 & 2 & 1 & 3 & 4 & 1 & 0 & 2 & 1 & 1 & 9 & $10 \mathrm{YR}$ & 7 & wet & permanent & 0 & Rice \\
\hline C061 & 1 & 11 & 2 & 1 & 3 & 4 & 1 & 0 & 2 & 2 & 1 & 33 & $5 \mathrm{Y}$ & 9 & wet & seasonal & 3 & Rice \\
\hline C062 & 1 & 11 & 2 & 1 & 3 & 4 & 1 & 0 & 2 & 1 & 3 & 9 & $10 \mathrm{R}$ & 3 & wet & seasonal & 3 & Rice, Veg \\
\hline $\mathrm{C} 063$ & 1 & 11 & 4 & 0 & 2 & 3 & 1 & 0 & 3 & 5 & 3 & 5 & $10 \mathrm{R}$ & 3 & wet & permanent & 0 & $\begin{array}{l}\text { Rice, Veg, } \\
\text { Fruit }\end{array}$ \\
\hline C064 & 1 & 11 & 2 & 1 & 2 & 3 & 1 & 0 & 2 & 5 & 3 & 7 & $5 \mathrm{YR}$ & 5 & wet & permanent & 0 & Rice, Veg \\
\hline $\mathrm{C} 065$ & 1 & 11 & 4 & 0 & 3 & 4 & 1 & 0 & 3 & 2 & 3 & 13 & - & - & wet & permanent & 0 & Rice, Veg \\
\hline C066 & 1 & 11 & 2 & 1 & 3 & 4 & 1 & 0 & 2 & 2 & 3 & 10 & $5 \mathrm{YR}$ & 5 & wet & permanent & 0 & Rice, Veg \\
\hline
\end{tabular}




\begin{tabular}{|c|c|c|c|c|c|c|c|c|c|c|c|c|c|c|c|c|c|c|}
\hline 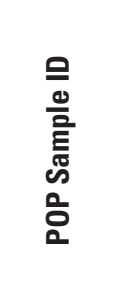 & $\begin{array}{l}\text { Ḋ } \\
\text { 言 }\end{array}$ & 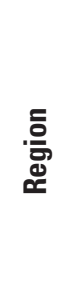 & 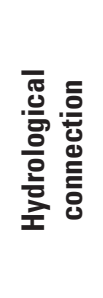 & 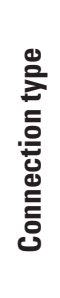 & $\begin{array}{l}\bar{E} \\
\text { s. } \\
\text { के }\end{array}$ & 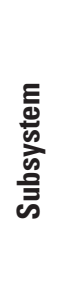 & 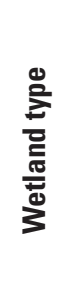 & 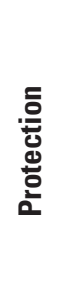 & 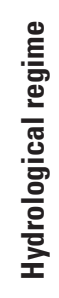 & 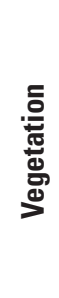 & 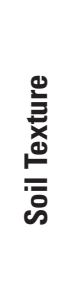 & 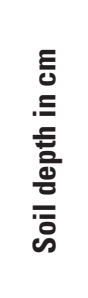 & 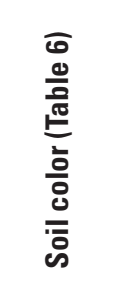 & 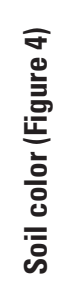 & 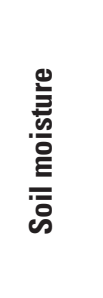 & 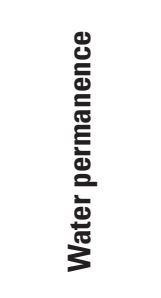 & 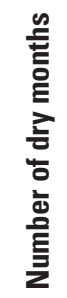 & 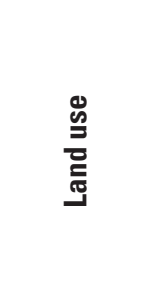 \\
\hline C067 & 1 & 11 & 2 & 1 & 3 & 4 & 1 & 0 & 2 & 2 & 1 & 12 & $2.5 \mathrm{YR}$ & 4 & moist & permanent & 0 & Rice, Veg \\
\hline C068 & 1 & 10 & 4 & 0 & 3 & 4 & 1 & 0 & 3 & 5 & 1 & 14 & $10 \mathrm{YR}$ & 7 & wet & permanent & 0 & Rice \\
\hline C069 & 1 & 10 & 2 & 1 & 3 & 4 & 1 & 0 & 2 & 5 & 3 & 33 & $10 \mathrm{YR}$ & 7 & wet & seasonal & 4 & Rice \\
\hline $\mathrm{C} 070$ & 1 & 10 & 4 & 0 & 3 & 4 & 1 & 0 & 3 & 2 & 3 & 14 & - & - & wet & permanent & 0 & Rice \\
\hline $\mathrm{C} 071$ & 1 & 10 & 2 & 1 & 3 & 4 & 1 & 0 & 2 & 2 & 1 & 15 & 10YR & 7 & wet & permanent & 0 & Rice \\
\hline $\mathrm{C} 072$ & 1 & 10 & 4 & 0 & 3 & 4 & 1 & 0 & 3 & 2 & 3 & 13 & $2.5 \mathrm{YR}$ & 4 & wet & permanent & 0 & Rice, Veg \\
\hline $\mathrm{C} 073$ & 1 & 10 & 4 & 0 & 3 & 4 & 1 & 0 & 3 & 2 & 3 & 19 & $10 \mathrm{R}$ & 3 & wet & permanent & 0 & Rice, Veg \\
\hline $\mathrm{C} 074$ & 1 & 10 & 4 & 0 & 2 & 2 & 1 & 0 & 3 & 2 & 1 & 12 & $5 \mathrm{R}$ & 1 & wet & permanent & 0 & Rice \\
\hline $\mathrm{C} 075$ & 1 & 10 & 4 & 0 & 2 & 2 & 1 & 0 & 3 & 2 & 1 & 34 & $5 \mathrm{R}$ & 1 & wet & permanent & 0 & Rice, Veg \\
\hline $\mathrm{C} 076$ & 1 & 10 & 4 & 0 & 2 & 3 & 1 & 0 & 3 & 1 & 3 & 20 & - & - & wet & permanent & 0 & Rice, Veg \\
\hline $\mathrm{C} 077$ & 1 & 10 & 2 & 1 & 2 & 3 & 1 & 0 & 2 & 5 & 4 & - & - & - & wet & - & - & - \\
\hline $\mathrm{C} 078$ & 1 & 10 & 2 & 1 & 3 & 4 & 1 & 0 & 2 & 5 & 4 & - & - & - & wet & - & - & - \\
\hline $\mathrm{C} 079$ & 1 & 10 & 2 & 1 & 2 & 3 & 1 & 0 & 2 & 5 & 4 & - & - & - & wet & - & - & - \\
\hline C080 & 1 & 10 & 2 & 1 & 2 & 3 & 1 & 0 & 2 & 5 & 4 & - & - & - & wet & - & - & - \\
\hline $\mathrm{C} 081$ & 1 & 10 & 2 & 1 & 2 & 3 & 1 & 0 & 2 & 5 & 4 & - & - & - & wet & - & - & - \\
\hline $\mathrm{C} 082$ & 1 & 10 & 2 & 1 & 2 & 3 & 1 & 1 & 2 & 5 & 4 & 27 & $5 \mathrm{Y}$ & 9 & wet & - & - & - \\
\hline $\mathrm{C} 083$ & 1 & 10 & 2 & 1 & 3 & 4 & 1 & 0 & 2 & 1 & 3 & 17.5 & 10YR & 7 & wet & - & - & - \\
\hline $\mathrm{C} 084$ & 1 & 10 & 2 & 1 & 3 & 4 & 1 & 0 & 2 & 3 & 1 & 10 & $5 \mathrm{YR}$ & 5 & wet & permanent & 0 & Rice \\
\hline $\mathrm{C} 085$ & 1 & 10 & 2 & 1 & 4 & 6 & 1 & 0 & 1 & 5 & 2 & - & - & - & wet & - & - & - \\
\hline $\mathrm{C} 085 \mathrm{~A}$ & 1 & 10 & 2 & 1 & 3 & 4 & 1 & 0 & 2 & 2 & 1 & 10 & $5 \mathrm{YR}$ & 5 & wet & - & - & - \\
\hline C086 & 1 & 9 & 2 & 1 & 3 & 4 & 2 & 0 & 2 & 4 & 3 & 10 & $5 \mathrm{YR}$ & 5 & wet & permanent & 0 & $\begin{array}{l}\text { Rice, } \\
\text { Fruit }\end{array}$ \\
\hline C087 & 1 & 9 & 4 & 0 & 2 & 3 & 2 & 0 & 3 & 5 & 5 & - & - & - & - & permanent & 0 & $\begin{array}{l}\text { Rice, } \\
\text { Fruit }\end{array}$ \\
\hline $\mathrm{C} 088$ & 1 & 9 & 2 & 1 & 2 & 3 & 1 & 0 & 2 & 1 & 5 & - & - & - & - & permanent & 0 & $\begin{array}{l}\text { Rice, } \\
\text { Fruit }\end{array}$ \\
\hline C089 & 1 & 9 & 2 & 1 & 3 & 4 & 1 & 0 & 2 & 5 & 5 & - & - & - & - & permanent & 0 & Rice \\
\hline $\mathrm{C} 090$ & 1 & 9 & 4 & 0 & 2 & 2 & 1 & 0 & 3 & 1 & 5 & - & - & - & - & permanent & 0 & Rice, Veg \\
\hline C091 & 1 & 9 & 2 & 1 & 2 & 3 & 1 & 0 & 2 & 5 & 5 & - & - & - & - & seasonal & - & Rice \\
\hline
\end{tabular}


Appendix 6. Wetland attribute data for all 531 persistent organic pollutant (POP) samples collected in Southeast Asia during 2011. Codes used for ecological region, river connection, wetland system, wetland subsystem, wetland type, wetland protection status, hydrological regime, wetland vegetation, and surface soil texture are listed in table

2. Country codes are listed as Cambodia (1), Lao PDR (2), Thailand (3), Vietnam (4), and Myanmar (5). Hydrological connection codes describe how rivers were connected to wetlands, such as surface flow only (1), channel flow (2), both channel and surface flow (3), and no connection to river (4). Measurements for surface soil texture, depth, color, and dampness refer to the top layer of soil only. Soil depth was measured in centimeters (cm). Soil color follows Munsell Color Chart codes (Munsell Soil Color Charts, 2009). Water permanence was measured only as water persisting all year round (permanent) or seasonal. The number of months that the wetland would dry in an average year was estimated. Finally, human use of lands surrounding each wetland was grouped into the following categories: rice, vegetable (veg), fruit, rubber (rub), eucalyptus (euc), coffee (cof), and none (natural surroundings). For all variables, dashes represent situations where data were absent. Only water permanence, number of months dry, and land use variables were collected through interviews that reflect the wetland in general. All other variables were collected from the P0Ps sampling point. The label C085 was mistakenly used twice, so " $A$ " distinguishes one sample from the other.-Continued

\begin{tabular}{|c|c|c|c|c|c|c|c|c|c|c|c|c|c|c|c|c|c|c|}
\hline $\begin{array}{l}\text { 으 } \\
\text { 흘 } \\
\text { 言 } \\
\text { 心 } \\
\text { 음 }\end{array}$ & 壱 & 흘 & $\begin{array}{l}\overline{\mathbb{J}} \\
\text { 흘 } \\
\text { 응 } \\
\text { 을 } \\
\text { 총 }\end{array}$ & 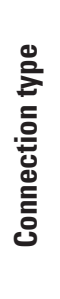 & 永 & 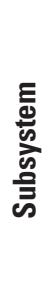 & 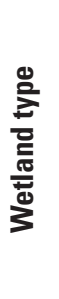 & 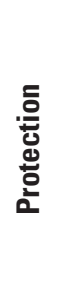 & 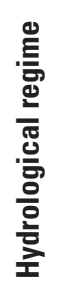 & 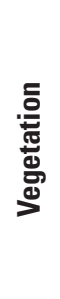 & 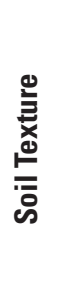 & 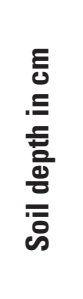 & 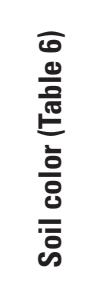 & 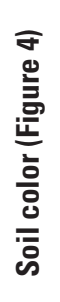 & 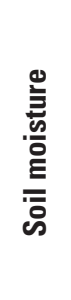 & 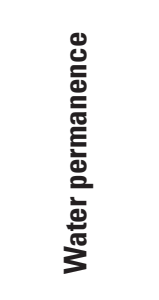 & 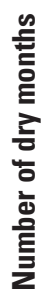 & 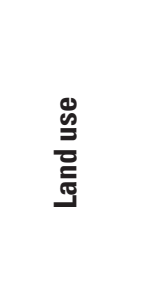 \\
\hline C092 & 1 & 9 & 4 & 0 & 2 & 3 & 1 & 0 & 3 & 5 & 3 & 3.2 & $10 \mathrm{YR}$ & 7 & wet & permanent & 0 & $\begin{array}{l}\text { Rice, } \\
\text { Fruit }\end{array}$ \\
\hline $\mathrm{C} 093$ & 1 & 9 & 2 & 1 & 2 & 3 & 1 & 0 & 2 & 5 & 1 & 30 & $10 \mathrm{YR}$ & 7 & wet & permanent & 0 & $\begin{array}{l}\text { Rice, } \\
\text { Fruit }\end{array}$ \\
\hline C094 & 1 & 9 & 2 & 1 & 3 & 4 & 1 & 0 & 2 & 1 & 3 & 13 & $10 \mathrm{YR}$ & 7 & wet & permanent & 0 & $\begin{array}{l}\text { Rice, } \\
\text { Fruit }\end{array}$ \\
\hline $\mathrm{C} 095$ & 1 & 9 & 4 & 0 & 2 & 2 & 1 & 0 & 3 & 1 & 5 & - & - & - & - & permanent & 0 & Rice \\
\hline C096 & 1 & 9 & 2 & 1 & 2 & 2 & 1 & 0 & 2 & 1 & 1 & 33 & $10 \mathrm{YR}$ & 7 & wet & permanent & 0 & $\begin{array}{l}\text { Rice, } \\
\text { Fruit }\end{array}$ \\
\hline C097 & 1 & 9 & 2 & 1 & 2 & 2 & 2 & 0 & 2 & 5 & 5 & 33 & $10 \mathrm{YR}$ & 7 & - & permanent & 0 & $\begin{array}{l}\text { Rice, Veg, } \\
\text { Fruit }\end{array}$ \\
\hline C098 & 1 & 9 & 2 & 1 & 2 & 2 & 1 & 0 & 2 & 1 & 1 & 54 & $10 \mathrm{YR}$ & 7 & wet & permanent & 0 & $\begin{array}{l}\text { Rice, } \\
\text { Fruit }\end{array}$ \\
\hline C099 & 1 & 9 & 2 & 1 & 2 & 3 & 1 & 0 & 2 & 5 & 3 & 9 & $10 \mathrm{YR}$ & 7 & wet & permanent & 0 & Rice \\
\hline $\mathrm{C} 100$ & 1 & 9 & 2 & 1 & 3 & 4 & 1 & 0 & 2 & 3 & 1 & 14 & $10 \mathrm{YR}$ & 7 & wet & permanent & 0 & Rice \\
\hline $\mathrm{C} 101$ & 1 & 9 & 2 & 1 & 3 & 4 & 1 & 0 & 2 & 2 & 3 & 8 & $10 \mathrm{YR}$ & 7 & wet & permanent & 0 & $\begin{array}{l}\text { Rice, } \\
\text { Fruit }\end{array}$ \\
\hline $\mathrm{C} 102$ & 1 & 8 & 2 & 1 & 3 & 4 & 2 & 0 & 2 & 5 & 5 & - & - & - & - & permanent & 0 & None \\
\hline $\mathrm{C} 103$ & 1 & 8 & 2 & 1 & 3 & 4 & 1 & 0 & 2 & 1 & 3 & 12 & $2.5 \mathrm{Y}$ & 8 & wet & permanent & 0 & Rice \\
\hline $\mathrm{C} 104$ & 1 & 8 & 4 & 0 & 3 & 4 & 2 & 1 & 3 & 2 & 3 & 4 & $10 \mathrm{YR}$ & 7 & wet & permanent & 0 & Rice \\
\hline $\mathrm{C} 105$ & 1 & 8 & 2 & 1 & 2 & 3 & 2 & 0 & 2 & 5 & 3 & 34 & $2.5 \mathrm{Y}$ & 8 & wet & permanent & 0 & None \\
\hline
\end{tabular}




\begin{tabular}{|c|c|c|c|c|c|c|c|c|c|c|c|c|c|c|c|c|c|c|}
\hline 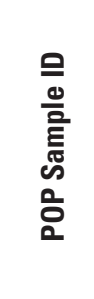 & 竎 & 흠 & 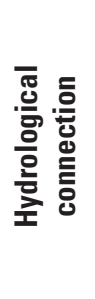 & 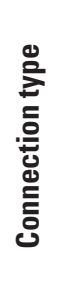 & 㷰 & 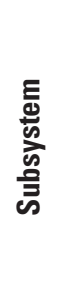 & 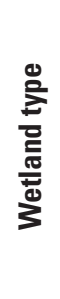 & 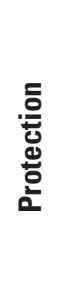 & 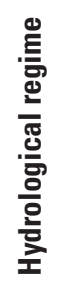 & 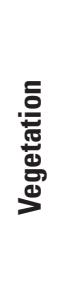 & 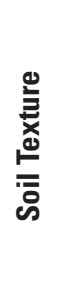 & 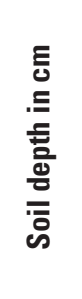 & $\begin{array}{l}0 \\
0 \\
\frac{0}{0} \\
\text { बढ } \\
\frac{2}{0} \\
\frac{0}{0} \\
\overline{0}\end{array}$ & 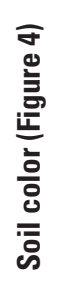 & $\begin{array}{l}\text { 늘 } \\
\text { 商 } \\
\text { 흘 }\end{array}$ & 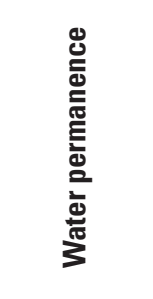 & 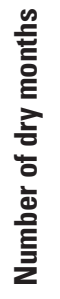 & 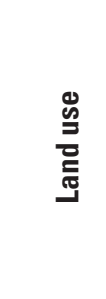 \\
\hline C106 & 1 & 8 & 2 & 1 & 3 & 4 & 1 & 0 & 2 & 5 & 5 & - & - & - & - & permanent & 0 & Rice \\
\hline $\mathrm{C} 107$ & 1 & 8 & 2 & 1 & 3 & 4 & 1 & 0 & 2 & 2 & 5 & - & - & - & - & permanent & 0 & None \\
\hline $\mathrm{C} 108$ & 1 & 8 & 2 & 1 & 2 & 3 & 1 & 0 & 1 & 5 & 5 & - & - & - & - & permanent & 0 & None \\
\hline C109 & 1 & 8 & 4 & 0 & 2 & 3 & 1 & 0 & 3 & 5 & 5 & - & - & - & - & permanent & 0 & None \\
\hline $\mathrm{C} 110$ & 1 & 8 & 2 & 1 & 4 & 6 & 1 & 0 & 3 & 5 & 5 & - & - & - & - & permanent & 0 & None \\
\hline C111 & 1 & 8 & 4 & 0 & 3 & 4 & 1 & 0 & 3 & 2 & 5 & - & - & - & - & permanent & 0 & None \\
\hline $\mathrm{C} 112$ & 1 & 8 & 2 & 1 & 3 & 4 & 1 & 1 & 2 & 2 & 5 & - & - & - & - & permanent & 0 & None \\
\hline C113 & 1 & 8 & 2 & 1 & 4 & 6 & 1 & 1 & 1 & 5 & 5 & - & - & - & - & permanent & 0 & Rice \\
\hline C114 & 1 & 8 & 4 & 0 & 3 & 4 & 1 & 0 & 3 & 2 & 3 & 25 & $10 \mathrm{YR}$ & 7 & wet & permanent & 0 & $\begin{array}{l}\text { Rice, } \\
\quad \text { Fruit }\end{array}$ \\
\hline C115 & 1 & 8 & 4 & 0 & 3 & 4 & 1 & 0 & 3 & 2 & 3 & 15 & $10 \mathrm{YR}$ & 7 & wet & permanent & 0 & None \\
\hline C116 & 1 & 8 & 4 & 0 & 3 & 4 & 1 & 1 & 3 & 2 & 3 & 32 & $10 \mathrm{YR}$ & 7 & wet & permanent & 0 & None \\
\hline $\mathrm{C} 117$ & 1 & 8 & 4 & 0 & 2 & 3 & 1 & 1 & 3 & 1 & 3 & 15 & $10 \mathrm{YR}$ & 7 & wet & permanent & 0 & None \\
\hline C118 & 1 & 8 & 4 & 0 & 2 & 3 & 1 & 0 & 3 & 5 & 5 & - & - & - & - & permanent & 0 & Rice \\
\hline C119 & 1 & 8 & 4 & 0 & 3 & 4 & 1 & 0 & 3 & 2 & 3 & 16.5 & $2.5 \mathrm{Y}$ & 8 & wet & permanent & 0 & None \\
\hline C120 & 1 & 8 & 4 & 0 & 3 & 4 & 1 & 0 & 3 & 2 & 5 & - & - & - & - & permanent & 0 & None \\
\hline $\mathrm{C} 121$ & 1 & 8 & 4 & 0 & 3 & 4 & 1 & 0 & 3 & 1 & 5 & - & - & - & - & permanent & 0 & None \\
\hline $\mathrm{C} 122$ & 1 & 8 & 4 & 0 & 2 & 2 & 1 & 0 & 3 & 1 & 5 & - & - & - & - & permanent & 0 & None \\
\hline $\mathrm{C} 123$ & 1 & 8 & 2 & 1 & 2 & 3 & 1 & 0 & 2 & 1 & 5 & - & - & - & - & permanent & 0 & None \\
\hline $\mathrm{C} 124$ & 1 & 8 & 4 & 0 & 2 & 3 & 1 & 0 & 3 & 5 & 5 & - & - & - & - & permanent & 0 & None \\
\hline $\mathrm{C} 125$ & 1 & 8 & 4 & 0 & 3 & 4 & 1 & 0 & 3 & 2 & 5 & - & - & - & - & permanent & 0 & None \\
\hline C126 & 1 & 8 & 4 & 0 & 3 & 4 & 1 & 0 & 3 & 2 & 5 & - & - & - & - & permanent & 0 & None \\
\hline $\mathrm{C} 127$ & 1 & 8 & 4 & 0 & 3 & 4 & 1 & 0 & 3 & 5 & 5 & - & - & - & - & permanent & 0 & None \\
\hline $\mathrm{C} 128$ & 1 & 8 & 4 & 0 & 3 & 4 & 1 & 0 & 3 & 5 & 5 & - & - & - & - & permanent & 0 & None \\
\hline C129 & 1 & 8 & 4 & 0 & 3 & 4 & 1 & 0 & 3 & 1 & 5 & - & - & - & - & permanent & 0 & None \\
\hline $\mathrm{C} 130$ & 1 & 8 & 2 & 1 & 4 & 6 & 1 & 1 & 1 & 5 & 5 & - & - & - & - & permanent & 0 & None \\
\hline C131 & 1 & 8 & 4 & 0 & 3 & 4 & 1 & 1 & 3 & 2 & 5 & - & - & - & - & permanent & 0 & None \\
\hline C132 & 1 & 8 & 4 & 0 & 3 & 4 & 1 & 0 & 3 & 2 & 3 & 24 & $2.5 \mathrm{Y}$ & 8 & wet & permanent & 0 & None \\
\hline
\end{tabular}


Appendix 6. Wetland attribute data for all 531 persistent organic pollutant (POP) samples collected in Southeast Asia during 2011. Codes used for ecological region, river connection, wetland system, wetland subsystem, wetland type, wetland protection status, hydrological regime, wetland vegetation, and surface soil texture are listed in table

2. Country codes are listed as Cambodia (1), Lao PDR (2), Thailand (3), Vietnam (4), and Myanmar (5). Hydrological connection codes describe how rivers were connected to wetlands, such as surface flow only (1), channel flow (2), both channel and surface flow (3), and no connection to river (4). Measurements for surface soil texture, depth, color, and dampness refer to the top layer of soil only. Soil depth was measured in centimeters (cm). Soil color follows Munsell Color Chart codes (Munsell Soil Color Charts, 2009). Water permanence was measured only as water persisting all year round (permanent) or seasonal. The number of months that the wetland would dry in an average year was estimated. Finally, human use of lands surrounding each wetland was grouped into the following categories: rice, vegetable (veg), fruit, rubber (rub), eucalyptus (euc), coffee (cof), and none (natural surroundings). For all variables, dashes represent situations where data were absent. Only water permanence, number of months dry, and land use variables were collected through interviews that reflect the wetland in general. All other variables were collected from the P0Ps sampling point. The label C085 was mistakenly used twice, so " $A$ " distinguishes one sample from the other.-Continued

\begin{tabular}{|c|c|c|c|c|c|c|c|c|c|c|c|c|c|c|c|c|c|c|}
\hline 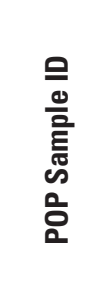 & 를 & 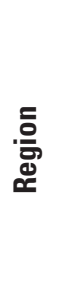 & 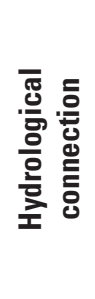 & 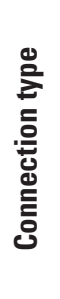 & $\begin{array}{l}E \\
\frac{\bar{d}}{\Delta} \\
\vec{\omega}\end{array}$ & 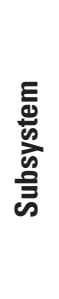 & 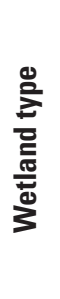 & $\begin{array}{l}\text { 흔 } \\
\text { dัّ } \\
\text { ㅎํㄴ }\end{array}$ & 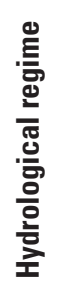 & $\begin{array}{l}\text { 흘 } \\
\text { 吾 } \\
\stackrel{0}{\mathrm{~J}}\end{array}$ & 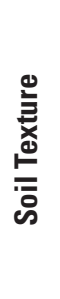 & $\begin{array}{l}E \\
\overline{0} \\
. \equiv \\
\overline{\bar{z}} \\
\frac{\overline{0}}{\overline{0}} \\
\overline{\bar{c}}\end{array}$ & 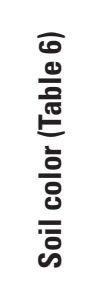 & 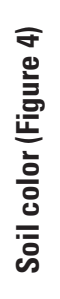 & 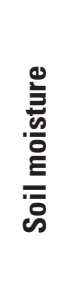 & 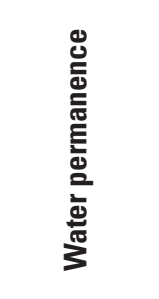 & 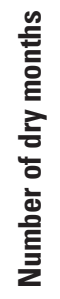 & 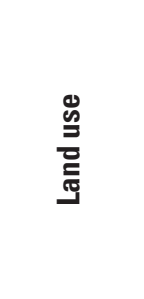 \\
\hline C133 & 1 & 8 & 4 & 0 & 3 & 4 & 1 & 0 & 3 & 2 & 3 & 8.5 & $10 \mathrm{YR}$ & 7 & wet & permanent & 0 & None \\
\hline C134 & 1 & 8 & 4 & 0 & 3 & 4 & 1 & 0 & 3 & 2 & 5 & - & - & - & - & permanent & 0 & None \\
\hline C135 & 1 & 8 & 4 & 0 & 3 & 4 & 1 & 0 & 3 & 2 & 3 & 21 & $2.5 \mathrm{Y}$ & 8 & wet & permanent & 0 & None \\
\hline C136 & 1 & 8 & 4 & 0 & 3 & 4 & 1 & 0 & 3 & 2 & 3 & 10 & $10 \mathrm{YR}$ & 7 & wet & permanent & 0 & None \\
\hline C137 & 1 & 8 & 4 & 0 & 3 & 4 & 1 & 0 & 3 & 2 & 3 & 4 & $2.5 \mathrm{Y}$ & 8 & wet & permanent & 0 & None \\
\hline C138 & 1 & 8 & 4 & 0 & 3 & 4 & 1 & 0 & 3 & 1 & 5 & - & - & - & - & permanent & 0 & None \\
\hline C139 & 1 & 8 & 4 & 0 & 3 & 4 & 1 & 1 & 3 & 2 & 5 & - & - & - & - & permanent & 0 & Rice \\
\hline C140 & 1 & 8 & 4 & 0 & 3 & 4 & 1 & 1 & 3 & 3 & 5 & - & - & - & - & permanent & 0 & Rice \\
\hline $\mathrm{C} 141$ & 1 & 8 & 4 & 0 & 3 & 4 & 1 & 1 & 3 & 2 & 3 & 57 & $2.5 \mathrm{Y}$ & 8 & wet & permanent & 0 & None \\
\hline C142 & 1 & 8 & 4 & 0 & 3 & 4 & 1 & 1 & 3 & 2 & 3 & 18 & $2.5 \mathrm{Y}$ & 8 & wet & permanent & 0 & None \\
\hline C143 & 1 & 8 & 2 & 1 & 2 & 3 & 2 & 0 & 2 & 1 & 5 & - & - & - & - & permanent & 0 & Rice, Rub \\
\hline C144 & 1 & 8 & 2 & 1 & 2 & 3 & 2 & 0 & 2 & 1 & 5 & - & - & - & - & permanent & 0 & Rub \\
\hline $\mathrm{C} 145$ & 1 & 8 & 4 & 0 & 2 & 3 & 1 & 0 & 3 & 5 & 5 & - & - & - & - & permanent & 0 & None \\
\hline C146 & 1 & 8 & 4 & 0 & 3 & 4 & 1 & 0 & 3 & 5 & 5 & - & - & - & - & permanent & 0 & None \\
\hline C147 & 1 & 8 & 4 & 0 & 2 & 3 & 1 & 0 & 3 & 5 & 5 & - & - & - & - & permanent & 0 & None \\
\hline C148 & 1 & 8 & 4 & 0 & 2 & 3 & 1 & 0 & 3 & 1 & 5 & - & - & - & - & permanent & 0 & Rub \\
\hline C149 & 1 & 8 & 4 & 0 & 2 & 3 & 2 & 0 & 3 & 5 & 5 & - & - & - & - & permanent & 0 & None \\
\hline $\mathrm{C} 150$ & 1 & 8 & 4 & 0 & 3 & 4 & 1 & 0 & 3 & 2 & 3 & 6 & $10 \mathrm{YR}$ & 7 & wet & permanent & 0 & Rub \\
\hline $\mathrm{C} 151$ & 1 & 8 & 4 & 0 & 3 & 4 & 1 & 0 & 3 & 2 & 5 & - & - & - & - & permanent & 0 & Rice, Rub \\
\hline
\end{tabular}




\begin{tabular}{|c|c|c|c|c|c|c|c|c|c|c|c|c|c|c|c|c|c|c|}
\hline $\begin{array}{l}\text { 응 } \\
\frac{0}{0} \\
\text { 言 } \\
\text { 心 } \\
0 \\
\text { 옴 }\end{array}$ & 竎 & 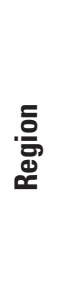 & 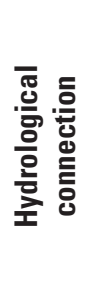 & 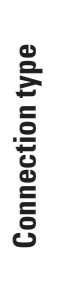 & 竞 & 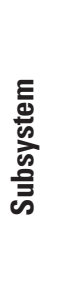 & 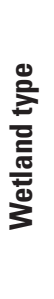 & 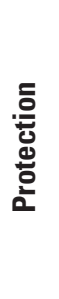 & 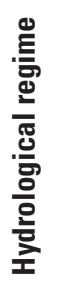 & 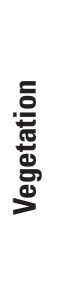 & 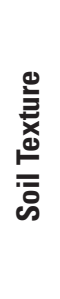 & 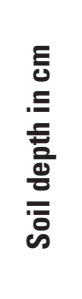 & 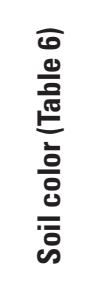 & 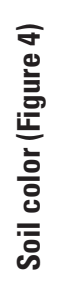 & 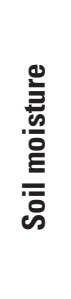 & 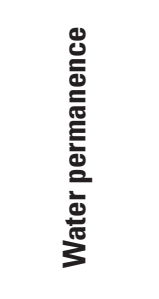 & 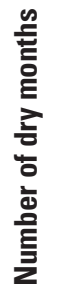 & 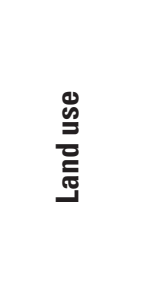 \\
\hline C152 & 1 & 8 & 2 & 1 & 2 & 3 & 1 & 0 & 2 & 1 & 5 & - & - & - & - & permanent & 0 & $\begin{array}{l}\text { Rice, Veg, } \\
\text { Fruit }\end{array}$ \\
\hline C153 & 1 & 8 & 2 & 1 & 3 & 4 & 1 & 0 & 2 & 2 & 5 & - & - & - & - & permanent & 0 & None \\
\hline C154 & 1 & 8 & 4 & 0 & 3 & 4 & 1 & 1 & 3 & 2 & 1 & 15 & $10 \mathrm{YR}$ & 7 & wet & permanent & 0 & None \\
\hline $\mathrm{C} 155$ & 1 & 8 & 4 & 0 & 3 & 4 & 1 & 1 & 3 & 2 & 5 & - & - & - & - & permanent & 0 & None \\
\hline C156 & 1 & 8 & 4 & 0 & 3 & 4 & 1 & 1 & 3 & 2 & 3 & 7.5 & $10 \mathrm{YR}$ & 7 & wet & permanent & 0 & None \\
\hline C157 & 1 & 8 & 4 & 0 & 3 & 4 & 1 & 0 & 3 & 2 & 5 & - & - & - & - & permanent & 0 & Rice \\
\hline $\mathrm{C} 158$ & 1 & 9 & 4 & 0 & 2 & 3 & 1 & 0 & 4 & 5 & 5 & - & - & - & - & permanent & 0 & Rub \\
\hline C159 & 1 & 9 & 4 & 0 & 2 & 3 & 1 & 0 & 4 & 5 & 5 & - & - & - & - & permanent & 0 & Rub \\
\hline $\mathrm{C} 160$ & 1 & 8 & 4 & 0 & 3 & 4 & 1 & 1 & 3 & 2 & 3 & 7 & $10 \mathrm{YR}$ & 7 & wet & permanent & 0 & None \\
\hline C161 & 1 & 8 & 4 & 0 & 3 & 4 & 1 & 1 & 3 & 2 & 3 & 6 & $2.5 \mathrm{Y}$ & 8 & wet & permanent & 0 & None \\
\hline C162 & 1 & 8 & 4 & 0 & 3 & 4 & 1 & 1 & 3 & 2 & 3 & 7 & $2.5 \mathrm{Y}$ & 8 & wet & permanent & 0 & None \\
\hline C163 & 1 & 8 & 4 & 0 & 3 & 4 & 1 & 1 & 3 & 2 & 3 & 5 & $10 \mathrm{YR}$ & 7 & wet & permanent & 0 & Rub \\
\hline C164 & 1 & 8 & 4 & 0 & 3 & 4 & 1 & 1 & 3 & 2 & 3 & 6 & $10 \mathrm{YR}$ & 7 & wet & permanent & 0 & None \\
\hline C165 & 1 & 8 & 4 & 0 & 3 & 4 & 1 & 1 & 3 & 2 & 3 & 9 & $2.5 \mathrm{Y}$ & 8 & wet & permanent & 0 & None \\
\hline C166 & 1 & 8 & 4 & 0 & 3 & 4 & 1 & 1 & 3 & 4 & 3 & 13 & $10 \mathrm{YR}$ & 7 & wet & permanent & 0 & None \\
\hline C167 & 1 & 8 & 2 & 1 & 3 & 4 & 1 & 1 & 2 & 1 & 3 & 13 & $2.5 \mathrm{Y}$ & 8 & wet & permanent & 0 & None \\
\hline C168 & 1 & 8 & 4 & 0 & 3 & 4 & 1 & 1 & 3 & 2 & 3 & 30 & $2.5 \mathrm{Y}$ & 8 & wet & permanent & 0 & None \\
\hline C169 & 1 & 8 & 4 & 0 & 2 & 2 & 1 & 1 & 3 & 1 & 3 & 10 & $2.5 \mathrm{Y}$ & 8 & wet & permanent & 0 & None \\
\hline $\mathrm{C} 170$ & 1 & 8 & 4 & 0 & 3 & 4 & 1 & 1 & 3 & 2 & 3 & 20 & $10 \mathrm{YR}$ & 7 & wet & permanent & 0 & None \\
\hline C171 & 1 & 8 & 4 & 0 & 3 & 4 & 1 & 1 & 3 & 2 & 3 & 12 & $2.5 \mathrm{Y}$ & 8 & wet & permanent & 0 & None \\
\hline C172 & 1 & 8 & 4 & 0 & 3 & 4 & 1 & 1 & 3 & 2 & 3 & 17 & $2.5 \mathrm{Y}$ & 8 & wet & permanent & 0 & None \\
\hline C173 & 1 & 8 & 4 & 0 & 2 & 2 & 1 & 1 & 3 & 2 & 3 & 9 & $2.5 \mathrm{Y}$ & 8 & wet & permanent & 0 & None \\
\hline C174 & 1 & 8 & 4 & 0 & 3 & 4 & 1 & 1 & 3 & 2 & 3 & 6 & $2.5 \mathrm{Y}$ & 8 & wet & permanent & 0 & None \\
\hline C175 & 1 & 8 & 4 & 0 & 3 & 4 & 1 & 1 & 3 & 2 & 3 & 7 & $2.5 \mathrm{Y}$ & 8 & wet & permanent & 0 & Rub \\
\hline C176 & 1 & 8 & 2 & 1 & 2 & 3 & 2 & 1 & 2 & 5 & 5 & - & - & - & - & permanent & 0 & Fruit \\
\hline C177 & 1 & 8 & 2 & 1 & 2 & 3 & 2 & 1 & 2 & 5 & 5 & - & - & - & - & permanent & 0 & Fruit \\
\hline C178 & 1 & 8 & 2 & 1 & 3 & 4 & 1 & 0 & 2 & 5 & 5 & - & - & - & - & permanent & 0 & Rub \\
\hline
\end{tabular}


Appendix 6. Wetland attribute data for all 531 persistent organic pollutant (POP) samples collected in Southeast Asia during 2011. Codes used for ecological region, river connection, wetland system, wetland subsystem, wetland type, wetland protection status, hydrological regime, wetland vegetation, and surface soil texture are listed in table

2. Country codes are listed as Cambodia (1), Lao PDR (2), Thailand (3), Vietnam (4), and Myanmar (5). Hydrological connection codes describe how rivers were connected to wetlands, such as surface flow only (1), channel flow (2), both channel and surface flow (3), and no connection to river (4). Measurements for surface soil texture, depth, color, and dampness refer to the top layer of soil only. Soil depth was measured in centimeters (cm). Soil color follows Munsell Color Chart codes (Munsell Soil Color Charts, 2009). Water permanence was measured only as water persisting all year round (permanent) or seasonal. The number of months that the wetland would dry in an average year was estimated. Finally, human use of lands surrounding each wetland was grouped into the following categories: rice, vegetable (veg), fruit, rubber (rub), eucalyptus (euc), coffee (cof), and none (natural surroundings). For all variables, dashes represent situations where data were absent. Only water permanence, number of months dry, and land use variables were collected through interviews that reflect the wetland in general. All other variables were collected from the P0Ps sampling point. The label C085 was mistakenly used twice, so " $A$ " distinguishes one sample from the other.-Continued

\begin{tabular}{|c|c|c|c|c|c|c|c|c|c|c|c|c|c|c|c|c|c|c|}
\hline 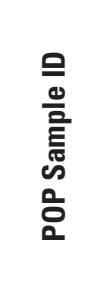 & 壱 & 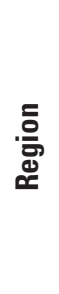 & $\begin{array}{l}\overline{\mathbb{J}} \\
\text { 흘 } \\
\text { 응 } \\
\text { 을 } \\
\text { 총 }\end{array}$ & 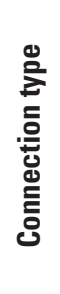 & 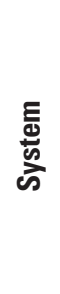 & 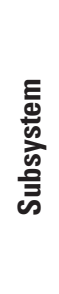 & 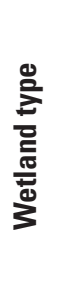 & 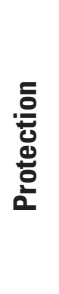 & 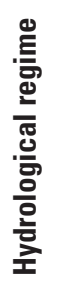 & 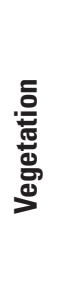 & 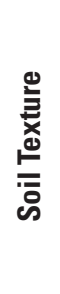 & 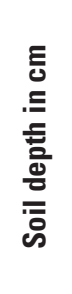 & 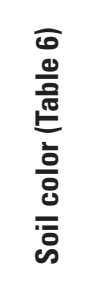 & 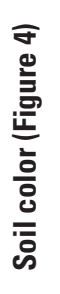 & 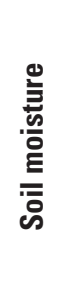 & 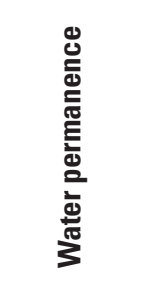 & 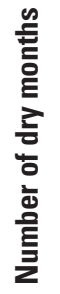 & 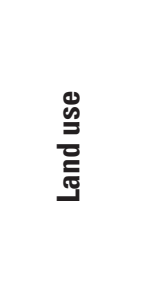 \\
\hline C179 & 1 & 8 & 2 & 1 & 2 & 3 & 2 & 1 & 2 & 5 & 5 & - & - & - & - & permanent & 0 & Rice, Rub \\
\hline $\mathrm{C} 180$ & 1 & 8 & 2 & 1 & 2 & 3 & 2 & 0 & 2 & 5 & 5 & - & - & - & - & permanent & 0 & None \\
\hline C181 & 1 & 8 & 2 & 1 & 2 & 2 & 2 & 0 & 2 & 2 & 5 & - & - & - & - & permanent & 0 & None \\
\hline C182 & 1 & 8 & 4 & 0 & 3 & 4 & 1 & 0 & 3 & 2 & 3 & 15 & $2.5 \mathrm{Y}$ & 8 & wet & permanent & 0 & None \\
\hline $\mathrm{C} 183$ & 1 & 8 & 2 & 1 & 3 & 4 & 2 & 0 & 2 & 5 & 5 & - & - & - & - & permanent & 0 & None \\
\hline $\mathrm{C} 184$ & 1 & 8 & 2 & 1 & 3 & 4 & 1 & 0 & 2 & 5 & 5 & - & - & - & - & permanent & 0 & Veg, Fruit \\
\hline C185 & 1 & 8 & 2 & 1 & 2 & 3 & 1 & 1 & 2 & 5 & 5 & - & - & - & - & permanent & 0 & Veg \\
\hline C186 & 1 & 8 & 2 & 1 & 2 & 3 & 1 & 0 & 2 & 5 & 5 & - & - & - & - & permanent & 0 & None \\
\hline C187 & 1 & 8 & 4 & 0 & 3 & 4 & 1 & 1 & 3 & 2 & 5 & - & - & - & - & permanent & 0 & None \\
\hline C188 & 1 & 8 & 4 & 0 & 3 & 4 & 1 & 1 & 3 & 2 & 3 & 7 & $2.5 \mathrm{Y}$ & 8 & wet & permanent & 0 & None \\
\hline C189 & 1 & 8 & 4 & 0 & 3 & 4 & 1 & 1 & 3 & 2 & 3 & 6 & $5 \mathrm{Y}$ & 9 & wet & permanent & 0 & None \\
\hline C190 & 1 & 8 & 4 & 0 & 3 & 4 & 1 & 0 & 3 & 2 & 5 & - & - & - & - & permanent & 0 & None \\
\hline C191 & 1 & 8 & 2 & 1 & 3 & 4 & 1 & 1 & 2 & 2 & 5 & - & - & - & - & permanent & 0 & None \\
\hline C192 & 1 & 8 & 2 & 1 & 3 & 4 & 1 & 1 & 2 & 2 & 3 & 9 & $5 \mathrm{Y}$ & 9 & wet & permanent & 0 & None \\
\hline C193 & 1 & 8 & 4 & 0 & 3 & 4 & 1 & 1 & 3 & 2 & 3 & 30 & $5 \mathrm{Y}$ & 9 & wet & permanent & 0 & Veg, Rub \\
\hline C194 & 1 & 8 & 4 & 0 & 3 & 4 & 1 & 0 & 3 & 2 & 5 & - & - & - & - & permanent & 0 & None \\
\hline C195 & 1 & 8 & 4 & 0 & 3 & 4 & 1 & 0 & 3 & 2 & 3 & 27 & $2.5 \mathrm{Y}$ & 8 & wet & permanent & 0 & None \\
\hline C196 & 1 & 8 & 4 & 0 & 3 & 4 & 1 & 0 & 3 & 2 & 5 & - & - & - & wet & permanent & 0 & None \\
\hline L001 & 2 & 1 & 2 & 1 & 3 & 4 & 1 & 0 & 3 & 1 & 1 & 10 & $10 \mathrm{R}$ & 3 & wet & permanent & 0 & Rice \\
\hline
\end{tabular}




\begin{tabular}{|c|c|c|c|c|c|c|c|c|c|c|c|c|c|c|c|c|c|c|}
\hline $\begin{array}{l}\text { 음 } \\
\frac{0}{0} \\
\text { 틀 } \\
\text { 心 } \\
\text { 옴 }\end{array}$ & 胥 & 咅 & 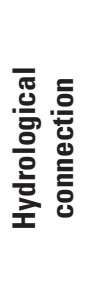 & 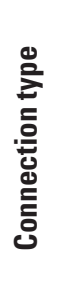 & 离 & 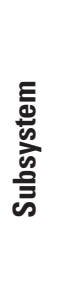 & 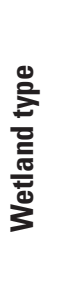 & 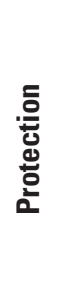 & 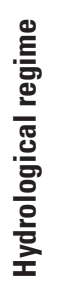 & 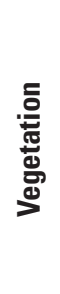 & 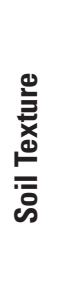 & 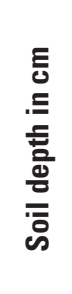 & 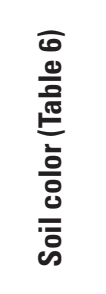 & 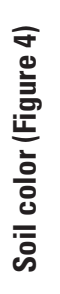 & 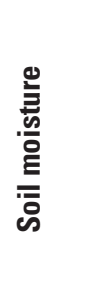 & 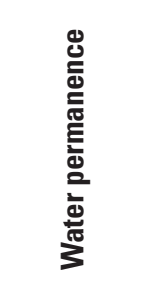 & 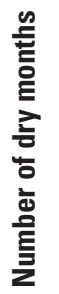 & 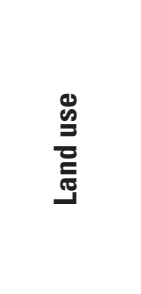 \\
\hline L002 & 2 & 1 & 4 & 0 & 3 & 4 & 1 & 0 & 3 & 2 & 1 & 7 & $10 \mathrm{R}$ & 3 & moist & permanent & 0 & Rice, Veg \\
\hline L003 & 2 & 1 & 3 & 1 & 3 & 4 & 1 & 0 & 1 & 2 & 1 & 10 & $10 \mathrm{R}$ & 3 & moist & permanent & 0 & $\begin{array}{c}\text { Rice, Veg, } \\
\text { Rub }\end{array}$ \\
\hline L004 & 2 & 1 & 4 & 0 & 3 & 4 & 1 & 0 & 3 & 1 & 1 & 11 & $10 \mathrm{YR}$ & 7 & wet & permanent & 0 & Rice, Veg \\
\hline L005 & 2 & 1 & 3 & 1 & 3 & 4 & 1 & 0 & 3 & 3 & 1 & 12 & $10 \mathrm{YR}$ & 7 & wet & permanent & 0 & Rub, Euc \\
\hline L006 & 2 & 1 & 3 & 1 & 3 & 4 & 1 & 0 & 1 & 3 & 3 & 13 & $10 \mathrm{YR}$ & 7 & moist & permanent & 0 & Rice, Veg \\
\hline L007 & 2 & 1 & 4 & 0 & 3 & 4 & 1 & 0 & 3 & 1 & 1 & 5 & $10 \mathrm{YR}$ & 7 & wet & permanent & 0 & None \\
\hline L008 & 2 & 1 & 3 & 1 & 3 & 4 & 1 & 1 & 1 & 2 & 3 & 5 & $10 \mathrm{YR}$ & 7 & wet & permanent & 0 & None \\
\hline L009 & 2 & 1 & 3 & 1 & 3 & 4 & 1 & 0 & 1 & 1 & 3 & 15 & $10 \mathrm{YR}$ & 7 & moist & permanent & 0 & $\begin{array}{c}\text { Rice, Veg, } \\
\text { Fruit, } \\
\text { Rub }\end{array}$ \\
\hline
\end{tabular}

\begin{tabular}{|c|c|c|c|c|c|c|c|c|c|c|c|c|c|c|c|c|c|c|}
\hline L010 & 2 & 1 & 4 & 0 & 3 & 4 & 1 & 0 & 3 & 2 & 2 & 10 & $10 \mathrm{YR}$ & 7 & wet & permanent & 0 & Veg \\
\hline L011 & 2 & 1 & 3 & 1 & 3 & 4 & 1 & 0 & 1 & 4 & 2 & 8 & $10 \mathrm{YR}$ & 7 & moist & permanent & 0 & $\begin{array}{l}\text { Rice, Veg, } \\
\text { Fruit }\end{array}$ \\
\hline L012 & 2 & 1 & 4 & 0 & 3 & 4 & 1 & 0 & 3 & 2 & 1 & 10 & $10 \mathrm{YR}$ & 7 & wet & permanent & 0 & None \\
\hline L013 & 2 & 1 & 4 & 0 & 3 & 4 & 1 & 0 & 3 & 2 & 1 & 8 & $10 \mathrm{YR}$ & 7 & moist & permanent & 0 & None \\
\hline L014 & 2 & 1 & 3 & 1 & 3 & 4 & 1 & 0 & 3 & 1 & 1 & 9 & $10 \mathrm{YR}$ & 7 & wet & permanent & 0 & None \\
\hline L015 & 2 & 1 & 3 & 1 & 3 & 4 & 1 & 0 & 3 & 2 & 3 & 11 & $10 \mathrm{YR}$ & 7 & wet & permanent & 0 & None \\
\hline L016 & 2 & 1 & 3 & 1 & 3 & 4 & 1 & 0 & 1 & 1 & 1 & 7 & $10 \mathrm{YR}$ & 7 & wet & permanent & 0 & Rice \\
\hline L017 & 2 & 1 & 4 & 0 & 3 & 4 & 1 & 0 & 3 & 2 & 1 & 10 & $10 \mathrm{YR}$ & 7 & wet & permanent & 0 & None \\
\hline L018 & 2 & 2 & 3 & 1 & 3 & 4 & 2 & 0 & 3 & 1 & 1 & 5 & $10 \mathrm{YR}$ & 7 & wet & permanent & 0 & $\begin{array}{c}\text { Rice, Veg, } \\
\text { Fruit }\end{array}$ \\
\hline L019 & 2 & 2 & 3 & 1 & 3 & 4 & 1 & 0 & 1 & 2 & 2 & 13 & $10 \mathrm{YR}$ & 7 & moist & permanent & 0 & Rice, Veg \\
\hline L020 & 2 & 2 & 4 & 0 & 3 & 4 & 1 & 1 & 3 & 2 & 3 & 7 & $10 \mathrm{YR}$ & 7 & moist & permanent & 0 & Rice, Veg \\
\hline L021 & 2 & 2 & 3 & 1 & 2 & 2 & 2 & 0 & 3 & 1 & 3 & 4 & $10 \mathrm{YR}$ & 7 & moist & permanent & 0 & None \\
\hline L022 & 2 & 2 & 3 & 1 & 3 & 4 & 1 & 0 & 3 & 1 & 3 & 7 & $10 \mathrm{YR}$ & 7 & moist & permanent & 0 & Rice \\
\hline L023 & 2 & 2 & 3 & 1 & 3 & 4 & 1 & 1 & 3 & 1 & 1 & 6 & $10 \mathrm{YR}$ & 7 & wet & permanent & 0 & Rice \\
\hline L024 & 2 & 2 & 3 & 1 & 3 & 4 & 1 & 0 & 3 & 2 & 4 & 15 & $10 \mathrm{YR}$ & 7 & wet & permanent & 0 & None \\
\hline L025 & 2 & 2 & 3 & 1 & 3 & 4 & 1 & 0 & 3 & 2 & 1 & 7 & $10 \mathrm{YR}$ & 7 & wet & permanent & 0 & Rice \\
\hline
\end{tabular}


Appendix 6. Wetland attribute data for all 531 persistent organic pollutant (POP) samples collected in Southeast Asia during 2011. Codes used for ecological region, river connection, wetland system, wetland subsystem, wetland type, wetland protection status, hydrological regime, wetland vegetation, and surface soil texture are listed in table

2. Country codes are listed as Cambodia (1), Lao PDR (2), Thailand (3), Vietnam (4), and Myanmar (5). Hydrological connection codes describe how rivers were connected to wetlands, such as surface flow only (1), channel flow (2), both channel and surface flow (3), and no connection to river (4). Measurements for surface soil texture, depth, color, and dampness refer to the top layer of soil only. Soil depth was measured in centimeters (cm). Soil color follows Munsell Color Chart codes (Munsell Soil Color Charts, 2009). Water permanence was measured only as water persisting all year round (permanent) or seasonal. The number of months that the wetland would dry in an average year was estimated. Finally, human use of lands surrounding each wetland was grouped into the following categories: rice, vegetable (veg), fruit, rubber (rub), eucalyptus (euc), coffee (cof), and none (natural surroundings). For all variables, dashes represent situations where data were absent. Only water permanence, number of months dry, and land use variables were collected through interviews that reflect the wetland in general. All other variables were collected from the P0Ps sampling point. The label C085 was mistakenly used twice, so " $A$ " distinguishes one sample from the other.-Continued

\begin{tabular}{|c|c|c|c|c|c|c|c|c|c|c|c|c|c|c|c|c|c|c|}
\hline $\begin{array}{l}\text { 으 } \\
\text { 을 } \\
\text { 言 } \\
\text { 心 } \\
\text { 음 }\end{array}$ & 壱 & 흘 & 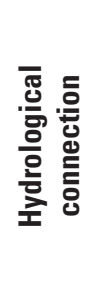 & 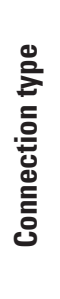 & 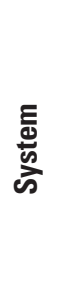 & 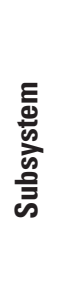 & 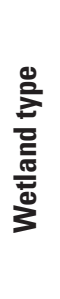 & 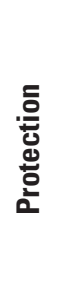 & 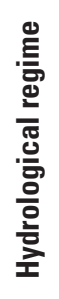 & 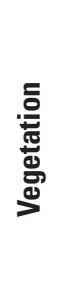 & 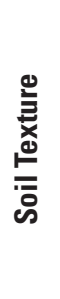 & 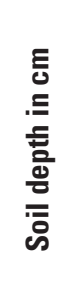 & 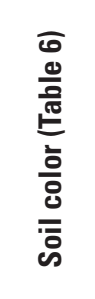 & 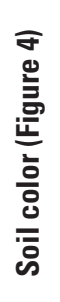 & 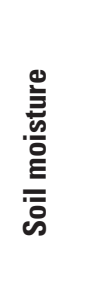 & 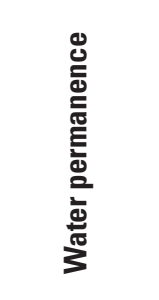 & 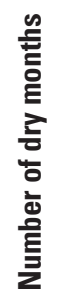 & 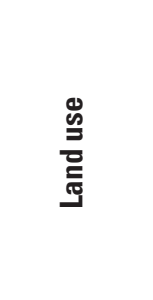 \\
\hline L026 & 2 & 2 & 4 & 0 & 3 & 4 & 1 & 0 & 3 & 2 & 2 & 8 & $10 \mathrm{YR}$ & 7 & wet & permanent & 0 & Rice, Veg \\
\hline L027 & 2 & 2 & 3 & 1 & 3 & 4 & 2 & 1 & 3 & 2 & 1 & 5 & $10 \mathrm{YR}$ & 7 & moist & permanent & 0 & Rice \\
\hline L028 & 2 & 2 & 3 & 1 & 3 & 4 & 1 & 1 & 1 & 2 & 4 & 7 & $10 \mathrm{YR}$ & 7 & moist & permanent & 0 & Rice \\
\hline L029 & 2 & 2 & 4 & 0 & 3 & 4 & 1 & 0 & 3 & 1 & 4 & 6 & 10YR & 7 & moist & permanent & 0 & Rice \\
\hline L030 & 2 & 2 & 4 & 0 & 3 & 4 & 1 & 0 & 3 & 1 & 3 & 13 & $10 \mathrm{YR}$ & 7 & moist & permanent & 0 & $\begin{array}{l}\text { Rice, Veg, } \\
\text { Fruit }\end{array}$ \\
\hline L031 & 2 & 2 & 4 & 0 & 3 & 4 & 1 & 0 & 3 & 2 & 1 & 16 & 10YR & 7 & wet & permanent & 0 & Rice \\
\hline L032 & 2 & 2 & 3 & 1 & 3 & 4 & 1 & 0 & 3 & 1 & 1 & 10 & 10YR & 7 & wet & permanent & 0 & Rice \\
\hline L033 & 2 & 2 & 3 & 1 & 3 & 4 & 1 & 0 & 1 & 1 & 4 & 16 & $10 \mathrm{YR}$ & 7 & wet & permanent & 0 & Rice, Veg \\
\hline L034 & 2 & 2 & 3 & 1 & 3 & 4 & 1 & 0 & 3 & 1 & 1 & 5 & $10 \mathrm{YR}$ & 7 & wet & permanent & 0 & None \\
\hline L035 & 2 & 2 & 3 & 1 & 3 & 4 & 1 & 0 & 3 & 2 & 3 & 4 & $10 \mathrm{YR}$ & 7 & moist & permanent & 0 & None \\
\hline L036 & 2 & 2 & 3 & 1 & 3 & 4 & 1 & 0 & 1 & 2 & 3 & 5 & $10 \mathrm{YR}$ & 7 & moist & permanent & 0 & Rice, Veg \\
\hline L037 & 2 & 3 & 3 & 1 & 3 & 4 & 1 & 1 & 3 & 2 & 1 & 7 & $10 \mathrm{YR}$ & 7 & wet & permanent & 0 & None \\
\hline L038 & 2 & 3 & 4 & 0 & 3 & 4 & 1 & 1 & 4 & 2 & 2 & 3 & $10 \mathrm{YR}$ & 7 & wet & permanent & 0 & Rice \\
\hline L039 & 2 & 3 & 3 & 1 & 3 & 4 & 1 & 1 & 3 & 2 & 4 & 3 & $10 \mathrm{YR}$ & 7 & moist & permanent & 0 & None \\
\hline L040 & 2 & 3 & 3 & 1 & 3 & 4 & 1 & 1 & 3 & 2 & 4 & 7 & $10 \mathrm{YR}$ & 7 & wet & permanent & 0 & None \\
\hline L041 & 2 & 3 & 3 & 1 & 3 & 4 & 1 & 1 & 3 & 2 & 1 & 6 & $10 \mathrm{YR}$ & 7 & wet & permanent & 0 & None \\
\hline L042 & 2 & 3 & 2 & 1 & 3 & 4 & 1 & 1 & 3 & 2 & 1 & 9 & $10 \mathrm{YR}$ & 7 & wet & permanent & 0 & None \\
\hline L043 & 2 & 3 & 3 & 1 & 3 & 4 & 1 & 1 & 3 & 2 & 1 & 7 & $10 \mathrm{YR}$ & 7 & wet & permanent & 0 & None \\
\hline
\end{tabular}




\begin{tabular}{|c|c|c|c|c|c|c|c|c|c|c|c|c|c|c|c|c|c|c|}
\hline $\begin{array}{l}\text { 으 } \\
\text { 흠 } \\
\text { 言 } \\
心 \\
\text { 음 }\end{array}$ & 壱 & 흠 & $\begin{array}{l}\overline{\bar{J}} \\
\text { 흘 } \\
\text { 응 } \\
\text { 을 } \\
\text { 총 }\end{array}$ & 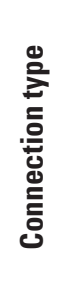 & 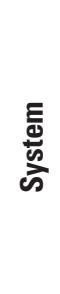 & 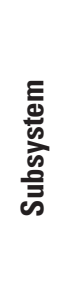 & 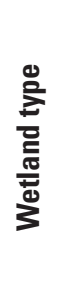 & $\begin{array}{l}\text { 뮬 } \\
\text { ㅎّㅁ } \\
\text { 이 }\end{array}$ & 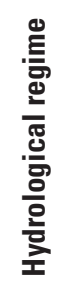 & 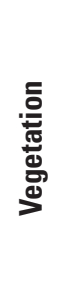 & 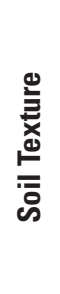 & 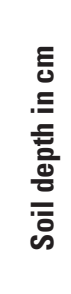 & 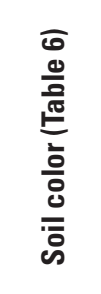 & 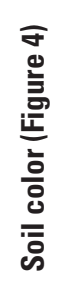 & 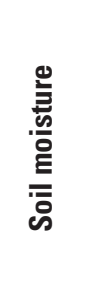 & 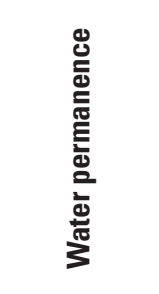 & 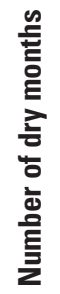 & 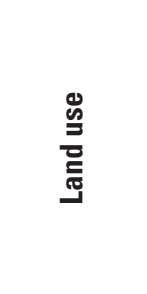 \\
\hline L044 & 2 & 3 & 3 & 1 & 3 & 4 & 1 & 1 & 3 & 2 & 1 & 6 & $10 \mathrm{YR}$ & 7 & wet & permanent & 0 & None \\
\hline L045 & 2 & 3 & 3 & 1 & 3 & 4 & 1 & 1 & 1 & 2 & 3 & 25 & 10YR & 7 & wet & permanent & 0 & $\begin{array}{c}\text { Rice, Veg, } \\
\text { Fruit }\end{array}$ \\
\hline L046 & 2 & 3 & 3 & 1 & 3 & 4 & 1 & 1 & 1 & 2 & 3 & 14 & 10YR & 7 & wet & permanent & 0 & Rice, Veg \\
\hline L047 & 2 & 3 & 4 & 0 & 3 & 4 & 1 & 1 & 3 & 1 & 2 & 13 & 10YR & 7 & wet & permanent & 0 & None \\
\hline L048 & 2 & 3 & 2 & 1 & 3 & 4 & 1 & 1 & 3 & 2 & 1 & 9 & $10 \mathrm{YR}$ & 7 & wet & permanent & 0 & None \\
\hline L049 & 2 & 3 & 2 & 1 & 3 & 4 & 1 & 1 & 3 & 2 & 1 & 6 & 10YR & 7 & wet & permanent & 0 & None \\
\hline L050 & 2 & 3 & 4 & 0 & 3 & 4 & 1 & 1 & 3 & 2 & 1 & 7 & 10YR & 7 & wet & permanent & 0 & None \\
\hline L051 & 2 & 3 & 2 & 1 & 3 & 4 & 1 & 1 & 3 & 2 & 1 & 9 & 10YR & 7 & wet & permanent & 0 & None \\
\hline L052 & 2 & 3 & 4 & 0 & 3 & 4 & 1 & 1 & 3 & 2 & 1 & 9 & $10 \mathrm{YR}$ & 7 & wet & permanent & 0 & None \\
\hline L053 & 2 & 3 & 4 & 0 & 3 & 4 & 1 & 1 & 3 & 2 & 1 & 8 & $10 \mathrm{YR}$ & 7 & moist & permanent & 0 & None \\
\hline L054 & 2 & 3 & 4 & 0 & 3 & 4 & 1 & 1 & 3 & 2 & 4 & 7 & $10 \mathrm{YR}$ & 7 & wet & permanent & 0 & None \\
\hline L055 & 2 & 3 & 3 & 1 & 3 & 4 & 1 & 1 & 3 & 2 & 3 & 7 & $10 \mathrm{YR}$ & 7 & wet & permanent & 0 & None \\
\hline L056 & 2 & 3 & 3 & 1 & 3 & 4 & 1 & 1 & 3 & 2 & 4 & 8 & $10 \mathrm{YR}$ & 7 & wet & permanent & 0 & None \\
\hline L057 & 2 & 3 & 2 & 1 & 3 & 4 & 1 & 1 & 3 & 1 & 1 & 10 & $10 \mathrm{YR}$ & 7 & wet & permanent & 0 & None \\
\hline L058 & 2 & 3 & 3 & 1 & 3 & 4 & 1 & 1 & 3 & 2 & 2 & 6 & $10 \mathrm{YR}$ & 7 & moist & permanent & 0 & None \\
\hline L059 & 2 & 3 & 3 & 1 & 3 & 4 & 1 & 1 & 3 & 2 & 3 & 3 & $10 \mathrm{YR}$ & 7 & wet & permanent & 0 & None \\
\hline L060 & 2 & 3 & 3 & 1 & 3 & 4 & 1 & 1 & 3 & 2 & 3 & 6 & $10 \mathrm{YR}$ & 7 & wet & permanent & 0 & None \\
\hline L061 & 2 & 3 & 3 & 1 & 3 & 4 & 1 & 1 & 3 & 4 & 3 & 10 & $10 \mathrm{YR}$ & 7 & wet & permanent & 0 & None \\
\hline L062 & 2 & 3 & 3 & 1 & 3 & 4 & 1 & 1 & 3 & 2 & 3 & 6 & $10 \mathrm{YR}$ & 7 & wet & permanent & 0 & None \\
\hline L063 & 2 & 3 & 3 & 1 & 3 & 4 & 1 & 1 & 3 & 2 & 3 & 6 & $10 \mathrm{YR}$ & 7 & wet & permanent & 0 & None \\
\hline L064 & 2 & 3 & 3 & 1 & 3 & 4 & 1 & 1 & 3 & 2 & 3 & 11 & $10 \mathrm{YR}$ & 7 & wet & permanent & 0 & None \\
\hline L065 & 2 & 3 & 3 & 1 & 3 & 4 & 1 & 1 & 3 & 2 & 1 & 7 & $10 \mathrm{YR}$ & 7 & wet & permanent & 0 & None \\
\hline L066 & 2 & 3 & 3 & 1 & 3 & 4 & 1 & 1 & 3 & 2 & 2 & 11 & $10 \mathrm{YR}$ & 7 & wet & permanent & 0 & - \\
\hline L067 & 2 & 3 & 3 & 1 & 3 & 4 & 1 & 0 & 3 & 2 & 1 & 8 & $10 \mathrm{YR}$ & 7 & wet & permanent & 0 & None \\
\hline L068 & 2 & 3 & 3 & 1 & 3 & 4 & 1 & 1 & 3 & 2 & 1 & 16 & $10 \mathrm{YR}$ & 7 & wet & permanent & 0 & Rice, Veg \\
\hline L069 & 2 & 3 & 3 & 1 & 3 & 4 & 1 & 1 & 3 & 2 & 1 & 6 & $10 \mathrm{YR}$ & 7 & wet & permanent & 0 & Rice, Veg \\
\hline L070 & 2 & 3 & 4 & 0 & 3 & 4 & 1 & 1 & 3 & 2 & 1 & 13 & $10 \mathrm{YR}$ & 7 & wet & permanent & 0 & None \\
\hline
\end{tabular}


Appendix 6. Wetland attribute data for all 531 persistent organic pollutant (POP) samples collected in Southeast Asia during 2011. Codes used for ecological region, river connection, wetland system, wetland subsystem, wetland type, wetland protection status, hydrological regime, wetland vegetation, and surface soil texture are listed in table

2. Country codes are listed as Cambodia (1), Lao PDR (2), Thailand (3), Vietnam (4), and Myanmar (5). Hydrological connection codes describe how rivers were connected to wetlands, such as surface flow only (1), channel flow (2), both channel and surface flow (3), and no connection to river (4). Measurements for surface soil texture, depth, color, and dampness refer to the top layer of soil only. Soil depth was measured in centimeters (cm). Soil color follows Munsell Color Chart codes (Munsell Soil Color Charts, 2009). Water permanence was measured only as water persisting all year round (permanent) or seasonal. The number of months that the wetland would dry in an average year was estimated. Finally, human use of lands surrounding each wetland was grouped into the following categories: rice, vegetable (veg), fruit, rubber (rub), eucalyptus (euc), coffee (cof), and none (natural surroundings). For all variables, dashes represent situations where data were absent. Only water permanence, number of months dry, and land use variables were collected through interviews that reflect the wetland in general. All other variables were collected from the P0Ps sampling point. The label C085 was mistakenly used twice, so " $A$ " distinguishes one sample from the other.-Continued

\begin{tabular}{|c|c|c|c|c|c|c|c|c|c|c|c|c|c|c|c|c|c|c|}
\hline $\begin{array}{l}\text { 으 } \\
\text { 음 } \\
\text { 틑 } \\
\text { 心 } \\
\text { 임 }\end{array}$ & 壱 & 홇 & 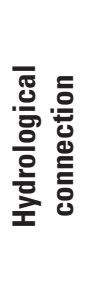 & 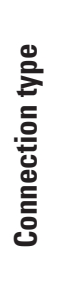 & $\begin{array}{l}E \\
\frac{\bar{d}}{\omega} \\
\vec{\omega}\end{array}$ & 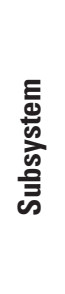 & 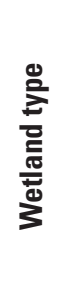 & 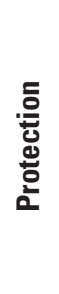 & 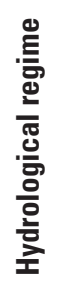 & 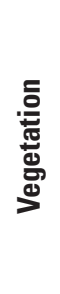 & 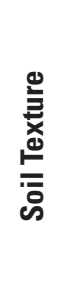 & 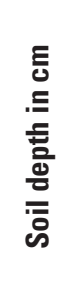 & 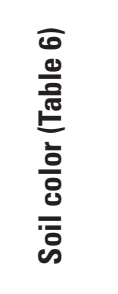 & 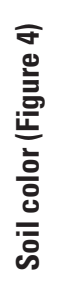 & 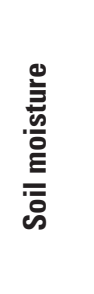 & 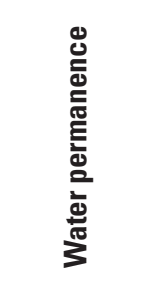 & 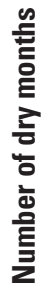 & 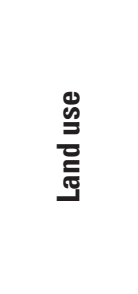 \\
\hline L071 & 2 & 3 & 3 & 1 & 3 & 4 & 1 & 0 & 3 & 2 & 1 & 11 & $10 \mathrm{YR}$ & 7 & moist & permanent & 0 & None \\
\hline L072 & 2 & 3 & 4 & 0 & 3 & 4 & 1 & 0 & 3 & 2 & 3 & 5 & $10 \mathrm{YR}$ & 7 & wet & permanent & 0 & None \\
\hline L073 & 2 & 3 & 4 & 0 & 3 & 4 & 1 & 0 & 3 & 2 & 3 & 12 & $10 Y R$ & 7 & moist & permanent & 0 & Rice, Veg \\
\hline L074 & 2 & 3 & 4 & 0 & 3 & 4 & 1 & 0 & 3 & 2 & 1 & 14 & $10 \mathrm{YR}$ & 7 & wet & permanent & 0 & None \\
\hline L075 & 2 & 3 & 2 & 1 & 3 & 4 & 1 & 0 & 3 & 2 & 1 & 5 & $7.5 \mathrm{YR}$ & 6 & moist & permanent & 0 & None \\
\hline L076 & 2 & 3 & 4 & 0 & 3 & 4 & 1 & 0 & 3 & 2 & 3 & 8 & $10 \mathrm{YR}$ & 7 & moist & permanent & 0 & None \\
\hline L077 & 2 & 3 & 4 & 0 & 3 & 4 & 1 & 0 & 3 & 2 & 1 & 13 & $10 \mathrm{YR}$ & 7 & wet & permanent & 0 & None \\
\hline L078 & 2 & 3 & 4 & 0 & 3 & 4 & 1 & 0 & 3 & 2 & 1 & 6 & $10 \mathrm{YR}$ & 7 & wet & permanent & 0 & None \\
\hline L079 & 2 & 3 & 3 & 1 & 3 & 4 & 1 & 0 & 3 & 2 & 1 & 8 & $10 \mathrm{YR}$ & 7 & wet & permanent & 0 & None \\
\hline L080 & 2 & 3 & 2 & 1 & 3 & 4 & 1 & 0 & 3 & 2 & 1 & 9 & $7.5 \mathrm{YR}$ & 6 & moist & permanent & 0 & None \\
\hline L081 & 2 & 2 & 3 & 1 & 3 & 4 & 1 & 0 & 3 & 2 & 1 & 4 & $10 \mathrm{YR}$ & 7 & moist & permanent & 0 & None \\
\hline L082 & 2 & 2 & 2 & 1 & 3 & 4 & 1 & 0 & 3 & 2 & 1 & 12 & $10 \mathrm{YR}$ & 7 & wet & permanent & 0 & None \\
\hline L083 & 2 & 2 & 3 & 1 & 3 & 4 & 1 & 0 & 3 & 2 & 1 & 5 & $10 \mathrm{YR}$ & 7 & wet & permanent & 0 & None \\
\hline L084 & 2 & 2 & 3 & 1 & 3 & 4 & 1 & 1 & 3 & 2 & 1 & 14 & $10 \mathrm{YR}$ & 7 & wet & permanent & 0 & None \\
\hline L085 & 2 & 2 & 2 & 1 & 3 & 4 & 1 & 1 & 3 & 2 & 1 & 4 & $10 \mathrm{YR}$ & 7 & wet & permanent & 0 & None \\
\hline L086 & 2 & 2 & 2 & 1 & 3 & 4 & 1 & 0 & 3 & 2 & 1 & 13 & $10 \mathrm{YR}$ & 7 & wet & permanent & 0 & None \\
\hline L087 & 2 & 2 & 2 & 1 & 3 & 4 & 1 & 0 & 3 & 2 & 1 & 8 & $10 \mathrm{YR}$ & 7 & wet & permanent & 0 & None \\
\hline L088 & 2 & 2 & 2 & 1 & 3 & 4 & 1 & 0 & 3 & 2 & 1 & 8 & $10 \mathrm{YR}$ & 7 & wet & permanent & 0 & None \\
\hline L089 & 2 & 2 & 3 & 1 & 3 & 4 & 1 & 0 & 3 & 2 & 1 & 2 & $10 \mathrm{YR}$ & 7 & wet & permanent & 0 & None \\
\hline
\end{tabular}




\begin{tabular}{|c|c|c|c|c|c|c|c|c|c|c|c|c|c|c|c|c|c|c|}
\hline 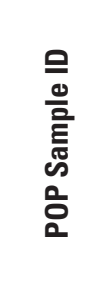 & 壱 & 흠ㅇㅀ & 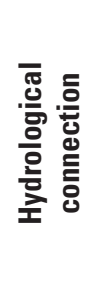 & 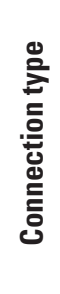 & $\begin{array}{l}\text { E़ } \\
\text { के } \\
\text { के }\end{array}$ & 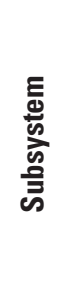 & 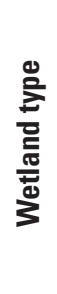 & 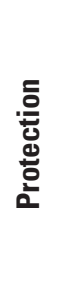 & 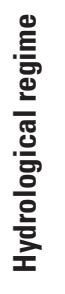 & 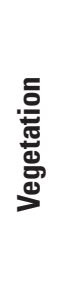 & 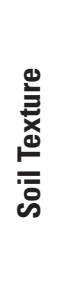 & 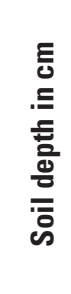 & 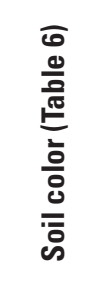 & 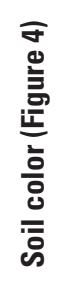 & 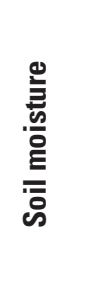 & 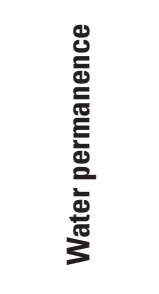 & 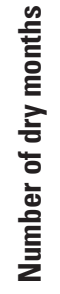 & 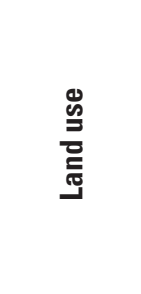 \\
\hline L090 & 2 & 2 & 3 & 1 & 2 & 2 & 1 & 0 & 1 & 1 & 1 & 10 & $10 \mathrm{YR}$ & 7 & wet & permanent & 0 & None \\
\hline L091 & 2 & 2 & 4 & 0 & 3 & 4 & 1 & 0 & 3 & 2 & 3 & 10 & $10 \mathrm{YR}$ & 7 & wet & permanent & 0 & None \\
\hline L092 & 2 & 2 & 3 & 1 & 3 & 4 & 1 & 0 & 3 & 2 & 1 & 12 & $10 \mathrm{YR}$ & 7 & wet & permanent & 0 & Rice \\
\hline L093 & 2 & 2 & 4 & 0 & 3 & 4 & 1 & 0 & 3 & 2 & 1 & 11 & $10 \mathrm{YR}$ & 7 & wet & permanent & 0 & Rice, Veg \\
\hline L094 & 2 & 2 & 2 & 1 & 3 & 4 & 1 & 0 & 3 & 2 & 3 & 11 & $5 \mathrm{YR}$ & 5 & wet & permanent & 0 & Rice \\
\hline L095 & 2 & 2 & 3 & 1 & 3 & 4 & 1 & 1 & 3 & 2 & 1 & 8 & $10 \mathrm{YR}$ & 7 & wet & permanent & 0 & None \\
\hline L096 & 2 & 2 & 2 & 1 & 3 & 4 & 1 & 1 & 3 & 2 & 3 & 10 & $10 \mathrm{YR}$ & 7 & wet & permanent & 0 & None \\
\hline L097 & 2 & 2 & 4 & 0 & 3 & 4 & 1 & 0 & 3 & 2 & 3 & 8 & $10 \mathrm{YR}$ & 7 & wet & permanent & 0 & Rice \\
\hline L098 & 2 & 2 & 3 & 1 & 3 & 4 & 1 & 0 & 1 & 2 & 3 & 8 & $10 \mathrm{YR}$ & 7 & moist & permanent & 0 & Rub \\
\hline L099 & 2 & 2 & 2 & 1 & 3 & 4 & 1 & 0 & 3 & 2 & 1 & 5 & $2.5 \mathrm{Y}$ & 8 & wet & permanent & 0 & Rice \\
\hline $\mathrm{L} 100$ & 2 & 2 & 3 & 1 & 3 & 4 & 1 & 0 & 3 & 2 & 1 & 8 & 10YR & 7 & wet & permanent & 0 & Rice \\
\hline L101 & 2 & 2 & 4 & 0 & 3 & 4 & 1 & 0 & 3 & 2 & 3 & 6 & $10 \mathrm{YR}$ & 7 & wet & permanent & 0 & None \\
\hline L102 & 2 & 2 & 2 & 1 & 3 & 4 & 1 & 0 & 3 & 2 & 3 & 7 & $10 \mathrm{YR}$ & 7 & wet & permanent & 0 & Rice \\
\hline L103 & 2 & 2 & 3 & 1 & 3 & 4 & 1 & 0 & 1 & 2 & 3 & 7 & $10 \mathrm{YR}$ & 7 & wet & permanent & 0 & None \\
\hline L104 & 2 & 2 & 3 & 1 & 3 & 4 & 1 & 0 & 3 & 2 & 1 & 6 & $10 \mathrm{YR}$ & 7 & wet & permanent & 0 & Rice \\
\hline L105 & 2 & 2 & 3 & 1 & 3 & 4 & 1 & 0 & 1 & 2 & 1 & 7 & $10 \mathrm{YR}$ & 7 & wet & permanent & 0 & Rice \\
\hline L106 & 2 & 2 & 3 & 1 & 3 & 4 & 1 & 0 & 3 & 2 & 1 & 8 & $10 \mathrm{YR}$ & 7 & wet & permanent & 0 & None \\
\hline L107 & 2 & 2 & 3 & 1 & 3 & 4 & 1 & 0 & 3 & 2 & 1 & 5 & $10 \mathrm{YR}$ & 7 & wet & permanent & 0 & Rice \\
\hline L108 & 2 & 2 & 3 & 1 & 3 & 4 & 1 & 0 & 3 & 2 & 1 & 5 & $5 \mathrm{Y}$ & 9 & wet & permanent & 0 & None \\
\hline L109 & 2 & 2 & 3 & 1 & 3 & 4 & 1 & 0 & 3 & 2 & 1 & 12 & $10 \mathrm{YR}$ & 7 & wet & permanent & 0 & None \\
\hline L110 & 2 & 2 & 3 & 1 & 3 & 4 & 1 & 0 & 3 & 2 & 1 & 13 & $10 \mathrm{YR}$ & 7 & wet & permanent & 0 & None \\
\hline L111 & 2 & 2 & 3 & 1 & 3 & 4 & 1 & 0 & 3 & 2 & 1 & 8 & $10 \mathrm{YR}$ & 7 & wet & permanent & 0 & None \\
\hline L112 & 2 & 2 & 3 & 1 & 3 & 4 & 1 & 0 & 3 & 2 & 1 & 11 & $10 \mathrm{YR}$ & 7 & wet & permanent & 0 & None \\
\hline L113 & 2 & 2 & 3 & 1 & 3 & 4 & 1 & 1 & 3 & 2 & 2 & 8 & $10 \mathrm{YR}$ & 7 & wet & permanent & 0 & None \\
\hline L114 & 2 & 2 & 4 & 0 & 3 & 4 & 1 & 0 & 3 & 2 & 1 & 7 & $10 \mathrm{YR}$ & 7 & wet & permanent & 0 & Rice \\
\hline L115 & 2 & 2 & 4 & 0 & 3 & 4 & 1 & 0 & 3 & 2 & 1 & 10 & $10 \mathrm{YR}$ & 7 & wet & permanent & 0 & Rice \\
\hline L116 & 2 & 2 & 3 & 1 & 3 & 4 & 1 & 0 & 3 & 2 & 1 & 15 & $10 \mathrm{YR}$ & 7 & wet & permanent & 0 & Rice \\
\hline L117 & 2 & 2 & 3 & 1 & 3 & 4 & 1 & 0 & 3 & 2 & 1 & 12 & $10 \mathrm{YR}$ & 7 & wet & permanent & 0 & Rice \\
\hline
\end{tabular}


Appendix 6. Wetland attribute data for all 531 persistent organic pollutant (POP) samples collected in Southeast Asia during 2011. Codes used for ecological region, river connection, wetland system, wetland subsystem, wetland type, wetland protection status, hydrological regime, wetland vegetation, and surface soil texture are listed in table

2. Country codes are listed as Cambodia (1), Lao PDR (2), Thailand (3), Vietnam (4), and Myanmar (5). Hydrological connection codes describe how rivers were connected to wetlands, such as surface flow only (1), channel flow (2), both channel and surface flow (3), and no connection to river (4). Measurements for surface soil texture, depth, color, and dampness refer to the top layer of soil only. Soil depth was measured in centimeters (cm). Soil color follows Munsell Color Chart codes (Munsell Soil Color Charts, 2009). Water permanence was measured only as water persisting all year round (permanent) or seasonal. The number of months that the wetland would dry in an average year was estimated. Finally, human use of lands surrounding each wetland was grouped into the following categories: rice, vegetable (veg), fruit, rubber (rub), eucalyptus (euc), coffee (cof), and none (natural surroundings). For all variables, dashes represent situations where data were absent. Only water permanence, number of months dry, and land use variables were collected through interviews that reflect the wetland in general. All other variables were collected from the P0Ps sampling point. The label C085 was mistakenly used twice, so " $A$ " distinguishes one sample from the other.-Continued

\begin{tabular}{|c|c|c|c|c|c|c|c|c|c|c|c|c|c|c|c|c|c|c|}
\hline $\begin{array}{l}\text { 으 } \\
\text { 음 } \\
\text { 辰 } \\
\text { 心 } \\
\text { 옴 }\end{array}$ & 壱 & 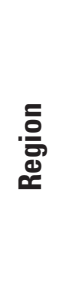 & 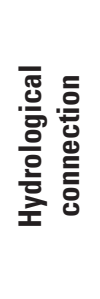 & 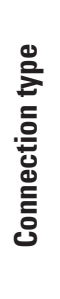 & 竞 & 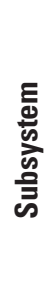 & 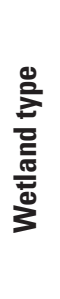 & 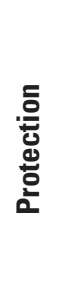 & 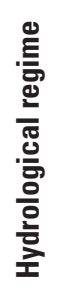 & 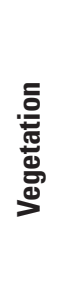 & 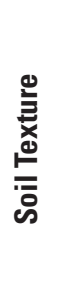 & 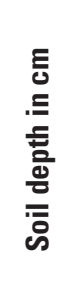 & 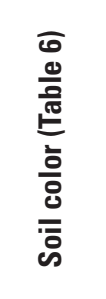 & 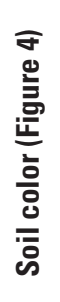 & 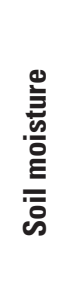 & 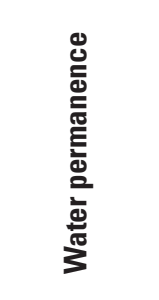 & 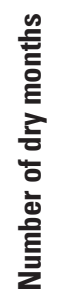 & 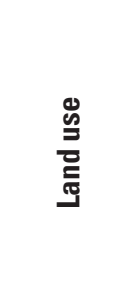 \\
\hline L118 & 2 & 2 & 3 & 1 & 3 & 4 & 1 & 0 & 3 & 4 & 1 & 14 & $10 \mathrm{YR}$ & 7 & wet & permanent & 0 & None \\
\hline L119 & 2 & 2 & 3 & 1 & 3 & 4 & 1 & 0 & 3 & 1 & 3 & 8 & $10 \mathrm{YR}$ & 7 & wet & permanent & 0 & Rice \\
\hline L120 & 2 & 2 & 3 & 1 & 3 & 4 & 1 & 0 & 3 & 1 & 1 & 14 & $10 \mathrm{YR}$ & 7 & wet & permanent & 0 & Rice \\
\hline M001 & 5 & 16 & 2 & 1 & 3 & 4 & 1 & 0 & 2 & 3 & 3 & 9 & $2.5 \mathrm{YR}$ & 4 & wet & permanent & 0 & Rice, Veg \\
\hline M002 & 5 & 16 & 2 & 1 & 3 & 4 & 1 & 0 & 2 & 3 & 3 & 5 & $2.5 \mathrm{YR}$ & 4 & dry & seasonal & 8 & Rice, Veg \\
\hline M003 & 5 & 16 & 2 & 1 & 3 & 4 & 1 & 0 & 2 & 3 & 3 & 5 & $10 \mathrm{YR}$ & 7 & dry & permanent & 0 & Rice, Veg \\
\hline M004 & 5 & 16 & 2 & 1 & 4 & 6 & 1 & 0 & 1 & 3 & 5 & - & - & - & - & permanent & 0 & Rice, Veg \\
\hline M005 & 5 & 16 & 2 & 1 & 4 & 6 & 1 & 0 & 2 & 3 & 3 & 10 & $7.5 \mathrm{YR}$ & 6 & wet & seasonal & 7 & Veg \\
\hline M006 & 5 & 16 & 3 & 1 & 4 & 6 & 1 & 0 & 2 & 3 & 3 & 10 & $7.5 \mathrm{YR}$ & 6 & wet & seasonal & 6 & Rice, Veg \\
\hline M007 & 5 & 16 & 3 & 1 & 3 & 4 & 1 & 0 & 2 & 3 & 5 & 9 & $5 \mathrm{YR}$ & 5 & wet & permanent & 0 & Rice, Veg \\
\hline M008 & 5 & 16 & 3 & 1 & 3 & 4 & 1 & 0 & 4 & 3 & 5 & 30 & $7.5 \mathrm{YR}$ & 6 & wet & seasonal & 7 & Veg \\
\hline M009 & 5 & 16 & 3 & 1 & 3 & 4 & 1 & 0 & 2 & 3 & 3 & 30 & 7.5YR & 6 & wet & permanent & 0 & Rice, Veg \\
\hline M010 & 5 & 16 & 2 & 1 & 4 & 6 & 1 & 0 & 1 & 3 & 3 & 30 & 7.5YR & 6 & wet & permanent & 0 & Rice, Veg \\
\hline M011 & 5 & 16 & 2 & 1 & 4 & 6 & 1 & 0 & 1 & 3 & 5 & 9 & $5 \mathrm{YR}$ & 5 & wet & permanent & 0 & Rice, Veg \\
\hline M012 & 5 & 16 & 2 & 1 & 3 & 4 & 1 & 0 & 2 & 3 & 3 & 9 & $2.5 \mathrm{YR}$ & 4 & wet & permanent & 0 & Rice, Veg \\
\hline M013 & 5 & 16 & 2 & 1 & 3 & 4 & 2 & 0 & 4 & 2 & 1 & 9 & $5 \mathrm{Y}$ & 9 & wet & permanent & 0 & Rice, Veg \\
\hline M014 & 5 & 16 & 2 & 1 & 3 & 4 & 2 & 0 & 4 & 2 & 1 & 30 & $10 \mathrm{YR}$ & 7 & wet & permanent & 0 & Rice, Veg \\
\hline M015 & 5 & 16 & 2 & 1 & 3 & 4 & 2 & 0 & 2 & 2 & 1 & 30 & $5 \mathrm{Y}$ & 9 & wet & permanent & 0 & Rice, Veg \\
\hline M016 & 5 & 16 & 2 & 1 & 3 & 4 & 2 & 0 & 2 & 2 & 1 & 20 & $5 \mathrm{R}$ & 1 & wet & permanent & 0 & Rice, Veg \\
\hline
\end{tabular}




\begin{tabular}{|c|c|c|c|c|c|c|c|c|c|c|c|c|c|c|c|c|c|c|}
\hline 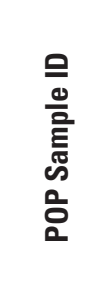 & 竎 & 흠 & $\begin{array}{l}\overline{\bar{J}} \\
\text { 흘 } \\
\text { 응 } \\
\text { 을 } \\
\text { 총 }\end{array}$ & 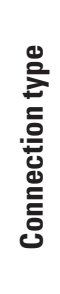 & $\frac{E}{\text { के }}$ & 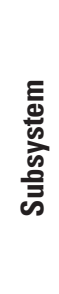 & 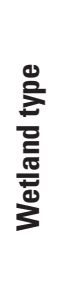 & 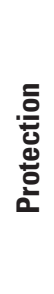 & 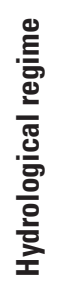 & 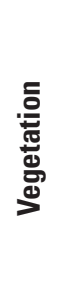 & 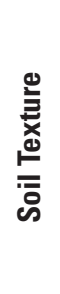 & 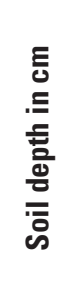 & 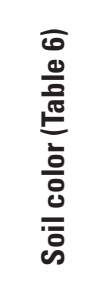 & 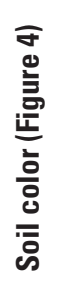 & 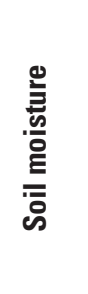 & 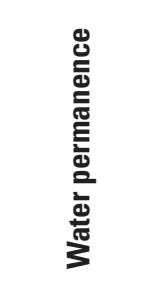 & 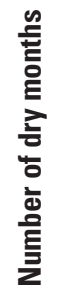 & 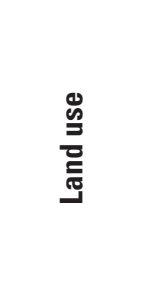 \\
\hline M017 & 5 & 16 & 2 & 1 & 3 & 4 & 1 & 0 & 2 & 2 & 1 & 10 & $2.5 \mathrm{YR}$ & 4 & wet & permanent & 0 & Rice, Veg \\
\hline M018 & 5 & 16 & 2 & 1 & 3 & 4 & 1 & 0 & 4 & 2 & 1 & 10 & $5 \mathrm{Y}$ & 9 & wet & permanent & 0 & Rice, Veg \\
\hline M019 & 5 & 16 & 2 & 1 & 3 & 4 & 1 & 0 & 2 & 2 & 1 & 10 & $5 \mathrm{Y}$ & 9 & wet & seasonal & 6 & Rice, Veg \\
\hline M020 & 5 & 16 & 2 & 1 & 3 & 4 & 2 & 0 & 4 & 2 & 3 & 30 & 10YR & 7 & wet & seasonal & 5 & Rice, Veg \\
\hline M021 & 5 & 16 & 2 & 1 & 3 & 4 & 2 & 0 & 2 & 3 & 1 & 30 & $5 \mathrm{Y}$ & 9 & wet & seasonal & 5 & Rice, Veg \\
\hline M022 & 5 & 16 & 4 & 0 & 3 & 4 & 2 & 0 & 4 & 2 & 1 & 26 & $5 \mathrm{Y}$ & 9 & wet & seasonal & 5 & Rice, Veg \\
\hline M023 & 5 & 16 & 3 & 1 & 2 & 2 & 1 & 0 & 3 & 3 & 1 & 30 & $5 \mathrm{Y}$ & 9 & wet & permanent & 0 & Rice, Veg \\
\hline M024 & 5 & 16 & 3 & 1 & 2 & 3 & 1 & 0 & 3 & 5 & 1 & 29 & $5 \mathrm{Y}$ & 9 & wet & permanent & 0 & Rice, Veg \\
\hline M025 & 5 & 16 & 3 & 1 & 2 & 3 & 1 & 0 & 3 & 5 & 1 & 30 & $5 \mathrm{Y}$ & 9 & wet & permanent & 0 & Rice, Veg \\
\hline M026 & 5 & 16 & 3 & 1 & 2 & 3 & 1 & 0 & 3 & 5 & 1 & 20 & $5 \mathrm{Y}$ & 9 & wet & permanent & 0 & Rice, Veg \\
\hline M027 & 5 & 16 & 3 & 1 & 3 & 4 & 1 & 0 & 2 & 2 & 1 & 30 & $5 \mathrm{Y}$ & 9 & wet & seasonal & 5 & Rice, Veg \\
\hline M028 & 5 & 16 & 3 & 1 & 3 & 4 & 1 & 0 & 2 & 2 & 3 & 30 & $10 \mathrm{YR}$ & 7 & wet & seasonal & 5 & Rice, Veg \\
\hline M029 & 5 & 16 & 3 & 1 & 3 & 4 & 2 & 0 & 2 & 3 & 5 & 29 & $10 \mathrm{YR}$ & 7 & wet & seasonal & 5 & Rice, Veg \\
\hline M030 & 5 & 16 & 3 & 1 & 3 & 4 & 2 & 0 & 2 & 3 & 3 & 29 & $5 \mathrm{YR}$ & 5 & wet & seasonal & 5 & Rice, Veg \\
\hline $\mathrm{T} 101$ & 3 & 7 & 2 & 1 & 3 & 4 & 1 & 0 & 3 & 2 & 1 & 10 & $10 \mathrm{YR}$ & 7 & moist & seasonal & 4 & Rice \\
\hline T102 & 3 & 7 & 2 & 1 & 2 & 3 & 2 & 0 & 3 & 5 & 2 & 30 & $10 \mathrm{YR}$ & 7 & wet & permanent & 0 & Rice, Euc \\
\hline T103 & 3 & 7 & 2 & 1 & 3 & 4 & 2 & 0 & 3 & 2 & 1 & 6 & $10 \mathrm{YR}$ & 7 & wet & permanent & 0 & Rice, Euc \\
\hline T104 & 3 & 7 & 3 & 1 & 3 & 4 & 1 & 0 & 3 & 1 & 1 & 5 & $10 \mathrm{YR}$ & 7 & wet & permanent & 0 & Rice, Euc \\
\hline T105 & 3 & 7 & 2 & 1 & 3 & 4 & 2 & 1 & 3 & 2 & 1 & 10 & $10 \mathrm{YR}$ & 7 & wet & permanent & 0 & $\begin{array}{c}\text { Rice, Veg, } \\
\text { Rub, } \\
\text { Euc }\end{array}$ \\
\hline
\end{tabular}

\begin{tabular}{|c|c|c|c|c|c|c|c|c|c|c|c|c|c|c|c|c|c|c|}
\hline T106 & 3 & 7 & 4 & 0 & 2 & 3 & 2 & 0 & 3 & 5 & 2 & 10 & $10 \mathrm{YR}$ & 7 & wet & permanent & 0 & Rice, Veg \\
\hline $\mathrm{T} 107$ & 3 & 7 & 3 & 1 & 3 & 4 & 2 & 0 & 3 & 1 & 2 & 8 & $10 \mathrm{YR}$ & 7 & wet & permanent & 0 & Rice, Euc \\
\hline T108 & 3 & 7 & 4 & 0 & 3 & 4 & 2 & 1 & 3 & 5 & 3 & 30 & $10 \mathrm{YR}$ & 7 & wet & permanent & 0 & Rice, Euc \\
\hline T109 & 3 & 7 & 2 & 1 & 3 & 4 & 2 & 0 & 3 & 5 & 2 & 10 & $10 \mathrm{YR}$ & 7 & wet & permanent & 0 & Rice \\
\hline $\mathrm{T} 110$ & 3 & 7 & 1 & 1 & 3 & 4 & 1 & 0 & 3 & 5 & 2 & 10 & $10 \mathrm{YR}$ & 7 & wet & permanent & 0 & $\begin{array}{c}\text { Rice, Veg, } \\
\text { Fruit }\end{array}$ \\
\hline
\end{tabular}


Appendix 6. Wetland attribute data for all 531 persistent organic pollutant (POP) samples collected in Southeast Asia during 2011. Codes used for ecological region, river connection, wetland system, wetland subsystem, wetland type, wetland protection status, hydrological regime, wetland vegetation, and surface soil texture are listed in table 2. Country codes are listed as Cambodia (1), Lao PDR (2), Thailand (3), Vietnam (4), and Myanmar (5). Hydrological connection codes describe how rivers were connected to wetlands, such as surface flow only (1), channel flow (2), both channel and surface flow (3), and no connection to river (4). Measurements for surface soil texture, depth, color, and dampness refer to the top layer of soil only. Soil depth was measured in centimeters (cm). Soil color follows Munsell Color Chart codes (Munsell Soil Color Charts, 2009). Water permanence was measured only as water persisting all year round (permanent) or seasonal. The number of months that the wetland would dry in an average year was estimated. Finally, human use of lands surrounding each wetland was grouped into the following categories: rice, vegetable (veg), fruit, rubber (rub), eucalyptus (euc), coffee (cof), and none (natural surroundings). For all variables, dashes represent situations where data were absent. Only water permanence, number of months dry, and land use variables were collected through interviews that reflect the wetland in general. All other variables were collected from the P0Ps sampling point. The label C085 was mistakenly used twice, so " $A$ " distinguishes one sample from the other.-Continued

\begin{tabular}{|c|c|c|c|c|c|c|c|c|c|c|c|c|c|c|c|c|c|c|}
\hline 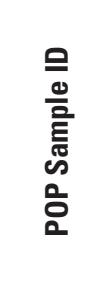 & 竞 & .흥 & 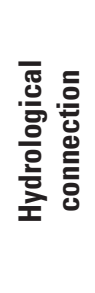 & 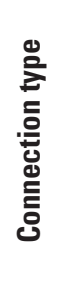 & $\frac{E}{d ্}$ & 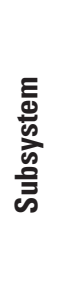 & 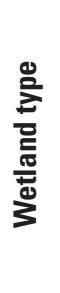 & 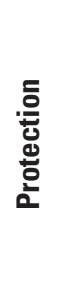 & 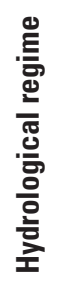 & 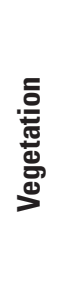 & 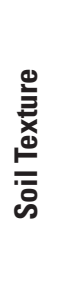 & 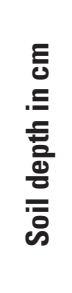 & 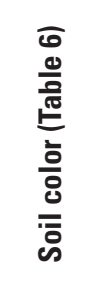 & 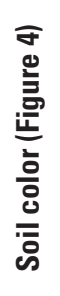 & 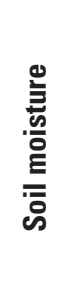 & 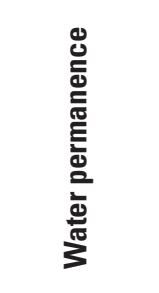 & 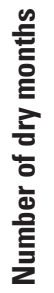 & 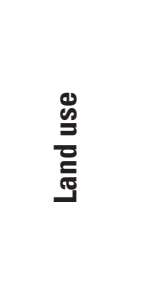 \\
\hline $\mathrm{T} 111$ & 3 & 7 & 2 & 1 & 3 & 4 & 2 & 0 & 3 & 5 & 1 & 30 & $10 \mathrm{YR}$ & 7 & wet & permanent & 0 & $\begin{array}{c}\text { Rice, Veg, } \\
\text { Rub, } \\
\text { Euc }\end{array}$ \\
\hline T112 & 3 & 7 & 2 & 1 & 2 & 3 & 2 & 0 & 3 & 5 & 1 & 30 & $10 \mathrm{YR}$ & 7 & wet & permanent & 0 & Rice, Euc \\
\hline T113 & 3 & 7 & 2 & 1 & 3 & 4 & 2 & 1 & 3 & 1 & 1 & 10 & $10 \mathrm{YR}$ & 7 & wet & permanent & 0 & Rice \\
\hline T114 & 3 & 7 & 4 & 0 & 2 & 3 & 2 & 0 & 3 & 5 & 1 & 12 & $10 \mathrm{YR}$ & 7 & wet & permanent & 0 & $\begin{array}{c}\text { Rice, Veg, } \\
\text { Fruit }\end{array}$ \\
\hline T115 & 3 & 7 & 2 & 1 & 3 & 4 & 1 & 1 & 3 & 2 & 1 & 30 & $10 \mathrm{YR}$ & 7 & wet & seasonal & 3 & $\begin{array}{l}\text { Rice, Veg, } \\
\text { Euc }\end{array}$ \\
\hline T116 & 3 & 7 & 2 & 1 & 2 & 3 & 2 & 0 & 3 & 5 & 3 & 5 & $10 \mathrm{YR}$ & 7 & wet & permanent & 0 & Rice, Veg \\
\hline T117 & 3 & 7 & 2 & 1 & 2 & 3 & 2 & 1 & 3 & 5 & 1 & 9 & $10 \mathrm{YR}$ & 7 & wet & permanent & 0 & Rice, Euc \\
\hline T118 & 3 & 7 & 4 & 0 & 3 & 4 & 1 & 0 & 3 & 2 & 1 & 12 & $10 \mathrm{YR}$ & 7 & wet & permanent & 0 & Rice \\
\hline T119 & 3 & 7 & 2 & 1 & 3 & 4 & 2 & 0 & 3 & 5 & 1 & 10 & $10 \mathrm{YR}$ & 7 & wet & permanent & 0 & $\begin{array}{l}\text { Rice, Veg, } \\
\text { Euc }\end{array}$ \\
\hline $\mathrm{T} 120$ & 3 & 7 & 3 & 1 & 3 & 4 & 1 & 0 & 3 & 2 & 2 & 3 & $10 \mathrm{YR}$ & 7 & wet & permanent & 0 & Rice, Euc \\
\hline $\mathrm{T} 121$ & 3 & 7 & 1 & 1 & 3 & 4 & 1 & 1 & 2 & 2 & 1 & 9 & $10 \mathrm{YR}$ & 7 & wet & permanent & 0 & Rice, Euc \\
\hline T201 & 3 & 6 & 1 & 1 & 3 & 4 & 1 & 1 & 3 & 2 & 1 & 30 & $10 \mathrm{YR}$ & 7 & wet & permanent & 0 & Rice \\
\hline T202 & 3 & 6 & 2 & 1 & 3 & 4 & 2 & 0 & 3 & 5 & 3 & 30 & $7.5 \mathrm{YR}$ & 6 & wet & permanent & 0 & Rice \\
\hline $\mathrm{T} 203$ & 3 & 6 & 2 & 1 & 3 & 4 & 1 & 1 & 3 & 2 & 1 & 10 & $7.5 \mathrm{YR}$ & 6 & wet & permanent & 0 & Rice, Euc \\
\hline T204 & 3 & 6 & 2 & 1 & 3 & 4 & 2 & 0 & 3 & 5 & 1 & 20 & $7.5 \mathrm{YR}$ & 6 & wet & permanent & 0 & Rice, Euc \\
\hline T205 & 3 & 6 & 2 & 1 & 3 & 4 & 1 & 1 & 3 & 2 & 2 & 10 & $7.5 \mathrm{YR}$ & 6 & wet & permanent & 0 & Rice, Euc \\
\hline
\end{tabular}




\begin{tabular}{|c|c|c|c|c|c|c|c|c|c|c|c|c|c|c|c|c|c|c|}
\hline $\begin{array}{l}\text { 으 } \\
\text { 흘 } \\
\text { 言 } \\
\text { 心 } \\
\text { 음 }\end{array}$ & 吂 & . & $\begin{array}{l}\overline{\mathbb{J}} \\
\text { 흘 } \\
\text { 응 } \\
\text { 을 } \\
\text { 총 }\end{array}$ & 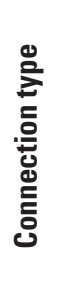 & $\begin{array}{l}\text { E } \\
\text { के } \\
\text { के }\end{array}$ & 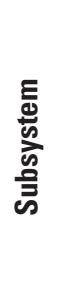 & 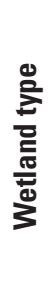 & 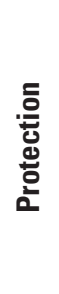 & 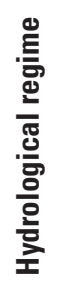 & 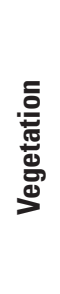 & 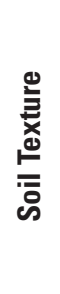 & 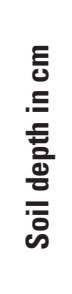 & 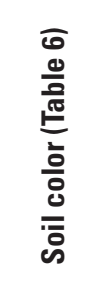 & 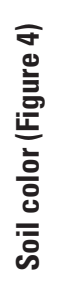 & 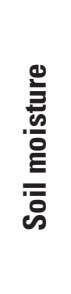 & 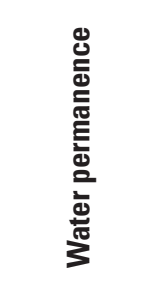 & 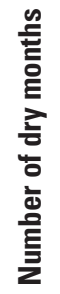 & 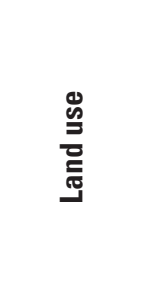 \\
\hline T206 & 3 & 6 & 2 & 1 & 3 & 4 & 2 & 0 & 3 & 5 & 3 & 30 & $5 \mathrm{YR}$ & 5 & wet & permanent & 0 & Rice, Euc \\
\hline T207 & 3 & 6 & 2 & 1 & 3 & 4 & 2 & 0 & 3 & 2 & 3 & 15 & $7.5 \mathrm{YR}$ & 6 & wet & permanent & 0 & Rice, Euc \\
\hline T208 & 3 & 6 & 1 & 1 & 3 & 4 & 2 & 0 & 4 & 5 & 1 & 5 & $7.5 \mathrm{YR}$ & 6 & wet & permanent & 0 & Rice, Euc \\
\hline T209 & 3 & 6 & 2 & 1 & 3 & 4 & 2 & 0 & 4 & 2 & 2 & 15 & $7.5 \mathrm{YR}$ & 6 & wet & permanent & 0 & Rice, Euc \\
\hline $\mathrm{T} 210$ & 3 & 6 & 2 & 1 & 3 & 4 & 2 & 0 & 3 & 5 & 3 & 10 & $7.5 \mathrm{YR}$ & 6 & wet & permanent & 0 & Rice, Euc \\
\hline $\mathrm{T} 211$ & 3 & 6 & 2 & 1 & 3 & 4 & 1 & 0 & 3 & 2 & 1 & 20 & $7.5 \mathrm{YR}$ & 6 & wet & permanent & 0 & Rice, Euc \\
\hline $\mathrm{T} 212$ & 3 & 6 & 2 & 1 & 3 & 4 & 2 & 0 & 3 & 2 & 1 & 30 & $7.5 \mathrm{YR}$ & 6 & wet & permanent & 0 & Rice, Euc \\
\hline $\mathrm{T} 213$ & 3 & 6 & 3 & 1 & 3 & 4 & 1 & 1 & 3 & 2 & 3 & 20 & $7.5 \mathrm{YR}$ & 6 & wet & permanent & 0 & Rice, Euc \\
\hline $\mathrm{T} 214$ & 3 & 6 & 2 & 1 & 3 & 4 & 1 & 0 & 3 & 2 & 1 & 30 & $10 \mathrm{YR}$ & 7 & wet & permanent & 0 & $\begin{array}{l}\text { Rice, } \\
\text { Fruit }\end{array}$ \\
\hline $\mathrm{T} 215$ & 3 & 6 & 2 & 1 & 3 & 4 & 2 & 0 & 4 & 2 & 3 & 10 & $7.5 \mathrm{YR}$ & 6 & wet & seasonal & 3 & Rice \\
\hline T216 & 3 & 6 & 2 & 1 & 3 & 4 & 1 & 0 & 4 & 2 & 3 & 30 & $7.5 \mathrm{YR}$ & 6 & wet & permanent & 0 & Rice, Euc \\
\hline $\mathrm{T} 217$ & 3 & 6 & 2 & 1 & 3 & 4 & 2 & 0 & 3 & 5 & 3 & 10 & $7.5 \mathrm{YR}$ & 6 & wet & permanent & 0 & Rice \\
\hline T218 & 3 & 6 & 3 & 1 & 2 & 3 & 2 & 0 & 3 & 5 & 3 & 30 & $7.5 \mathrm{YR}$ & 6 & wet & permanent & 0 & Rice \\
\hline T219 & 3 & 6 & 2 & 1 & 3 & 4 & 1 & 0 & 3 & 2 & 1 & 30 & $7.5 \mathrm{YR}$ & 6 & wet & permanent & 0 & Euc \\
\hline $\mathrm{T} 220$ & 3 & 6 & 2 & 1 & 3 & 4 & 1 & 0 & 3 & 2 & 1 & 30 & $7.5 \mathrm{YR}$ & 6 & wet & permanent & 0 & None \\
\hline $\mathrm{T} 221$ & 3 & 6 & 2 & 1 & 2 & 3 & 1 & 1 & 3 & 5 & 3 & 30 & $7.5 \mathrm{YR}$ & 6 & wet & permanent & 0 & Rice, Euc \\
\hline T301 & 3 & 7 & 4 & 0 & 3 & 4 & 1 & 0 & 3 & 1 & 2 & 8 & $10 \mathrm{YR}$ & 7 & wet & permanent & 0 & $\begin{array}{l}\text { Rice, } \\
\text { Fruit, } \\
\text { Euc }\end{array}$ \\
\hline T302 & 3 & 7 & 3 & 1 & 3 & 4 & 1 & 0 & 2 & 2 & 1 & 12 & $10 \mathrm{YR}$ & 7 & wet & permanent & 0 & Rice, Euc \\
\hline T303 & 3 & 7 & 2 & 1 & 3 & 4 & 1 & 0 & 2 & 1 & 2 & 10 & $10 \mathrm{YR}$ & 7 & wet & seasonal & 2 & Rice, Euc \\
\hline T304 & 3 & 7 & 2 & 1 & 2 & 2 & 1 & 0 & 2 & 1 & 3 & 12 & $10 \mathrm{YR}$ & 7 & wet & permanent & 0 & Rice, Rub \\
\hline T305 & 3 & 7 & 3 & 1 & 2 & 2 & 2 & 0 & 2 & 1 & 2 & 30 & $10 \mathrm{YR}$ & 7 & wet & permanent & 0 & $\begin{array}{c}\text { Rice, Veg, } \\
\text { Fruit }\end{array}$ \\
\hline $\mathrm{T} 401$ & 3 & 4 & 2 & 1 & 2 & 2 & 1 & 1 & 1 & 1 & 1 & 20 & $10 \mathrm{YR}$ & 7 & wet & permanent & 0 & None \\
\hline T402 & 3 & 4 & 2 & 1 & 2 & 2 & 1 & 0 & 2 & 1 & 1 & 50 & $10 \mathrm{YR}$ & 7 & wet & permanent & 0 & $\begin{array}{l}\text { Rice, } \\
\text { Fruit, } \\
\text { Euc }\end{array}$ \\
\hline
\end{tabular}


Appendix 6. Wetland attribute data for all 531 persistent organic pollutant (POP) samples collected in Southeast Asia during 2011. Codes used for ecological region, river connection, wetland system, wetland subsystem, wetland type, wetland protection status, hydrological regime, wetland vegetation, and surface soil texture are listed in table 2. Country codes are listed as Cambodia (1), Lao PDR (2), Thailand (3), Vietnam (4), and Myanmar (5). Hydrological connection codes describe how rivers were connected to wetlands, such as surface flow only (1), channel flow (2), both channel and surface flow (3), and no connection to river (4). Measurements for surface soil texture, depth, color, and dampness refer to the top layer of soil only. Soil depth was measured in centimeters (cm). Soil color follows Munsell Color Chart codes (Munsell Soil Color Charts, 2009). Water permanence was measured only as water persisting all year round (permanent) or seasonal. The number of months that the wetland would dry in an average year was estimated. Finally, human use of lands surrounding each wetland was grouped into the following categories: rice, vegetable (veg), fruit, rubber (rub), eucalyptus (euc), coffee (cof), and none (natural surroundings). For all variables, dashes represent situations where data were absent. Only water permanence, number of months dry, and land use variables were collected through interviews that reflect the wetland in general. All other variables were collected from the P0Ps sampling point. The label C085 was mistakenly used twice, so " $A$ " distinguishes one sample from the other.-Continued

\begin{tabular}{|c|c|c|c|c|c|c|c|c|c|c|c|c|c|c|c|c|c|c|}
\hline $\begin{array}{l}\text { 으 } \\
\text { 을 } \\
\text { 틀 } \\
\text { 心 } \\
\text { 음 }\end{array}$ & 壱 & 흠 & $\begin{array}{l}\overline{\mathbb{J}} \\
\text { 흘 } \\
\text { 응 } \\
\text { 을 } \\
\text { 종 }\end{array}$ & 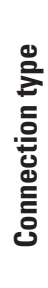 & $\begin{array}{l}E \\
\text { 总 } \\
\text { के }\end{array}$ & है & 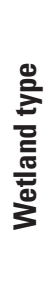 & 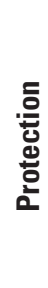 & 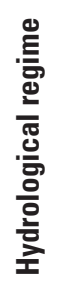 & 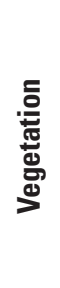 & 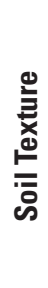 & 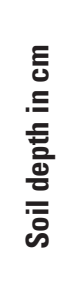 & $\begin{array}{l}\text { ঢ } \\
\frac{0}{0} \\
\frac{0}{\pi} \\
\frac{0}{0} \\
\frac{0}{0} \\
\frac{0}{0}\end{array}$ & 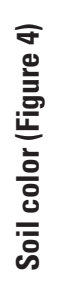 & 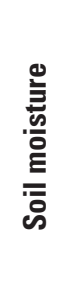 & 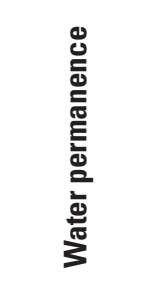 & 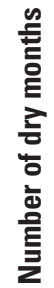 & 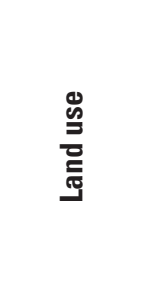 \\
\hline T403 & 3 & 4 & 2 & 1 & 2 & 2 & 1 & 1 & 2 & 2 & 1 & 15 & $10 \mathrm{YR}$ & 7 & wet & permanent & 0 & Rice \\
\hline $\mathrm{T} 404$ & 3 & 4 & 2 & 1 & 3 & 4 & 1 & 1 & 2 & 1 & 1 & 50 & $10 \mathrm{YR}$ & 7 & wet & permanent & 0 & Rub, Euc \\
\hline $\mathrm{T} 405$ & 3 & 4 & 2 & 1 & 3 & 4 & 2 & 0 & 2 & 5 & 1 & 15 & $10 \mathrm{YR}$ & 7 & wet & permanent & 0 & None \\
\hline T406 & 3 & 4 & 4 & 0 & 3 & 4 & 1 & 0 & 3 & 1 & 1 & 7 & 10YR & 7 & wet & permanent & 0 & Rice, Euc \\
\hline $\mathrm{T} 407$ & 3 & 4 & 2 & 1 & 2 & 3 & 1 & 0 & 2 & 5 & 1 & 30 & $5 \mathrm{YR}$ & 5 & wet & permanent & 0 & $\begin{array}{l}\text { Rice, } \\
\text { Fruit, } \\
\text { Euc }\end{array}$ \\
\hline T408 & 3 & 4 & 2 & 1 & 2 & 3 & 1 & 1 & 2 & 5 & 1 & 30 & 10YR & 7 & wet & permanent & 0 & $\begin{array}{l}\text { Rice, } \\
\text { Fruit, } \\
\text { Rub }\end{array}$ \\
\hline T409 & 3 & 4 & 2 & 1 & 3 & 4 & 1 & 0 & 1 & 2 & 1 & 50 & 10YR & 7 & wet & seasonal & 1 & $\begin{array}{c}\text { Rice, Veg, } \\
\text { Fruit }\end{array}$ \\
\hline $\mathrm{T} 410$ & 3 & 4 & 2 & 1 & 2 & 3 & 1 & 1 & 3 & 5 & 2 & 20 & $10 \mathrm{YR}$ & 7 & wet & permanent & 0 & $\begin{array}{l}\text { Rice, } \\
\text { Fruit, } \\
\text { Euc }\end{array}$ \\
\hline T501 & 3 & 5 & 2 & 1 & 2 & 2 & 1 & 1 & 3 & 2 & 1 & 45 & 10YR & 7 & wet & permanent & 0 & Rice, Euc \\
\hline T502 & 3 & 5 & 4 & 0 & 3 & 4 & 2 & 0 & 3 & 2 & 2 & 20 & 10YR & 7 & wet & permanent & 0 & Rice, Euc \\
\hline T503 & 3 & 5 & 4 & 0 & 3 & 4 & 1 & 0 & 3 & 1 & 1 & 50 & $10 \mathrm{YR}$ & 7 & wet & permanent & 0 & Rice \\
\hline T504 & 3 & 5 & 2 & 1 & 3 & 4 & 1 & 0 & 3 & 2 & 1 & 10 & $10 \mathrm{YR}$ & 7 & wet & permanent & 0 & Rice \\
\hline T505 & 3 & 5 & 2 & 1 & 3 & 4 & 1 & 1 & 3 & 2 & 1 & 40 & 10YR & 7 & wet & permanent & 0 & Rice, Euc \\
\hline T506 & 3 & 5 & 4 & 0 & 3 & 4 & 1 & 1 & 3 & 2 & 1 & 30 & $10 Y R$ & 7 & wet & permanent & 0 & Euc \\
\hline
\end{tabular}

ruit,

(1)e, Rub Fruit

Fruit,

,e, Euc 


\begin{tabular}{|c|c|c|c|c|c|c|c|c|c|c|c|c|c|c|c|c|c|c|}
\hline 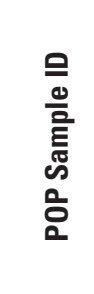 & 站 & .흄 & 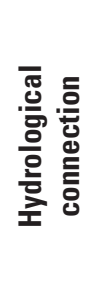 & 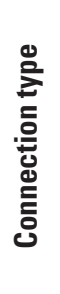 & E & 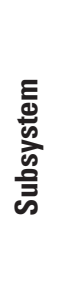 & 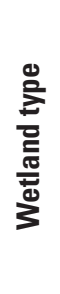 & $\begin{array}{l}\text { 흘 } \\
\text { 巳ัँ } \\
\text { ㅎํㄴ }\end{array}$ & 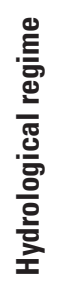 & 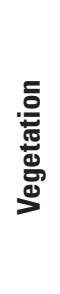 & 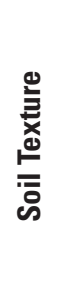 & 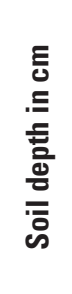 & 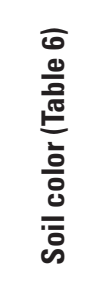 & 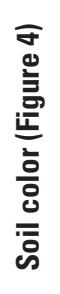 & 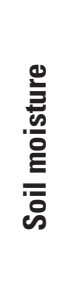 & 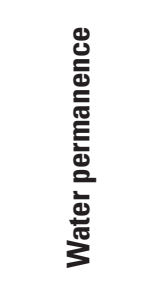 & 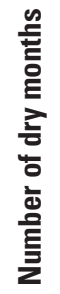 & 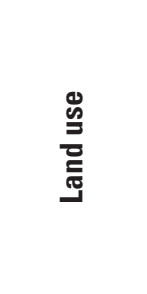 \\
\hline T507 & 3 & 5 & 4 & 0 & 3 & 4 & 2 & 0 & 3 & 2 & 1 & 35 & $10 \mathrm{YR}$ & 7 & wet & permanent & 0 & Rice, Euc \\
\hline T508 & 3 & 5 & 4 & 0 & 3 & 4 & 1 & 1 & 3 & 2 & 1 & 60 & $10 Y R$ & 7 & wet & permanent & 0 & Rice, Euc \\
\hline T509 & 3 & 5 & 2 & 1 & 2 & 3 & 2 & 0 & 3 & 2 & 2 & 15 & $10 \mathrm{YR}$ & 7 & wet & permanent & 0 & Rub \\
\hline T510 & 3 & 5 & 2 & 1 & 3 & 4 & 1 & 0 & 3 & 2 & 1 & 10 & $10 \mathrm{YR}$ & 7 & wet & permanent & 0 & $\begin{array}{l}\text { Rice, } \\
\text { Rub, } \\
\text { Euc }\end{array}$ \\
\hline T511 & 3 & 5 & 2 & 1 & 3 & 4 & 1 & 1 & 3 & 1 & 1 & 10 & $10 \mathrm{YR}$ & 7 & wet & permanent & 0 & Rice \\
\hline T512 & 3 & 5 & 2 & 1 & 3 & 4 & 1 & 0 & 2 & 2 & 1 & 10 & $10 \mathrm{YR}$ & 7 & wet & permanent & 0 & Rice, Euc \\
\hline T513 & 3 & 5 & 2 & 1 & 3 & 4 & 1 & 0 & 2 & 2 & 1 & 20 & $10 \mathrm{YR}$ & 7 & wet & permanent & 0 & Rice, Euc \\
\hline T514 & 3 & 5 & 2 & 1 & 3 & 4 & 1 & 1 & 3 & 2 & 2 & 15 & 10YR & 7 & wet & permanent & 0 & $\begin{array}{c}\text { Rice, } \\
\text { Rub, } \\
\text { Euc }\end{array}$ \\
\hline T515 & 3 & 5 & 4 & 0 & 2 & 3 & 1 & 0 & 3 & 2 & 1 & 25 & $10 \mathrm{YR}$ & 7 & wet & permanent & 0 & None \\
\hline T516 & 3 & 5 & 2 & 1 & 2 & 3 & 2 & 0 & 3 & 5 & 1 & 7 & $10 \mathrm{YR}$ & 7 & wet & permanent & 0 & Rice, Veg \\
\hline T517 & 3 & 5 & 3 & 1 & 3 & 4 & 1 & 1 & 2 & 4 & 1 & 10 & $10 \mathrm{YR}$ & 7 & wet & seasonal & 3 & Rice, Euc \\
\hline T518 & 3 & 5 & 4 & 0 & 3 & 4 & 1 & 0 & 3 & 2 & 1 & 10 & $10 \mathrm{YR}$ & 7 & wet & permanent & 0 & Rice, Euc \\
\hline T519 & 3 & 5 & 1 & 1 & 3 & 4 & 1 & 0 & 3 & 2 & 1 & 10 & $10 \mathrm{YR}$ & 7 & wet & permanent & 0 & $\begin{array}{c}\text { Rice, } \\
\text { Rub, } \\
\text { Euc }\end{array}$ \\
\hline T520 & 3 & 5 & 2 & 1 & 3 & 4 & 2 & 0 & 1 & 3 & 1 & 30 & $10 \mathrm{YR}$ & 7 & wet & permanent & 0 & Rice, Euc \\
\hline T521 & 3 & 5 & 4 & 0 & 2 & 2 & 2 & 0 & 3 & 1 & 1 & 40 & $5 Y R$ & 5 & wet & permanent & 0 & Rice, Euc \\
\hline T522 & 3 & 5 & 2 & 1 & 3 & 4 & 1 & 1 & 3 & 2 & 1 & 20 & $10 \mathrm{YR}$ & 7 & wet & permanent & 0 & Rice \\
\hline T523 & 3 & 5 & 2 & 1 & 3 & 4 & 1 & 0 & 2 & 1 & 1 & 10 & $10 \mathrm{YR}$ & 7 & wet & permanent & 0 & $\begin{array}{l}\text { Rice, } \\
\text { Rub, } \\
\text { Euc }\end{array}$ \\
\hline T524 & 3 & 5 & 2 & 1 & 2 & 2 & 2 & 0 & 3 & 1 & 3 & 20 & $10 \mathrm{YR}$ & 7 & wet & permanent & 0 & $\begin{array}{l}\text { Rice, Veg, } \\
\text { Euc }\end{array}$ \\
\hline V001 & 4 & 15 & 3 & 1 & 3 & 4 & 2 & 1 & 2 & 2 & 1 & 20 & - & - & wet & seasonal & 2 & Rice, Veg \\
\hline V002 & 4 & 15 & 3 & 1 & 3 & 4 & 1 & 1 & 2 & 2 & 1 & 15 & 10YR & 7 & wet & - & - & - \\
\hline V003 & 4 & 15 & 3 & 1 & 3 & 4 & 1 & 1 & 2 & 2 & 2 & 20 & 10YR & 7 & wet & - & - & - \\
\hline
\end{tabular}


Appendix 6. Wetland attribute data for all 531 persistent organic pollutant (POP) samples collected in Southeast Asia during 2011. Codes used for ecological region, river connection, wetland system, wetland subsystem, wetland type, wetland protection status, hydrological regime, wetland vegetation, and surface soil texture are listed in table 2. Country codes are listed as Cambodia (1), Lao PDR (2), Thailand (3), Vietnam (4), and Myanmar (5). Hydrological connection codes describe how rivers were connected to wetlands, such as surface flow only (1), channel flow (2), both channel and surface flow (3), and no connection to river (4). Measurements for surface soil texture, depth, color, and dampness refer to the top layer of soil only. Soil depth was measured in centimeters (cm). Soil color follows Munsell Color Chart codes (Munsell Soil Color Charts, 2009). Water permanence was measured only as water persisting all year round (permanent) or seasonal. The number of months that the wetland would dry in an average year was estimated. Finally, human use of lands surrounding each wetland was grouped into the following categories: rice, vegetable (veg), fruit, rubber (rub), eucalyptus (euc), coffee (cof), and none (natural surroundings). For all variables, dashes represent situations where data were absent. Only water permanence, number of months dry, and land use variables were collected through interviews that reflect the wetland in general. All other variables were collected from the P0Ps sampling point. The label C085 was mistakenly used twice, so " $A$ " distinguishes one sample from the other.-Continued

\begin{tabular}{|c|c|c|c|c|c|c|c|c|c|c|c|c|c|c|c|c|c|c|}
\hline $\begin{array}{l}\frac{0}{0} \\
\frac{0}{0} \\
\overline{\bar{E}} \\
\text { 心 } \\
\text { 옴 }\end{array}$ & 豙 & 흠 & 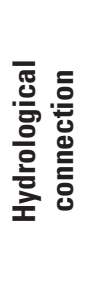 & 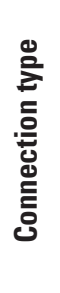 & $\begin{array}{l}\text { E } \\
\frac{0}{0} \\
\text { क }\end{array}$ & 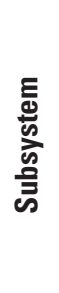 & 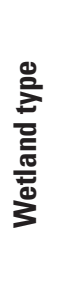 & 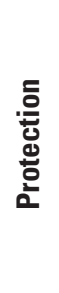 & 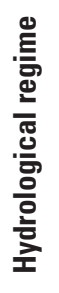 & 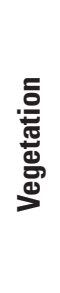 & 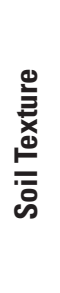 & 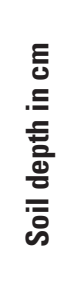 & 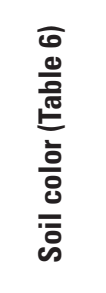 & 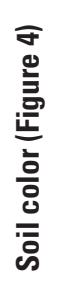 & 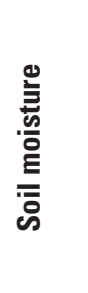 & 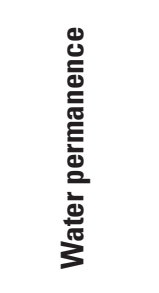 & 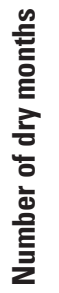 & 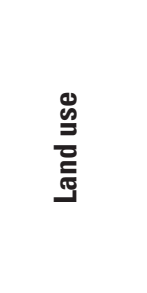 \\
\hline V004 & 4 & 15 & 3 & 1 & 3 & 4 & 2 & 1 & 1 & 2 & 5 & - & - & - & - & - & - & - \\
\hline V005 & 4 & 15 & 3 & 1 & 3 & 4 & 1 & 1 & 2 & 2 & 1 & 10 & $10 \mathrm{YR}$ & 7 & moist & - & - & - \\
\hline V006 & 4 & 15 & 3 & 1 & 3 & 4 & 2 & 1 & 2 & 2 & 5 & - & - & - & - & - & - & - \\
\hline V007 & 4 & 15 & 1 & 1 & 3 & 4 & 1 & 1 & 4 & 2 & 1 & 10 & $10 \mathrm{YR}$ & 7 & wet & permanent & 0 & Rice \\
\hline V008 & 4 & 15 & 3 & 1 & 3 & 4 & 2 & 1 & 1 & 2 & 2 & 19 & $5 \mathrm{Y}$ & 9 & wet & - & - & - \\
\hline V009 & 4 & 15 & 3 & 1 & 3 & 4 & 1 & 1 & 1 & 2 & 2 & 9.5 & $2.5 \mathrm{Y}$ & 8 & wet & - & - & - \\
\hline V010 & 4 & 15 & 3 & 1 & 3 & 4 & 1 & 1 & 2 & 2 & 2 & 43 & $2.5 \mathrm{Y}$ & 8 & wet & - & - & - \\
\hline V011 & 4 & 15 & 3 & 1 & 3 & 4 & 1 & 1 & 2 & 2 & 2 & 20 & $2.5 \mathrm{Y}$ & 8 & wet & - & - & - \\
\hline V012 & 4 & 15 & 2 & 1 & 3 & 4 & 1 & 0 & 2 & 2 & 1 & 20 & - & - & wet & - & - & - \\
\hline V013 & 4 & 15 & 2 & 1 & 3 & 4 & 1 & 0 & 2 & 2 & 2 & - & - & - & wet & - & - & - \\
\hline V014 & 4 & 15 & 2 & 1 & 4 & 7 & 2 & 1 & 1 & 5 & 2 & - & - & - & wet & - & - & - \\
\hline V015 & 4 & 15 & 2 & 1 & 3 & 4 & 2 & 1 & 1 & 2 & 2 & - & - & - & wet & permanent & 0 & $\begin{array}{l}\text { Rice, Veg, } \\
\text { Fruit, } \\
\text { Euc }\end{array}$ \\
\hline V016 & 4 & 15 & 2 & 1 & 3 & 4 & 2 & 1 & 1 & 2 & 2 & - & - & - & wet & - & - & - \\
\hline V017 & 4 & 15 & 4 & 0 & 3 & 4 & 2 & 1 & 4 & 4 & 1 & - & - & - & wet & - & - & - \\
\hline V018 & 4 & 15 & 2 & 1 & 4 & 7 & 1 & 0 & 1 & 5 & 3 & - & - & - & wet & - & - & - \\
\hline V019 & 4 & 15 & 2 & 1 & 4 & 7 & 1 & 0 & 1 & 5 & 3 & - & - & - & wet & - & - & - \\
\hline V020 & 4 & 15 & 2 & 1 & 4 & 7 & 1 & 0 & 1 & 1 & 2 & - & - & - & wet & - & - & - \\
\hline
\end{tabular}




\begin{tabular}{|c|c|c|c|c|c|c|c|c|c|c|c|c|c|c|c|c|c|c|}
\hline 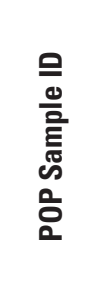 & 豆 & 六 & 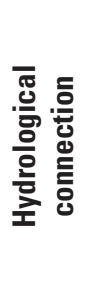 & 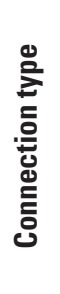 & 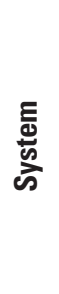 & 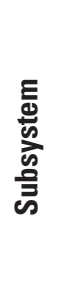 & 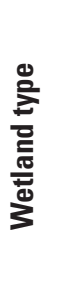 & 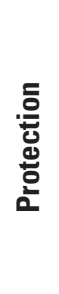 & 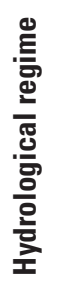 & 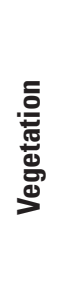 & 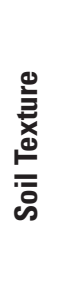 & 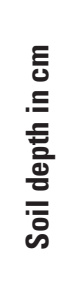 & 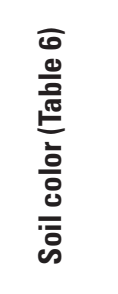 & 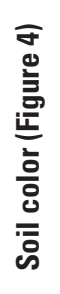 & 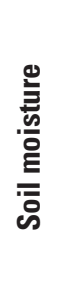 & 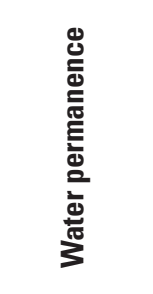 & 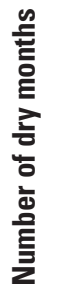 & $\begin{array}{l}\text { હ } \\
\text { હ } \\
\text { 芯 }\end{array}$ \\
\hline V021 & 4 & 15 & 2 & 1 & 4 & 7 & 2 & 0 & 1 & 1 & 2 & - & - & - & wet & permanent & 0 & $\begin{array}{l}\text { Rice, } \\
\text { Fruit }\end{array}$ \\
\hline V022 & 4 & 15 & 2 & 1 & 3 & 4 & 2 & 0 & 2 & 2 & 2 & 60 & $10 \mathrm{YR}$ & 7 & wet & - & - & - \\
\hline V023 & 4 & 15 & 2 & 1 & 3 & 4 & 2 & 0 & 1 & 2 & 2 & 5 & $2.5 \mathrm{YR}$ & 4 & wet & - & - & - \\
\hline V024 & 4 & 15 & 2 & 1 & 2 & 3 & 1 & 0 & 1 & 2 & 2 & - & $2.5 \mathrm{YR}$ & 4 & wet & permanent & 0 & None \\
\hline V025 & 4 & 15 & 2 & 1 & 2 & 3 & 1 & 0 & 1 & 2 & 2 & - & $2.5 \mathrm{YR}$ & 4 & wet & - & - & - \\
\hline V026 & 4 & 15 & 2 & 1 & 2 & 3 & 1 & 0 & 1 & 2 & 2 & - & $2.5 \mathrm{YR}$ & 4 & wet & - & - & - \\
\hline V027 & 4 & 15 & 2 & 1 & 2 & 2 & 1 & 0 & 1 & 2 & 2 & - & $2.5 \mathrm{YR}$ & 4 & wet & - & - & - \\
\hline V028 & 4 & 15 & 2 & 1 & 3 & 4 & 2 & 1 & 1 & 4 & 4 & - & $2.5 \mathrm{YR}$ & 4 & wet & permanent & 0 & Rice \\
\hline V029 & 4 & 15 & 2 & 1 & 3 & 4 & 2 & 1 & 1 & 4 & 4 & - & $2.5 \mathrm{YR}$ & 4 & wet & - & - & - \\
\hline V030 & 4 & 15 & 3 & 1 & 3 & 4 & 1 & 1 & 1 & 2 & 4 & - & $2.5 \mathrm{YR}$ & 4 & wet & - & - & - \\
\hline V031 & 4 & 15 & 2 & 1 & 3 & 4 & 2 & 1 & 1 & 2 & 2 & - & $2.5 \mathrm{YR}$ & 4 & wet & - & - & - \\
\hline V032 & 4 & 14 & 3 & 1 & 3 & 4 & 1 & 0 & 2 & 2 & 4 & 10 & $10 \mathrm{YR}$ & 7 & wet & - & - & - \\
\hline V033 & 4 & 14 & 4 & 0 & 3 & 4 & 1 & 0 & 4 & 2 & 4 & 8 & $2.5 \mathrm{YR}$ & 4 & wet & - & - & - \\
\hline V034 & 4 & 14 & 2 & 1 & 3 & 4 & 1 & 0 & 2 & 2 & 4 & 20 & $2.5 \mathrm{YR}$ & 4 & wet & - & - & - \\
\hline V035 & 4 & 14 & 3 & 1 & 1 & 1 & 1 & 0 & 1 & 5 & 2 & 9.5 & $2.5 \mathrm{YR}$ & 4 & wet & - & - & - \\
\hline V036 & 4 & 14 & 4 & 0 & 3 & 4 & 1 & 0 & 3 & 2 & 4 & - & $10 \mathrm{YR}$ & 7 & wet & permanent & 0 & Rice \\
\hline V037 & 4 & 14 & 4 & 0 & 3 & 4 & 1 & 0 & 3 & 2 & 4 & - & $5 \mathrm{YR}$ & 5 & wet & - & - & - \\
\hline V038 & 4 & 14 & 2 & 1 & 3 & 4 & 1 & 1 & 1 & 2 & 4 & - & $2.5 \mathrm{YR}$ & 4 & wet & permanent & 0 & $\begin{array}{l}\text { Rice, Veg, } \\
\text { Fruit }\end{array}$ \\
\hline V039 & 4 & 14 & 2 & 1 & 3 & 4 & 2 & 1 & 1 & 2 & 4 & - & $10 \mathrm{YR}$ & 7 & wet & - & - & - \\
\hline V040 & 4 & 14 & 2 & 1 & 3 & 4 & 2 & 1 & 1 & 2 & 1 & - & $2.5 \mathrm{YR}$ & 4 & wet & - & - & - \\
\hline V041 & 4 & 14 & 2 & 1 & 3 & 4 & 2 & 1 & 1 & 2 & 4 & - & $10 \mathrm{YR}$ & 7 & wet & - & - & - \\
\hline V042 & 4 & 14 & 2 & 1 & 3 & 4 & 2 & 1 & 1 & 2 & 4 & - & $2.5 \mathrm{YR}$ & 4 & wet & - & - & - \\
\hline V043 & 4 & 14 & 2 & 1 & 1 & 1 & 1 & 0 & 1 & 5 & 1 & - & $2.5 \mathrm{YR}$ & 4 & wet & - & - & - \\
\hline V044 & 4 & 14 & 2 & 1 & 1 & 1 & 1 & 0 & 1 & 5 & 2 & - & $2.5 \mathrm{YR}$ & 4 & wet & - & - & - \\
\hline V045 & 4 & 14 & 2 & 1 & 1 & 1 & 1 & 0 & 1 & 5 & 2 & - & $2.5 \mathrm{YR}$ & 4 & wet & - & - & - \\
\hline V046 & 4 & 14 & 2 & 1 & 1 & 1 & 1 & 0 & 1 & 5 & 2 & - & $10 \mathrm{YR}$ & 7 & wet & - & - & - \\
\hline
\end{tabular}


Appendix 6. Wetland attribute data for all 531 persistent organic pollutant (POP) samples collected in Southeast Asia during 2011. Codes used for ecological region, river connection, wetland system, wetland subsystem, wetland type, wetland protection status, hydrological regime, wetland vegetation, and surface soil texture are listed in table

2. Country codes are listed as Cambodia (1), Lao PDR (2), Thailand (3), Vietnam (4), and Myanmar (5). Hydrological connection codes describe how rivers were connected to wetlands, such as surface flow only (1), channel flow (2), both channel and surface flow (3), and no connection to river (4). Measurements for surface soil texture, depth, color, and dampness refer to the top layer of soil only. Soil depth was measured in centimeters (cm). Soil color follows Munsell Color Chart codes (Munsell Soil Color Charts, 2009). Water permanence was measured only as water persisting all year round (permanent) or seasonal. The number of months that the wetland would dry in an average year was estimated. Finally, human use of lands surrounding each wetland was grouped into the following categories: rice, vegetable (veg), fruit, rubber (rub), eucalyptus (euc), coffee (cof), and none (natural surroundings). For all variables, dashes represent situations where data were absent. Only water permanence, number of months dry, and land use variables were collected through interviews that reflect the wetland in general. All other variables were collected from the P0Ps sampling point. The label C085 was mistakenly used twice, so " $A$ " distinguishes one sample from the other.-Continued

\begin{tabular}{|c|c|c|c|c|c|c|c|c|c|c|c|c|c|c|c|c|c|c|}
\hline 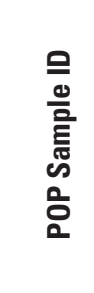 & 壱 & 흠요 & $\begin{array}{l}\bar{J} \\
\text { 응 } \\
\text { 응 } \\
\text { 늘 } \\
\text { 총 }\end{array}$ & 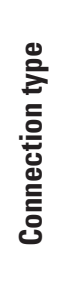 & 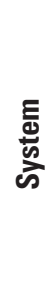 & 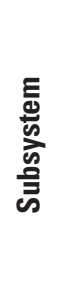 & 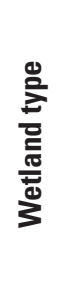 & & 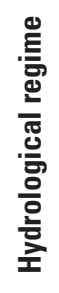 & 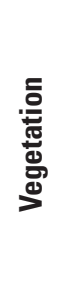 & 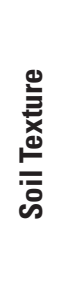 & 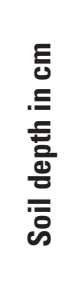 & 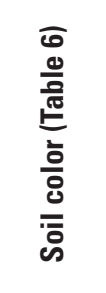 & 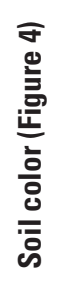 & 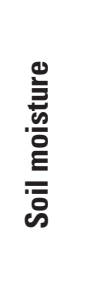 & 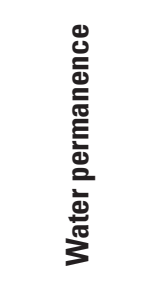 & 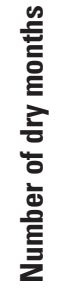 & 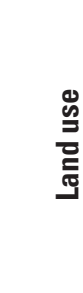 \\
\hline V047 & 4 & 14 & 3 & 1 & 4 & 7 & 1 & 0 & 1 & 5 & 2 & - & $10 \mathrm{YR}$ & 7 & wet & - & - & - \\
\hline V048 & 4 & 14 & 3 & 1 & 3 & 4 & 1 & 0 & 2 & 4 & 1 & 22 & $5 \mathrm{YR}$ & 5 & wet & - & - & - \\
\hline V049 & 4 & 14 & 2 & 1 & 1 & 1 & 2 & 0 & 1 & 5 & 2 & - & $10 \mathrm{YR}$ & 7 & wet & - & - & - \\
\hline V050 & 4 & 14 & 2 & 1 & 1 & 1 & 2 & 0 & 1 & 5 & 3 & - & $10 \mathrm{YR}$ & 7 & wet & - & - & - \\
\hline V051 & 4 & 14 & 2 & 1 & 1 & 1 & 1 & 0 & 1 & 5 & 2 & - & $10 \mathrm{YR}$ & 7 & wet & - & - & - \\
\hline V052 & 4 & 14 & 3 & 1 & 1 & 1 & 1 & 0 & 4 & 5 & 2 & - & $10 \mathrm{YR}$ & 7 & wet & - & - & - \\
\hline V053 & 4 & 14 & 3 & 1 & 3 & 4 & 1 & 1 & 1 & 4 & 2 & 9 & $10 \mathrm{YR}$ & 7 & wet & - & - & - \\
\hline V054 & 4 & 14 & 3 & 1 & 3 & 4 & 1 & 1 & 2 & 4 & 1 & 8 & $10 \mathrm{YR}$ & 7 & wet & - & - & - \\
\hline V055 & 4 & 14 & 3 & 1 & 1 & 1 & 1 & 1 & 1 & 4 & 2 & 10 & $10 \mathrm{YR}$ & 7 & wet & - & - & - \\
\hline V056 & 4 & 14 & 3 & 1 & 1 & 1 & 1 & 1 & 1 & 5 & 2 & - & $10 \mathrm{YR}$ & 7 & wet & - & - & - \\
\hline V057 & 4 & 14 & 4 & 0 & 3 & 4 & 2 & 1 & 4 & 2 & 2 & - & $10 \mathrm{YR}$ & 7 & wet & - & - & - \\
\hline V058 & 4 & 14 & 4 & 0 & 3 & 4 & 2 & 1 & 4 & 2 & 2 & - & $2.5 \mathrm{YR}$ & 4 & wet & - & - & - \\
\hline V059 & 4 & 14 & 4 & 0 & 3 & 4 & 2 & 1 & 4 & 2 & 4 & - & $2.5 \mathrm{YR}$ & 4 & wet & - & - & - \\
\hline V060 & 4 & 14 & 2 & 1 & 3 & 4 & 2 & 1 & 1 & 5 & 4 & 3 & $10 \mathrm{YR}$ & 7 & wet & - & - & - \\
\hline V061 & 4 & 12 & 2 & 1 & 3 & 4 & 1 & 0 & 4 & 3 & 3 & 65 & $10 \mathrm{YR}$ & 7 & moist & permanent & 0 & None \\
\hline V062 & 4 & 12 & 2 & 1 & 4 & 6 & 1 & 0 & 1 & 5 & 3 & 43 & $10 \mathrm{YR}$ & 7 & moist & permanent & 0 & None \\
\hline V063 & 4 & 12 & 3 & 1 & 3 & 4 & 1 & 0 & 3 & 1 & 4 & 28 & $5 \mathrm{YR}$ & 5 & moist & permanent & 0 & Rice \\
\hline V064 & 4 & 12 & 2 & 1 & 3 & 4 & 1 & 0 & 4 & 3 & 3 & 35 & $10 \mathrm{YR}$ & 7 & dry & permanent & 0 & Veg \\
\hline V065 & 4 & 12 & 2 & 1 & 3 & 4 & 1 & 0 & 4 & 3 & 1 & 12 & $2.5 \mathrm{YR}$ & 4 & moist & permanent & 0 & None \\
\hline
\end{tabular}




\begin{tabular}{|c|c|c|c|c|c|c|c|c|c|c|c|c|c|c|c|c|c|c|}
\hline 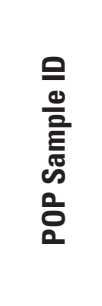 & $\begin{array}{l}\text { Ḋ } \\
\text { 咅 }\end{array}$ & 高 & 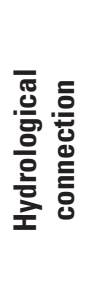 & 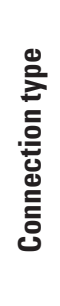 & $\begin{array}{l}\text { E्ञ } \\
\text { के } \\
\bar{\omega}\end{array}$ & 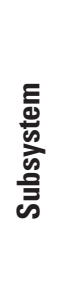 & 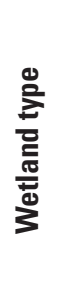 & 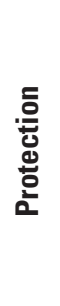 & 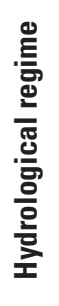 & 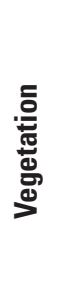 & 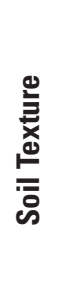 & 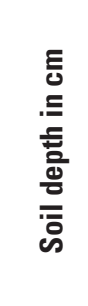 & 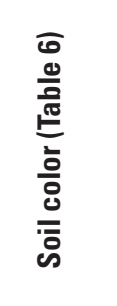 & 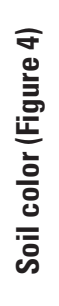 & 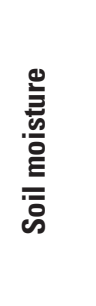 & 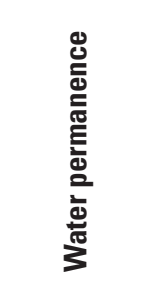 & 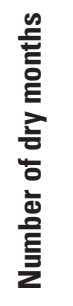 & 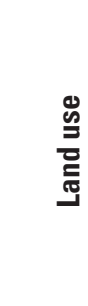 \\
\hline V066 & 4 & 12 & 2 & 1 & 3 & 4 & 1 & 0 & 4 & 3 & 1 & 35 & $7.5 \mathrm{YR}$ & 6 & moist & permanent & 0 & None \\
\hline V067 & 4 & 12 & 2 & 1 & 4 & 6 & 1 & 0 & 1 & 5 & 3 & 16 & $2.5 \mathrm{Y}$ & 8 & wet & permanent & 0 & None \\
\hline V068 & 4 & 12 & 2 & 1 & 4 & 6 & 1 & 0 & 1 & 5 & 1 & 80 & $2.5 \mathrm{Y}$ & 8 & moist & permanent & 0 & None \\
\hline V069 & 4 & 12 & 2 & 1 & 4 & 6 & 1 & 0 & 1 & 5 & 3 & 70 & $7.5 \mathrm{YR}$ & 6 & moist & permanent & 0 & None \\
\hline V070 & 4 & 12 & 2 & 1 & 3 & 4 & 1 & 0 & 4 & 3 & 2 & 7 & $7.5 \mathrm{YR}$ & 6 & moist & permanent & 0 & None \\
\hline V071 & 4 & 12 & 3 & 1 & 3 & 4 & 1 & 0 & 3 & 1 & 1 & 22 & $5 \mathrm{Y}$ & 9 & wet & permanent & 0 & None \\
\hline V072 & 4 & 12 & 3 & 1 & 2 & 2 & 1 & 0 & 3 & 1 & 4 & 20 & $5 \mathrm{Y}$ & 9 & wet & permanent & 0 & None \\
\hline V073 & 4 & 12 & 3 & 1 & 2 & 2 & 1 & 0 & 3 & 1 & 4 & 20 & $5 \mathrm{Y}$ & 9 & wet & permanent & 0 & None \\
\hline V074 & 4 & 12 & 3 & 1 & 2 & 3 & 1 & 0 & 3 & 1 & 4 & 20 & $5 \mathrm{Y}$ & 9 & wet & permanent & 0 & None \\
\hline V075 & 4 & 12 & 3 & 1 & 3 & 4 & 1 & 0 & 4 & 2 & 1 & 20 & $5 \mathrm{Y}$ & 9 & wet & permanent & 0 & Rice \\
\hline V076 & 4 & 12 & 4 & 0 & 3 & 4 & 1 & 0 & 3 & 2 & 1 & 100 & - & - & wet & permanent & 0 & None \\
\hline V077 & 4 & 12 & 2 & 1 & 3 & 4 & 1 & 0 & 4 & 2 & 4 & - & - & - & - & permanent & 0 & Rice \\
\hline V078 & 4 & 12 & 2 & 1 & 3 & 4 & 1 & 0 & 2 & 3 & 3 & 30 & $10 \mathrm{YR}$ & 7 & moist & permanent & 0 & Rice \\
\hline V079 & 4 & 12 & 2 & 1 & 3 & 4 & 2 & 0 & 4 & 2 & 1 & 30 & $5 \mathrm{YR}$ & 5 & moist & permanent & 0 & None \\
\hline V080 & 4 & 12 & 4 & 0 & 3 & 4 & 2 & 0 & 3 & 2 & 4 & 30 & $5 \mathrm{Y}$ & 9 & wet & permanent & 0 & Rice \\
\hline V081 & 4 & 12 & 2 & 1 & 3 & 4 & 1 & 0 & 4 & 3 & 1 & 9 & $10 \mathrm{YR}$ & 7 & wet & permanent & 0 & None \\
\hline V082 & 4 & 12 & 2 & 1 & 3 & 4 & 1 & 0 & 2 & 2 & 4 & 18 & $5 \mathrm{Y}$ & 9 & wet & permanent & 0 & None \\
\hline V083 & 4 & 12 & 2 & 1 & 3 & 4 & 1 & 0 & 2 & 2 & 1 & 100 & $5 \mathrm{YR}$ & 5 & moist & permanent & 0 & None \\
\hline V084 & 4 & 12 & 2 & 1 & 3 & 4 & 1 & 0 & 2 & 3 & 1 & 100 & $7.5 \mathrm{YR}$ & 6 & moist & permanent & 0 & None \\
\hline V085 & 4 & 12 & 2 & 1 & 3 & 4 & 1 & 1 & 4 & 4 & 1 & 26 & $7.5 \mathrm{YR}$ & 6 & moist & permanent & 0 & None \\
\hline V086 & 4 & 12 & 2 & 1 & 3 & 4 & 1 & 1 & 2 & 4 & 1 & 100 & $10 \mathrm{YR}$ & 7 & wet & permanent & 0 & None \\
\hline V087 & 4 & 12 & 3 & 1 & 3 & 4 & 1 & 1 & 4 & 4 & 1 & 20 & $10 \mathrm{YR}$ & 7 & moist & permanent & 0 & None \\
\hline V088 & 4 & 12 & 2 & 1 & 3 & 4 & 1 & 0 & 1 & 5 & 1 & 19 & $10 \mathrm{YR}$ & 7 & moist & permanent & 0 & None \\
\hline V089 & 4 & 12 & 2 & 1 & 4 & 6 & 1 & 0 & 1 & 5 & 1 & 70 & $7.5 \mathrm{YR}$ & 6 & moist & permanent & 0 & None \\
\hline V090 & 4 & 12 & 2 & 1 & 3 & 4 & 1 & 0 & 2 & 2 & 1 & 20 & $10 \mathrm{YR}$ & 7 & moist & permanent & 0 & None \\
\hline V091 & 4 & 12 & 2 & 1 & 4 & 6 & 1 & 0 & 1 & 5 & 1 & 3 & $10 \mathrm{YR}$ & 7 & wet & permanent & 0 & None \\
\hline V092 & 4 & 13 & 2 & 1 & 4 & 6 & 1 & 0 & 1 & 5 & 3 & 100 & $10 \mathrm{YR}$ & 7 & moist & permanent & 0 & None \\
\hline V093 & 4 & 13 & 2 & 1 & 4 & 6 & 1 & 0 & 1 & 5 & 3 & 28 & $7.5 \mathrm{YR}$ & 6 & wet & permanent & 0 & None \\
\hline
\end{tabular}


Appendix 6. Wetland attribute data for all 531 persistent organic pollutant (POP) samples collected in Southeast Asia during 2011. Codes used for ecological region, river connection, wetland system, wetland subsystem, wetland type, wetland protection status, hydrological regime, wetland vegetation, and surface soil texture are listed in table 2. Country codes are listed as Cambodia (1), Lao PDR (2), Thailand (3), Vietnam (4), and Myanmar (5). Hydrological connection codes describe how rivers were connected to wetlands, such as surface flow only (1), channel flow (2), both channel and surface flow (3), and no connection to river (4). Measurements for surface soil texture, depth, color, and dampness refer to the top layer of soil only. Soil depth was measured in centimeters (cm). Soil color follows Munsell Color Chart codes (Munsell Soil Color Charts, 2009). Water permanence was measured only as water persisting all year round (permanent) or seasonal. The number of months that the wetland would dry in an average year was estimated. Finally, human use of lands surrounding each wetland was grouped into the following categories: rice, vegetable (veg), fruit, rubber (rub), eucalyptus (euc), coffee (cof), and none (natural surroundings). For all variables, dashes represent situations where data were absent. Only water permanence, number of months dry, and land use variables were collected through interviews that reflect the wetland in general. All other variables were collected from the POPs sampling point. The label C085 was mistakenly used twice, so "A" distinguishes one sample from the other.-Continued

\begin{tabular}{|c|c|c|c|c|c|c|c|c|c|c|c|c|c|c|c|c|c|c|}
\hline 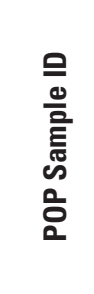 & 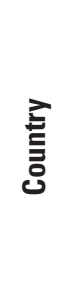 & 흐웜 & $\begin{array}{l}\overline{\mathbb{J}} \\
\text { 흠을 } \\
\text { 응 } \\
\text { 늘 } \\
\text { 종 }\end{array}$ & 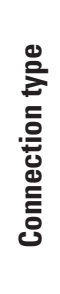 & $\frac{E}{\infty}$ & 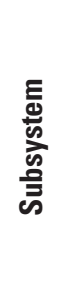 & 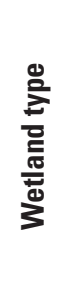 & 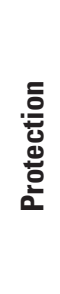 & 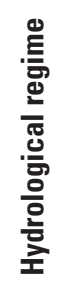 & 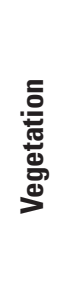 & 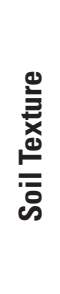 & 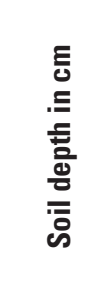 & 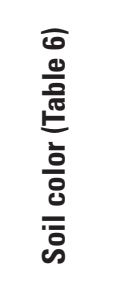 & 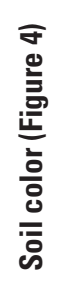 & 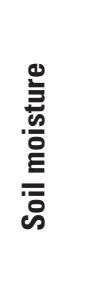 & 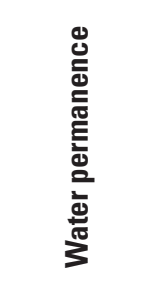 & 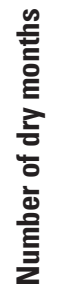 & 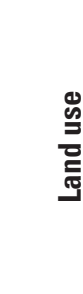 \\
\hline V094 & 4 & 13 & 2 & 1 & 3 & 4 & 1 & 0 & 4 & 3 & 1 & 40 & $7.5 \mathrm{YR}$ & 6 & moist & permanent & 0 & None \\
\hline V095 & 4 & 13 & 2 & 1 & 4 & 6 & 1 & 0 & 1 & 5 & 3 & 10 & 10YR & 7 & moist & permanent & 0 & None \\
\hline V096 & 4 & 13 & 2 & 1 & 4 & 6 & 1 & 0 & 1 & 5 & 3 & 100 & $10 \mathrm{YR}$ & 7 & moist & permanent & 0 & None \\
\hline V097 & 4 & 13 & 2 & 1 & 4 & 6 & 1 & 0 & 1 & 5 & 3 & 20 & 10YR & 7 & moist & permanent & 0 & None \\
\hline V098 & 4 & 13 & 2 & 1 & 1 & 1 & 1 & 0 & 4 & 3 & 1 & 40 & 7.5YR & 6 & moist & permanent & 0 & None \\
\hline V099 & 4 & 14 & 2 & 1 & 1 & 1 & 1 & 0 & 3 & 4 & 1 & 12 & $2.5 \mathrm{Y}$ & 8 & wet & permanent & 0 & None \\
\hline V100 & 4 & 14 & 2 & 1 & 1 & 1 & 1 & 0 & 3 & 4 & 1 & 12 & $2.5 \mathrm{Y}$ & 8 & wet & permanent & 0 & None \\
\hline V101 & 4 & 14 & 3 & 1 & 1 & 1 & 1 & 0 & 3 & 4 & 1 & 10 & $2.5 \mathrm{Y}$ & 8 & wet & permanent & 0 & None \\
\hline V102 & 4 & 14 & 2 & 1 & 1 & 1 & 1 & 0 & 3 & 4 & 1 & 15 & $2.5 \mathrm{Y}$ & 8 & wet & permanent & 0 & None \\
\hline V103 & 4 & 14 & 2 & 1 & 1 & 1 & 1 & 0 & 3 & 4 & 1 & 15 & $2.5 \mathrm{Y}$ & 8 & wet & permanent & 0 & None \\
\hline
\end{tabular}




\section{Appendix 7.}

Results of logistic regression for organochlorine pesticide residues in relation to wetland environment predictors. We considered 8 categorical predictors: region (16 levels), connection (2 levels), wetland system (7 levels), wetland (2 levels), protection (2 levels), flow regime (4 levels), vegetation (5 levels), soil (5 levels); and 3 numeric predictors: streamdist (distance from to the nearest stream), sourcedist (distance to the beginning of the Mekong River), and popplacedist (distance to the nearest urban area). We considered 3 interaction terms: streamdist* sourcedist, streamdist ${ }^{*}$ popplacedist, and sourcedist* ${ }^{*}$ popplacedist. Backward elimination procedure was used to select the best logistic regression models. 
1 Endosulfan (combination of Alpha-Endosulfan, Beta-Endosulfan, and Endosulfan Sulfate) Best model:

$\operatorname{glm}($ formula $=$ response $\sim$ region, family $=$ "binomial", data $=\mathrm{d})$

Deviance Residuals:

Min 1Q Median 3Q Max

$-1.9728-0.9331-0.61330 .88262 .5211$

Coefficients:

Estimate Std. Error z value $\operatorname{Pr}(>|z|)$

(Intercept) -3.1355 $1.0213-3.0700 .002140 * *$

region2 $2.89711 .05442 .7480 .006005 * *$

region3 $2.57591 .06832 .4110 .015901 *$

region1 $2.52941 .14052 .2180 .026565 *$

region8 1.96391 .05001 .8700 .061448 .

region9 2.1800 1.1489 1.8970.057769.

region10 0.91631 .12460 .8150 .415217

region11 1.56001 .11541 .3990 .161959

region12 $3.87741 .09123 .5530 .000380 * * *$

region13 $4.92731 .48653 .3150 .000918 * * *$

region14 $3.13551 .07742 .9100 .003610 * *$

region15 $3.87741 .09123 .5530 .000380 * * *$

region16 2.8672 1.08572.6410.008270 **

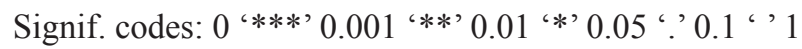

(Dispersion parameter for binomial family taken to be 1)

Null deviance: 612.66 on 473 degrees of freedom

Residual deviance: 528.74 on 461 degrees of freedom

AIC: 554.74

Number of Fisher Scoring iterations: 5

2 Endrin

Best model:

$\operatorname{glm}($ formula $=$ response $\sim$ region + system + streamdist + sourcedist +

streamdist:sourcedist, family = "binomial", data $=\mathrm{d}$ )

Deviance Residuals:

Min 1Q Median 3Q Max

$-1.53584-0.70890-0.30528-0.012712 .90040$

Coefficients:

Estimate Std. Error z value $\operatorname{Pr}(>|z|)$

(Intercept) $-1.697 \mathrm{e}+011.108 \mathrm{e}+03-0.0150 .98778$

region $2.454 \mathrm{e}+001.570 \mathrm{e}+001.5630 .11804$

region $32.852 \mathrm{e}+002.218 \mathrm{e}+001.2860 .19854$

region8 $6.090 \mathrm{e}-012.514 \mathrm{e}+000.2420 .80858$

region $123.827 \mathrm{e}+002.806 \mathrm{e}+001.3640 .17263$

region13 $4.581 \mathrm{e}+002.592 \mathrm{e}+001.7680 .07714$.

region $142.232 \mathrm{e}+003.218 \mathrm{e}+000.6930 .48800$

region $152.858 \mathrm{e}+003.063 \mathrm{e}+000.9330 .35080$

region $11.740 \mathrm{e}+001.322 \mathrm{e}+001.3170 .18796$

system $111.513 \mathrm{e}+011.108 \mathrm{e}+030.0140 .98910$

system $221.514 \mathrm{e}+011.108 \mathrm{e}+030.0140 .98910$

system $341.595 \mathrm{e}+011.108 \mathrm{e}+03 \quad 0.0140 .98851$

system $461.525 \mathrm{e}+011.108 \mathrm{e}+03 \quad 0.0140 .98902$

system $471.771 \mathrm{e}+011.108 \mathrm{e}+030.0160 .98724$

streamdist -1.009e-03 3.773e-04 -2.674 $0.00749 * *$

sourcedist -1.066e-06 2.310e-06 -0.462 0.64441

streamdist:sourcedist 3.692e-10 1.396e-10 2.6450 .00817 **

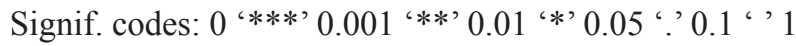


(Dispersion parameter for binomial family taken to be 1)

Null deviance: 316.04 on 345 degrees of freedom

Residual deviance: 247.58 on 329 degrees of freedom

AIC: 281.58

Number of Fisher Scoring iterations: 17

3 DDE

Best model:

$\operatorname{glm}($ formula $=$ response $\sim$ region + soil + sourcedist + popplacedist,

family = "binomial", data $=\mathrm{d}$ )

Deviance Residuals:

Min 1Q Median 3Q Max

$-1.9394-0.8815-0.65901 .13472 .3360$

Coefficients:

Estimate Std. Error $\mathrm{z}$ value $\operatorname{Pr}(>|\mathrm{z}|)$

(Intercept) 4.376e+00 3.079e+00 1.4210 .155206

region2 7.665e-01 8.410e-01 0.9110 .362062

region3 1.844e+00 9.013e-01 2.0460 .040746 *

region4 -1.332e-01 $1.338 \mathrm{e}+00-0.1000 .920713$

region5 $1.406 \mathrm{e}+009.102 \mathrm{e}-011.5450 .122467$

region1 7.741e-01 $1.118 \mathrm{e}+000.6920 .488635$

region7 $1.685 \mathrm{e}+008.921 \mathrm{e}-011.8890 .058922$.

region $83.375 \mathrm{e}+001.003 \mathrm{e}+003.3650 .000764 * * *$

region9 $3.429 \mathrm{e}+001.137 \mathrm{e}+003.0140 .002575 * *$

region10 2.206e+00 9.569e-01 2.305 $0.021171 *$

region11 3.432e+00 1.143e+00 $3.0040 .002665 * *$

region $123.487 \mathrm{e}+001.144 \mathrm{e}+003.0480 .002307 * *$

region13 $4.309 \mathrm{e}+001.254 \mathrm{e}+003.4350 .000592 * * *$

region14 2.823e+00 1.360e+00 2.0750 .037943 *

region15 2.157e+00 1.271e+00 1.6960 .089804 .

region16 2.319e+00 $1.217 \mathrm{e}+001.9050 .056790$.

soill 5.448e-01 2.876e-01 1.8940 .058168 .

soil2 $1.307 \mathrm{e}+004.264 \mathrm{e}-013.0650 .002180$ **

soil4 4.302e-01 4.509e-01 0.9540 .340093

soil5 7.466e-01 3.897e-01 1.9160 .055396 .

sourcedist $-2.959 \mathrm{e}-06$ 1.420e-06 $-2.0830 .037269 *$

popplacedist $-1.294 \mathrm{e}-053.480 \mathrm{e}-06-3.7180 .000201 * * *$

Significant codes: 0 '***’ 0.001 '**’ 0.01 '** 0.05 '. 0.1 ' ' 1

(Dispersion parameter for binomial family taken to be 1)

Null deviance: 694.89 on 530 degrees of freedom

Residual deviance: 618.09 on 509 degrees of freedom

AIC: 662.09

Number of Fisher Scoring iterations: 4

4 DDD

Best model:

glm $($ formula $=$ response $\sim$ connection + regime + streamdist + popplacedist +

streamdist:popplacedist, family = "binomial", data $=\mathrm{d}$ )

Deviance Residuals:

Min 1Q Median 3Q Max

$-0.8783-0.4456-0.3413-0.26392 .5788$

Coefficients:

Estimate $\operatorname{Std}$. Error $\mathrm{z}$ value $\operatorname{Pr}(>|\mathrm{z}|)$

(Intercept) -1.507e+00 7.846e-01 -1.921 0.0547 .

connection1 7.746e-01 5.432e-01 1.4260 .1538

regime2 $-1.143 \mathrm{e}+00$ 5.946e-01 -1.922 0.0547 .

regime3 -2.406e-01 5.285e-01 -0.455 0.6489 
regime $4-1.655 \mathrm{e}+011.269 \mathrm{e}+03-0.0130 .9896$

streamdist $-1.673 \mathrm{e}-048.245 \mathrm{e}-05-2.0290 .0425$ *

popplacedist $-1.268 \mathrm{e}-056.654 \mathrm{e}-06-1.9060 .0567$.

streamdist:popplacedist 1.766e-09 9.478e-10 1.8630 .0624 .

Significant codes: 0 '***’ 0.001 '**’ 0.01 '*’ 0.05 ' ' 0.1 ' ' 1

(Dispersion parameter for binomial family taken to be 1)

Null deviance: 212.32 on 394 degrees of freedom

Residual deviance: 196.77 on 387 degrees of freedom

AIC: 212.77

Number of Fisher Scoring iterations: 17

5 DDT

Best model:

$\operatorname{glm}($ formula $=$ response $\sim$ connection + protection + soil, family $=$ "binomial", data $=\mathrm{d})$

Deviance Residuals:

Min 1Q Median 3Q Max

$-0.8116-0.5391-0.4683-0.35742 .3891$

Coefficients:

Estimate Std. Error $\mathrm{z}$ value $\operatorname{Pr}(>|\mathrm{z}|)$

(Intercept) $-2.15490 .3878-5.5572 .75 \mathrm{e}-08 * * *$

connection $1-0.56400 .3243-1.7390 .082017$.

protection1 $-0.63980 .3729-1.7160 .086191$.

soil1 $0.86350 .42482 .0330 .042085 *$

soil2 $1.77740 .51063 .4810 .000499 * * *$

soil4 1.04070 .57471 .8110 .070169 .

soil5 0.16090 .55420 .2900 .771525

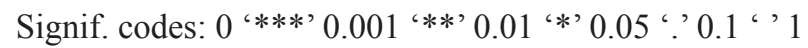

(Dispersion parameter for binomial family taken to be 1)

Null deviance: 334.2 on 449 degrees of freedom

Residual deviance: 317.4 on 443 degrees of freedom

AIC: 331.4

Number of Fisher Scoring iterations: 5

$\operatorname{glm}($ formula $=$ response $\sim$ connection + protection + soil, family $=$ "binomial", data $=\mathrm{d}$ )

Deviance Residuals:

Min 1Q Median 3Q Max

$-0.8144-0.5542-0.4587-0.35212 .4120$

Coefficients:

Estimate $\operatorname{Std}$. Error $\mathrm{z}$ value $\operatorname{Pr}(>|\mathrm{z}|)$

(Intercept) -2.1988 $0.4033-5.4524 .99 \mathrm{e}-08 * * *$

connection $1-0.55100 .3318-1.6600 .096825$.

protection $1-0.65390 .3735-1.7510 .079946$.

soill 0.95390 .44782 .1300 .033152 *

soil2 $1.81650 .52803 .4400 .000581 * * *$

soil4 1.07830 .59071 .8260 .067909 .

soil5 0.27110 .56890 .4760 .633728

Signif. codes: 0 '***’ 0.001 '**’ 0.01 '*' 0.05 ' .0 .1 ' ' 1

(Dispersion parameter for binomial family taken to be 1)

Null deviance: 318.43 on 419 degrees of freedom

Residual deviance: 301.74 on 413 degrees of freedom

AIC: 315.74

Number of Fisher Scoring iterations: 5

6 DDTs (combination of DDT, DDE, DDD)

Best model: 
$\operatorname{glm}($ formula $=$ response $\sim$ region + soil + popplacedist, family $=$ "binomial",

data $=\mathrm{d}$ )

Deviance Residuals:

Min 1Q Median 3Q Max

$-1.9108-1.0289-0.70261 .15122 .2681$

Coefficients:

Estimate Std. Error $\mathrm{z}$ value $\operatorname{Pr}(>|\mathrm{z}|)$

(Intercept) $-1.971 \mathrm{e}+007.930 \mathrm{e}-01-2.4860 .01293 *$

region2 $1.825 \mathrm{e}+007.971 \mathrm{e}-012.2900 .02201 *$

region3 $1.692 \mathrm{e}+008.148 \mathrm{e}-012.0760 .03789 *$

region $41.213 \mathrm{e}+001.111 \mathrm{e}+001.0920 .27480$

region5 $1.873 \mathrm{e}+008.662 \mathrm{e}-012.1630 .03056$ *

region1 2.195e+00 9.108e-01 2.4090 .01598 *

region7 $1.357 \mathrm{e}+008.718 \mathrm{e}-011.5560 .11965$

region8 $2.269 \mathrm{e}+008.333 \mathrm{e}-012.7230 .00648 * *$

region9 2.333e+00 9.168e-01 $2.5450 .01092 *$

region10 $1.969 \mathrm{e}+008.094 \mathrm{e}-012.4330 .01499 *$

region11 $2.215 \mathrm{e}+008.288 \mathrm{e}-012.6730 .00752 * *$

region12 2.400e+00 8.465e-01 $2.8350 .00458 * *$

region13 4.108e+00 1.324e+00 3.1020 .00192 **

region14 $1.363 \mathrm{e}+008.488 \mathrm{e}-011.6060 .10819$

region15 $1.639 \mathrm{e}+008.547 \mathrm{e}-011.9180 .05516$.

region16 3.942e+00 8.880e-01 4.439 9.04e-06***

soil1 4.762e-01 2.675e-01 1.780 0.07509 .

soil2 $1.017 \mathrm{e}+003.987 \mathrm{e}-012.5500 .01076 *$

soil4 3.245e-01 4.138e-01 0.7840 .43292

soil5 5.143e-01 3.760e-01 1.3680 .17137

popplacedist -9.168e-06 3.235e-06 -2.834 $0.00459 * *$

Significant codes: 0 '***’ 0.001 '**’ 0.01 '*' 0.05 ' 0.1 ' ' 1

(Dispersion parameter for binomial family taken to be 1)

Null deviance: 729.55 on 530 degrees of freedom

Residual deviance: 667.88 on 510 degrees of freedom

AIC: 709.88

Number of Fisher Scoring iterations: 4

7 Hexachlorobenzene

Best models:

$\operatorname{glm}($ formula $=$ response $\sim$ region + vegetation + soil + sourcedist + popplacedist,

family = "binomial", data $=\mathrm{d}$ )

Deviance Residuals:

Min 1Q Median 3Q Max

$-1.9024-0.5730-0.3685-0.20502 .8780$

Coefficients:

Estimate Std. Error $\mathrm{z}$ value $\operatorname{Pr}(>|\mathrm{z}|)$

(Intercept) $1.026 \mathrm{e}+015.681 \mathrm{e}+001.8060 .07097$.

region $-1.177 \mathrm{e}+001.895 \mathrm{e}+00-0.6210 .53441$

region $3-7.897 \mathrm{e}-011.650 \mathrm{e}+00-0.4790 .63226$

region $4-2.314 \mathrm{e}+002.661 \mathrm{e}+00-0.8700 .38454$

region5 -2.641e-01 $1.907 \mathrm{e}+00-0.1380 .88990$

region6 $-6.661 \mathrm{e}-011.741 \mathrm{e}+00-0.3830 .70201$

region7 $-1.672 \mathrm{e}-01 \quad 1.595 \mathrm{e}+00-0.1050 .91650$

region8 $5.949 \mathrm{e}-011.159 \mathrm{e}+000.5130 .60779$

region $1-2.101 \mathrm{e}+002.419 \mathrm{e}+00-0.8690 .38511$

region $108.285 \mathrm{e}-01 \quad 1.304 \mathrm{e}+000.6350 .52537$

region $111.808 \mathrm{e}+00 \quad 1.343 \mathrm{e}+001.3470 .17802$

region12 2.313e+00 1.336e+00 1.7310 .08347 . 
region13 2.459e+00 $1.507 \mathrm{e}+001.6320 .10266$ region14 3.784e+00 $1.415 \mathrm{e}+002.6740 .00749 * *$

region $153.240 \mathrm{e}+001.335 \mathrm{e}+002.4270 .01522 *$

region $165.894 \mathrm{e}-012.650 \mathrm{e}+000.2220 .82398$

vegetation1 4.172e-01 4.186e-01 0.9970 .31882

vegetation $3-2.375 \mathrm{e}+00$ 8.661e-01 -2.742 $0.00610 * *$

vegetation $4.851 \mathrm{e}-016.411 \mathrm{e}-011.3800 .16744$

vegetation5 3.077e-01 3.868e-01 0.7950 .42641

soil1 -5.521e-01 4.199e-01 -1.315 0.18851

soil2 -4.169e-02 5.418e-01 -0.077 0.93868

soil4 -1.065e-01 5.661e-01 -0.188 0.85081

soil5 $1.558 \mathrm{e}+006.510 \mathrm{e}-012.3930 .01671$ *

sourcedist -5.180e-06 2.161e-06 -2.398 0.01651*

popplacedist $-1.462 \mathrm{e}-055.229 \mathrm{e}-06-2.7960 .00518 * *$

Significant codes: 0 '***’ 0.001 '**’ 0.01 '*’ 0.05 ‘ $0.1^{\prime}$ ' 1

(Dispersion parameter for binomial family taken to be 1)

Null deviance: 453.57 on 530 degrees of freedom

Residual deviance: 363.05 on 505 degrees of freedom

AIC: 415.05

Number of Fisher Scoring iterations: 6

8 All organochlorines

$\operatorname{glm}($ formula $=$ response $\sim$ region + popplacedist, family $=$ "binomial",

data $=\mathrm{d})$

Deviance Residuals:

Min 1Q Median 3Q Max

$-2.6433-1.06650 .36410 .93291 .9226$

Coefficients:

Estimate $\operatorname{Std}$. Error $\mathrm{z}$ value $\operatorname{Pr}(>|\mathrm{z}|)$

(Intercept) -9.939e-01 6.024e-01 -1.650 0.098922 .

region2 2.436e+00 6.299e-013.868 $0.000110 * * *$

region3 $2.467 \mathrm{e}+006.525 \mathrm{e}-013.7810 .000156 * * *$

region4 4.373e-01 9.867e-01 0.4430 .657668

region5 $1.374 \mathrm{e}+006.953 \mathrm{e}-011.9760 .048177$ *

region1 $2.604 \mathrm{e}+007.876 \mathrm{e}-013.3060 .000947 * * *$

region7 9.416e-01 6.973e-01 1.3500 .176893

region8 $1.640 \mathrm{e}+006.144 \mathrm{e}-012.6690 .007615$ **

region9 $1.742 \mathrm{e}+007.372 \mathrm{e}-012.3630 .018125 *$

region10 $1.405 \mathrm{e}+006.286 \mathrm{e}-012.2350 .025413 *$

region11 1.672e+00 6.611e-01 $2.5290 .011444 *$

region12 $4.635 \mathrm{e}+001.164 \mathrm{e}+003.9836 .80 \mathrm{e}-05 * * *$

region13 $1.888 \mathrm{e}+011.494 \mathrm{e}+030.0130 .989916$

region14 3.285e+00 7.751e-01 4.238 2.26e-05***

region15 $1.881 \mathrm{e}+017.088 \mathrm{e}+020.0270 .978829$

region16 4.250e+00 9.236e-01 4.602 4.19e-06***

popplacedist $-6.500 \mathrm{e}-063.347 \mathrm{e}-06-1.9420 .052137$.

Significant. codes: 0 ‘***’ 0.001 '**’ 0.01 '*’ 0.05 '? 0.1 ' ' 1

(Dispersion parameter for binomial family taken to be 1)

Null deviance: 692.58 on 530 degrees of freedom

Residual deviance: 553.58 on 514 degrees of freedom

AIC: 587.58 Number of Fisher Scoring iterations: 16 

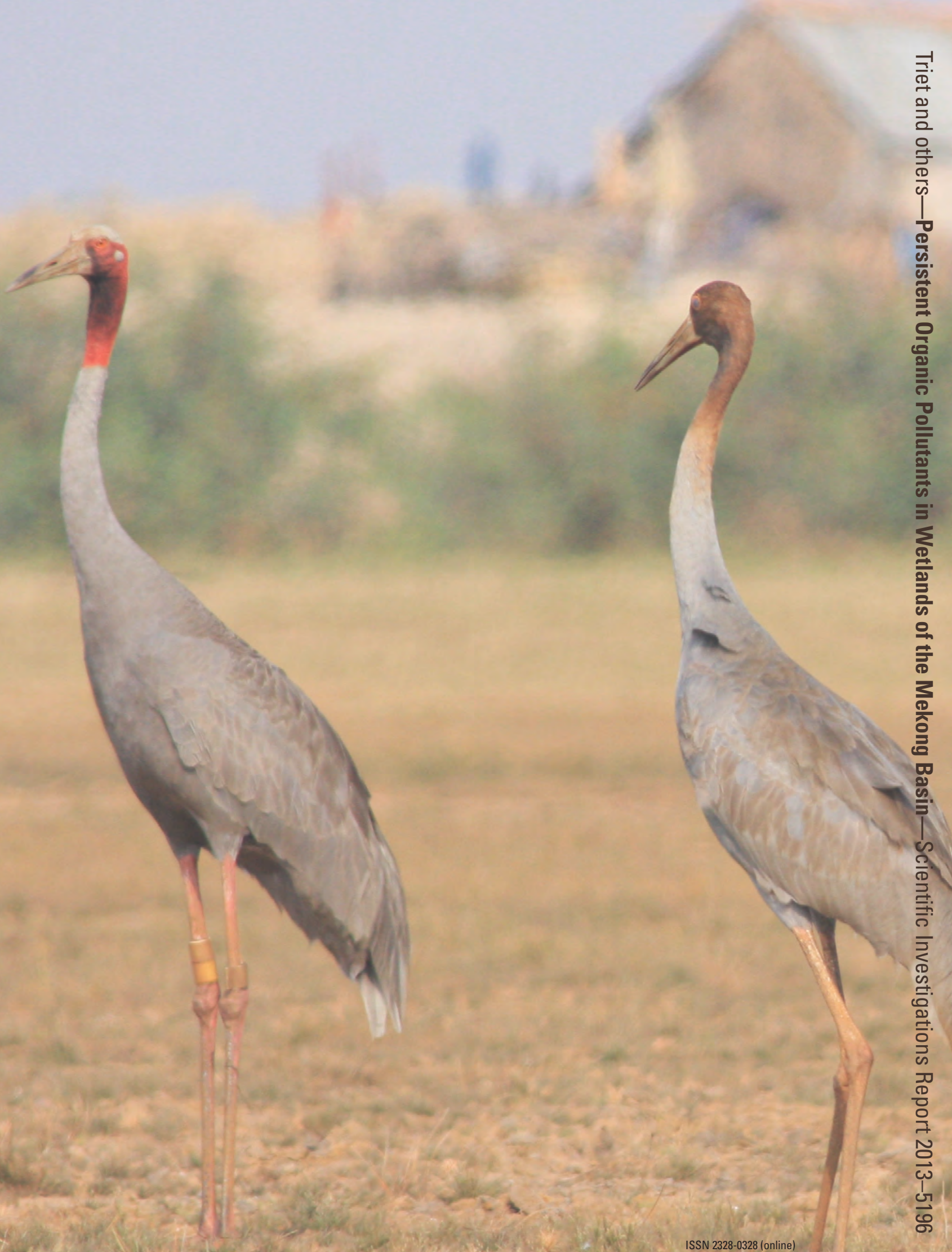